UNIVERSIDADE DE SÃO PAULO
FACULDADE DE ZOOTECNIA E ENGENHARIA DE ALIMENTOS

DANNY ALEXANDER ROJAS MORENO

Avaliação Econômica e Emergética da Ovinocultura Paulista

Pirassununga

2021 
DANNY ALEXANDER ROJAS MORENO

\title{
Avaliação Econômica e Emergética da Ovinocultura Paulista
}

\author{
Versão Corrigida
}

Dissertação apresentada à Faculdade de Zootecnia e Engenharia de Alimentos da Universidade de São Paulo, como parte dos requisitos para obtenção de título de Mestre em Ciências.

Área de Concentração: Qualidade e produtividade animal

Orientador: Prof. Ives Claudio da Silva Bueno Coorientador: Prof. Dr. Augusto Hauber Gameiro 


\section{Avaliação Econômica e Emergética da Ovinocultura Paulista}

Dissertação apresentada à Faculdade de Zootecnia e Engenharia de Alimentos da Universidade de São Paulo, como parte dos requisitos para obtenção de título de Mestre em Ciências.

Área de concentração: Qualidade e Produtividade Animal

Data de aprovação: $13 / 12 / 2021$

Banca Examinadora:

Prof. Dr. Augusto Hauber Gameiro

Instituição: FMVZ/USP

Presidente da Banca Examinadora

Prof. Dr. Feni Dalano Roosevelt Agostinho

Instituição: Universidade Paulista (UNIP)

Prof. Dr. Rubens Nunes

Instituição: FZEA/USP 
Ficha catalográfica elaborada pelo

Serviço de Biblioteca e Informação, FZEA/USP, com os dados fornecidos pelo(a) autor(a)

Rojas-Moreno, Danny Alexander Avaliação Econômica e Emergética da Ovinocultura Paulista / Danny Alexander Rojas-Moreno ; orientador Ives Claudio da Silva Bueno; coorientador Augusto Hauber Gameiro. -Pirassununga, 2021.

$197 \mathrm{f}$.

Dissertação (Mestrado - Programa de Pós-Graduação em Zootecnia) -- Faculdade de Zootecnia e Engenharia de Alimentos, Universidade de São Paulo.

1. Economia Ecológica. 2. Contabilidade biofísica. 3. Gestão de custos. 4. Pressão Ambiental. 5. Ovinos. I. da Silva Bueno, Ives Claudio, orient. II. Hauber Gameiro, Augusto, coorient. III. Título. 


\section{USP - FACULDADE DE \\ ZOOTECNIA E ENGENHARIA \\ DE ALIMENTOS DA \\ UNIVERSIDADE DE SÃO}

\section{PARECER CONSUBSTANCIADO DO CEP}

\section{DADOS DO PROJETO DE PESQUISA}

Título da Pesquisa: Avaliação Econômica e Emergética da Ovinocultura Paulista

Pesquisador: IVES CLAUDIO DA SILVA BUENO

Área Temática:

Versão: 3

CAAE: 35964920.8 .0000 .5422

Instituição Proponente: UNIVERSIDADE DE SAO PAULO

Patrocinador Principal: Financiamento Próprio

\section{DADOS DO PARECER}

Número do Parecer: 4.548 .303

\section{Apresentação do Projeto:}

A proposta está apresentada de forma clara e foi bem elaborada.

A participação de seres humanos se dará por meio de reuniões entre os pesquisadores grupos de participantes de diversas cidades, em um total de 84 participantes. A pesquisa destaca o crescimento significativo do setor da ovinocultura brasileira nesta última década (2008 -2018), porem ainda é possível encontrar problemas de gerenciamento de custo, como também de impacto ambiental deste setor. Assim, a proposta visa realizar uma análise comparativa dos sistemas produtivos ovinos do Estado de São Paulo, pormeio do cálculo de custo de produção de acordo aos preceitos da Teoria Econômica Neoclássica, e da Síntese Energética, embasada na Teoria da Economia Ecológica; e assim fornecer dados que auxiliem os produtores.

\section{Objetivo da Pesquisa:}

A pesquisa proposta tem como objetivo realizar análise e comparação dos sistemas produtivos de ovinos presentes no Estado de São Paulo, por meio do cálculo dos custos de produção de acordo aos preceitos da Teoria Econômica Neoclássica e a da Síntese Energética embasada na Teoria da Economia Ecológica.

\section{Avaliação dos Riscos e Benefícios:}

Os riscos apresentados pelos pesquisadores estão claros e podem ser desconforto decorrente ao encontro que poderá durar até cinco (05) horas e constrangimentos em algumas questões do questionário.

Esta pesquisa não apresenta benefício direto ao participante.

\section{Comentários e Considerações sobre a Pesquisa:}

Pesquisa importante e com potencial de extensão.

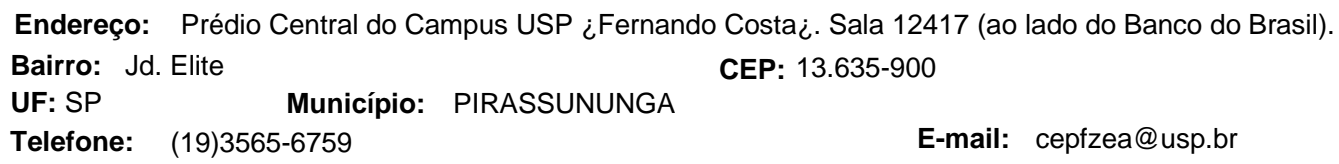




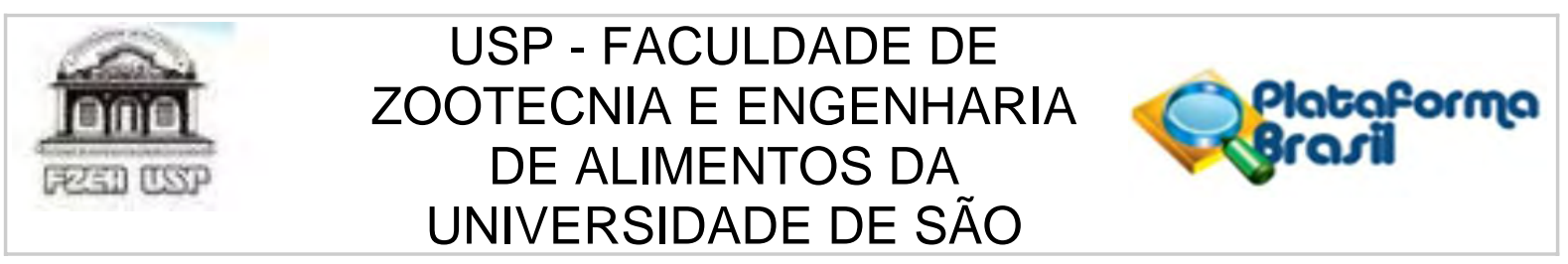

Continuação do Parecer: 4.548.303

Considerações sobre os Termos de apresentação obrigatória:

Os termos obrigatórios foram apresentados corretamente.

\section{Recomendações:}

NDA

\section{Conclusões ou Pendências e Lista de Inadequações:}

Projeto encontra-se dentro do esperado e com os termos obrigatórios apresentados de maneira correta.

\section{Considerações Finais a critério do CEP:}

Este CEPH FZEA aprova o desenvolvimento do projeto, a partir desta data.

Este parecer foi elaborado baseado nos documentos abaixo relacionados:

\begin{tabular}{|l|l|c|l|c|}
\hline \multicolumn{1}{|c|}{ Tipo Documento } & \multicolumn{1}{|c|}{ Arquivo } & Postagem & \multicolumn{1}{c|}{ Autor } & Situação \\
\hline Informações Básicas & PB_INFORMAÇÕES & $29 / 01 / 2021$ & & Aceito \\
& BÁSICAS_DO_PROJ & $18: 22: 32$ & & \\
& ETO_1595919.pdf & & & \\
\hline Recurso Anexado & questionario.pdf & $29 / 01 / 2021$ & IVES CLAUDIO & Aceito \\
pelo Pesquisador & & $18: 21: 10$ & DA SILVA BUENO & \\
\hline Outros & Cartaaoparecerista.pdf & $\begin{array}{c}29 / 01 / 2021 \\
18: 19: 50\end{array}$ & $\begin{array}{l}\text { IVES CLAUDIO } \\
\text { DA SILVA BUENO }\end{array}$ & Aceito \\
\hline Cronograma & CRONOGRAMA.pdf & $29 / 01 / 2021$ & IVES CLAUDIO & Aceito \\
& & $18: 15: 59$ & DA SILVA BUENO & \\
\hline Orçamento & Orcamento.pdf & $29 / 01 / 2021$ & IVES CLAUDIO & Aceito \\
& & $18: 15: 24$ & DA SILVA BUENO & \\
\hline TCLE / Termos de & TCLE.pdf & $29 / 01 / 2021$ & IVES CLAUDIO & Aceito \\
Assentimento / Justificativa & & $18: 15: 05$ & DA SILVA BUENO & \\
deAusência & & & & \\
\hline Declaração do Patrocinador & declaracaodospatrocin & $17 / 01 / 2021$ & IVES CLAUDIO & Aceito \\
& adores.pdf & $22: 15: 57$ & DA SILVA BUENO & \\
\hline Declaração de Pesquisadores & declaracaodospesquis & $17 / 01 / 2021$ & IVES CLAUDIO & Aceito \\
& adores.pdf & $22: 02: 18$ & DA SILVA BUENO & \\
\hline Folha de Rosto & folhaDeRosto.pdf & $21 / 07 / 2020$ & IVES CLAUDIO & Aceito \\
& & $08: 34: 39$ & DA SILVA BUENO & \\
\hline Projeto Detalhado / & Projeto.pdf & $18 / 07 / 2020$ & IVES CLAUDIO & Aceito \\
Brochura Investigador & & $17: 21: 56$ & DA SILVA BUENO & \\
\hline Declaração de concordância & declaracao.pdf & $13: 47: 53$ & IVES CLAUDIO & Aceito \\
& & & \\
\hline
\end{tabular}

\footnotetext{
Endereço: Prédio Central do Campus USP ¿Fernando Costa¿. Sala 12417 (ao lado do Banco do Brasil). 


\section{USP - FACULDADE DE ZOOTECNIA E ENGENHARIA DE ALIMENTOS DA UNIVERSIDADE DE SÃO}

Continuação do Parecer: 4.548.303

Situação do Parecer:

Aprovado

Necessita Apreciação da CONEP:

Não

PIRASSUNUNGA, 19 de

fevereiro de 2021

Assinado por:

Judite das Graças Lapa

Guimarães(Coordenador(a))

Endereço: Prédio Central do Campus USP ¿Fernando Costa ¿. Sala 12417 (ao lado do Banco do Brasil). 
À mãe natureza, suporte de tudo o que amo na Terra.

Aos meus avós e minha mãe, Ernesto, Isabel e Luz Dary, que sempre me apoiaram, tornando-se minha maior motivação.

A minha namorada Yuli, a quem admiro profundamente, e agradeço seu apoio, companhia e amor.

Aos meus irmãos e meu pai, Andres, Yesid e Carlos, quem apesar das nossas diferenças, sempre têm me apoiado.

Ao Brasil e sua gente, por me brindar com a oportunidade de renascer intelectualmente. 


\section{AGRADECIMENTOS}

Agradeço à Universidade de São Paulo (USP) que me recebeu com os braços abertos e me permitiu evoluir pessoal e profissionalmente. Agradeço também à Faculdade de Engenharia de Alimentos e Zootecnia (FZEA) e ao Departamento de Nutrição e Produção Animal (VNP) da Faculdade de Medicina Veterinária e Zootecnia (FMVZ), que me acolheram desde minha chegada ao Brasil e fizeram de minha estada uma boa experiência. Obrigado!

Dou meus mais sinceros agradecimentos ao Prof. Dr. Augusto Hauber Gameiro, pela disposição e dedicação de me orientar, ensinar e ajudar ao longo desta etapa da minha vida. Obrigado por me obsequiar com essa visão holística do mundo e por motivarem a ir além da produção animal. Agradeço a confiança em mim depositada e pela amizade. Você é um grande ser humano, verdadeiro educador e orientador.

Ao Prof. Dr. Ives Bueno da Silva, que foi uma excelente pessoa e profissional comigo ao longo do meu processo de formação na USP. Agradeço a liberdade e confiança oferecida no desenvolvimento desta pesquisa. Você sempre esteve à disposição para me ajudar e apoiar em tudo o que foi necessário.

Ao amigo e Doutor Gustavo Sartorello Lineu, pela paciência e disposição de me ajudar a ser melhor profissional. Sempre serei agradecido pelo seu apoio e amizade oferecidos ao longo da minha estada no Brasil. Seus conhecimentos foram fundamentais na elaboração desta dissertação.

Sem dúvidas, a Síntese em Emergia é a coluna estrutural desta pesquisa, e sem o entendimento dos aportes feito pelo Ecólogo Howard Thomas Odum, esta dissertação não poderia ter sido feita. Por isso, agradeço ao Prof. Dr. Feni Agostinho, que sempre esteve à disposição para me ensinar e explicar esta metodologia. Além disso, suas

contribuições intelectuais foram de grande importância na construção do presente trabalho. Obrigado!

Ao meu amigo Rafael, que também foi peça fundamental no entendimento da Síntese em Emergia. Agradeço muito sua paciência e tempo, foram muitas as horas de 
reunião e discussão sobre a Emergia. Tenho a certeza de que você vai ser um pesquisador referência no mundo da Emergia.

Agradeço aos membros pertencentes ao Grupo de Estudo em Síntese em Emergia (EMgrupo): Prof. Augusto, Rafael, Vanessa, Miguel, Vitória, Taynara, Carmo, Tamires e Belni. Foram muitas as horas nas que estudamos as obras do Odum, e com certeza foi tudo esse trabalho em equipe que me ajudou na compreensão teórica da Síntese em Emergia.

Manifesto meus mais sinceros agradecimentos ao Dr. Hélio de Almeida Ricardo e à Associação Paulista de Criadores de Ovinos (ASPACO), que me ajudaram na procura dos sistemas de produção ovinos que foram avaliados nesta pesquisa. Do mesmo modo, agradeço aos produtores que participaram deste trabalho: Márcio, Marina e José. Foram eles quem me abriram as postas das suas fazendas e me permitiram fazer este belo trabalho.

Agradeço à Yuli Peña, Andréia Bonelli e José de Oliveira (“Joca”) pela ajuda, apoio e disposição na coleta dos dados primários deste trabalho; sem vocês isto não teria sido possível.

Aos meus amigos do Laboratório de Análises Socioeconômicas e Ciência Animal (LAE) e do Laboratório de Fermentabilidade Ruminal (LFR): Prof. Augusto, Gustavo, Rafael, Laya, Vanessa, Ricardo, Leriana, Andréia, Carmo, Miguel, Guilherme, Cinthia, Joca, Beatriz, Taynara, Vitória, Prof. Ives, Richard, Yuli, Priscila, Rafaela e Anne, pela amizade, apoio e carinho ao longo deste caminho. Vocês se tornaram minha família neste belo país.

Quero a gradecer ao meu amigo Ricardo Barboza que me ajudou a redescobrir o gosto e a importância de conhecer a história da humanidade. Além disso, você juntamente com o Prof. Augusto -, inspirou o meu carinho, orgulho e sentido de pertencimento ao povo Latino-americano, nosso povo!

Agradeço à minha família da Colômbia, pelo apoio e motivação de lutar pela vida, Ernesto (Papí), Isabel (Chabela), Luz Dary (Madre mia), Yuli (Jacinta), Carlos, 
Andres, Yesid, Isaac, Mariana, Yaqueline, Jhon, Yuli, Ivan, Jhoana, Richard, Santy, Ernesto, Jeisson, Johan; a "La Pandillita", Richar, Carlos, Cristian, Deicy y Sebastian, pela sua amizade, vocês se tornaram mais que amigos, vocês se converteram parte da minha família. Também agradeço aos meus sogros Ligia e Efraín pelo apoio ao longo destes anos.

Ao Branco, Agatha, Jujuba e Alicia: seu apoio emocional foi fundamental na escrita desta dissertação.

À Coordenação de Aperfeiçoamento de Pessoal de Nível Superior - Brasil (CAPES) - Código Financeiro 001, e à Fundação de Amparo à Pesquisa do Estado de São Paulo (Fapesp), pelo auxílio financeiro ao projeto 2020/10039-5, sem as quais não teria sido possível a minha dedicação integral ao mestrado.

Por fim, quero deixar expresso meus puros sentimentos de gratidão ao Brasil e ao seu povo, pois é graças a vocês que pude fazer o mestrado. Serei eternamente agradecido pela oportunidade. Se no mundo todo tivesse feito o que a USP e o Brasil fizeram por mim (sem dar importância à nacionalidade, cor, raça nem ideologia), nossa sociedade seria totalmente diferente. Por isso, devemos aprender a pensar como sociedade e não como indivíduo, pois todos vivemos no mesmo sistema (a Terra) que é caraterizado por possuir limites biofísicos e recursos naturais finitos, os quais devemos alocar de maneira realmente racional, pensando em todos os seres vivos com quem convivemos e não apenas no lucro que estes possam nos deixar. 
"Há algo de fundamentalmente errado em tratar a Terra como se fosse um negócio em liquidação".

Herman E. Daly

"Hay algo fundamentalmente incorrecto en tratar la Tierra como si fuera un negocio en liquidación". Herman E. Daly

"There is something fundamentally wrong in treating the Earth as if it were a business in liquidation". Herman E. Daly 


\section{RESUMO}

ROJAS-MORENO, D. A. Avaliação econômica e emergética da ovinocultura paulista. 2021. 198 p. Dissertação de Mestrado (Mestrado em Ciências) - Faculdade de Zootecnia e Engenharia de Alimentos, Universidade de São Paulo, Pirassununga, 2021.

A ovinocultura tem demostrado um papel de destaque no setor agropecuário brasileiro nas duas últimas décadas. Contudo, o crescimento da população, o aumento da demanda de produtos alimentares e o sistema econômico atual, têm forçado os ovinocultores a implementar estratégias e tecnologias que aumentem sua produtividade e eficiência, para se manterem ativos no mercado. Apesar disso, em um mundo com recursos finitos e limites biofísicos, o crescimento econômico contínuo torna-se insustentável, repercutindo de maneira negativa o simples incremento da produtividade e do consumo na degradação dos ecossistemas naturais. Neste sentido, o presente estudo teve dois objetivos principais: i) realizar diagnóstico do desempenho econômico e ambiental da produção de cordeiros de corte sob diferentes níveis de tecnificação no Estado de São Paulo, Brasil; e ii) propor um novo esquema de alocação dos fluxos emergéticos baseado nos tipos de custos segundos os preceitos da Teoria Econômica Neoclássica. Foram realizadas visitas a campo com entrevistas aos proprietários de três propriedades características do estado de São Paulo (sistemas denominados: Intensivo, Confinamento e Semi-intensivo). Por outro lado, na proposta conceitual foram utilizados conceitos teóricos tanto como da Teoria dos Custos e da Síntese em Emergia. $\mathrm{Na}$ análise econômica foram considerados todos os itens de custo, divididos em: custos variáveis (VCost); custos fixos operacionais (FCost); e remuneração de fatores de produção (capital variável, fixo e da terra); sendo o custo total (TCost) a somatória de todos os custos envolvidos na produção. Além dos custos, foram levados em consideração indicadores de desempenho econômico, como: lucro líquido (NProf) e a relação custo-benefício (CBR). Em relação à avaliação de desempenho ambiental foi utilizada a Síntese em Emergia, sendo calculados índices: Transformidade (Tr), Renovabilidade (\%Ren), Razão de rendimento emergético (EYR), Razão de

investimento emergético (EIR), Razão de carga ambiental (ELR), Índice de 
sustentabilidade emergético (ESI), e Índice de intercâmbio emergético (EER). As análises foram realizadas no software Microsoft Excel®, a partir da caracterização de cada uns dos sistemas avaliados. Observou-se que o sistema Semi-intensivo foi o único sistema que apresentou prejuízo econômico, com um NProf de US\$ -7.922, exibindo um CBR de -0,10. Em contraste, Confinamento e Intensivo apresentaram lucros positivos de US\$ 9.845 e US $\$ 4.287$, na devida ordem, obtendo CBR de 0,06 e 0,05, respetivamente. No desempenho ambiental, Semi-intensivo foi aquele que apresentou a maior renovabilidade (\%Ren $=30,63 \%)$, seguido de Confinamento $(22,46 \%)$ e Intensivo $(19,81 \%)$. Quanto à dependência do sistema econômico, Confinamento foi a propriedade mais dependente $(E I R=101,01)$, seguida por Intensivo e Semi-intensivo (11,94 e 5,75). Por outo lado, Intensivo e Confinamento foram os sistemas que apresentaram maior carga ambiental (ELR, 4,05 e 3,45, respetivamente) e menor sustentabilidade ambiental (ESI, 1,08 e 1,01, respetivamente), quando compradas com os valores do sistema Semi-Intensivo $(E L R=2,26$ e $E S I=1,17)$. Com base nestes resultados, o primeiro estudo mostrou que o atual sistema econômico influencia na insustentabilidade ambiental da produção ovina, uma vez que os ovinocultores, em busca da lucratividade, estão sendo pressionados a utilizar maior quantidade de insumos não-renováveis para se tornarem mais competitivos. Este comportamento gera efeitos negativos sobre o ambiente.

Palavras-chaves: Gestão de custos. Pressão ambiental. Contabilidade biofísica. Economia Ecológica. Decrescimento econômico. 


\section{ABSTRACT}

Rojas-Moreno D.A. Economic and Emergetic Evaluation of Sheep Farming in São Paulo. [Avaliação Econômica e Emergética da Ovinocultura Paulista.]. 2021. 198 p. Master's thesis (Master's in Science) - Faculty of Animal Science and Food Engineering, University of Sao Paulo, Pirassununga, 2021

Sheep farming has shown a prominent role in the Brazilian agricultural sector in the last two decades. However, population growth, increased demand for food products and the current economic system have forced sheep farmers to implement strategies and technologies that increase their productivity and efficiency, to remain active in the market. Despite this, in a world with finite resources and biophysical limits, continuous economic growth becomes unsustainable, reflecting the increase in productivity and consumption in the degradation of natural ecosystems. In this sense, the present study had two main objectives: i) to carry out a diagnosis of the economic and environmental performance of meat lamb production under different levels of technification in the State of São Paulo, Brazil; and ii) to propose a new allocation scheme for emergy flows based on the types of costs according to the precepts of neoclassical economic theory. Field visits were carried out with interviews with the owners of three representative farms of the state of São Paulo, with different levels of technification (Intensive, Feedlot and Semi-Intensive). On the other hand, theoretical concepts were used in the conceptual proposal, such as Cost Theory and Emergy Synthesis (ES). In the economic analysis, all cost items were considered, divided into variable costs (VCost); fixed operating costs (FCost); and remuneration of production factors (variable, fixed and land capital); the total cost (TCost) being the sum of all costs involved in production. In addition to costs, economic performance indicators were considered, such as: net profit (NProf) and the cost-benefit ratio (CBR). Regarding the assessment of environmental performance, the Emergy Synthesis was used, and the indexes: Transformity ( $\operatorname{Tr}$ ), Renewability (\%Ren), Emergy Yield Ratio (EYR), Emergy Investment Ratio (EIR), Environmental Charge Ratio (ELR), Emergy Sustainability Index (ESI), and Emergy Exchange Index (EER) were calculated. Analyzes were performed using Microsoft Excel® software. It was observed that the Semi-intensive system was the only system that showed economic loss, with an 
NProf of US $\$-7,922$, exhibiting a CBR of -0.10 . In contrast, Feedlot and Intensive positive values of US $\$ 9,845$ and US $\$ 4,287$, in this order, with CBRs of 0.06 and 0.05 , respectively. In relation to environmental performance, Semi-intensive was the farm with the highest renewability (\%Ren $=30.63 \%$ ), followed by Feedlot $(22.46 \%$ ) and Intensive (19.81\%). As for dependence on the economic system, Feedlot was the most dependent farm $(E I R=101.01)$, followed by Intensive and Semi-Intensive (11.94 and 5.75). On the other hand, Intensive and Feedlot were the systems that presented the highest environmental load (ELR, 4.05 and 3.45, respectively) and the lowest environmental sustainability (ESI, 1.08 and 1.01, respectively), when purchased with the Semiintensive system values $(E L R=2.26$ and $E S I=1.17)$. Based on these results, the study showed that the current economic system influences the environmental unsustainability of sheep production, since sheep farmers, in search of profitability, are being pressured to use non-renewable inputs to be more competitive. This behavior generates negative effects on the environment.

Keywords: Costs management. Environmental pressure. Biophysical accounting. Ecological Economy. Economic degrowth. 


\section{RESUMEN}

Rojas-Moreno D.A. Evaluación Económica e Emergética de la Ovinocultura

Paulista. [Avaliação Econômica e Emergética da Ovinocultura Paulista.]. 2021. 198 p. Tesis de Maestría (Maestría en Ciencias) - Facultad de Zootecnia e Ingeniería de alimentos, Universidad de Sao Paulo, Pirassununga, 2021

La producción ovina ha desempeñado un papel relevante en el sector agropecuario brasileño en las últimas dos décadas. Sin embargo, el crecimiento de la población, el aumento de la demanda por productos alimenticios y el sistema económico actual, han obligado a los productores a implementar estrategias y tecnologías que aumentan su productividad y eficiencia, con el fin de mantenerse activos en el mercado. A pesar de esto, en un mundo con recursos finitos y límites biofísicos, el crecimiento económico continuo se vuelve insostenible, impactando negativamente el simple aumento de la productividad y el consumo en la degradación de los ecosistemas naturales. En este sentido, el presente estudio tuvo dos objetivos principales: i) realizar un diagnóstico del desempeño económico y ambiental de la producción de engorde de corderos bajo diferentes niveles de tecnificación en el Estado de São Paulo, Brasil; y ii) proponer un nuevo esquema de asignación de flujos de emergía, basado en los tipos de costos según los preceptos de la Teoría Económica Neoclásica. Se realizaron visitas de campo con entrevistas a los propietarios de tres predios característicos (Intensivo, Confinamiento y Semi-Intensivo). Por otro lado, en la propuesta conceptual se utilizaron conceptos teóricos como la Teoría de Costos y la Síntesis Emergética. En el análisis económico se consideraron todos los ítems de costos, divididos en: costos variables (VCost); costos operativos fijos (FCost); y remuneración de los factores de producción (capital variable, fijo y de la tierra); siendo el costo total (TCost) la sumatoria de todos los costos involucrados en la producción. Además de los costos, se tomaron en cuenta indicadores de desempeño económico, tales como: utilidad neta (NProf) y la relación costo-beneficio (CBR). En relación a la evaluación del desempeño ambiental, se utilizó la contabilidad en emergía, para el cálculo de los índices de: Transformidad (Tr), Renovabilidad (\% Ren), Relación de rendimiento en emergía (EYR), Ratio de inversión en emergía (EIR), Relación de carga ambiental (ELR), Índice de sostenibilidad en 
emergía (ESI) y el índice de intercambio en emergía (EER). Los análisis fueron realizados mediante el uso del software Microsoft Excel®. Se observo que el sistema Semi-intensivo fue el único sistema que mostró pérdidas económicas, con un NProf de US\$ -7.922, exhibiendo un CBR de -0,10. En contraste, Confinamiento e Intensivo obtuvieron valores positivos de US\$ 9.845 y US\$ 4.287, respectivamente, y CBR de 0,06 y 0,05 , respectivamente. En relación al desempeño ambiental, Semi-intensivo fue el sistema que presento mayor renovabilidad (\%Ren $=30,63 \%)$, seguido de Confinamiento $(22,46 \%)$ e Intensivo $(19,81 \%)$. En cuanto a la dependencia del sistema económico, Confinamiento fue la propiedad más dependiente $(E I R=101,01)$, seguida de Intensivo y Semi-Intensivo (11,94 y 5,75). Por otro lado, Intensivo y Confinamiento fueron los sistemas que presentaron mayor carga ambiental (ELR, 4,05 y 3,45, respectivamente) y menor sustentabilidad ambiental (ESI, 1,08 y 1,01, respectivamente), cuando se compraron con los valores del sistema Semi-intensivo. $(E L R=2,26$ y $E S I=1,17)$. Con base en estos resultados, el primer estudio mostró que el sistema económico actual influye en la insostenibilidad ambiental de la producción ovina, ya que los ovinocultores, en busca de rentabilidad, están siendo presionados a utilizar una mayor cantidad de insumos no renovables para ser más competitivos. Este comportamiento tiene efectos negativos sobre el medio ambiente.

Palabras claves: Gestión de costos. Presión ambiental. Contabilidad biofísica. Economía Ecológica. Decrecimiento económico. 


\section{LISTA DE TABELAS}

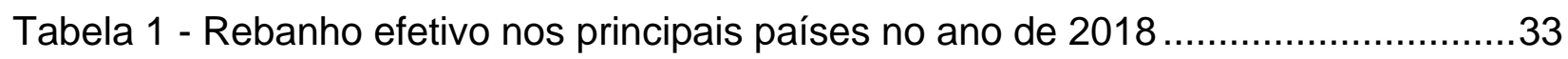

Tabela 2 - Principais países exportadores de carne de cordeiro em 2017 ....................34

Tabela 3 - Principais países importadores de carne de cordeiro em 2017...................34

Tabela 4 - Comportamento do rebanho efetivo brasileiro entre os anos de 2009 e 2018

Tabela 5 - Número de frigoríficos e abatedouros de ovinos registrados no Brasil por região

Tabela 6 - Principais índices zootécnicos das propriedades representativas para as regiões do Brasil em 2016

Tabela 7 - Efetivo total do rebanho do Estado de São Paulo por regiões intermediárias

Tabela 8 - Esquema de organização de uma tabela de cálculo dos fluxos de emergia .71

Table 9 - Main characteristics of the three evaluated sheep farm systems ..................98

Table 10 - Description of the economic indices used in this study ............................100

Table 11 - Description of the emergy indices used in this study .................................102

Table 12 - Economic indicators for the three lamb farms evaluated ............................104

Table 13 - Emergy flows of the three sheep production systems evaluated (emergy flows

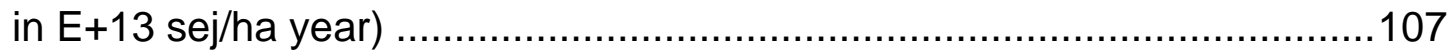

Table 14 - Emergy indices for the three sheep production systems evaluated in this work 112

Table 15 - Intensive sheep farming system of full-cycle (Intensive) ..........................148

Table 16 - Intensive lamb finishing system (Feedlot) .............................................149

Table 17 - Semi-intensive sheep farming system with lamb finishing (Semi-intensive) 150

Table 18 - Annual costs for the production of meat lambs in the Intensive sheep farming

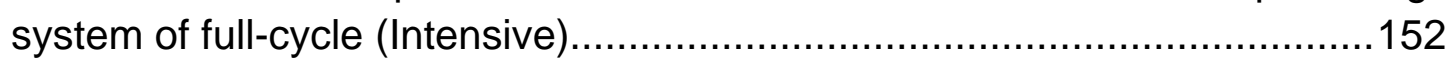

Table 19 - Annual costs for the production of meat lambs in the Intensive lamb finishing system (Feedlot)

Table 20 - Annual costs for the production of meat lambs in the Semi-intensive sheep farming system with lamb finishing (Semi-intensive).... 
Table 21 - Emergy tables with detailed calculations of flows of Intensive sheep farming

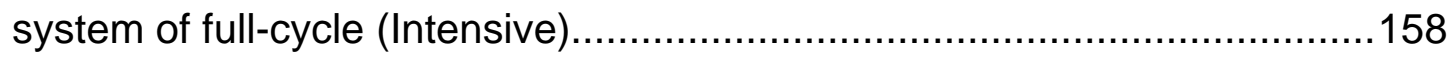

Table 22 - Detailed calculations for the emergy flows of Intensive sheep farming system

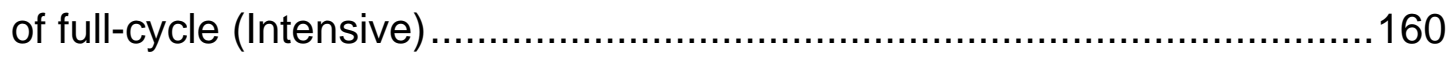

Table 23 - Emergy tables with detailed calculations of flows of Intensive lamb finishing

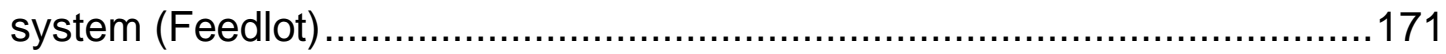

Table 24 - Detailed calculations for the emergy flows of Intensive lamb finishing system (Feedlot)

Table 25 - Emergy tables with detailed calculations of flows of Semi-intensive sheep farming system with lamb finishing (Semi-intensive) 183

Table 26 - Detailed calculations for the emergy flows of Semi-intensive sheep farming system with lamb finishing (Semi-intensive) 185 


\section{LISTA DE FIGURAS}

Figura 1 - Importações de carne de cordeiro no Brasil entre o 2009 e 2018 ..................37

Figura 2 - Tipos de sistemas termodinâmicos .......................................................57

Figura 3 - Fluxo de energia e matéria segundo a economia ecologia ..........................60

Figura 4 - Abordagens para a estimativa dos valores do capital natural .......................65

Figura 5 - Diagrama que mostra a transformação do fluxo de energia .........................67

Figura 6 - Diagrama de fluxo da energia e o dinheiro operando dentro da estrutura

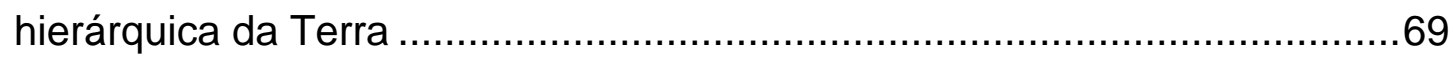

Figura 7 - Representação de um diagrama de fluxo de energia de um sistema tradicional de cordeiros de corte.............................................................

Figura 8 - Diagrama do processo da troca de emergia solar e da transação econômica na venda de carcaça de cordeiro e a forma como ela é calculada.................75

Figure 9 - General flow diagrams of the three evaluated sheep farms systems .............96

Figure 10 - Representation of an energy flow diagram of representative a sheep production system

Figure 11 - Representation of the emergy flows (in \%) on total emergy for each lamb farm system evaluated

Figure 12 - Emergy performance profile of the farming systems evaluated

Figure 13 - Relationship between global efficiency and the emergy sustainability index (ESI) for the three evaluated sheep farms.

Figure 14 - Comparison between the market price, cost of production and emergy cost of the lamb carcass $\mathrm{kg}$ of the three sheep farms considered

Figura 15 - Diagrama de energia de um sistema de produção ovina tradicional..... 135

Figura 16 - Diagrama do processo da troca de emergia solar e da transação econômica na venda de carcaça de cordeiro e a forma como ela é calculada.

Figura 17 - Diagrama de energia exemplificando os fluxos fixos e variáveis que inferem na produção de cordeiro de corte.

Figure 18 - Energy diagram of Intensive sheep farming system of full-cycle (Intensive)

Figure 19 - Energy diagram of Intensive lamb finishing system (Feedlot) 156

Figure 20 - Energy diagram of Semi-intensive sheep farming system with lamb finishing (Semi-intensive). 


\section{LISTA DE QUADROS}

Quadro 1 - Alocação dos custos de um sistema de produção de suínos ........................48

Quadro 2 - Alocação dos custos de produção para bovinos confinados .........................49

Quadro 3 - Alocação dos custos de produção agrícola ................................................49

Quadro 4 - Alocação dos custos de produção na ovinocultura paulista ..........................50

Quadro 5 - Alocação dos custos de produção na ovinocultura no Paraná ......................51

Quadro 6 - Esquema resumido de alocação dos fluxos de emergia em um sistema de

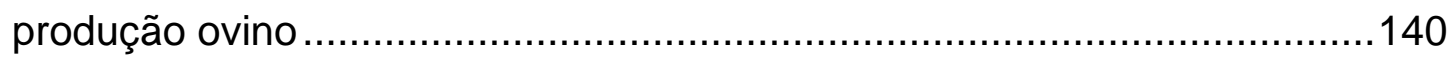




\section{SUMÁRIO}

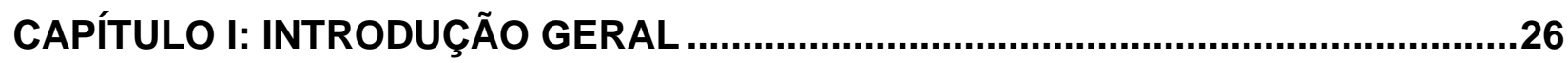

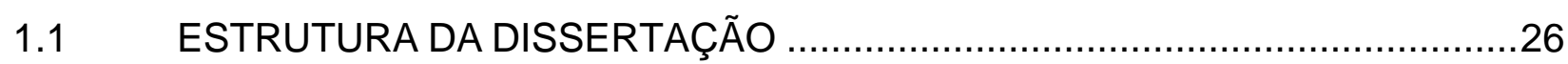

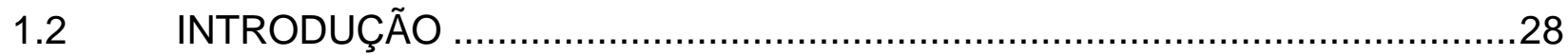

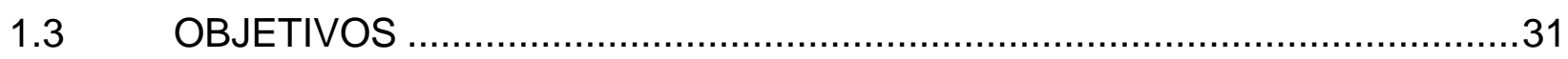

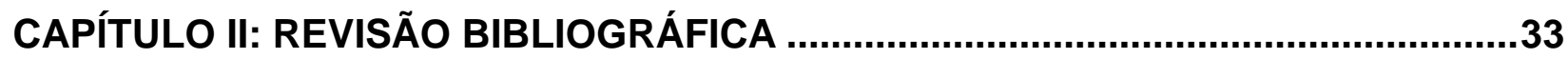

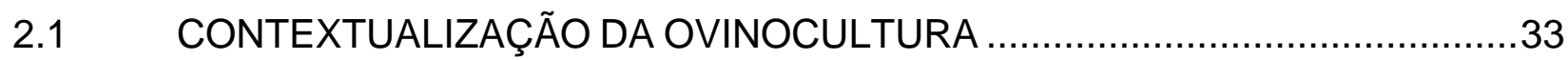

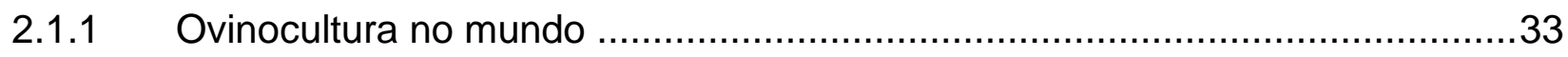

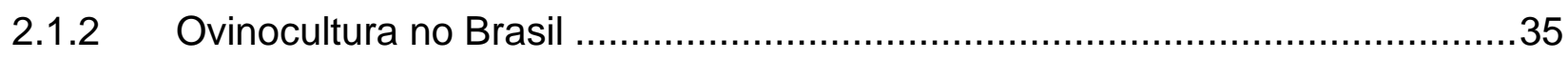

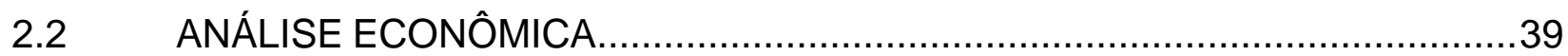

2.2.1 Uma breve introdução ao pensamento econômico do custo ............................40

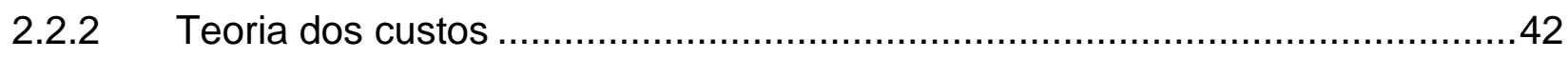

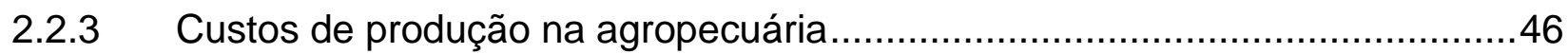

2.2.3.1 Alocação dos custos de produção na ovinocultura........................................50

2.3 IMPACTO AMBIENTAL E MUDANÇA CLIMÁTICA ....................................51

2.3.1 O impacto ambiental e seu efeito na agropecuária ........................................53

2.3.2 Desenvolvimento sustentável na agropecuária ...........................................54

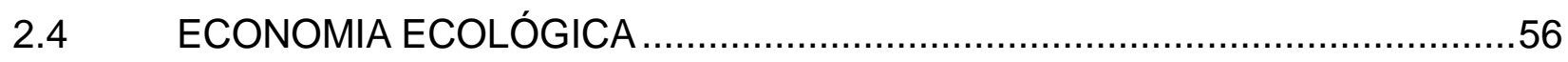

2.4.1 Origem do pensamento econômico-ecológico................................................56

2.4.2 As leis da Termodinâmica como base da Economia Ecológica.......................58

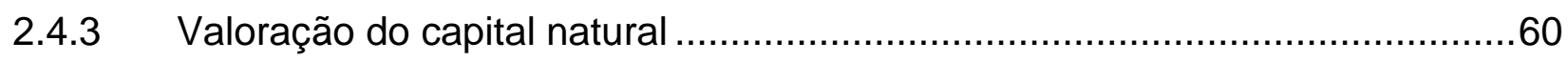

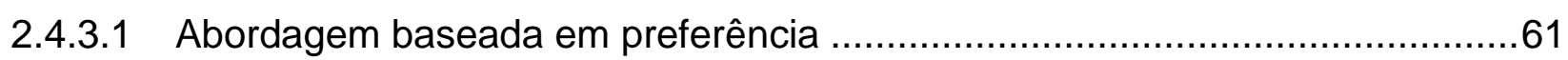

2.4.3.2 Abordagem de Contabilidade Biofísica.........................................................63

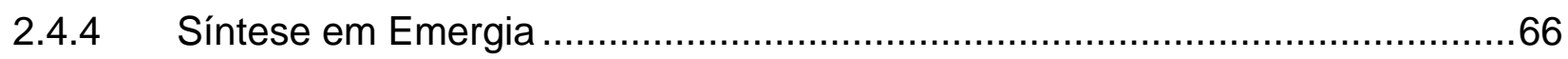

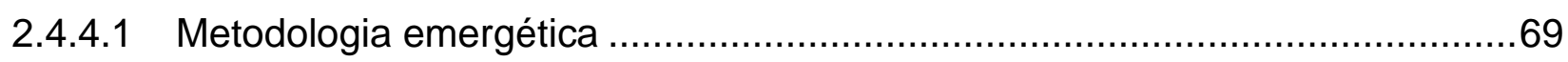

2.4.4.2 Síntese em Emergia na ovinocultura ...........................................................

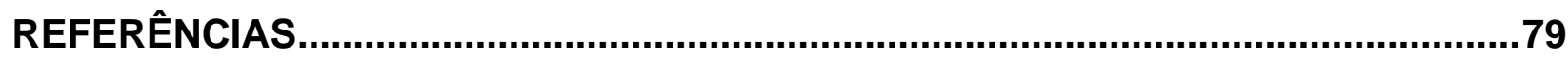


CAPÍTULO III: CAN WE OBTAIN HIGHER PRODUCTIVITY ALLIED TO ENVIRONMENTAL GAINS? AN EMERGY-ECONOMIC STUDY OF SHEEP

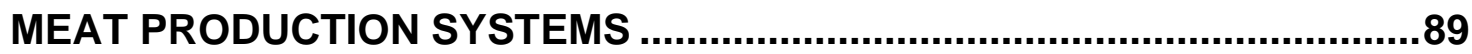

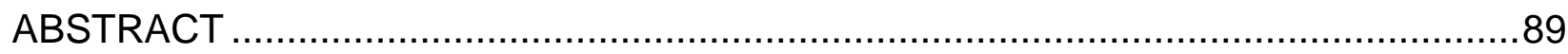

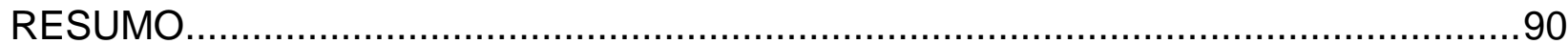

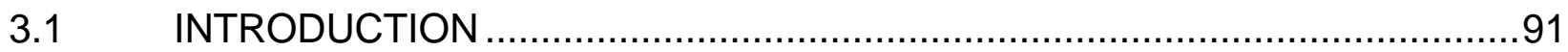

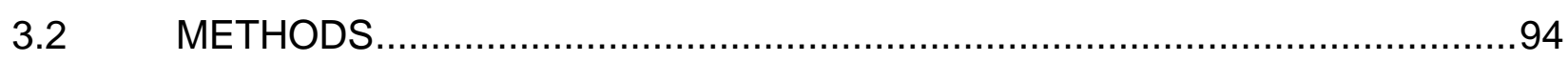

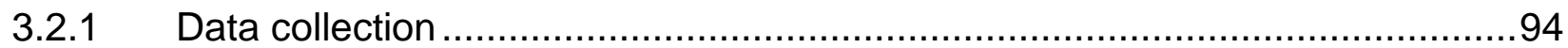

3.2.2 Description of the evaluated sheep farming systems .................................95

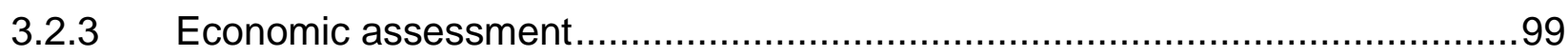

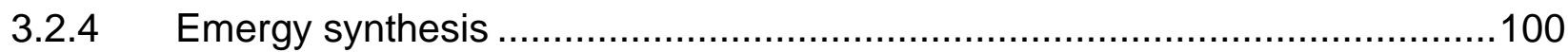

3.2.5 Method of analysis and discussion of results............................................. 103

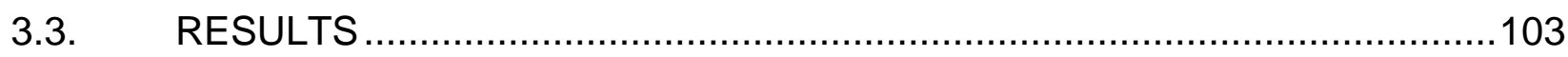

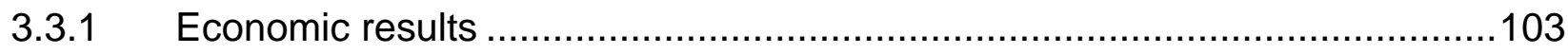

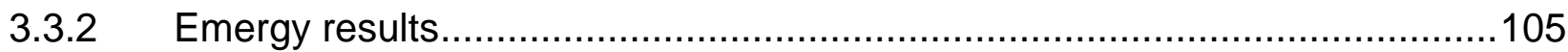

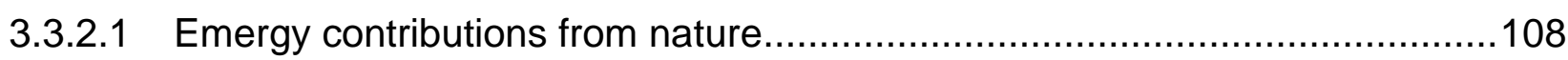

3.3.2.2 Emergy feedback from the larger economy .............................................. 108

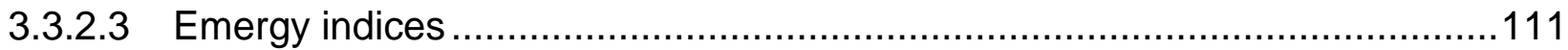

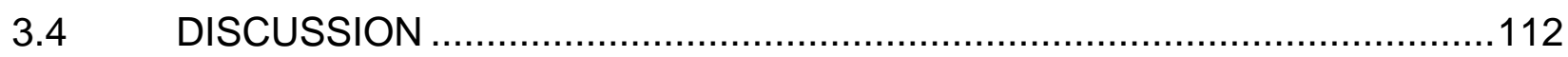

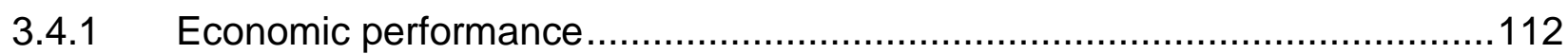

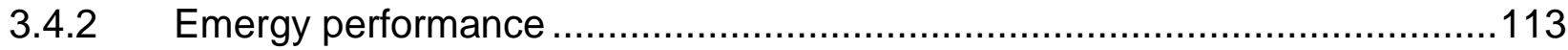

3.4.3 Traditional economy and emergy: divergencies and complementary views ..115

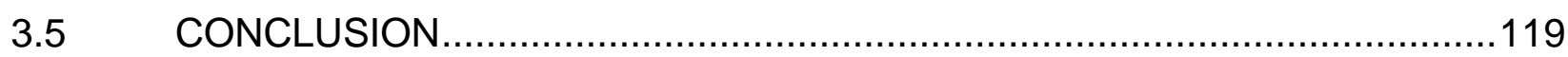

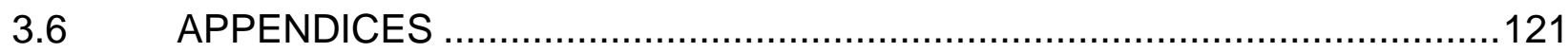

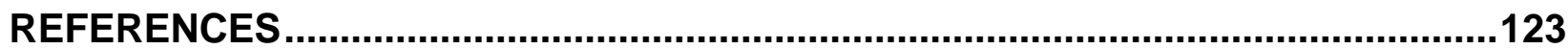

CAPÍTULO IV: A SÍNTESE EM EMERGIA COMO FERRAMENTA DE CUSTEIO E GESTÃO ECONÔMICO-AMBIENTAL: PROPOSTA CONCEITUAL NA AGROPECUÁRIA ...........................................................................130

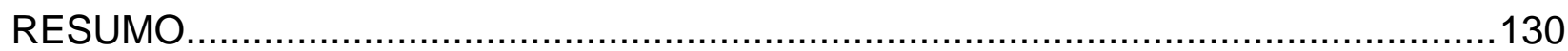

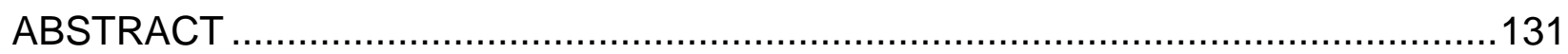


4.1 ASPECTOS TEÓRICOS.

4.1.1 Teoria e conceito de mensuração dos custos de produção .........................131

4.1.2 Teoria e conceitos relacionados à Síntese em Emergia................................134

4.2 ALOCAÇÃO DOS FLUXOS EMERGÉTICOS BASEADO NO TIPO DE CUSTO:

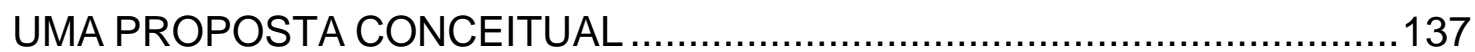

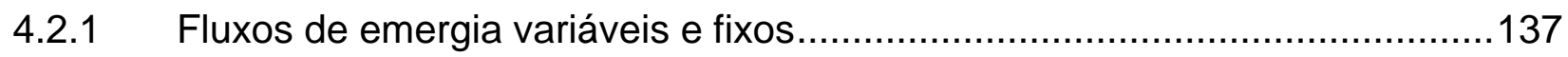

4.2.2 Fluxos de emergia variáveis e fixos provenientes da natureza ....................138

4.2.3 Fluxos de emergia variáveis e fixos do feedback da economia....................139

4.2.4 Fluxo de emergia total e alocação geral dos fluxos .....................................139

4.3 CONSIDERAÇÕES SOBRE A PROPOSTA ............................................142

$4.4 \quad$ PROPOSTA PARA TRABALHOS FUTUROS ............................................. 142

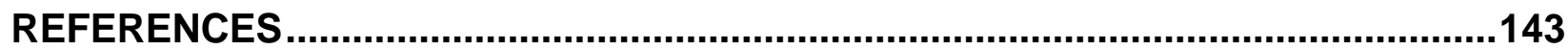

CAPÍTULO V: CONSIDERAÇÕES FINAIS ........................................................146

SUPPLEMENTARY MATERIAL ......................................................................148

6.1 SUPPLEMENTARY MATERIAL A - CHARACTERIZATION AND PRODUCTIVE INDICES OF

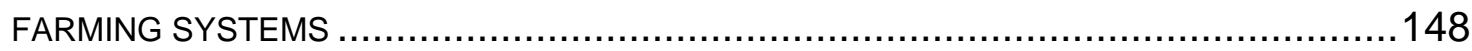

6.2 SUPPLEMENTARY MATERIAL B - ECONOMIC ANALYSIS .....................................152

6.3 SUPPLEMENTARY MATERIAL C - ENERGY DIAGRAMS OF THE THREE CONTRASTING

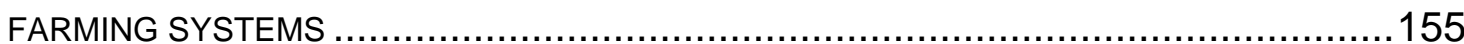

6.4 SUPPLEMENTARY MATERIAL D - EMERGY TABLES WITH DETAILED CALCULATION OF FLOWS AND RENEWABILITY FRACTION...................................................... 158

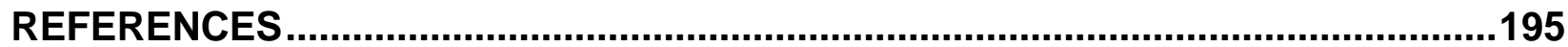




\section{CAPÍTULO I: INTRODUÇÃO GERAL}

\subsection{ESTRUTURA DA DISSERTAÇÃO}

A presente dissertação foi organizada em formato de artigos e está composta por cinco capítulos. Assim, para facilitar o entendimento do conjunto da obra, bem como da pesquisa realizada, o Capítulo I comtempla o componente textual introdutório, a problemática envolvida e a justificativa da pesquisa. Na sequência, encontram-se os objetivos que nortearam o desenvolvimento do estudo.

O Capítulo I/ apresenta a revisão bibliográfica, base para o andamento deste trabalho. A revisão foi segmentada em quatro grandes tópico principais: i) Contextualização da ovinocultura, no qual apresentam-se informações relevantes sobre o cenário da ovinocultura mundial, brasileira e paulista, de forma de facilitar a compreensão dos fatores que caracterizam a ovinocultura no estado de São Paulo; ii) Análise econômica, na qual discorre-se acerca da Economia e em especial sobre a Teorias de Custos, ressaltando seu contexto histórico, e importância destes nos sistemas produtivos, além de alguns exemplos metodológicos aplicados ao setor; iii) Impacto ambiental e mudança climática: passa-se a tratar os efeitos dos processos produtivos sobre os ecossistemas naturais; e por fim, iv) Economia ecológica, na qual trata-se do desenvolvimento do pensamento econômico-ecológico e seus avanços na valoração do capital natural, fazendo-se ênfase na metodologia de contabilidade biofísica, chamada de Síntese em Emergia (ODUM, 1996), cujo método é baseado no ponto de vista da biosfera, sendo contabilizadas as contribuições da natureza por meio dos recursos naturais que usualmente são considerados "gratuitos" pelas análises econômicas convencionais.

O primeiro artigo produto desta pesquisa contempla o Capítulo III. Neste artigo foram tomados os resultados das duas metodologias aplicadas no estudo (custos de produção e Síntese em Emergia). Posteriormente foi feita uma discussão de forma isolada, tanto para os resultados econômicos, quanto para os indicadores emergéticos. Na sequência, foram utilizados alguns indicadores das duas metodologias e apresentada uma discussão abrangente, na qual lavado em conta o componente econômico e ecológico, analisandos as forças e fraquezas desses componentes dentro de cada sistema. 
No Capítulo IV estruturou-se, de forma concisa, uma proposta conceitual na utilização dos tipos de custos (fixos e variáveis), caraterizados pela Teoria de Custos, na alocação dos fluxos de emergia (recursos da natureza e do sistema econômico) obtidos pela Síntese em Emergia.

As considerações finais da presente dissertação são expostas como um todo no Capítulo $V$, incluindo os fatos relevantes da pesquisa e suas implicações.

Por fim, na seção Supplementary Material encontra-se o material que contém as características e indicadores zootécnicos de cada propriedade avaliada neste estudo, como também, os resultados detalhados das análises econômicas e emergéticas base desta pesquisa. 


\subsection{INTRODUÇÃO}

Ao longo dos 4.550 milhões de anos que tem a Terra, a vida tem evoluído de diferentes formas, dando origem a infinidade de espécies animais e vegetais, e consigo diversos ecossistemas. Um claro exemplo do "sucesso" evolutivo somos nós, os Homo sapiens, espécie que no princípio viveu sob as restrições impostas pelos sistemas ecológicos. Contudo, após da descoberta da agricultura e a domesticação dos animais, por volta do ano 10.000 a.C., e mais tarde com a revolução industrial no século XVIII, e posterior revolução verde na segunda metade do século XX, os sapiens conseguiriam a colonização do globo terrestre, alterando os ecossistemas naturais na procura do seu "bem-estar".

Este processo evolutivo levou as sociedades a tornarem-se cada vez maiores e complexas, exigindo um aumento na produtividade e eficiência dos diferentes setores produtivos. Nessa ordem de ideias, o desenvolvimento de teorias e indicadores de desempenho por parte da economia tem se tornado importante para o avanço das sociedades. Um indicador que é amplamente utilizado pelo sistema econômico moderno é o Produto Interno Bruto (PIB), índice que quantifica monetariamente os bens e serviços finais produzidos em uma região, país, estado ou cidade em determinado período. Deste modo, estimou-se que o PIB mundial de 2020 foi de US\$ 84,7 trilhões (WORLD BANK, 2021a), no qual a economia brasileira se posicionou como a $12^{\underline{a}}$ maior economia do mundo, com um PIB de aproximadamente US\$1,4 trilhões ou $\mathrm{R} \$ 7,45$ trilhões. Contudo, o Brasil se tornou a $2^{-}$maior economia do continente americano, depois dos Estados Unidos e a $1^{\underline{a}}$ da América Latina e o Caribe, representando o $29,8 \%$ do PIB desta última região para o ano 2020 (WORLD BANK, 2021b).

De acordo com o Instituto Brasileiro de Geografia e Estatística - IBGE (2021), o setor agropecuário apresentou participação de 6,8\% do PIB nacional em 2020, com um valor de $\mathrm{R} \$ 506,45$ bilhões; além disso, este setor tem exibido um crescimento médio anual de 5,5\% nas últimas duas décadas (entre 2000 e 2020). Segundo dados do Censo Agropecuário 2017 (IBGE, 2019), no Brasil há cerca de 5,1 milhões de estabelecimentos agropecuários, que ocupam $41 \%$ da área total do país (351,2 milhões de hectares). Entretanto, ao comparar esses valores com dados do Censo Agropecuário 2006 (IBGE, 2006), observou-se aumento de 5,8\% na área 
de ocupação da terra, mas, apesar desse aumento, o número de unidades produtivas rurais diminuiu 2,6\% (130.806 unidades rurais) entre 2006 e 2017.

Desde os anos 90, com a abertura comercial do Brasil, a competição entre os agentes econômicos tem aumentado, com uma tendência de redução das margens de lucratividade. No caso da ovinocultura, o comportamento tem sido um pouco diferente. Entre os anos 2008 e 2018 houve crescimento de 12,7\% no rebanho efetivo (IBGE, 2019) e nas importações de carne ovina, as quais estiveram em torno das 83 mil toneladas anuais (AGROSTAT, 2019). Entretanto, em relação ao número de unidades produtivas ovinas nas regiões Sudeste e Centro-Oeste evidenciou-se redução de 33,5\% e 10,6\%, respectivamente, entre 2006 e 2017, sendo as regiões Nordeste, Norte e Sul as que impulsaram o crescimento do rebanho efetivo (EMBRAPA, 2018).

Não obstante a evidente redução da atividade ovina na região Sudeste, não se evitou que o estado de São Paulo, seja considerado como um dos principais mercados consumidores desta espécie no país (FIRETTI et al., 2017), não apenas pela sua alta população (IBGE, 2021), mas também pela alta concentração de abatedouros certificados para ovinos: $28 \%$ do total nacional (EMBRAPA, 2019). Apesar do papel de destaque, $77,7 \%$ dos sistemas produtivos ovinos no estado de São Paulo são constituídos por fazendas com uma superfície inferior a 50 ha (EMBRAPA, 2018), produto da decorrência e competição por terras por parte de outras atividades agrícolas, como a produção de cana-de-açúcar (GABARDO; CALDARELLI, 2016; RUDORFF et al., 2010).

Sob essa ótica, a produção ovina tem se mostrado como uma atividade com crescimento promissório, não só pelo seu mercado, mas também, como alternativa de diversificação para os sistemas agropecuários, sendo um importante componente de resiliência de alguns sistemas (FARIAS et al., 2014). Ainda assim, na busca da rentabilidade econômica, os ovinocultores da região têm sido estimulados a adotar práticas de produção cada vez mais intensivas, visando aumentar sua produtividade em menor tempo e área. Cabrera (2014) concluiu que o sucesso empresarial dos sistemas agropecuários depende de inúmeras variáveis que se afetam mutuamente, e em alguns casos o produtor tem pouco e nenhum controle sobre elas, como, por exemplo, condições ambientais, o preço de compra de insumos, e/ou o preço de 
venda do produto no mercado. Portanto, ações como nutrição, sanidade, produtividade e administrativas, que resultam no aumento da produtividade ou diminuição dos custos, e que possam ser controladas pelo produtor, precisam de maior atenção (GAMEIRO, 2009).

Analisando os dados apresentados para o Brasil do ponto de vista da economia neoclássica a qual se baseia no crescimento econômico, é possível evidenciar que o setor agropecuário, inclusive a ovinocultura, tem colaborado no desenvolvimento da sociedade brasileira. Contudo, a intensificação da produção agropecuária não só interfere no incremento da produtividade e dos indicadores econômicos, mas é também no aumento do uso intensivo da terra e de insumos não renováveis, em detrimento do potencial produtivo futuro, comprometendo a segurança alimentar no longo prazo (BARIONI et al., 2019; TILMAN; CLARK, 2014). Além disso, a intensificação aumenta a discrepância entre os interesses econômicos e a conservação dos ecossistemas naturais, estimulando o aumento da problemática ambiental (CASTELLINI et al., 2006; SMITH et al., 2016; WILHELM; SMITH, 2018). Deste modo, na busca por satisfazer as necessidades atuais da sociedade e alcançar aumento da lucratividade, surge o problema do desequilíbrio entre eficiência e sustentabilidade ambiental, onde, geralmente, sistemas com altos níveis de produtividade e lucratividade apresentam baixos níveis de sustentabilidade (KOCJANČIČ et al., 2018; PAUL et al., 2019). Portanto, apresenta-se o seguinte questionamento: é possível alcançar um equilíbrio entre o desempenho econômico e a sustentabilidade ambiental na produção de cordeiros?

De acordo com diversos autores (CECHIN, 2010; DALY; FARLEY, 2011; ODUM; ODUM, 2001), a análise do desempenho global de um sistema deve levar em consideração não só os fluxos econômicos, mas torna-se importante contemplar também os fluxos de energia e materiais que compõem o funcionamento do sistema. Odum (1996), com uma visão abrangente, propôs a Síntese em Emergia, metodologia que estima as contribuições dos ecossistemas naturais e do sistema econômico em termos de energia solar agregada, ou emergia utilizada na geração de recursos, produtos ou serviços. Deste modo a Síntese em Emergia proporciona uma análise integral das ações antrópicas na biosfera (BROWN; ULGIATI, 2004a, 2004b). 
$\mathrm{Na}$ literatura científica encontram-se diferentes pesquisas com foco no entendimento dos sistemas de produção ovinos. Por um lado, tem se utilizado a teoria de custos na avaliação da competitividade produtiva destes sistemas em termos meramente econômicos (BARROS et al., 2009; DEBORTOLI et al., 2021; MENDES et al., 2016; RAINERI; ROJAS; GAMEIRO, 2015; RAINERI; STIVARI; GAMEIRO, 2015b). Por outro lado, a Síntese em Emergia tem sido utilizada na avaliação e caraterização do nível de sustentabilidade ambiental (HADEN, 2002; RODRÍGUEZ-ORTEGA et al., 2017; SALAS et al., 2017). Apesar disso, os resultados obtidos nestes estudos, por não possuir uma integração dos conjuntos econômico e ecológico nas suas análises, às vezes, tornam-se inapropriados para avaliar ou generalizar os resultados da ovinocultura paulista. Em vista disso, aplicar uma abordagem que caracterize o desempenho econômico e emergético dos diferentes níveis de tecnificação utilizados pela ovinocultura de corte desta região, torna-se em uma interessante oportunidade de pesquisa, devido ao fato de que a ausência de uma visão abrangente do setor, pode implicar na criação de barreiras que dificultem a tomada de decisões políticas e privadas em matéria de produção e impacto ambiental.

Isso demostra a importância de desenvolver trabalhos que permitam analisar os diferentes tipos de sistemas produtivos ovinos no estado de São Paulo, possibilitando caracterizar os perfis de desempenho econômico e ambiental destes sistemas, e assim, poder contribuir com resultado e conclusões científicas que auxiliem a tomada de decisão. Por conseguinte, o presente trabalho tem por objetivo realizar um diagnóstico do desempenho econômico e ambiental da produção de cordeiro de corte sob diferentes níveis de tecnificação no Estado de São Paulo, Brasil.

\subsection{OBJETIVOS}

Objetivo geral

Realizar um diagnóstico do desempenho econômico e ambiental por meio da integração de aspectos da teoria de custos e a Síntese em Emergia na produção de 
cordeiro de corte sob diferentes níveis de tecnificação no Estado de São Paulo, Brasil.

Objetivos específicos

i. Realizar levantamento do perfil técnico-produtivo de três propriedades representativas do Estado de São Paulo, com diferentes níveis de tecnificação na criação de cordeiros de corte;

ii. Determinar os custos de produção e as receitas de cada sistema produtivo analisando-os de acordo aos preceitos da Teoria Econômica;

iii. Avaliar o desempenho ambiental de cada um dos sistemas produtivos analisados utilizando como instrumento a Síntese em Emergia;

iv. Realizar uma análise comparativa entre a eficiência produtiva e o nível de sustentabilidade ambiental dos sistemas analisados;

v. Estimar o preço de equilíbrio que deveria de ser pago pelo quilograma de carcaça de cordeiro para cada um dos sistemas analisados, por meio do índice de Razão de Intercâmbio Emergético (EER);

vi. Realizar uma análise comparativa entre o preço de mercado, o custo de produção e o preço de equilíbrio do quilograma de carcaça de cordeiro dos sistemas analisados; $\mathrm{e}$

vii. Propor um modelo conceitual que integre aspectos da teoria de custos na Síntese em Emergia, visando contabilizar o custo de produção biofísico em Emdólar para a produção de cordeiros de corte. 


\section{CAPÍTULO II: REVISÃO BIBLIOGRÁFICA}

\subsection{CONTEXTUALIZAÇÃO DA OVINOCULTURA}

\subsubsection{Ovinocultura no mundo}

Entre o 2009 e 2018, a ovinocultura no mundo apresentou crescimento de 8,9\% (FAOSTAT, 2019). O rebanho efetivo passou de 1.102 milhões em 2009 para 1.209 milhões de ovinos em 2018. No entanto, $45,6 \%$ do rebanho efetivo encontrase localizado em dez países, dos quais a China possui mais de $13 \%$, conforme é demostrado na Tabela 1. O Brasil ocupou a décima nona posição (19ª) neste ranking, sendo o primeiro país do continente americano com o maior rebanho efetivo (FAOSTAT, 2019).

Tabela 1 - Rebanho efetivo nos principais países no ano de 2018

\begin{tabular}{clrc}
\hline Posição & \multicolumn{1}{c}{ País } & $\begin{array}{c}\text { Efetivo do rebanho } \\
\text { (animais) }\end{array}$ & $\begin{array}{c}\text { Proporção do } \\
\text { total mundial }(\%)\end{array}$ \\
\hline 1 & China & 164.079 .093 & 13,57 \\
2 & Austrália & 70.067 .316 & 5,80 \\
3 & Índia & 61.666 .343 & 5,10 \\
4 & Nigéria & 42.971 .860 & 3,55 \\
5 & Sudão & 40.846 .000 & 3,38 \\
6 & Irã & 39.670 .704 & 3,28 \\
7 & Reino Unido & 33.781 .000 & 2,79 \\
8 & Ucrânia & 33.677 .636 & 2,79 \\
9 & Chade & 33.215 .051 & 2,75 \\
10 & Etiópia & 31.688 .157 & 2,62 \\
\hline
\end{tabular}

Fonte: FAOSTAT (2019), adaptado pelo autor.

Por sua vez, Austrália e Nova Zelândia foram considerados os principais exportadores de carne de cordeiro no mundo, tendo uma participação do $69,6 \%$ das exportações realizadas em 2017 (Tabela 2). Em relação ao continente americano, Uruguai é um dos principais exportadores deste produto, com uma participação de $0,9 \%$ das exportações realizadas no mundo para aquele mesmo ano (FAOSTAT, 2019). 
Tabela 2 - Principais países exportadores de carne de cordeiro em 2017

\begin{tabular}{clrc}
\hline Posto & \multicolumn{1}{c}{ País } & Toneladas & $\begin{array}{c}\text { Proporção do total } \\
\text { exportado (\%) }\end{array}$ \\
\hline 1 & Austrália & 426.587 & 36,19 \\
2 & Nova Zelândia & 394.494 & 33,47 \\
3 & Reino Unido & 89.221 & 7,57 \\
4 & Irlanda & 55.546 & 4,71 \\
5 & Países Baixos & 36.811 & 3,12 \\
6 & Espanha & 35.242 & 2,99 \\
7 & Índia & 22.889 & 1,94 \\
8 & Bélgica & 13.769 & 1,17 \\
9 & Uruguai & 11.307 & 0,96 \\
10 & Emirados Árabes & 9.130 & 0,77 \\
\hline \multicolumn{4}{c}{ Fonte: FAOSTAT (2019), adaptado pelo autor. }
\end{tabular}

Em 2017 foram comercializadas no mercado internacional cerca de 1,2 milhão de toneladas de carne de cordeiro, cujos principais consumidores foram a China, que apesar de contar com o maior rebanho efetivo, foi considerado o principal importador, com uma participação do $24 \%$, seguida dos Estados Unidos e da França (Tabela 3) (FAOSTAT, 2019). Por sua vez, o Brasil naquele mesmo ano importou cerca de 8 mil toneladas de carne ovina, tornando-se o principal importador deste produto na América Latina (AGROSTAT, 2019).

Tabela 3 - Principais países importadores de carne de cordeiro em 2017

\begin{tabular}{clrc}
\hline Posto & \multicolumn{1}{c}{ País } & Toneladas & $\begin{array}{c}\text { Proporção do total } \\
\text { exportado (\%) }\end{array}$ \\
\hline 1 & China & 273.223 & 24,05 \\
2 & Estados Unidos & 101.126 & 8,90 \\
3 & França & 88.651 & 7,80 \\
4 & Reino Unido & 75.286 & 6,63 \\
5 & Emirados Árabes & 45.650 & 4,02 \\
6 & Alemanha & 42.716 & 3,76 \\
7 & Malásia & 38.344 & 3,38 \\
8 & Países Baixos & 37.869 & 3,33 \\
9 & Arábia Saudita & 37.018 & 3,26 \\
10 & Jordânia & 24.528 & 2,16 \\
\hline \multicolumn{4}{c}{ Fonte: FAOSTAT (2019), adaptado pelo autor. }
\end{tabular}

A Organização para Cooperação e Desenvolvimento Econômico - OCDE, em conjunto com a $F A O$, em seu último relatório (OCDE/FAO, 2019) projetou aumento da demanda de carne de cordeiro a nível mundial. Isto devido à diminuição da oferta por parte da Oceania, pois se prevê uma redução dos rebanhos na Austrália produto 
das secas, combinado com uma forte demanda da China, em razão da diminuição na produção de carne suína como consequência do surgimento da peste suína. Além disso, segundo o mesmo relatório, a demanda de carne ovina nos países em desenvolvimento seguirá sendo impulsionada pelo crescimento demográfico, a urbanização e pelas variações nas preferências e hábitos alimentares dos consumidores, fortalecendo os preços da carne ovina no mercado (OCDE/FAO, 2019).

\subsubsection{Ovinocultura no Brasil}

A ovinocultura no Brasil tem mostrado crescimento. Dados do IBGE (2019) mostraram que o rebanho efetivo em 2009 passou de 16,8 milhões para 18,9 milhões de ovinos em 2018, incrementando $12,7 \%$ no período. Esse acréscimo foi maior nas regiões Nordeste e Norte do país, com 32,1\% e 21,6\%, respectivamente, naquele mesmo período. Por sua vez, as regiões Sudeste, Sul e Centro-Oeste apresentaram redução no número de animais de $19,9 \%, 16,6 \%$ e $8,9 \%$, na devida ordem (Tabela 4).

Tabela 4 - Comportamento do rebanho efetivo brasileiro entre os anos de $2009 \mathrm{e}$ 2018

\begin{tabular}{lrrrr}
\hline \multicolumn{1}{c}{ Região } & $\begin{array}{c}\text { Número de } \\
\text { Animais 2009 }\end{array}$ & $\begin{array}{c}\text { \% por região } \\
2009\end{array}$ & $\begin{array}{c}\text { Número de } \\
\text { animais 2018 }\end{array}$ & $\begin{array}{c}\text { \% por região } \\
2018\end{array}$ \\
\hline Nordeste & 9.566 .968 & 56,9 & 12.634 .412 & 66,7 \\
Sul & 4.807 .596 & 28,6 & 4.010 .916 & 21,2 \\
Centro-Oeste & 1.127 .878 & 6,7 & 1.027 .452 & 5,4 \\
Norte & 547.146 & 3,3 & 665.370 & 3,5 \\
Sudeste & 762.133 & 4,5 & 610.784 & 3,2 \\
Brasil & 16.811 .721 & 100,0 & 18.948 .934 & 100,0 \\
\hline \multicolumn{4}{c}{}
\end{tabular}

Apesar das regiões Nordeste e Sul possuírem a maior concentração do rebanho ovino em 2018 (87,9\%), estas apresentaram um menor número de frigoríficos e abatedouros registrados pelo Serviço de Inspeção Federal (SIF), dispondo apenas de $20 \%$ destes locais a nível nacional, conforme é demonstrado na Tabela 5 (EMBRAPA, 2019). Assim, é possível observar uma inadequada na distribuição dos abatedouros e frigoríficos pelo território brasileiro, favorecendo, assim, o abate clandestino. Esta informalidade do mercado compromete, por sua vez, a qualidade, segurança sanitária e confiança do consumidor, ocasionando um 
impacto negativo sobre a cadeia produtiva deste setor (RAMOS et al., 2014; FIRETTI et al., 2017).

Tabela 5 - Número de frigoríficos e abatedouros de ovinos registrados no Brasil por região

\begin{tabular}{lrrrr}
\hline \multirow{2}{*}{ Regiões } & \multicolumn{4}{c}{ Frigoríficos e abatedouros } \\
\cline { 2 - 5 } & SIF1 $^{1}$ & $\mathrm{NI}^{2}$ & Total & \% por região \\
\hline Centro-Oeste & 75 & 89 & 164 & 33 \\
Sudeste & 128 & 11 & 139 & 28 \\
Norte & 47 & 51 & 98 & 20 \\
Sul & 2 & 60 & 62 & 12 \\
Nordeste & 34 & 5 & 39 & 8 \\
Brasil & 286 & 216 & 502 & 100 \\
Inspeção Federal; ${ }^{2}$ Não Identificado. Fonte: Embrapa (2019), adaptado pelo autor.
\end{tabular}

Outro aspecto na ovinocultura nacional é o crescimento nas importações de carne de cordeiro acontecidas entre 2009 e 2018. Segundo a base de dados de Estatísticas de Comércio Exterior do Agronegócio Brasileiro - AGROSTAT (2019), neste período foram importadas cerca de 83 mil toneladas de carne ovina, provenientes principalmente de países como Uruguai e Argentina.

Na Figura 1, descreve-se o comportamento instável das importações de carne de cordeiro entre os anos 2009 e 2018, sendo o 2014 o ano com maiores importações deste produto (11,3 mil toneladas), seguida de uma diminuição de $33 \%$ em 2016. Já no ano 2017 e 2018 se observou um novo aumento de $11 \%$, demostrando assim, que os níveis de carne ovina demandados pelo mercado consumidor se encontram acima da oferta nacional desse produto, determinando a necessidade de importações. 
Figura 1 - Importações de carne de cordeiro no Brasil entre o 2009 e 2018

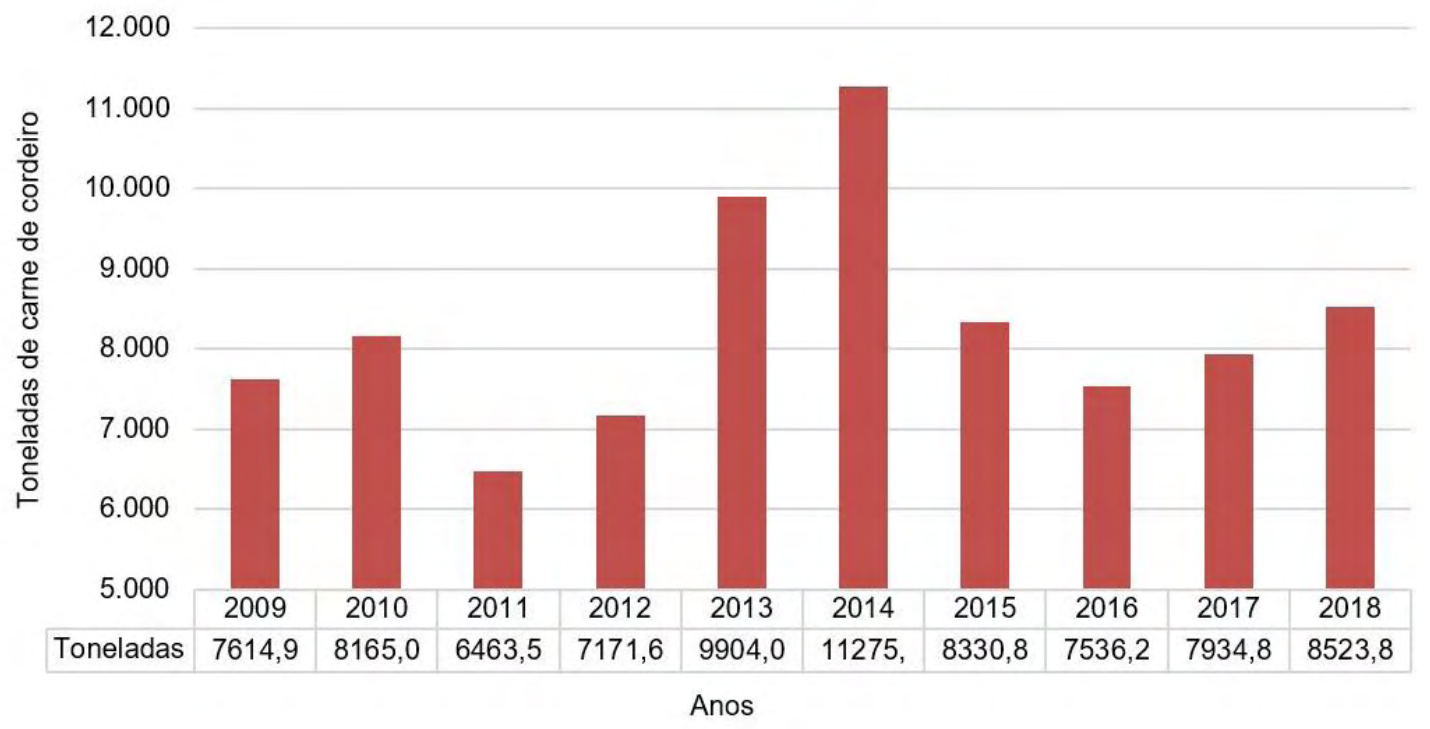

Fonte: AGROSTAT (2019), elaborado pelo autor.

A região Sudeste, apesar de contar com o menor rebanho efetivo do país, apresenta importância notória na comercialização de carne ovina. Silva et al. (2009), Barreto (2010) e Ramos et al. (2014) identificaram que a carne de cordeiro tem conquistado consumidores de diversos centros urbanos nesta região, permitindo ao setor atingir mercados mais exigentes, demandando que os produtores utilizem técnicas mais modernas para estimular o consumo do produto. Por esse motivo, a ovinocultura da região Sudeste quando comparada com as demais regiões do país é conduzida de forma mais intensiva, apresentando uma maior prolificidade, baixa taxa de mortalidade durante a lactação e pós desmama (Tabela 6). Além disso, é influenciada por uma área reduzida das propriedades, maior custo de oportunidade da terra e às exigências do mercado dos consumidores finais, somado a uma maior concentração de centros de pesquisa e universidades (MAGALHÃES et al., 2016; FIRETTI et al., 2017).

Tabela 6 - Principais índices zootécnicos das propriedades representativas para as regiões do Brasil em 2016

\begin{tabular}{lrrrr}
\hline \multicolumn{1}{c}{ Indicador zootécnico } & Nordeste & Sul & Centro-Oeste & Sudeste \\
\hline Taxa de natalidade (\%) & 85 & 75 & 85 & 85 \\
Prolificidade (média) & 1,15 & 1,2 & 1 & 1,3 \\
Taxa mortalidade lactação (\%) & 21,5 & 11 & 25 & 12,5 \\
Taxa mortalidade pós desmame (\%) & 6,5 & 5 & 4,5 & 4 \\
Peso ao desmame (Kg) & 14,5 & 17,5 & 25 & 17 \\
Peso vivo de venda para abate $(\mathrm{Kg})$ & 25,5 & 40 & 35 & 35 \\
\hline
\end{tabular}


O Estado de São Paulo, pertencente à região Sudeste, possui 38,6\% do rebanho efetivo desta região (235.647 animais de 610.754 ovinos de toda a região); $57 \%$ do rebanho efetivo deste estado encontra-se localizado em três das 11 regiões intermediárias (Campinas, São José do Rio Preto e Sorocaba) como se observa na Tabela 7.

Apesar do potencial que apresenta a região Sudeste e nela o Estado de São Paulo (FIRETTI et al., 2017), os sistemas de produção ovinos ainda são caraterizados como unidades de produção de tamanho médio em sua maioria, com proprietários de escolaridade média ou superior, cujo objetivo de produção é a carne, ainda que não seja a principal fonte de renda, ou ao menos para consumo próprio (CARDOSO et al., 2015; EMBRAPA, 2018). Em vista disso, a ovinocultura tornou-se um segmento vulnerável na cadeia agroindustrial, devido às limitações tecnológicas e gerenciais que apresenta, dificultando sua participação ativa na econômica do estado (RAINERI; ROJAS; GAMEIRO, 2015). Assim, o conhecimento e a gestão dos custos de produção são importantes ferramentas para o sucesso da atividade no auxílio da tomada de decisões pelo produtor.

Tabela 7 - Efetivo total do rebanho do Estado de São Paulo por regiões intermediárias

\begin{tabular}{lcc}
\hline $\begin{array}{c}\text { Região Geográfica } \\
\text { Intermediária }\end{array}$ & $\begin{array}{c}\text { Efetivo do } \\
\text { rebanho (animais) }\end{array}$ & $\begin{array}{c}\text { Proporção do total } \\
\text { do estado (\%) }\end{array}$ \\
\hline Campinas & 48.982 & 20,8 \\
São José do Rio Preto & 37.649 & 16,0 \\
Sorocaba & 26.326 & 11,2 \\
Araçatuba & 22.529 & 9,6 \\
Presidente Prudente & 22.241 & 9,4 \\
Marília & 20.196 & 8,6 \\
Bauru & 20.033 & 8,5 \\
Ribeirão Preto & 17.468 & 7,4 \\
Araraquara & 9.827 & 4,2 \\
São José dos Campos & 8.397 & 3,6 \\
São Paulo & 1.999 & 0,8 \\
Total & 235.647 & 100,0 \\
\hline
\end{tabular}

Fonte: IBGE (2019), elaborado pelo autor. 


\subsection{ANÁLISE ECONÔMICA}

A escassez é uma condição universal que surge da falta de recursos necessários para satisfazer as necessidades humanas, quando essas são consideradas ilimitadas. Em um sentido amplo, os recursos e bens podem ser considerados finitos, mas, ao para o ser, as necessidades tornam-se infinitas, devido a isso, a gestão dos recursos apresenta importante relevância para a sociedade. Sob essa ótica, uma definição clássica da economia é o auxílio das decisões racionais no processo de alocação dos recursos escassos diante de usos concorrentes (GAMEIRO, 2009; PEREIRA et al., 1990).

O pensamento econômico é composto por diversas correntes, contudo, a corrente prevalente na atualidade é a Neoclássica. Sob essa ótica, a microeconomia, concentra seus estudos no comportamento dos agentes econômicos (indivíduos e empresas) e sua inter-relação nos mercados (FORTINO, 2012). Para tal fim, a microeconomia tem utilizado a teoria do consumidor no estudo do desempenho dos indivíduos no sistema econômico; enquanto as empresas são analisadas mediante as teorias da produção, dos custos e dos rendimentos, teorias que compõem a teoria econômica das firmas (PASSOS; NOGAMI, 2008).

Na economia capitalista moderna, as firmas convertem-se na unidade básica de produção do sistema econômico, transformando os recursos que de maneira tradicional a economia tem chamado de fatores de produção - terra (recursos naturais), trabalho (pessoas) e capital (maquinário, equipamentos e instalações) em bens e serviços, os quais posteriormente são colocados à disposição dos consumidores para suprir as suas necessidades. Deste modo, as firmas são as encarregadas de produzir a riqueza do sistema econômico (PASSOS; NOGAMI, 2008). Em razão disso, o propósito que norteia as ações de toda organização é a maximização do lucro; contudo, o empresário tem só duas alternativas para alcançar esse objetivo, maximizar a produção para um dado custo ou minimizar o custo para um determinado nível de produção (PINHO, 2013).

Em consequência, o conhecimento e gestão dos custos de produção apresentam especial relevância para as firmas. Contudo, nas empresas do setor agropecuário o destaque ainda deve ser maior, pois estas ao serem tomadoras de 
preços de mercado, a análise de custo torna-se em uma importante ferramenta na procura da maximização do lucro. Assim, antes de passar ao entendimento da teoria dos custos, será apresentada uma breve evolução do pensamento econômico do custo.

\subsubsection{Uma breve introdução ao pensamento econômico do custo}

Em princípio a escola clássica definiu o custo de maneira objetiva. Para Adam Smith - principal representante desta escola - o valor podia ter dois distintos significados, seja por sua utilidade como "valor de uso" ou pelo poder de compra de outros bens como "valor de troca" (BUCHANAN, 1969). Smith (1776) chegaria a esta conclusão pela ideia do paradoxo "água-diamante" por meio do qual concluiu que as coisas que têm grande valor de uso, como a água, geralmente, têm pouco ou nenhum valor de troca. Entretanto, aquelas que têm grande valor de troca, como no caso do diamante, às vezes têm pouco ou nenhum valor de uso, mas, com este podem ser adquiridas maiores quantidades de bens. Em razão disso, Smith voltou sua atenção para a compreensão do denominado "valor de troca", pressupondo que as previsões sobre as relações de produção, as razões entre insumo e produção apresentam precisão consideravelmente maior do que as previsões sobre os padrões da demanda (BUCHANAN, 1969). Em outras palavras, a teoria econômica clássica parte dos custos relativos de produção (insumos utilizados) para definir o valor de troca do produto, dando menor importância à demando do bem. Contudo, esta teoria ao desconsiderar a influência que a demanda tem sobre o valor de troca, deu espaço ao surgimento de novos teóricos e escolas do pensamento.

Ao final do Século XIX nasce o pensamento Neoclássico, no qual a percepção clássica do custo de produção foi substituída pelo princípio da utilidade marginal proposta paralelamente pelos economistas William Stanley na Inglaterra, Carl Menger na Áustria e Léon Walras na Suíça. Estes teóricos se fundamentaram na determinação do valor de troca por meio da utilidade marginal, no qual o valor relativo ou preço de um bem decrescia conforme mais unidades deste eram consumidas (BUCHANAN, 1969; STANLEY, 2006). Assim, os marginalistas consideravam que o valor de troca era determinado pela demanda do produto. No entanto, ao ser substituída a teoria clássica por uma teoria subjetiva, que explicasse os valores da troca por meio das utilidades marginais relativas, teve-se a perda do 
conteúdo objetivo empírico no cálculo do custo de produção clássico (MENGER, 1976).

$\mathrm{Na}$ tentativa de reduzir a subjetividade aderente do modelo marginal, no começo do Século XX a escola de Viena ou também conhecida como escola austríaca, liderada pelo Carl Menger e alguns seguidores, como Böhm-Bawerk e Freidrich Wieser, por meio do uso da lógica dedutiva seguiram uma rota diferente no cálculo do valor de troca. Para esses teóricos o custo de produção devia de ser mensurado monetariamente e refletir o valor da produção que poderia ter sido gerado se os mesmos insumos fossem utilizados racionalmente em atividades alternativas (BUCHANAN, 1969). Desta maneira, a escola austríaca foi a encarregada de dar origem ao denominado "custo de oportunidade", contudo, este custo alternativo era subjetivo devido ao fato de que o valor dos bens e serviços ainda estavam influenciados pela utilidade marginal relativa.

Por outro lado, o economista estadunidense Knight Frank em uma série de trabalhos escritos no final da década de 1920 e início de 1930, estabeleceu a concepção do custo de produto alternativo ou de oportunidade que se tornou o paradigma para a atual Teoria dos Preços (STANLEY, 2006). Para o Knight (1928), em uma primeira instância, o custo de produção de uma unidade era simplesmente medido pelo produto real alternativo que poderia ter sido produzido se os recursos usados na produção tivessem sido racionalmente realocados para outros usos, sendo assim, omitidas as noções de "sacrifício" ou de "gastos". Apesar disso, Knight (1934) tentou modificar sua definição do custo de produção alternativo, ao considerar as diferenças na aplicação e distribuição dos recursos. Knight conclui que se um trabalhador aceita uma recompensa pecuniária inferior pelo seu trabalho mais agradável, o pagamento de uma unidade monetária pelos fatores utilizados na atividade escolhida será transferido para a segunda opção não escolhida, aumentando assim, o valor da segunda opção em mais de uma unidade monetária frente a opção escolhida.

Deste modo, Knight foi o teórico que de fato formulou o conceito do custo de oportunidade, o qual, nada mais é que os benefícios que poderiam ter sido obtidos a partir de uma oportunidade não escolhida, que seria então a segunda melhor opção (BUCHANAN, 1969; RAINERI; ROJAS; GAMEIRO, 2015). Assim, o custo de 
oportunidade de um fator de produção não é apenas o seu melhor uso alternativo interno, mas também o valor de seu melhor uso fora da empresa. Portanto, para determinar o custo de oportunidade de um fator de produção, deve-se considerar o valor da oportunidade renunciada (preço de mercado), atribuindo esse valor ao custo de produção e, consequentemente, ao produto final (SARTORELLO, 2016).

O desenvolvimento no conceito do custo levou ao nascimento de distintas lógicas sobre o mesmo assunto. Assim, a economia e a contabilidade começaram a ter percepções diferentes nas análises dos custos de produção (MARQUES, 2009). Por um lado, as análises contáveis devido a sua função fiscal, só consideram os custos explícitos, que correspondem aos pagamentos que efetua a firma na aquisição dos fatores de produção (saída direita de dinheiro); enquanto que as análises econômicas além de comtemplar os custos explícitos, estas incluem também os implícitos que correspondem ao custo de oportunidade relacionados à utilização dos fatores de produção próprios da empresa, e pelo geral, este custo não envolve uma saída de dinheiro (GAMEIRO, 2009). De acordo com Passo e Nogami (2008), na abordagem neoclássica pode ser definido o custo de oportunidade de uma empresa como a somatória dos custos explícitos mais os implícitos, sendo possível assim, obter o custo de produção "verdadeiro" ou também chamado de custo econômico da firma.

De acordo com essa perspectiva econômica dos custos e na busca para atingir os objetivos deste estudo, se dará sequência à compreensão da teoria dos custos segundo o pensamento econômico neoclássico.

\subsubsection{Teoria dos custos}

A palavra "teoria" refere-se a um conjunto organizado de ideias que tentam explicar um fenômeno, deduzido da observação, experiência ou raciocínio lógico. Por outro lado, a palavra "custo" faz referência à remuneração associada aos fatores de produção alocados em um sistema produtivo, para a produção de bem o serviço. Assim, a Teoria dos Custos está voltada ao estudo, análise e interpretação dos custos de produção que incorrem as firmas no processo produtivo.

Antes de dar sequência à categorização dos custos de produção, é importante entender que na análise do processo de produção (teoria da produção) a 
economia classifica os fatores de produção utilizados em fixos e variáveis, quando se está no chamado "curto prazo" (PASSOS; NOGAMI, 2008). Os fatores fixos envolvem aqueles que não podem ser mudados de imediato no momento em que se deseja uma variação na produção da firma (maquinário, instalações, terra etc.); por outro lado, os fatores variáveis, são aqueles cuja quantidade pode ser variada facilmente, quando se deseja um aumento ou diminuição na produção (mão de obra, combustíveis, insumos alimentares etc.).

Os economistas estabeleceram a noção de períodos de tempos relevantes nas análises das firmas, podendo-se classificar estas em curto e longo prazo. Contudo, o intervalo de tempo não vai depender de um período específico como acontece na contabilidade (KOUTSOYIANNIS, 2002). De acordo com Passo e Nogami (2008), o curto prazo faz referência ao período em que pelo menos um dos fatores de produção tem sua quantidade fixa, seja qual for seu nível de produção. Já quando a firma consegue alterar todos os seus fatores (até então tidos como fixos), seja para mais ou para menos, nesse momento passarão a ser todos os fatores variáveis, e por conseguinte a firma terá atingido o longo prazo. Em razão disso, e de acordo com o foco deste estudo, a análise econômica a ser realizada será de curto prazo.

Da mesma forma que podem ser categorizados os fatores de produção em fixos e variáveis no curto prazo, os custos de produção também conseguem ser classificados em custos fixos, custos variáveis e custo total (KOUTSOYIANNIS, 2002; PASSOS; NOGAMI, 2008).

- $\quad$ Custos fixos (CF)

Estão associados ao emprego dos fatores fixos (instalações, maquinário, reprodutores, matrizes, etc.) tornando-se nos gastos que a firma deve fazer tendo ou não produção. Este tipo de custos caracteriza-se por não variar com o nível de produção e só podem ser eliminados se a empresa deixar de operar.

- Custos variáveis (CV)

Custos associados aos recursos variáveis (mão de obra, insumos alimentares, transporte etc.) os quais variam quando o nível de produção varia. 
- Custo total (CT):

É custo de produção total necessário para a produção de determinada quantidade de produto. Este custo é obtido pela soma dos custos fixos e dos custos variáveis (Equação 1).

$$
C T=C F+C V
$$

Em que:

CT: Custo total;

CF: Custos fixos; e

CV: Custos variáveis.

Diversos autores (KOUTSOYIANNIS, 2002; PASSOS; NOGAMI, 2008; SAMUELSON; NORDHAUS; PEREZ, 2003) têm concluído que uma análise econômica adequada da firma no curto prazo, além de realizar os cálculos dos diferentes tipos de custo nomeados anteriormente, deve conhecer também o comportamento dos custos por unidade ou custos médios (custo fixo médio, custo variável médio) e do custo marginal. Assim, serão apresentadas algumas definições:

- Custo fixo médio (CFMe)

Ao ser CF um valor constante que não é influenciado pelo nível de produção, o valor do CFMe (Equação 2) será sempre decrescente, pois cada unidade produzida representa uma parcela menor do CF:

$$
\text { CFMe }=\frac{C F}{Q}
$$

Em que:

CFMe: Custo fixo médio;

CF: Custos fixos; e

Q: Quantidade total do produto.

- Custo variável médio (CVMe)

Em ração de que $\mathrm{CV}$ inicia em zero e varia conforme aumenta a produção, o CVMe (Equação 3) inicialmente decrescerá até um ponto mínimo, onde iniciará o posterior aumento. 


$$
C V M e=\frac{C V}{Q}
$$

Em que:

CVMe: Custo total;

CV: Custos variáveis; e

Q: Quantidade total do produto.

- $\quad$ Custo médio (CMe)

Refere-se ao custo por unidade de produto. O CMe (Equação 4) será igual ao CT quando seja produzida a primeira unidade. Após disso, o CMe cairá à medida que o CF vai sendo diluído pela adição de novos produtos até atingir um valor mínimo, e sobe em consequência do aumento CV.

$$
C M e=\frac{C T}{Q}
$$

Em que:

CMe: Custo total médio;

CT: Custo total; e

Q: Quantidade total do produto.

- $\quad$ Custo marginal $(\mathrm{Cmg})$

Refere-se às variações de custo, quando se altera a produção. Deste modo, Cmg (Equação 5) mostra o custo adicional que o empresário tem que pagar por cada unidade a mais produzida.

$$
C m g=\frac{\Delta C T}{\Delta Q}
$$

Em que:

Cmg: Custo marginal;

$\Delta \mathrm{CT}$ : Varação no custo total; e

$\Delta \mathrm{Q}$ : Variação quantidade produzida.

Após a compreensão teórica dos custos de produção dá-se sequência à aplicabilidade destes no setor agropecuário. 


\subsubsection{Custos de produção na agropecuária}

O conceito de eficiência produtiva começou a apresentar relevância no processo de modernização do setor agropecuário brasileiro ao longo do século XX, trazendo consigo a necessidade da maximização dos fatores de produção, na procura do aumento nos níveis de produtividade e rentabilidade das firmas (VIANA; SILVEIRA, 2008; VIANA; WAQUIL, 2014). Isto fez com que o empresário rural tivesse que se converter em um tomador de decisões mais profissional. Contudo, o setor produtivo tem se tornado um dos elos mais vulneráveis da cadeia agroindustrial, não só pela pressão de competição e limitações tecnológicas, mas também por não poder controlar os preços de venda dos seus produtos no mercado, convertendo-os em tomadores de preço.

Fundamentando-se nisso, considera-se que o cálculo do custo de produção se converteu uma ferramenta de controle e gerenciamento dos fatores produtivos, ao transformar dados isolados em informações que permitem ao produtor rural conhecer os resultados financeiros obtidos em um determinado período, o que irá apoiá-lo na tomada de decisões assertivas (CONAB, 2010; LAMPERT, 2003; RAINERI; ROJAS; GAMEIRO, 2015).

Raineri et al. (2015) concluíram que o cálculo do custo de produção é o ponto de partida para qualquer análise econômica aplicado aos sistemas agropecuários, devido ao fato de que todo processo, tecnologia ou ação que se queira avaliar, tem um custo envolvido. Apesar da importância que representa o cálculo do custo econômico, não há um protocolo padrão para o cálculo deste e que mensure os diversos parâmetros existentes na produção animal. No entanto, existem vários métodos de cálculo de custos que basearam sua operação nos princípios da teoria de custos, e os mais utilizados são: custeio por absorção, custeio baseado em atividades (ABC), custeio variável, entre outros (CARARETO et al., 2006).

O custeio por absorção é um método derivado da aplicação dos princípios da contabilidade, no qual todos os gastos relacionados à produção (custos variáveis/direitos) são distribuídos na produção, enquanto custos fixos (na sua maioria indiretos) são rateados aos produtos, obtendo assim, um custo mensurável da produção (MAHER, 2001). Por outro lado, o Custeio Baseado em Atividades ou 
$A B C$ pelas suas siglas em inglês (Activity Based Costing) é uma metodologia de rastreamento de custos das atividades ou processos realizados pela firma. Esse método baseia-se no funcionamento do princípio de que não são os produtos que consomem recursos, mas sim as atividades, as quais serão consumidas pelos produtos (DURAN; RADAELLI, 2000; MEGLIORINI, 2006). Atualmente o método $A B C$ tem mostrado avanços e contribuições na gestão da empresa rural (FILIPIN; VIEIRA; WINCK, 2013; ROSADO; LOBATO, 2020; MORAES et al., 2014; VAQUEIRO; JÚNIOR, 2005).

Por sua vez, a aplicação do método de custeio variável fundamenta-se na identificação dos custos variáveis e fixos que incorreu a firma no curto prazo (CARARETO et al., 2006). Esta metodologia de custeio é uma das metodologias mais utilizada na avaliação e gerenciamento das atividades agropecuárias devido a sua simplicidade e objetividade em comparação as anteriores metodologias. Devido a isso, diversos autores e instituições fizeram adaptações da metodologia de acordo as necessidades do sistema produtivo a ser analisado e assim obter um custo mais aproximado à realidade. Alves et al. (2021) propõem uma alocação dos custos da atividade em custos variáveis e fixos operacionais para mensurar o custo operacional da produção de suínos (Quadro 1); além desses custos, foram levados em conta a remuneração do capital e da terra para a obtenção do custo total da produção do cevado por cabeça, por arroba e por quilo vivo produzido em granjas representativas no Estado de São Paulo. 
Quadro 1 - Alocação dos custos de um sistema de produção de suínos

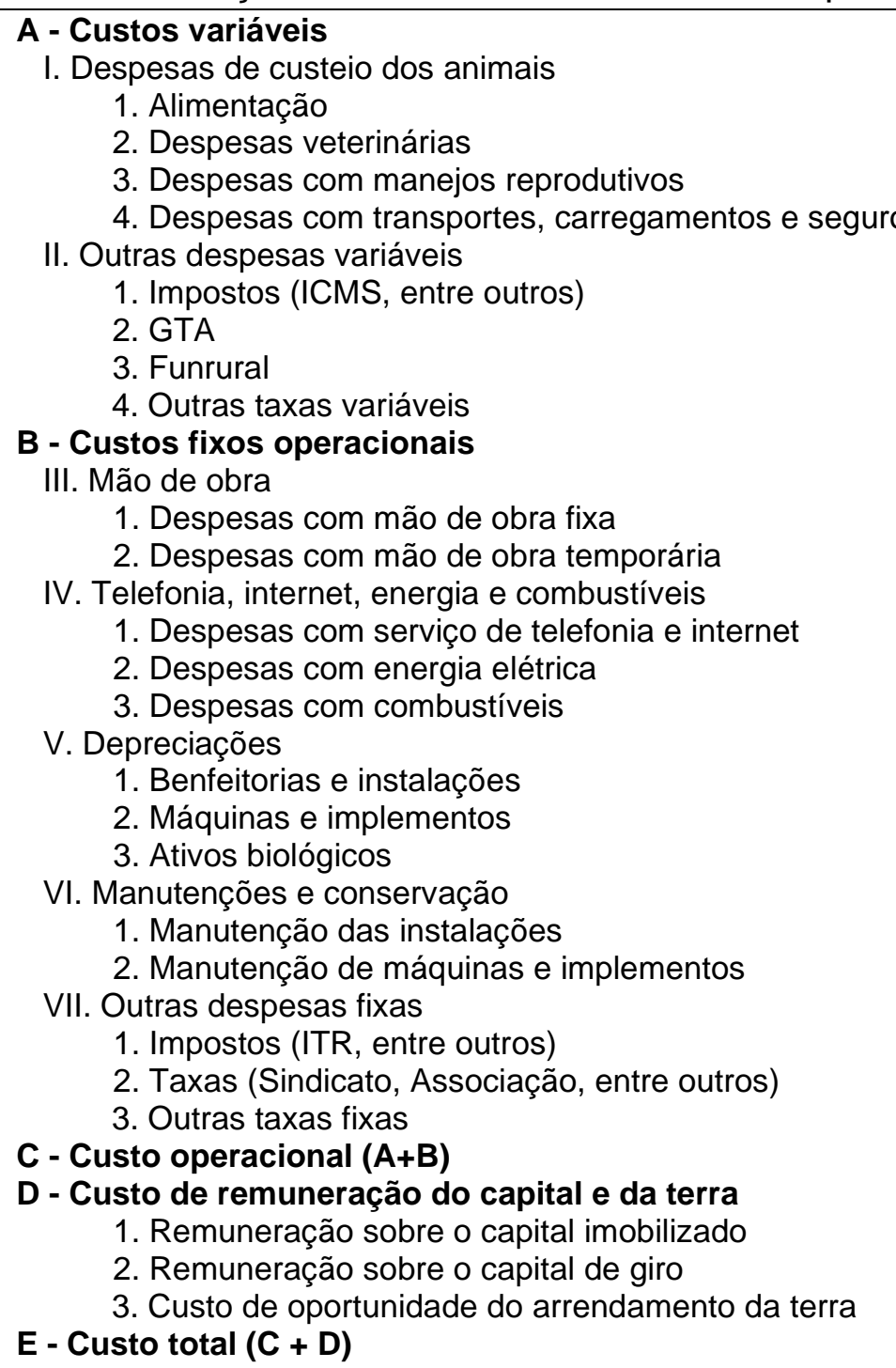

Fonte: Alves (2021), adaptado pelo autor.

Por outro lado, no cálculo do custo econômico por cabeça, arroba e diária de bovinos de corte confinados nos Estados de Goiás e de São Paulo, Sartorello et al. (2018) sugeriram uma alocação de custos na qual além de serem divididos os custos em fixos e variáveis, tiveram em conta os custos semifixos (Quadro 2). Segundo os autores os custos semifixos aumentam à medida que o faz a produção, mas em menor grau quando comparado com as variações dos custos variáveis. 
Quadro 2 - Alocação dos custos de produção para bovinos confinados

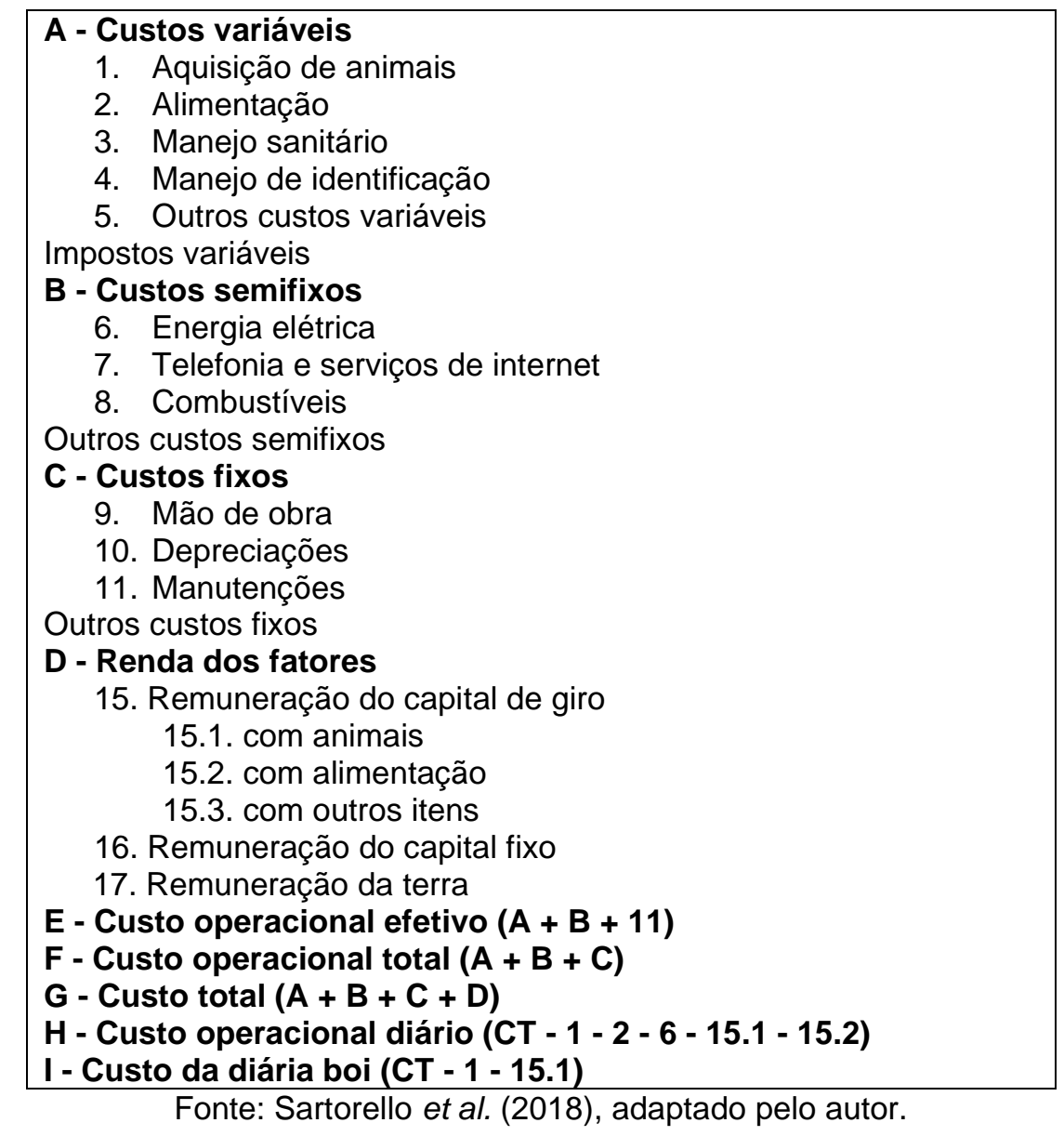

Já a Companhia Nacional de Abastecimento (CONAB, 2010) propôs na produção agrícola uma alocação dos custos (Quadro 3) divididos em itens mais específicos para uma mensuração mais precisa dos custos. Contudo, na remuneração dos fatores foram tidos unicamente a remuneração sobre os fatores fixos (capital fixo e terra), sendo omitido o custo de oportunidade sobre a remuneração dos fatores variáveis.

Quadro 3 - Alocação dos custos de produção agrícola

\begin{tabular}{|l|}
\hline A - CUSTO VARIÁVEL \\
I. Despesas de custeio da lavoura \\
1. Operação com aviões \\
2. Operação com máquinas \\
3. Aluguel de máquinas \\
4. Mão de obra temporária \\
5. Mão de obra permanente \\
6. Sementes \\
7. Fertilizantes \\
8. Agrotóxicos \\
9. Despesas administrativas \\
II. Despesas pós-colheita \\
1. Transporte externo \\
\hline
\end{tabular}




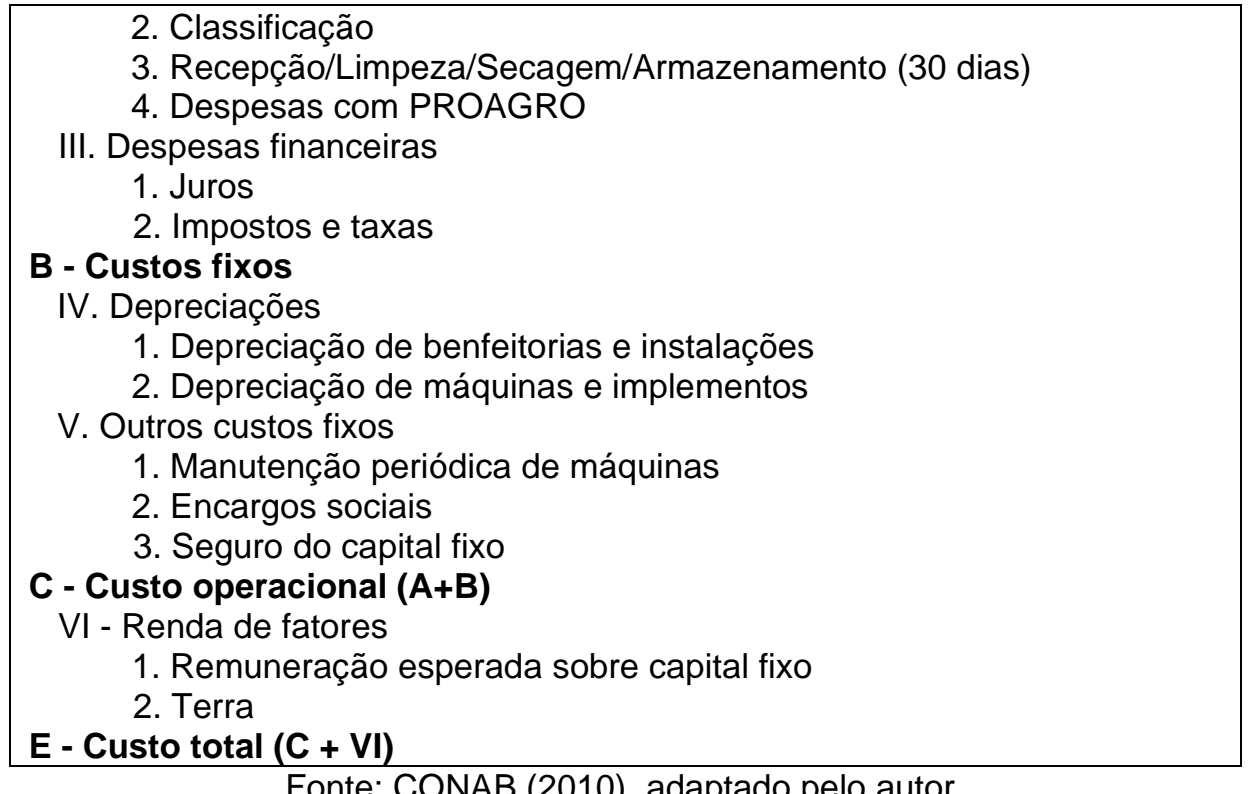

\subsubsection{Alocação dos custos de produção na ovinocultura}

Em relação ao custo de produção dos sistemas de produção ovinos de corte, Raineri et al. (2015a) propuseram um modelo de alocação dos custos composto por custos variáveis, fixos e renda dos fatores, com o intuito de apurar todos os custos e defini-los melhor para os sistemas produtivos do Estado de São Paulo (Quadro 4). Esta alocação permitiu calcular o custo econômico por cabeça, kg de peso vivo e kg de carcaça, unidades que apresentam utilidade na tomada de decisões por parte dos produtores.

Quadro 4 - Alocação dos custos de produção na ovinocultura paulista

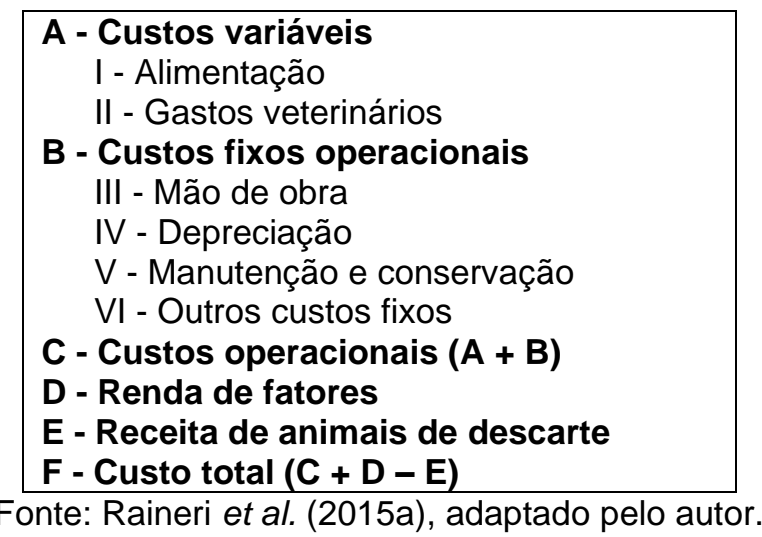

Por outro lado, em estudos mais recentes Debortoli (2017) ao determinar os custos e as receitas nos sistemas de produção de ovinos de corte no estado de Paraná, sugeriram uma locação detalhada dos diferentes gastos que incorreram 
empreendimento rurais, com isso, colaborando na compreensão do custo mais próximo da realidade econômica.

Quadro 5 - Alocação dos custos de produção na ovinocultura no Paraná

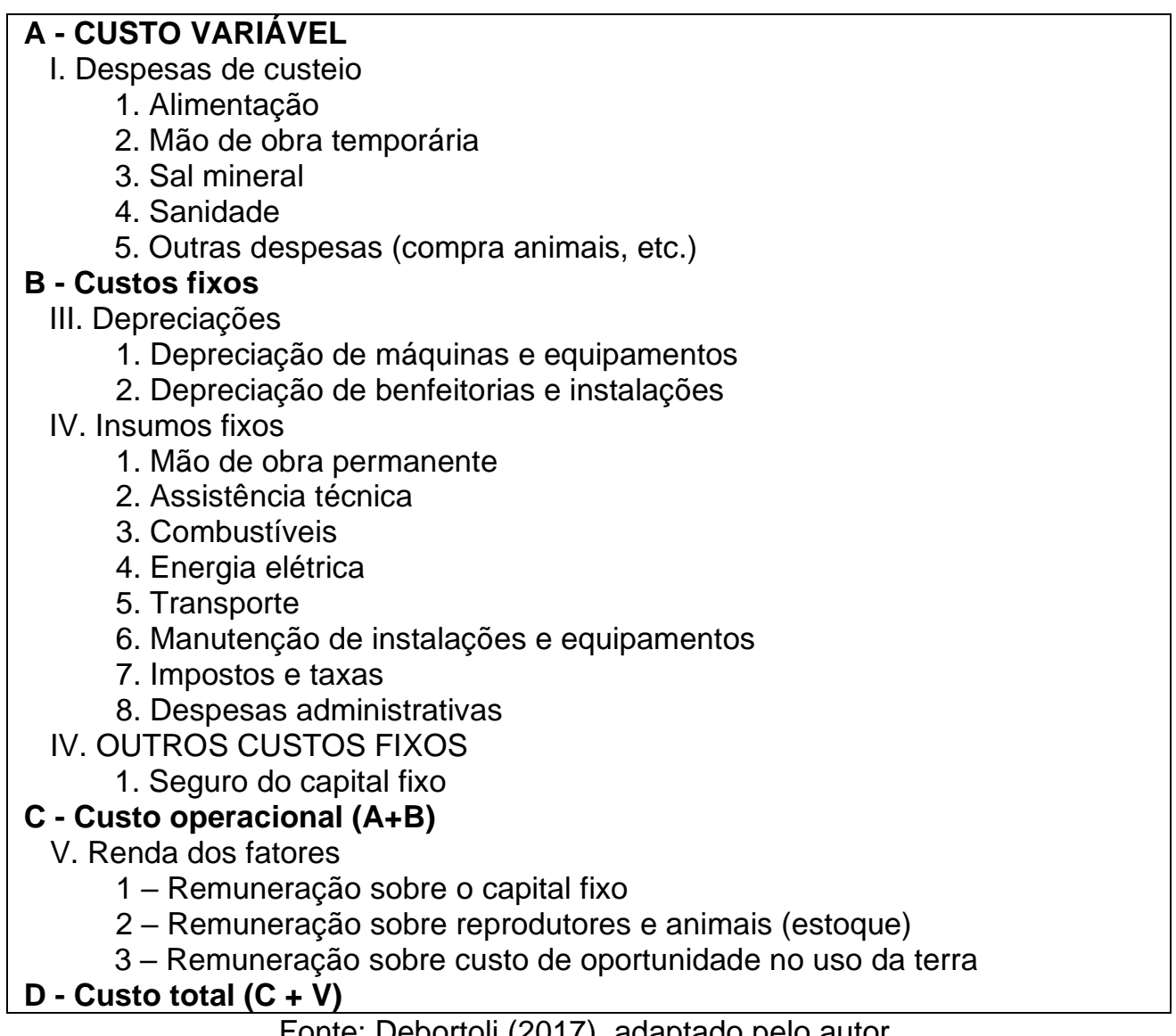

Fonte: Debortoli (2017), adaptado pelo autor.

Após de descrever a importância dos custos de produção na agropecuária, passa-se a tratar dos efeitos dos processos econômicos sobre o ecossistema.

\subsection{IMPACTO AMBIENTAL E MUDANÇA CLIMÁTICA}

Ao longo do tempo, a Terra tem passado por diversos períodos de mudanças ambientais significativas. Apesar disso, as condições ecológicas do planeta têm sido estáveis nos últimos 10.000 anos, quando teve origem o início do Holoceno, período geológico no qual diversas civilizações se desenvolverem e prosperarem na Terra, produto da estabilidade climática (DANSGAARD et al., 1993). Contudo, diversas organizações como o Painel Intergovernamental sobre Mudanças Climáticas - IPCC (2014, 2021), têm demostrado um incremento considerável da temperatura desde 
início do Século $X X$, impulsado sobretudo pelas emissões antrópicas de gases de efeito estufa, conduzidas em grande parte pelas atividades humanas. Crutzen e Stoermer (2000) propuseram o termo Antropoceno pela primeira vez como o período mais recente na história da Terra, caraterizado pela deterioração dos ecossistemas naturais produto das atividades humanas.

No relatório intitulado "Ecossistemas e bem-estar humano: síntese" da Millennium Ecosystem Assessment (2005) ou MA pelas suas siglas em inglês, demostra-se como os serviços ecossistêmicos estão associados ao bem-estar humano e à capacidade de regeneração dos ecossistemas naturais. Segundo o MA (2005), os serviços ecossistêmicos ou ambientais são todos aqueles recursos (bens e serviços) que a natureza fornece ao ser humano, tornando estes indispensáveis para a sua sobrevivência. Sua geração depende da capacidade da natureza de levar a cabo as complexas interações biológicas, químicas e físicas que, por sua vez, estão sendo afetadas pelas atividades humanas. Deste modo, o MA (2005) dividiu os serviços ecossistêmicos em quatro categorias:

- De apoio: ciclo de nutrientes, formação do solo, produção primária etc.;

- De aprovisionamento: alimento, água doce, madeira, fibra, combustíveis etc.;

- De regulação: do clima, purificação da água, inundações, doenças etc.; e

- Culturais: estético, espiritual, educação, recreação etc.

Por sua vez, esses quatro grupos são os encarregados de suportar e interagir com os cinco atributos fundamentais do bem-estar humano (seguridade, vida digna, saúde, boas relações sociais e liberdade de escolha e ação). Contudo, o crescimento populacional estimado passará de 7,7 para 9,7 bilhões do ano 2020 ao 2050 (UNDESA, 2019), representando um crescimento demográfico de $26 \%$ aproximadamente. Isso poderia gerar a desestabilidade nas relações existentes entre os serviços ecossistêmicos e o bem-estar humano, dado que, à medida que a população e o padrão de vida global crescem, da mesma maneira o faz a demanda de bens e serviços, prevendo assim, um aumento na demanda dos serviços impulsionado pelo crescimento populacional e econômico (BENTON et al., 2018).

Em razão disso, diversos pesquisadores têm proposto a ideia da intensificação no uso da terra, evitando a conversão de terras adicionais às 
atividades primarias como a agricultura, permitindo que outras terras possam fornecer serviços ecossistêmicos sem comprometer o equilíbrio da biosfera (BENTON et al., 2018; GARNETT et al., 2013). Todavia, Smith et al. (2016) e Wilhelm et al. (2018) concluíram que um uso intensivo da terra pode levar a danos ecológicos irreversíveis como a degradação do solo, resultando na perda da função que sustenta diversos serviços ambientais. Desta forma, ao atingir as metas de produção no curto prazo por meio da intensificação no uso da terra, é causado em detrimento no potencial produtivo futuro, comprometendo a segurança alimentar a longo prazo (BARIONI et al., 2019; TILMAN; CLARK, 2014).

\subsubsection{O impacto ambiental e seu efeito na agropecuária}

De acordo com a FAOSTAT (2017), dos 13,5 bilhões de hectares terrestres no mundo, 4,8 bilhões foram classificadas como terras de uso agropecuário, o que representa $35,8 \%$ da área total da terra dedicada a esta atividade (69\% pastagens permanentes, $28 \%$ da área agrícola e 3\% culturas permanentes). Estes dados demonstram que um terço da área terrestre da Terra é ocupada por estabelecimentos rurais. Em razão disso, esta atividade tem sido criticada como uma das principais responsáveis na alteração dos ecossistemas, devido à conversão de florestas naturais em pastagens e lavouras, degradando o solo, causando perda da biodiversidade, além de emitir quantidades consideráveis de gases de efeito estufa à atmosfera -responsável pela contribuição de 14,5\% das emissões antropogênicas totais (GERBER et al., 2013; GITZ et al., 2016; MARQUES, 2018; ROJASDOWNING et al., 2017; SMITH et al., 2016).

Sukhdev et al. (2010) propuseram que os fluxos dos serviços ecossistêmicos podem ser considerados como o dividendo (lucro) que a sociedade recebe do capital natural. Motivo pelo qual, a manutenção e preservação das reservas nos ecossistemas naturais permitem a oferta sustentada dos serviços ecossistêmicos no futuro, ajudando a garantir a continuidade do bem-estar humano. Assim, do ponto de vista econômico, a produção intensiva não só traz consigo a degradação dos ecossistemas naturais, também pode causar prejuízos crescentes em termos econômicos; isto, produto do esgotamento dos recursos naturais, causando uma inversão nos pesos relativos dos fatores econômicos e dos fatores ambientais na concepção das crises ambientais (MARQUES, 2018). 
O comentário anterior pode ser corroborado no setor agropecuária, a qual se está vendo perturbado na competição por terra e água com outras atividades econômicas (THORNTON, 2010), incremento na incidência de doenças e estresse térmico nos animais (GARNETT, 2009), baixa produtividade de biomassa pela degradação dos solos (SMITH; PEARCE; WOLFE, 2012) entre outras problemáticas. Estes efeitos têm levado aos sistemas produtivos a apresentar maiores dependências de insumos não-renováveis, procurando manter ou aumentar sua produtividade. Este comportamento incide no aumento dos custos de produção e na degradação do meio ambiente (PRETTY, 2008; PRETTY; BHARUCHA, 2014; TRABELSI et al., 2016).

\subsubsection{Desenvolvimento sustentável na agropecuária}

Diversas narrativas têm sido estabelecidas ao redor da palavra "sustentabilidade", termo proposto há cerca de 30 anos, que tem sido designado por alguns como sinônimo de "crescimento econômico verde" (MARQUES, 2018). Contudo, um sistema socioeconômico torna-se sustentável quando o seu desenvolvimento não destrói a biodiversidade, e não altera as características ambientais a uma velocidade superior à sua capacidade de regeneração e adaptação, podendo assim, satisfazer as necessidades presentes, sem comprometer a capacidade das gerações futuras de poder suprir suas próprias necessidades (BRUNDTLAND, 1987).

Deste modo, a sustentabilidade da biosfera e da sociedade depende de nossa capacidade coletiva de proteger o ambiente dos impactos negativos das atividades econômicas. O desenvolvimento sustentável tem-se tornado o princípio que norteia a tomada de decisões de alguns setores econômicos e políticos. Motivo pelo qual, atingir a sustentabilidade do setor agropecuário é visto como essencial no caminho para um desenvolvimento global sustentável (SIEBRECHT, 2020). Deste modo, o informe da Lei e Alimentos, Agricultura, Conservação e Comércio publicado pelo Departamento de Agricultura dos Estados Unidos ou USDA (2007) definiu a "agropecuária sustentável" como um sistema integrado de práticas para a produção vegetal e/ou animal que têm por objetivo:

- Satisfazer as necessidades humanas de alimentos e fibras; 
- Melhorar a qualidade ambiental, pois esta é a base de recursos naturais dos quais depende a economia agrícola;

- Fazer uso eficiente dos recursos renováveis e não-renováveis, integrando quando for apropriado, ciclos e controles biológicos naturais;

- Sustentar a viabilidade econômica das atividades agropecuárias; e

- Melhorar a qualidade de vida dos produtores rurais e da sociedade como um todo.

Baseados nesses objetivos da agricultura sustentável, diversos autores (TRABELSI et al., 2016; VELTEN et al., 2015) concluíram que um empreendimento rural pode ser considerado sustentável quando este faz um uso razoável dos bens e serviços ambientais, sem danificar significativamente a biosfera. Para isso, Pretty et al. $(2008 ; 2014)$ propuseram seis princípios-chave na busca da sustentabilidade desses sistemas:

- Utilizar variedade genética de sementes e raças animais;

- Integrar processos biológicos e ecológicos, como ciclagem de nutrientes, fixação de nitrogênio, regeneração do solo, alelopatia, competição, predação e parasitismo em processos de produção de alimentos;

- Reduzir o uso de insumos não-renováveis, em especial aqueles que causam danos ao meio ambiente e à saúde das pessoas;

- Fazer uso produtivo do capital humano na forma de conhecimento e capacidade, melhorando a sua autossuficiência para evitar a substituição de capital humano por insumos externos custosos;

- Fazer uso produtivo das capacidades coletivas das pessoas para trabalharem juntas na solução de problemas comuns de recursos agrícolas e naturais; e

- Minimizar os impactos da gestão do sistema, como: emissões de gases de efeito estufa (GEE), água limpa, sequestro de carbono, biodiversidade, dispersão de pragas e patógenos.

Desse modo, espera-se que os sistemas agropecuários que fundamentem seu comportamento na procura da sustentabilidade tenham como resultado a distinção dos seus processos em relação aos sistemas convencionais. Contudo, a medição do desempenho no processo da transição para uma produção sustentável 
pode ser feita por meio de um conjunto de indicadores relativos ao meio ambiente, a sociedade e a economia, sendo possível avaliar e interpretar a relação entre estes. Por esse motivo, analisar os aspectos (ecologia, sociedade e economia) dos sistemas de maneira isolada pode gerar resultados que não terão efeitos relevantes ao serem aplicados na sociedade (TRABELSI et al., 2016). Um claro exemplo disto, são os indicadores econômicos, os quais por si só permanecem focados apenas nos critérios financeiros ao nível da firma, sem contemplar o impacto ambiental e social que gera o funcionamento destas.

Em função de todos esses aspectos, é possível observar que o setor agropecuário se encontra diante de um grande desafio, pois, é necessário conciliar a crescente demanda de alimento e a rentabilidade financeira dos sistemas, sem causar a depredação dos ecossistemas naturais. Em razão isso, a Economia Ecológica ou Bioeconomia poderia oferecer uma alternativa àquela problemática.

\subsection{ECONOMIA ECOLÓGICA}

\subsubsection{Origem do pensamento econômico-ecológico}

O termo "Economia Ecológica" ou "Bioeconomia" surge como possível resposta à problemática atual entre a dinâmica socioeconômica e ambiental (MARTÍNEZ-ALIER; ROCA, 2015). Deste modo, ao acrescentar o prefixo "bio" ao termo "economia" significa que a área do conhecimento emergente trabalha de mãos dadas: a economia com a ecologia, na procura de atingir o desenvolvimento sustentável da sociedade (VIVIEN et al., 2019). Esta linha do pensamento econômico foi institucionalizada apenas em 1989 com o estabelecimento da Sociedade Internacional de Economia Ecológica (International Society for Ecological Economics - ISEE) e o periódico Ecological Economics.

Contudo, as bases desta área do conhecimento tiveram suas origens no final do Século XIX e começo do Século XX, sendo diversos autores - não necessariamente economistas - os encarregados de dar os primeiros passos. $O$ médico russo, Sergei Podolinsky, que tentou estudar a economia como um sistema de conversão de energia, propôs a substituição do trabalho pela energia na teoria do 
valor de Karl Marx (MARTINEZ-ALIER; NAREDO, 1982; MARTÍNEZ-ALIER; ROCA; SÁNCHEZ, 1998). Por outro lado, Frederick Soddy, prêmio Novel de química em 1921, buscou demostrar que a noção de riqueza utilizada pelos economistas (dinheiro) nos seus trabalhos era virtual, pois não representa uma realidade física (CECHIN, 2010). Deste modo, ambos pesquisadores deram os primeiros contornos entre a economia e a ecologia pelo uso da Termodinâmica, pois enxergavam o sistema econômico como um sistema termodinâmico aberto, o qual precisa de energia e matéria para seu funcionamento.

A termodinâmica tem por objetivo estudar a energia, suas formas e transformações, bem como suas interações com a matéria nos sistemas termodinâmicos, os quais por sua vez são uma parte isolada ou delimitada do universo a partir de uma dada fronteira para seu estudo. Estes sistemas podem ser divididos em três grupos (Figura 1): i) sistema isolado, que não trocam matéria ou energia com seu entorno; ii) sistema fechado, que trocam energia (calor e trabalho), mas não matéria com o entorno, permanecendo sua massa constante; e, iii) sistema aberto, que trocam energia e matéria com o ambiente que os rodeia (HOWELL; BUCKIUS, 1990). Neste sentido, no último encontra-se todo sistema de produção que estão na Terra, como é o caso da produção agropecuária.

Figura 2 - Tipos de sistemas termodinâmicos

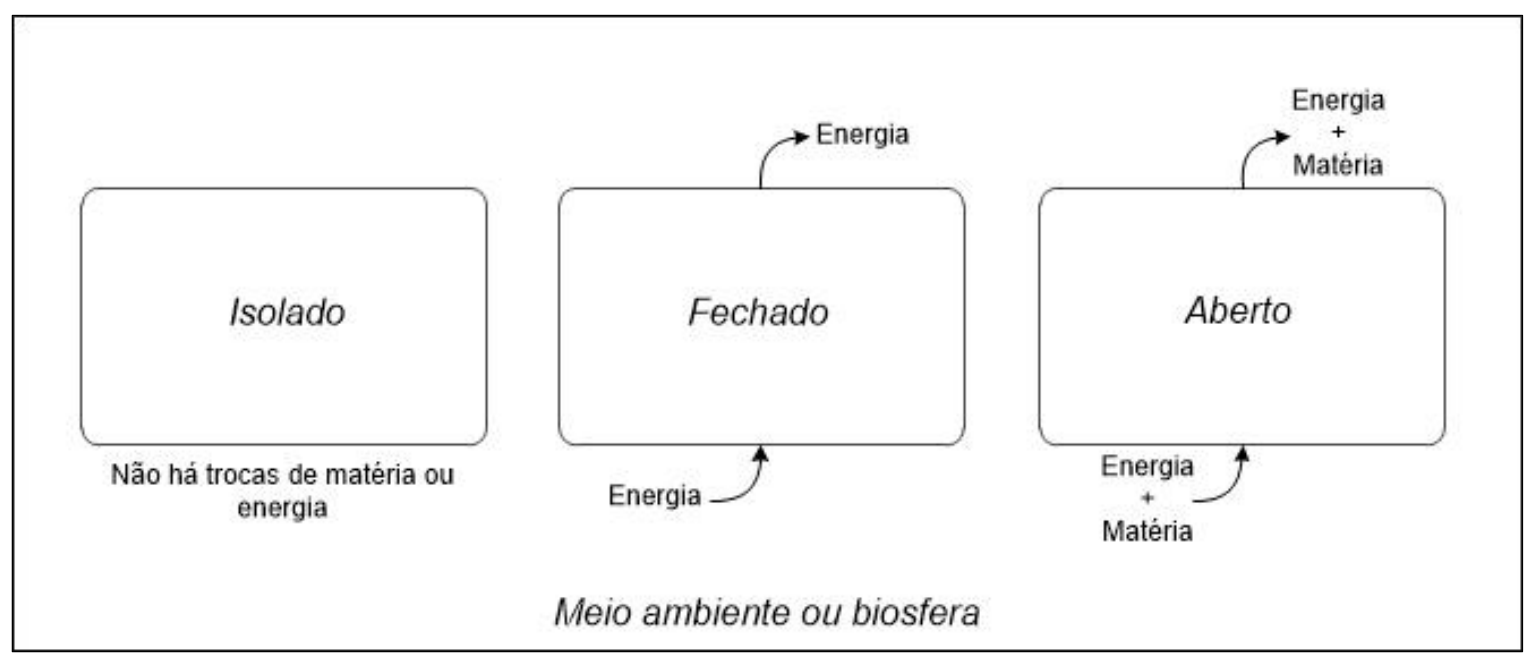

Fonte: Própria autoria. 


\subsubsection{As leis da Termodinâmica como base da Economia Ecológica}

Apesar dessas primeiras contribuições à Economia Ecológica, está só foi consolidada na década de 1960 e anos posteriores graças às contribuições independentes de Kenneth E. Boulding, Herman E. Daly, Robert U. Ayres, Allen Kneese e Howard T. Odum (CECHIN, 2010); no entanto, foram aos aportes do matemático, estatístico e economista romeno Nicholas Georgescu-Roegen (1971) que impulsionou este pensamento, ao envolver as leis da termodinâmica ao processo econômico.

Para esses teóricos, o fluxo circular da economia - modelo que busca explicar a interação entre os agentes econômicos no processo de intercâmbio de bens e/ou serviços - é exemplo de um sistema termodinâmico fechado e isolado, mas, ao ser necessário o ingresso e saída de energia e matéria para seu funcionamento, o pensamento econômico-ecológico o considerou como um sistema termodinâmico aberto (CECHIN, 2010).

Em razão disso, Heman Daly et al. (2011) baseado nos trabalhos do Georgescu-Roegen (1971), concluíram que o fluxo circular da economia ignora dois princípios: (i) o processo de transumo (do inglês, throughput), no qual a energia e matéria é transformada em lixo e energia degradada; e (ii) o fluxo metabólico das entradas de matéria-prima para as saídas de resíduos. No transumo aplica-se a Primeira Lei da Termodinâmica, conhecida como a Lei da conservação e que estabelece que "a energia pode ser transformada de um tipo a outro, mas, não pode ser criada ou destruída". Ao estar sujeita ao processo de transumo, na equação 6 observa-se que se houver acumulação $(A>0)$, o subsistema econômico está crescendo, pois, a saída seria menor que a entrada $(\mathrm{O}<\mathrm{I})$; porém, no equilíbrio de estado estacionário, o crescimento seria igual a zero $(A=0)$ e o fluxo de entrada seria o mesmo ao fluxo de saída $(I=0)$. Em outras palavras, todas as entradas de matéria-prima acabam se transformando em saída de resíduos. Assim, o processo de transumo do sistema teria dois fins: o esgotamento de fontes ambientais e a poluição de sumidouros ambientais. Deste modo, ignorar o transumo no processo de produção é o mesmo que ignorar o esgotamento e a poluição. 


$$
I=O+A
$$

Em que:

I: Entrada;

O: Saída; e

A: acumulação.

Por outro lado, ao contrário do valor de troca, o transumo não é circular; é um fluxo de transformação de energia e matéria em uma via de mão única e de mudança irreversível, no qual são alteradas fontes de baixa entropia para sumidouros de alta entropia (DALY; FARLEY, 2011; GEORGESCU-ROEGEN, 1971). Esta é uma consequência da Segunda Lei da Termodinâmica, ou lei da entropia ("em", em; "trope", transformação). A lei da entropia assegura que não pode ser utilizada a mesma energia indefinidamente, pois, de ser possível não haveria escassez, nem resíduos no processo produtivo, pudendos se reciclar $100 \%$ da energia (CECHIN, 2010). É deste modo que nenhum animal pode reciclar diretamente seus próprios resíduos como seu alimento, e se pudesse, seria uma máquina de movimento perpétuo. Em estrita analogia, nenhuma economia pode funcionar reutilizando diretamente apenas seus próprios resíduos como matériaprima.

Por meio destes princípios e suportado nas leis da termodinâmica, a economia ecológica enxerga o sistema econômico como um subsistema inserido dentro da sociedade, que por sua vez faz parte de um sistema global maior e finito (biosfera). Assim, o subsistema econômico ao consumir e transformar energia e matéria (recursos de baixa entropia) para produzir bens e/ou serviços que posteriormente supriram as necessidades da sociedade, são gerados através do processo transumo (seu "sistema digestório") energia e matéria de alta entropia (resíduos e emissões) que voltam aos ecossistemas, afetando o equilíbrio termodinâmico da biosfera (DALZOTTO et al., 2020; KLEIDON, 2010) (Figura 3). 
Figura 3 - Fluxo de energia e matéria segundo a economia ecologia

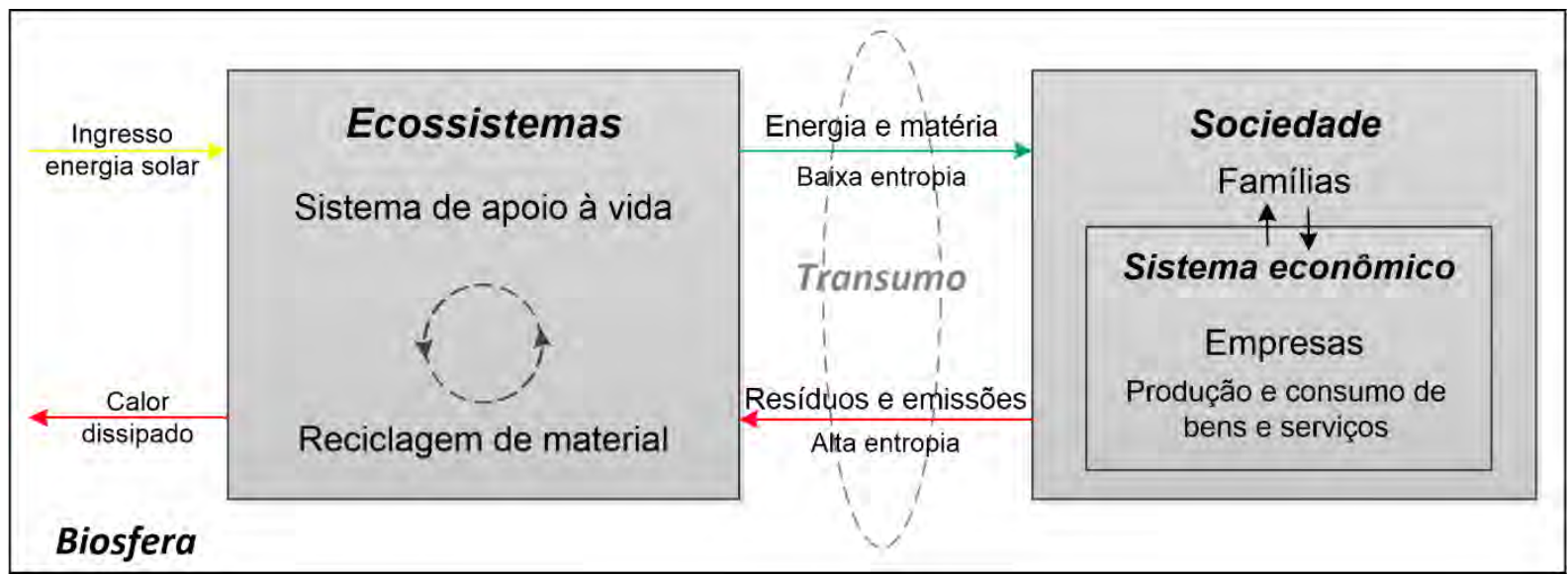

Fonte: Própria autoria.

\subsubsection{Valoração do capital natural}

A essência do conceito de capital deriva da economia, em que os estoques de capital (ativos) possuem a capacidade de fornecer fluxos de bens e/ou serviços que contribuem para o bem-estar humano. A economia clássica identificou três tipos de estoque de capital: terra, trabalho e capital manufaturado (chamado apenas de 'capital'). Por outro lado, grande parte da economia neoclássica em sua representação das funções de produção algumas vezes omite a terra e se concentraram apenas no trabalho e no capital (EKINS et al., 2003). Contudo, o aumento na conscientização sobre o papel dos recursos naturais levou aos economistas Paul Ekins e Manfred Max-Neef (1992) a proporem a divisão do estoque de capital em quatro grupos de capitais que são os encarregados de produzir um fluxo que servem como insumos os serviços no processo produtivo. Os quaro grupos de capitais são:

- Capital manufaturado: fabricado pelos homens e mulheres. Tradicionalmente este tipo de capital é caraterizado por ser ativos produzidos e utilizados para produzir outros bens e serviços;

- Capital humano: refere-se à saúde, ao bem-estar e ao potencial produtivo de cada pessoa. Os tipos de capital humano incluem saúde mental e física, educação, motivação e habilidades para o trabalho;

- Capital social ou organizacional: relacionado ao bem-estar humano, mas em um nível social e não individual. Consiste nas redes sociais que 
sustentam uma sociedade eficiente, coesa e facilitam as interações sociais e intelectuais entre seus membros; e

- Capital natural (também chamado ecológico ou ambiental): são contemplados os recursos naturais tradicionais, como madeira, água, reservas energéticas, minerais, entre outros. Contudo, o capital natural é composto por ativos naturais que não são facilmente valorizados monetariamente, como biodiversidade, espécies ameaçadas de extinção e os ecossistemas que realizam serviços ecossistêmicos.

A combinação destes quatro tipos de capital dá origem ao fluxo de bens e serviços que as pessoas desejam. Deste modo, a conservação dos estoques de capital torna-se de vital importância, já que se um destes não for mantido, eventualmente o fluxo de bens e serviços diminuiria, afetando assim, o bem-estar dos consumidores (EKINS et al., 2003).

Apesar disso, o capital natural é um dos estoques que mais tem sido afetado, produto da ausência de valoração monetária. Sukhdev et al. (2010), concluíram que a incapacidade de contabilizar o valor econômico total dos ecossistemas e da biodiversidade tem sido um fator significativo na sua contínua perda e degradação, já que, os resultados dessa invisibilidade econômica do capital natural está levando à diminuição e o perigo de extinção da biodiversidade global, e perda do bem-estar humano. Em razão disso, diferentes pensamentos de valorização do capital natural têm sido desenvolvidos. Uma revisão dessas metodologias permite identificar dois paradigmas bem diferenciados de avaliação: i) métodos baseados em preferências, os quais são mais comumente usados pelo sistema econômico dominante - o neoclássico; e ii) métodos de contabilidade biofísica, constituídos por uma variedade de abordagens biofísicas que permitem obter informação sobre os sistemas biológicos (Figura 4). A seguir são descritas as duas abordagens conceituais utilizadas na estimativa de valorização do capital natural:

\subsubsection{Abordagem baseada em preferência}

Os estudos da Economia Ambiental - vertente da Economia Neoclássica para tratar as questões ambientais - baseiam-se no entendimento dos recursos naturais como um bem público, e dos impactos ambientais, como externalidades geradas 
pelo funcionamento do processo econômico (MAY, 2018). Contudo, a valorização dos recursos e dos impactos ambientais não são percebidos na esfera de funcionamento dos mercados devido às falhas que este apresenta, embora podem ser estimados na medida em que se possa conhecer a disposição da sociedade e dos indivíduos a pagar pela preservação ou conservação dos recursos e serviços ambientais (MARQUES, 2004).

Os aspectos teóricos do método de valoração da econômica ambiental, foram propostos pelos economistas Pearce e Turner (1990) que consideraram que o valor econômico total (VET) de um recurso natural ou serviço ecossistêmico é composto pela soma dos valores de uso diretos (VUD), indiretos (VUI) e de opção (VO). Por outro lado, o valor de existência (VE) do recurso natural, se caracteriza como um valor de não-uso.

$$
V E T=V U D+V U I+V O+V E
$$

Em que:

VET: Valor econômico total;

VUD: Valor de uso direto;

VUI: Valor de uso indireto;

VO: Valor de opção; e

VE: Valor existencial.

O valor de uso de um recurso natural é representado pelo valor atribuído pelas pessoas. De este modo, o VUD é aquele derivado da sua utilização ou consumo diária, sendo que o mesmo recurso natural pode ter vários usos distintos e, dessa maneira, ter vários valores de uso diretos. O valor monetário dos recursos madeireiros fornecidos pelas florestas seria um exemplo de valor de uso direto. Por outro lado, o VUI é advindo das funções ecológicas do recurso natural ou daqueles derivados de uso ex-situ ao ambiente do recurso. Os serviços de regulação que oferece as florestas, como: sequestro de $\mathrm{CO}_{2}$, qualidade do ar, entre outros, são exemplos de uso indireto do capital natural. O VO faz referência à quantidade que os indivíduos estariam dispostos a pagar hoje pela opção de usar o não usar o recurso natural no futuro (MAY, 2018). 
Por último o VE ou valor de não-uso do capital natural, está relacionado com a satisfação pessoal em saber que o recurso está disponível, sem que o indivíduo tenha vantagem direta ou indireta sobre sua presença (MAY, 2018). Como exemplo deste tipo de valor, são aquelas pessoas que estão em disposição de pagar para diminuir o desmatamento de alguma floresta, isto, apesar de que os indivíduos que pagaram não tenham contato direto com a floresta ou chegassem a consumiram algum dos seus recursos.

Por fim, as abordagens de preferência declarada induzidas pela ciência política, simulam um mercado e a demanda por recursos e serviços ecossistêmicos através de pesquisas sobre mudanças hipotéticas na provisão desses ativos. Os métodos de preferência declarada podem ser usados para estimar os valores de uso e não-uso dos ecossistemas, quando não existe um mercado substituto do qual o valor dos ecossistemas possa ser deduzido (SUKHDEV et al., 2010).

\subsubsection{Abordagem de Contabilidade Biofísica}

Embora, vários autores tenham procurado aumentar a conscientização e dependência da sociedade pelos serviços ecossistêmicos, por meio da valorização monetário do capital natural, implementando métodos de avaliação orientados para o mercado. Sua principal desvantagem é que a avaliação, é aplicada com base na valoração monetária e na disposição a pagar (MELLINO; BUONOCORE; ULGIATI, 2015). Tal critério de avaliação não é apropriado para quantificar adequadamente os serviços ecossistêmicos nas escalas temporais e espaciais da biosfera (as únicas escalas que importam para a sobrevivência), posto que apenas reflete valores para a sociedade de hoje, sem levar em consideração as futuras gerações e outras espécies (DONG et al., 2012; LAGERBERG; BROWN, 1999; ODUM; ODUM, 2001).

Por outro lado, a contabilidade biofísica por meio de uma perspectiva de mais abrangente, e baseada nas medições dos custos físicos (em termos de trabalho, requisitos de superfície, energia ou insumos de materiais) das entradas (insumos) que interagem no processo de transformação dentro do sistema, consegue realizar uma valorização mais adequada dos recursos naturais ao quantificar seu valor em unidades físicas (valores absolutos), deixando de lado unidades monetárias (MAY, 2018; SUKHDEV et al., 2010). 
De acordo com Sukhdev et al. (2010), as medidas biofísicas podem ser mais eficientes na avaliação dos estoques de capital natural, em particular, para calcular a depreciação dos recursos. Alguns exemplos de métodos biofísicos (Figura 4) na avaliação ou contabilidade do capital natural são: análise de energia incorporada (COSTANZA, 1980), Síntese em Emergia (ODUM, 1996), Análise de Exergia (WALL, 1977; WALL; GONG, 2001), Pegada Ecológica (WACKERNAGEL et al., 1999), Análise de Fluxo de Material (DANIELS; MOORE, 2001), e Fluxo de Cobertura do Solo (EEA, 2006).

Baseado nessa exposição e de acordo com o escopo do presente trabalho, segue-se para o entendimento da Síntese em Emergia, metodologia de contabilidade biofísica que baseia sua análise nos valores ecológicos intrínsecos, motivo pelo qual foi utilizada para calcular o valor real na produção do cordeiro de corte paulista. 
Figura 4 - Abordagens para a estimativa dos valores do capital natural

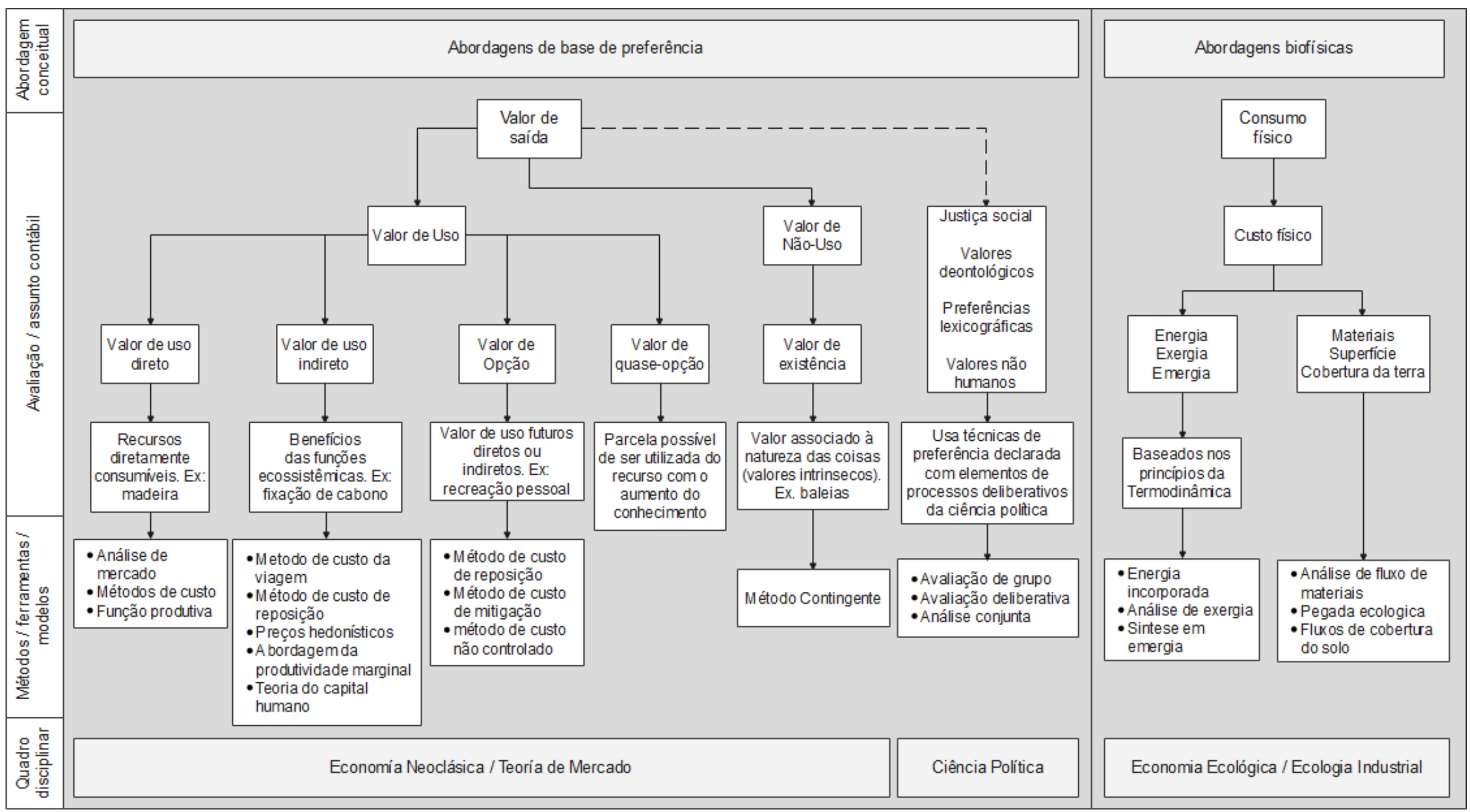

Fonte: Sukhdev et al. (2010), elaborado pelo autor. 


\subsubsection{Síntese em Emergia}

Aqueles aspectos têm gerado crescente preocupação do ponto de vista biofísico, principalmente na procura do uso eficiente dos recursos naturais e na redução do impacto ambiental, motivo pelo qual tem sido desenvolvidas diferentes metodologias que buscam avaliar o grau relativo da sustentabilidade nos sistemas de produção, delimitando esses em três dimensões interdependentes (ambiental, social e econômica). Contudo, a avaliação da sustentabilidade nessas dimensões pode ser difícil de conciliar, devido ao fato de que as variáveis usadas para mensurar a sustentabilidade convencional têm diferentes unidades de medida, tornando-se difícil avaliar as interações e interdependências entre estas (ZHEN; ROUTRAY, 2003). Embora métodos multicritérios estejam sendo desenvolvidos, a avaliação da sustentabilidade dos sistemas agropecuários exige indicadores que aproximem as três dimensões em uma mesma base comparável, podendo captar os impactos positivos e negativos das atividades do sistema à biosfera (DALZOTTO et al., 2020).

Em razão disso, a Síntese em Emergia (com "m") converte-se em uma ferramenta de avaliação integral e sistêmica, capaz de quantificar em uma mesma unidade (emergia solar expressa em emjoules solares, sej) a energia potencial (exergia) proveniente do trabalho direto e indireto realizado pela natureza e o sistema econômico na produção de um recurso, produto ou serviço (BROWN; ULGIATI, 2004a; ODUM, 1996). Contudo, antes de dar continuidade a um entendimento mais amplo da Síntese em Emergia, serão apresentados alguns conceitos básicos para a sua compreensão.

Tradicionalmente a energia (com " $\mathrm{n}$ ") tem sido definida como "a capacidade de fazer um determinado trabalho", mas, para realizá-lo é indispensável o ingresso de energia ao sistema, além de levar em consideração sua forma e o tipo de sistema (BROWN; ULGIATI, 2004a). Os físicos do Século XIX concluíram que a energia não é uma entidade única e facilmente definível, devido a seu conceito abstrato, já que são diversos os fenômenos naturais e antropogênicos que geram diferentes tipos de energia, como: mecânica, térmica, elétrica, química, eletromagnética, solar, eólica e geotérmica (SMIL, 2006). No entanto, o princípio básico de transformação da energia é independente do tipo de energia. Assim, os cientistas definiram a energia 
potencial (exergia) como aquela energia que está disponível para realizar trabalho, mas, após a finalização do trabalho uma porção desta torna-se degradada e inutilizável (ODUM; ODUM, 2001).

De acordo com Odum et al. (2001) a cadeia de transformação de energia no planeta Terra inicia com a entrada dos raios solares, cuja absorção e transformação ocorre nos ecossistemas naturais, os quais fornecem os recursos indispensáveis para o funcionamento das atividades socioeconômicas realizadas pelo ser humano. $\mathrm{Na}$ Figura 4, observa-se um sistema aberto no qual ingressa uma fonte de energia e só uma porção dela é disponível $(\mathrm{E})$. Já no processo de transformação, a exergia gera trabalho (W) e um fluxo de energia degradada (Q) que é dissipado em calor de baixa intensidade. Contudo, para que este processo seja contínuo, além do processo de transformação há um laço de retroalimentação, que nasce do armazenamento de energia no estoque de recursos, o qual será utilizado para reforçar o seguinte processo de transformação.

Figura 5 - Diagrama que mostra a transformação do fluxo de energia

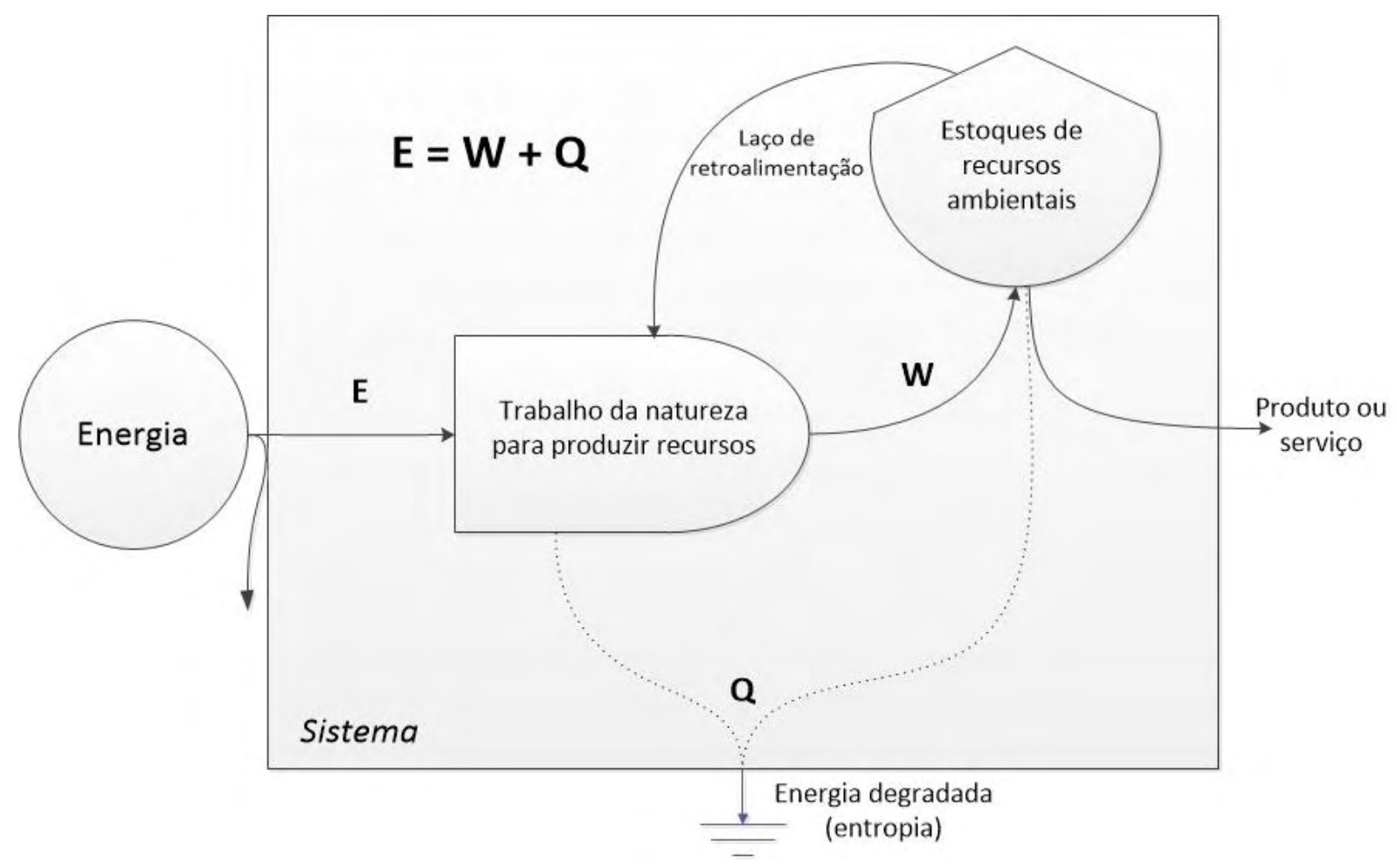

Fonte: Odum (1996), adaptada pelo autor.

No processo de transformação de um tipo de energia disponível em grande quantidade, parte dela é consumida para produzir outro tipo de energia de menor 
quantidade, mas de melhor qualidade. Isso significa que os diversos tipos de energia podem ser organizados em sequência hierárquica, baseado na quantidade de energia básica requerida para produzir a seguinte (ODUM, 1996; ODUM; ODUM, 2001). Um exemplo disso ocorre no fluxo de energia da cadeia alimentar dos ecossistemas naturais, na qual a energia solar (a energia mais abundante na Terra, mas de baixa qualidade) é absorvida pelas plantas no processo de fotossíntese para gerar energia química (menos abundante, mas de melhor qualidade), que posteriormente será consumida por um herbívoro, gerando outro tipo de energia ainda menos abundante, mas de maior qualidade que as anteriores.

Após a consideração da hierarquização da energia nos ecossistemas naturais, Odum (1973) deu sequência ao entendimento das interações da energia para uma escala maior, entre os sistemas naturais e o sistema socioeconômico. Deste modo, percebeu-se que existem diferentes tipos de energia (calorias, BTU's, quilowatts etc.) que conformam os fluxos energéticos que circularam entre os dois sistemas. Não obstante, concluiu que as diversas unidades que mensuravam a quantidade de energia nos sistemas, não eram suficientes para quantificar ou representar a escala de qualidade dessas.

Além da perceber a ausência de caraterização da qualidade na energia, Odum (1976) observou que no atual modelo econômico o dinheiro é utilizado como elemento de troca de bens e serviços, circulando em uma escala de tempo e espaço menor, quando comprada com a energia (Figura 5). Deste modo, o dinheiro só consegue medir o trabalho realizado pelo homem na produção de produtos e/ou serviços, sem levar em conta a contribuição que a biosfera faz às atividades socioeconômicas (BACIC; ORTEGA; KASSAI, 2010; ODUM, 1996).

No final da década de 1970 Odum foca seus trabalhos no aperfeiçoamento da teoria da qualidade energética e a sua definição quantitativa. Assim, foi desta maneira que aquele ecólogo começou a usar o termo "energia incorporada" para se referir às diferenças da qualidade de energia em termos de seus custos de geração e concentração de energia (BROWN; ULGIATI, 2004a). No entanto, na procura de evitar confusões com outros termos sementes utilizados na época, David Scienceman, pesquisador e colega do Odum, propôs, em 1983, pela primeira vez o termo "emergia" (emergy) ao em vez da energia incorporada (embodied energy), e 
"emjoules" para distinguir as unidades emergéticas das unidades de energia disponível.

Figura 6 - Diagrama de fluxo da energia e o dinheiro operando dentro da estrutura hierárquica da Terra

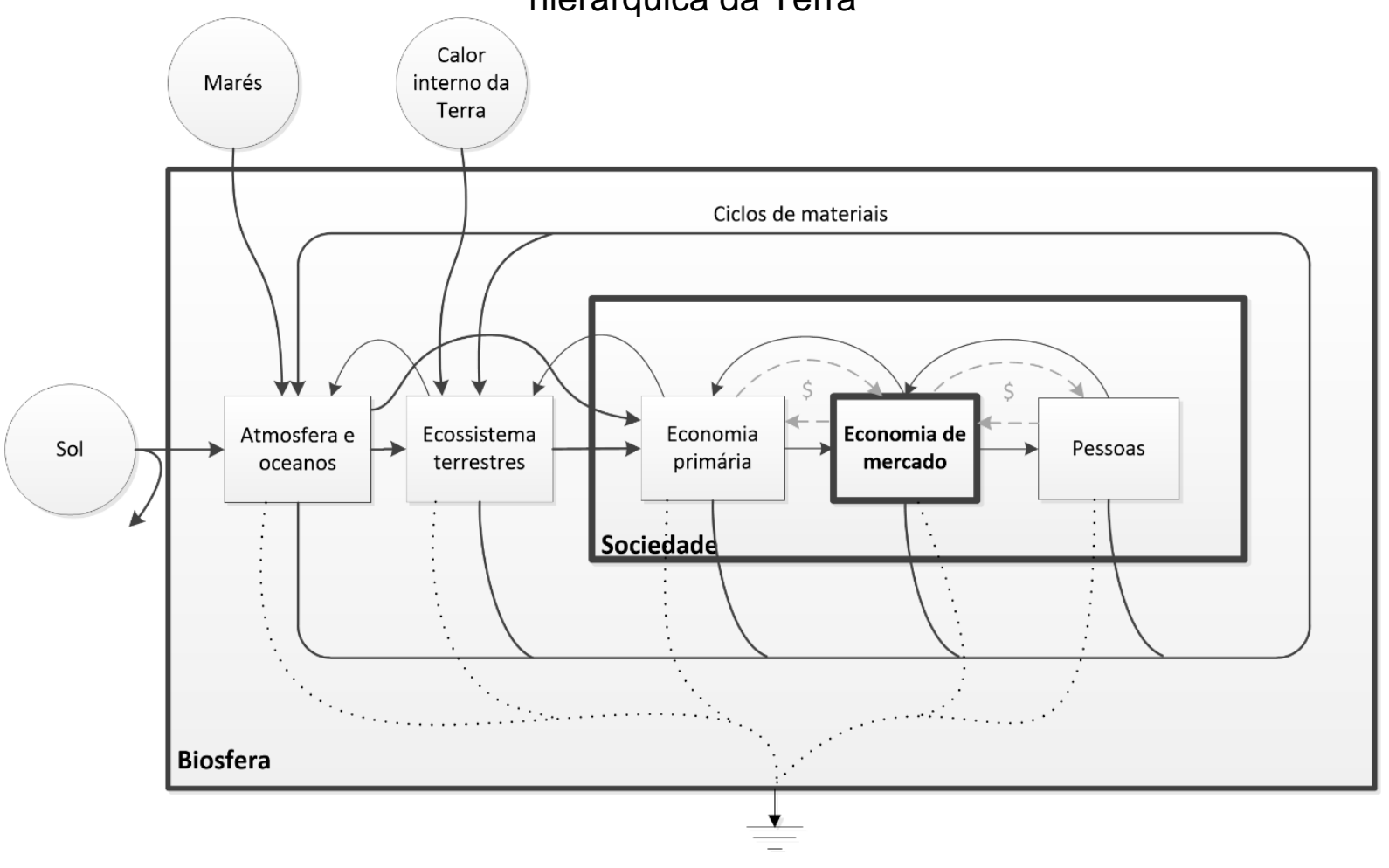

Fonte: Odum et al. (2001), adaptado pelo autor.

A emergia tem sido definida como toda a exergia (energia potencial disponível), de um determinado tipo (convertida em energia solar equivalente), que fui utilizada direta ou indiretamente na produção de um recurso, produto ou serviço (ODUM, 1996). Contudo, por serem diversos os tipos de inputs (fertilizantes, insumos alimentares, água, combustíveis, aço, etc.) que fornecem energia ao sistema, estes devem sofrer um processo de conversão em unidades emergéticas por meio de um fator denominado "transformidade". A transformidade é definida como a emergia de um tipo necessária para gerar uma unidade de energia de outro tipo; sua unidade é expressa em sej/J, ou seja, joules de emergia solar por joule (ODUM, 1996).

\subsubsection{Metodologia emergética}

A Síntese em Emergia proposta por Odum (1996) tem seus fundamentos na análise de energia de sistemas biológicos (LOTKA, 1922), a Teoria Geral de 
Sistemas (VON BERTALANFFY, 1968) e a Ecologia de Sistemas (ODUM, 1983). A aplicação desta consiste em três etapas: i) construção do diagrama sistêmico; ii) elaboração da tabela de avaliação emergética; e iii) cálculo dos índices emergéticos.

\section{i. Construção do diagrama sistêmico}

$\mathrm{Na}$ construção do diagrama de fluxo de energia, devem de ser utilizados os símbolos da linguagem dos sistemas de energia proposta por Odum (1996; 1976). Cada sistema deve de ser delimitado em uma janela de observação, a fim de conhecer as interações existentes dos insumos (entradas ou inputs) no sistema. Todas as entradas ao sistema podem ser classificadas em dois grupos: contribuições da natureza (I) e feedback da economia (F). O "I" se origina da soma dos recursos locais renováveis $(\mathrm{R})$ e não-renováveis $(\mathrm{N})$ (entrando à esquerda do diagrama); enquanto "F" é composto pelos materiais (M) e serviços (S) do sistema econômico (entrando pela parte superior do diagrama). Na Figura 7, observa-se o diagrama de fluxo de energia de um sistema tradicional de produção de cordeiros de corte.

Figura 7 - Representação de um diagrama de fluxo de energia de um sistema tradicional de cordeiros de corte

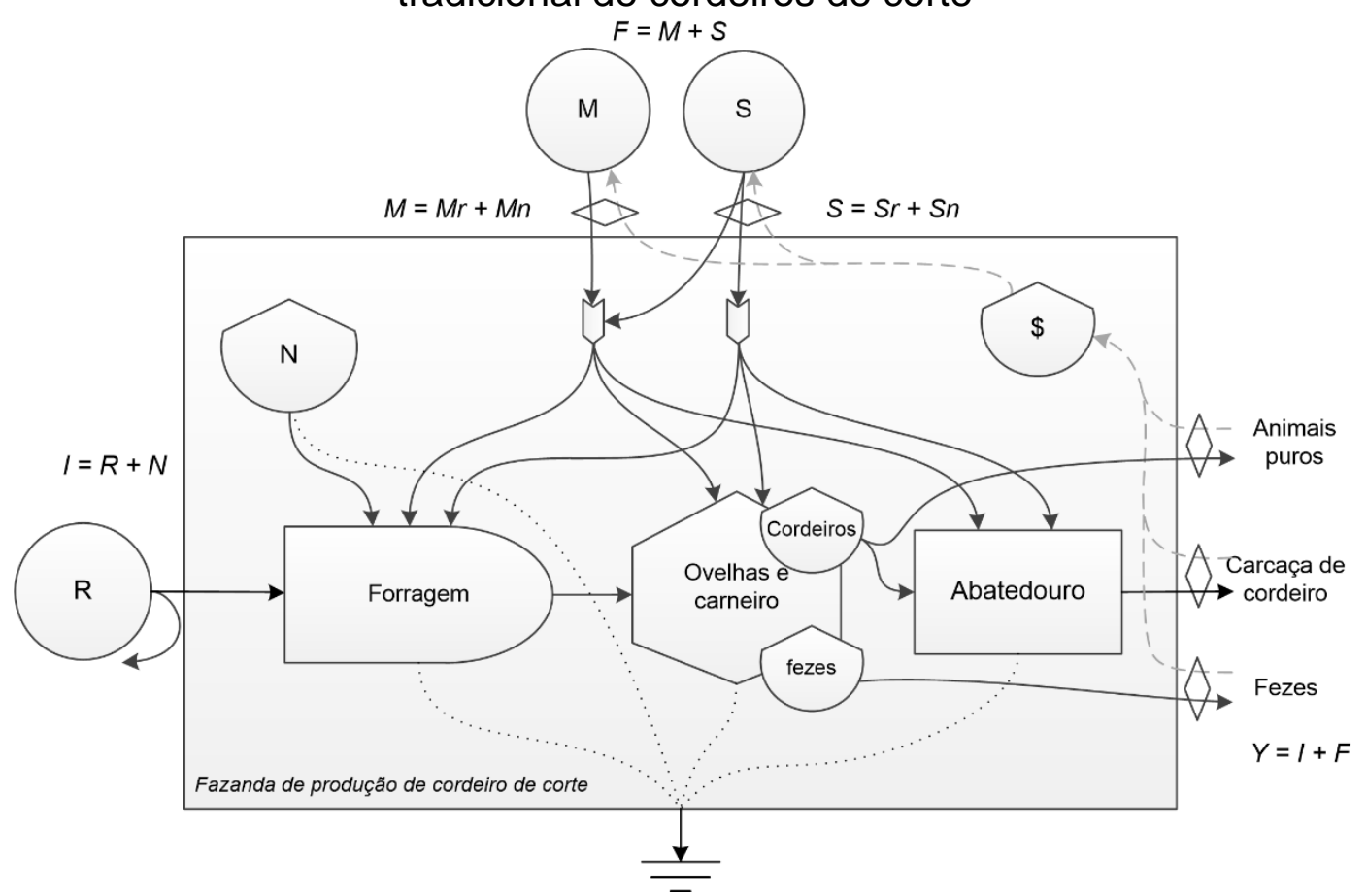

R: recursos renováveis da natureza; N: recursos Tocais não-renováveis; I: contribuição da natureza; $\mathrm{M}$ : materiais, (Mr e Mn representam a fração renovável e não não-renovável de $\mathrm{M}$ ); S: serviços, (Sr e Sn representam a fração renovável e não- renovável de S); F: feedback da economia; e Y: emergia total demandada pelo sistema. Fonte: Odum (1996), adaptado pelo autor. 
ii. Elaboração das tabelas de cálculo dos fluxos de emergia

Após representar os fluxos de energia no diagrama sistêmico, cada um deles deve ser convertido em linhas de cálculo na tabela de avaliação de emergia (Tabela 8). A conversão dos fluxos de energia, massa e dinheiro em emergia é feita multiplicando-se a quantidade de cada entrada pelos seus correspondentes valores unitários de emergia (UEV), que é definida como a relação emergética para uma unidade de produto, por exemplo: emergia por energia (transformidade, sej/J), emergia por massa (emergia específica, sej/g) e emergia por unidade monetária (relação emergia/dinheiro - EMR, sej/US\$). Por fim, uma vez que todos os insumos são convertidos para a mesma base comum (sej), esses são somados para se obter o fluxo emergético total $(Y)$ investido na geração de um produto, subproduto ou serviço.

$\mathrm{Na}$ contabilização emergética deste trabalho, foram considerados os fatores de renovabilidade (RNF) dos insumos que entram no sistema, dividindo-se cada um deles em frações renováveis e não-renováveis. De acordo com Ortega et al. (2002; 2005) e Cavalett et al. (2006), os fluxos emergéticos podem ser agregados de acordo com sua origem considerando o RNF de cada material e serviço. Desta forma, quando considerados o RNF, o desempenho emergético dos sistemas avaliados pode ser melhor representado. Os valores de RNF usados nesta pesquisa foram tomados de estudos agropecuários realizados principalmente no Brasil (AGOSTINHO et al., 2008, 2019; ALLEGRETTI et al., 2018; CAVALETT; QUEIROZ; ORTEGA, 2006; ORTEGA et al., 2005; TAKAHASHI; ORTEGA, 2010).

Tabela 8 - Esquema de organização de uma tabela de cálculo dos fluxos de emergia

\begin{tabular}{|c|c|c|c|c|c|c|c|c|c|}
\hline Nota $^{1}$ & Item $^{2}$ & $\begin{array}{l}\text { Quantidade } \\
\text { do fluxo }\end{array}$ & Unidade $^{4}$ & UEV $^{5}$ & $\begin{array}{l}\text { Fluxo de } \\
\text { emergia } 6\end{array}$ & $\mathrm{RNF}^{7}$ & $\begin{array}{c}\text { Fluxo } \\
\mathrm{R}^{8}\end{array}$ & $\begin{array}{c}\text { Fluxo } \\
\mathrm{N}^{9}\end{array}$ & $\begin{array}{l}\% \text { do } \\
\text { fluxo } 10\end{array}$ \\
\hline & \multicolumn{9}{|c|}{ R: Recursos renováveis da natureza } \\
\hline & \multicolumn{9}{|c|}{ N: Recursos não-renováveis da natureza } \\
\hline & $\mathrm{F}: \mathrm{Co}$ & $\begin{array}{l}\text { ribuição da e } \\
\text { M: Recursos } \\
\text { S: serviços pr }\end{array}$ & $\begin{array}{l}\text { nomia } \\
\text { ovenientes } \\
\text { venientes }\end{array}$ & $\begin{array}{l}\text { da econ } \\
\text { econôl }\end{array}$ & $\begin{array}{l}\text { mia } \\
\text { ica }\end{array}$ & & & & \\
\hline & & & & Total & Emergia & & & & $100 \%$ \\
\hline
\end{tabular}

${ }^{1}$ Referência numérica do fluxo analisado; ${ }^{2}$ Referência nominal do fluxo (insumo); ${ }^{3}$ Quantidade do fluxo utilizada pelo sistema no ano (J/ha, g/ha ou US\$/ha); ${ }^{4}$ Unidade de quantidade utilizada; ${ }^{5} \mathrm{UEV}$ : Valor da unidade de emergia por ano (sej/J; sej/g; sej/UD\$); ${ }^{6}$ Fluxo de emergia, produto da multiplicação da quantidade total fluxo do insumo (coluna 3) pelo seu respetivo UEV (coluna 5); ${ }^{7}$ RNF: fração renovabilidade do input; ${ }^{8}$ Quantidade do fluxo renovável do input; ${ }^{9}$ Quantidade do fluxo não renovável 
do input; e ${ }^{8}$ Porcentagem do fluxo de emergia em relação ao total. Fonte: Odum (1996), elaborado pelo autor.

iii. Cálculo dos indicadores em emergia

Na terceira e última etapa da Síntese em Emergia são calculados os índices em emergia, com base na relação entre os fluxos de emergia provenientes da natureza e do subsistema econômico. Nestes índices são apoiadas as discussões sobre a eficiência global, renovabilidade, emergia disponível à sociedade, carga ambiental, sustentabilidade ambiental, dependência ao sistema econômico e preço de equilíbrio do produto. Os índices são os seguintes:

- $\quad$ Transformidade (Tr)

Este índice avalia a eficiência do fluxo de emergia, permitindo fazer comparações com outras formas de energia de outros sistemas (ODUM, 1996). A transformidade do recurso gerado por um sistema é obtida por meio da equação 8 .

$$
\operatorname{Tr}=\frac{Y}{E p}
$$

Em que:

Tr: transformidade;

Y: fluxo de emergia total incorporou ao produto; e

Ep: energia do produto produzida pelo sistema.

- $\quad$ Porcentagem de renovabilidade $(\% \mathrm{R})$

Consegue mensurar, em termos de porcentagem, a renovabilidade do sistema (Equação 9).

$$
\% R=\frac{R+M_{r}+S_{r}}{Y}
$$

Em que:

\%R: porcentagem de renovabilidade;

R: fluxo de emergia dos recursos renováveis da natureza;

Mr: fluxo de emergia da fração renovável dos materiais;

Sr: fluxo de emergia da fração renovável dos serviços; e

Y: fluxo de emergia total incorporou ao produto. 
- Razão de rendimento de emergia (EYR):

É uma medida de incorporação de emergia proveniente da natureza. Indica quanta energia local da natureza ("gratuita") foi utilizada no processo, quantificando assim, quantidade de emergia que foi armazenada (não utilizada) e agora está sendo disponibilizada para uso pela sociedade (BROWN; ULGIATI, 1997). EYR é obtida por meio da equação 10.

$$
E Y R=\frac{Y}{M+S}
$$

Em que:

EYR: razão de rendimento de emergia;

Y: fluxo de emergia total incorporou ao produto;

M: fluxo de emergia dos materiais; e

S: fluxo de emergia dos serviços.

- Taxa de carga ambiental (ELR)

É um indicador da pressão do processo produtivo sobre o ambiente local. Pode ser considerado como uma medida do estresse ou carga ambiental gerada pela atividade produtiva (BROWN; ULGIATI, 1997). ELR é obtida por meio da equação 11.

$$
E L R=\frac{N+M_{n}+S_{n}}{R+M_{r}+S_{r}}
$$

Em que:

ELR: taxa de carga ambiental;

$\mathrm{N}$ : fluxo de emergia dos recursos locais não-renováveis;

Mn: fluxo de emergia da fração não-renovável dos materiais;

Sn: fluxo de emergia da fração não-renovável dos serviços;

$\mathrm{R}$ : fluxo de emergia dos recursos renováveis da natureza;

Mr: fluxo de emergia da fração renovável dos materiais; e

Sr: fluxo de emergia da fração renovável dos serviços. 
- Índice de sustentabilidade em emergia (ESI)

Indicador que qualifica o nível de sustentabilidade ambiental do sistema. Assume que a função objetivo da sustentabilidade é obter a maior disponibilidade de emergia com a menor carga ambiental (Equação 12). De maneira geral, indica a compatibilidade econômica e ecológica do processo (ULGIATI; BROWN, 1998).

$$
E S I=\frac{E Y R}{E L R}
$$

Em que:

ESI: índice de sustentabilidade em emergia;

EYR: razão de rendimento de emergia; e

ELR: taxa de carga ambiental.

- Razão de investimento emergético (EIR)

Mede o investimento da sociedade para produzir determinado bem em relação à contribuição da natureza (BROWN; ULGIATI, 1997). Assim, este indicador quantifica a dependência que tem a unidade produtiva do sistema econômico (Equação 13).

$$
E I R=\frac{M+S}{R+N}
$$

Em que:

EIR: razão de investimento emergético;

M: fluxo de emergia dos materiais;

S: fluxo de emergia dos serviços.

$R$ : fluxo de emergia recursos renováveis da natureza; e

$\mathrm{N}$ : fluxo de emergia recursos locais não-renováveis.

- Taxa de intercâmbio emergético (EER)

É a razão entre a emergia solar e o rendimento da emergia representada pelo dinheiro pago pelo comprador. Este indicador quantifica o "valor real" ou "preço equilíbrio" que deveria ser pago pelo produto que gerou o sistema (CUADRA; RYDBERG, 2006). Este indicador mostra a vantagem econômica que pode recair sobre um dos agentes econômicos (produtor ou consumidor), fornecendo uma 
medida de quem "ganha" e quem "perde" na transação econômica (BROWN; ULGIATI, 2001). EYR é obtido por meio da equação 14.

$$
E E R=\frac{Y}{U S \$ \times E M R}
$$

Em que:

EER: Taxa de intercâmbio emergético;

Y: emergia que o sistema incorporou ao produto;

US\$: dinheiro pago pelo produto; e

EMR: razão emergia por dinheiro, em sej/US\$.

Para entender o índice EER como a relação de intercâmbio de emergia em uma transação comercial, torna-se importante compreender que o comércio de mercadorias pode ser feito entre duas comodities ou com a venda de alguma delas (CUADRA; RYDBERG, 2006). Deste modo, quando um bem é vendido e o dinheiro é recebido em troca, ambos fluxos (produto e dinheiro) são convertidos em unidades de emergia (sej) expressando qual dos agentes econômicos apresentou vantagem comercial relativa sobre o outro (Figura 8).

Figura 8 - Diagrama do processo da troca de emergia solar e da transação econômica na venda de carcaça de cordeiro e a forma como ela é calculada

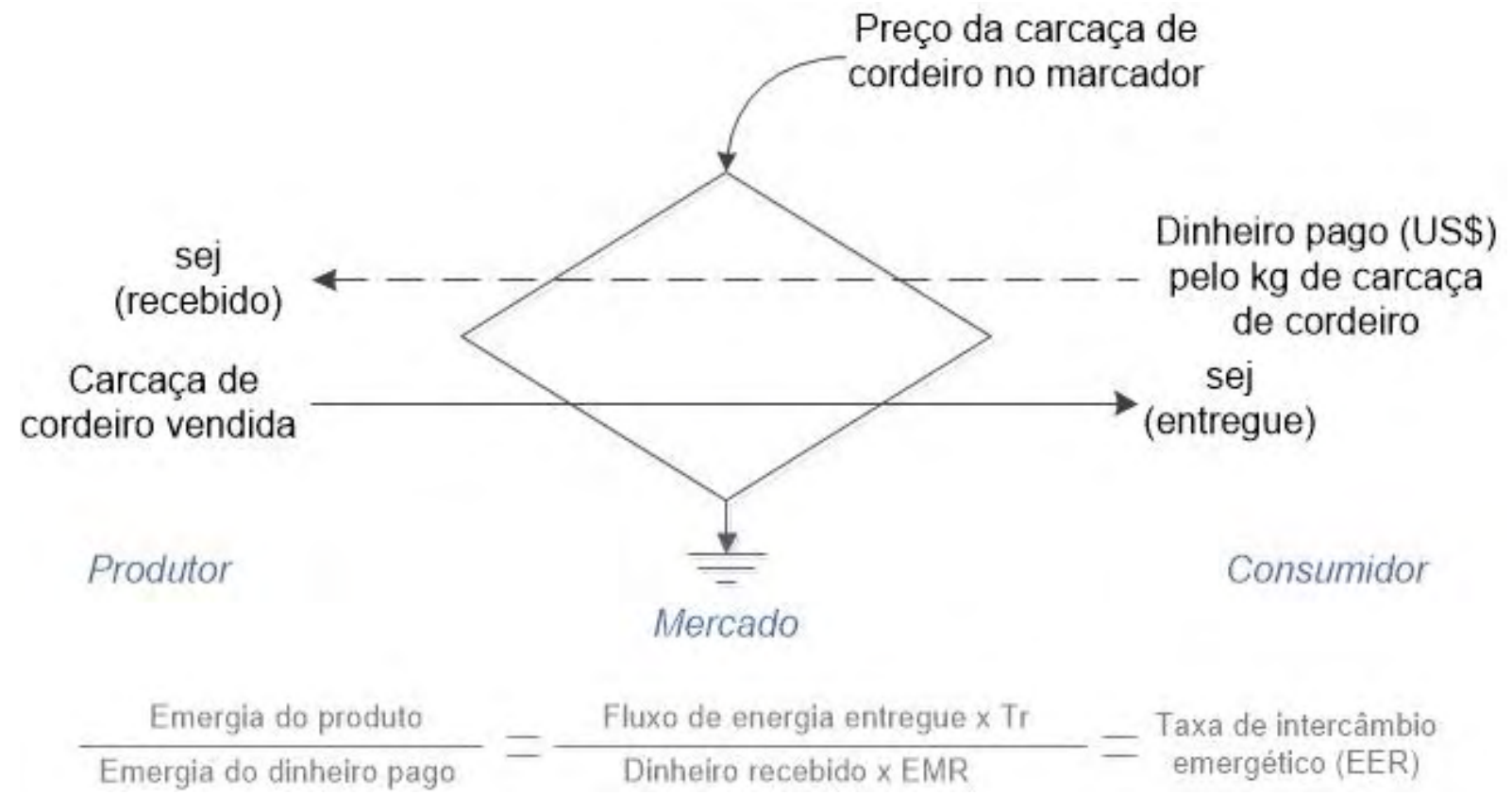

sej: Joules de emergia solar; Tr: transformidade; EMR: razão emergia por dinheiro, em sej/US\$.

Fonte: Odum (1996), adaptado pelo autor. 
Por meio da Razão emergia/moeda (EMR, Emergy to Money Ratio) torna-se possível a avaliação econômica e de emergia (CAMPBELL et al., 2005). O EMR representa a emergia total disponível que sustenta o Produto Interno Bruto por um ano e país. Ou seja, os recursos existentes no país, ali produzidos ou o saldo entre os recursos importados e exportados que estão na base da economia daquele ano. Este indicador permite conhecer a emergia incorporada na moeda durante um ano permitindo a atribuição de um valor emergético ao dinheiro recebido por um produto.

Deste modo, o Emdólar (Em\$) que é obtido da divisão entre a emergia entregue pelo EMR, indicando o dinheiro circulante cujo poder de compra está estabelecido pelo uso de uma determinada quantidade de emergia, em outras palavras, seu valor representa a quantidade de unidades de emergia (sej) que pode ser adquirida com uma unidade de dólar (US\$1,00).

Deste modo, a Síntese em Emergia torna-se uma ferramenta de contabilidade ambiental com enfoque biofísico, que possibilita a quantificação das contribuições feitas pela natureza (energia solar, chuva, água de poços ou nascentes, solo, etc.) e o sistema econômico (insumos, maquinarias, combustíveis fósseis, mão de obra, pagamentos em moeda etc.) na produção de produtos e/ou serviços oferecidos à sociedade (BROWN; ULGIATI, 1997, 2002; ODUM, 1996).

\subsubsection{Síntese em Emergia na ovinocultura}

De acordo com He et al. (2020), a maioria das pesquisas que utilizam a Síntese em Emergia tem se concentrado na avaliação da sustentabilidade de diferentes sistemas e processos. É assim como a Síntese em Emergia tem apresentado ótimos resultados de aplicabilidade nos sistemas de produção agropecuários, devido à interface entre as esferas "natural" e "humana" em que se encontram nesses sistemas (CASTELLINI et al., 2006).

A análise do desempenho da ovinocultura por meio da Síntese em Emergia tem sido usada. Alguns destes estudos são apresentados na sequência.

Haden (2002) usou a Síntese em Emergia para avaliar a sustentabilidade ecológica de uma pequena fazenda familiar de produtores de ovinos de corte na llha de Lopez, no estado de Washington. O pesquisador calculou os índices de emergia 
por produto e da fazenda como um todo, com base em: i) o rendimento emergético do processo de produção estudado; ii) a carga que o processo de produção coloca no ambiente local; e iii) a eficiência termodinâmica geral do processo de produção. A análise mostrou que as várias áreas de manejo na fazenda apresentam níveis amplamente diferentes de produção de emergia, carga ambiental e eficiência em transformação de energia. Em geral, concluiu-se que as áreas de gestão que dependiam em maior medida dos fluxos de emergia renovável locais e menos na aquisição de insumos, trabalho humano e serviços, exibiam maior sustentabilidade do que aquelas altamente dependentes de fluxos de emergia adquiridos e não renováveis.

Rodríguez-Ortega et al. (2017) aplicaram a Síntese em Emergia em três sistemas de criação de ovinos contrastantes de acordo com diferentes graus de especialização, integração e intensificação da Espanha mediterrânea. Nesse estudo foram analisados os fluxos de emergia, valores de transformidade e índices de emergia ao nível do sistema e por produto (carne de cordeiro; culturas permanentes: azeitona de sequeiro e amêndoa; culturas arvenses: cevada de sequeiro, cevada irrigada, alfafa e girassol). Os resultados mostraram que o sistema especializado de ovinos a pasto apresentou menor intensidade e eficiência, mas, maior sustentabilidade, ao contrário do sistema misto parcialmente integrado. Os pesquisadores concluíram que é necessário um maior apoio ao desenvolvimento da agrícola baseado em recursos naturais renováveis, como também são necessárias melhores práticas para garantir a sustentabilidade da agricultura no longo prazo e o bem-estar social.

Salas et al. (2017) propuseram a utilização da Síntese em Emergia como metodologia para caracterizar a eficiência e a conservação de agroecossistemas de produção ovina na Mesopotâmia central da Argentina e na Região do Alto Camaquã, no Brasil. O uso da Síntese em Emergia permitiu identificar que os percentuais de renovabilidade (\%R), carga ambiental (ELR) e a razão de rendimento de emergia (EYR) foram capazes de expressar a interação entre a comunidade local e o agroecossistema produtor de ovinos. Esses índices demostraram que os sistemas apresentam desempenhos semelhantes nos dois territórios, e ajudam a preservação da biodiversidade local. 
Reis et al. (2021) avaliaram o desempenho econômico e ambiental de um sistema produção de ovinos representativo para a região de São Jose do Rio Preto (SJRP), localizado no estado de São Paulo Brasil. Nessa pesquisa foram calculados o custo de produção e os indicadores em emergia, para posterior comparação com outros resultados científicos. Os resultados obtidos na análise de emergia demostraram que os insumos adquiridos no sistema econômico representaram $59,8 \%$ de toda a emergia demandada pelo sistema, sendo a soja e o milho os principais insumos que contribuíram com 16,14\% e 11,38\%, respectivamente, neste fluxo. Além disso, esses insumos também contribuíram significativamente nos custos de produção com $14,63 \%$ e $12,55 \%$ do custo total, respectivamente. Ao ser comparado o sistema estudado frente a outros sistemas de produção, o SJRP apresentou uma menor taxa de produção de emergia (EYR) e maior taxa de carga ambiental (ELR), o que reduz o índice de sustentabilidade de emergia (ESI). Os autores concluíram que o sistema deve ser reestruturado para se tornar mais sustentável, principalmente na etapa de confinamento de cordeiros, etapa a qual requer de maior quantidade de concentrado (milho e soja), insumos provenientes de fora do sistema. 


\section{REFERÊNCIAS}

AGOSTINHO, F. et al. The use of emergy assessment and the Geographical Information System in the diagnosis of small family farms in Brazil. Ecological Modelling, Amsterdam, v. 210, n. 1-2, p. 37-57, 2008.

AGOSTINHO, F. et al. Emergy accounting as a support for a strategic planning towards a regional sustainable milk production. Agricultural Systems, Barking, v. 176, n. 102647, 2019.

AGROSTAT. Estatísticas de comercio exterior do agronegócio brasileiro. Disponível em: http://indicadores.agricultura.gov.br/agrostat/index.htm. Acesso em: 20 jan. 2020.

ALLEGRETTI, G. et al. Insect as feed : An emergy assessment of insect meal as a sustainable protein source for the Brazilian poultry industry. Journal of Cleaner Production, Amsterdam, v. 171, p. 403-412, 2018.

ALVES, S. L. K. Desenvolvimento de modelo de cálculo e de indicador de custos de produção de suínos. 2021. 195 f. Tese (Doutorado) - Faculdade de Zootecnia e Engenharia de Alimentos, Universidade de São Paulo, Pirassununga, 2021.

BACIC, M.; ORTEGA, E.; KASSAI, J. Aplicação do Conceito de Emergia na Contabilidade de Gestão Ambiental. In: CONGRESSO BRASILEIRO DE CUSTOS, 17., Belo Horizonte, MG. Anais [...]. Belo Horizonte, MG, 2010. p. 1-15.

BARIONI, L. et al. Food security. In: SHUKLA, P. R. et al. (ed.). Climate change and land: an IPCC special report on climate change, desertification, land degradation, sustainable land management, food security, and greenhouse gas fluxes in terrestrial ecosystems. [S.I.]: IPCC, 2019. Chapter 5.

BARRETO, A. Posicionamento estratégico do setor de carnes de caprinos e ovinos no mercado de carnes brasileiro. Tecnologia \& Ciência Agropecuária, João Pessoa, 2010. Disponível em: file:///D:/Users/User/Downloads/tca09_posiciona.pdf. Acesso em: 10 ago. 2021.

BARROS, C. et al. Rentabilidade da produção de ovinos de corte em pastagem e em Economic return of sheep production on pasture and in feedlot. Revista Brasileira de Zootecnia, Viçosa, v. 38, n. 11, p. 2270-2279, 2009.

BENTON, T. G. et al. Designing sustainable landuse in a $1.5^{\circ} \mathrm{C}$ world: the complexities of projecting multiple ecosystem services from land. Current Opinion in Environmental Sustainability, Oxford, v. 31, p. 88-95, 2018.

BROWN, M.; ULGIATI, S. Emergy-based indices and ratios to evaluate sustainability: Monitoring economies and technology toward environmentally sound innovation.

Ecological Engineering, Amsterdam, v. 9, n. 1-2, p. 51-69, 1997.

BROWN, M.; ULGIATI, S. Emergy measures of carrying capacity to evaluate economic investments. Population and Environment, [s.l.], v. 22, n. 5, p. 471-501, 2001. 
BROWN, M.; ULGIATI, S. Emergy evaluations and environmental loading of electricity production systems. Journal of Cleaner Production, Amsterdam, v. 10, n. 4, p. 321-334, 2002.

BROWN, M.; ULGIATI, S. Energy quality, emergy, and transformity: H.T. Odum's contributions to quantifying and understanding systems. Ecological Modelling, Amsterdam, v. 178, n. 1-2, p. 201-213, 2004a.

BROWN, M.; ULGIATI, S. Emergy analysis and environmental accounting. Encyclopedia of Energy, Amsterdam, v. 2, p. 329-354, 2004b.

BRUNDTLAND, G. H. Our common future - the world commission on environment and development. Oxford: University Oxford University Press,1987. Disponível em: https://ambiente.wordpress.com/2011/03/22/relatrio-brundtland-a-verso-original/. Acesso em: 20 jun. 2021.

BUCHANAN, J. Cost and choice: an inquiry in economic theory. Indianapolis, IN: Liberty Fund, Inc., 1969.

CABRERA, V. Economics of fertility in high-yielding dairy cows on confined TMR systems. Animal, Cambridge, v. 8, n. s1, p. 211-221, 2014.

CAMPBELL D.; BRANDT-WILLIAMS S.; MEISCH M. Environmental Accounting Using Emergy: Evaluation of the State of West Virginia. U S Environ Prot Agency. 2005.

CARARETO, S. et al. Gestão estratégica de custos: custos na tomada de decisão. Revista de Economia da Universidade Estadual de Goiás, Anápolis, v. 2, n. 2, p. 1-24, 2006.

CARDOSO, M. et al. Caracterização da caprinocultura e ovinocultura no estado de São Paulo. Arquivos do Instituto Biológico, São Paulo, v. 82, p. 1-15, 2015.

CASTELLINI, C. et al. Sustainability of poultry production using the emergy approach: Comparison of conventional and organic rearing systems. Agriculture, Ecosystems and Environment, Amsterdam, v. 114, n. 2-4, p. 343-350, 2006.

CAVALETT, O.; QUEIROZ, J. F. DE; ORTEGA, E. Emergy assessment of integrated production systems of grains, pig and fish in small farms in the South Brazil.

Ecological Modelling, Amsterdam, v. 193, n. 3-4, p. 205-224, 2006.

CECHIN, A. A natureza como limite da economia, a contribuição de Nicholas Georgescu-Roegen. São Paulo: Senac, 2010.

CONAB - COMPANHIA NACIONAL DE ABASTECIMENTO. Custos de produção agrícola: a metodologia da conab. Brasília: Equipe da Biblioteca da Conab, 2010.

COSTANZA, R. Embodied energy and economic valuation. Science, New York, v. 210, n. 4475, p. 1219-1224, 1980.

CRUTZEN, P. J.; STOERMER, F. E. The anthropocene. Global Change News Letter, Stockholm, v. 1, n. 41, p. 17-18, 2000.

CUADRA, M.; RYDBERG, T. Emergy evaluation on the production, processing and 
export of coffee in Nicaragua. Ecological Modelling, Amsterdam, v. 196, n. 3-4, p. 421-433, 2006.

DALY, E. H.; FARLEY, J. Ecological economics: principles and applications. 2nd. ed. Washington, DC.: ISLANDPRESS, 2011.

DALZOTTO, F. et al. Science of the total environment emergy unsustainability index for agricultural systems assessment : a proposal based on the laws of thermodynamics. Science of the Total Environment, Amsterdam, n. 759, art. 143524, 2020.

DANIELS, P. L.; MOORE, S. Approaches for quantifying the metabolism of physical economies: Part I: Methodological overview. Journal of Industrial Ecology, Malden, v. 5, n. 4, p. 69-93, 2001.

DANSGAARD, W. et al. Evidence for general instability of past climate from a 250kyr ice-core record. Nature, London, v. 364, n. 6434, p. 218-220, 1993.

DEBORTOLI, C. E. Análise econômica e organizacional de sistemas de produção de ovinos para carne no estado do paraná. 2017. 275 f. Tese (Doutorado) Universidade Federal do Paraná, Curitiba, 2017.

DEBORTOLI, E. et al. Meat sheep farming systems according to economic and productive indicators: A case study in Southern Brazil. Revista Brasileira de Zootecnia, Viçosa, v. 50, n. June, p. 1-12, 2021.

DONG, X. et al. The impact of human activities on natural capital and ecosystem services of natural pastures in North Xinjiang, China. Ecological Modelling, Amsterdam, v. 225, p. 28-39, 2012.

DURAN, O.; RADAELLI, L. Metodologia ABC: implantação numa microempresa. Gestão \& Produção, São Carlos, v. 7, n. 2, p. 118-135, 2000.

EEA - European Environment Agency. Land accounts for Europe 1990-2000: towards integrated land and ecosystem accounting. Copenhagen, Denmark: EEA, 2006. (Report No 11/2006). Disponível em:

http://scholar.google.com/scholar?hl=en\&btnG=Search\&q=intitle:Land+accounts+for +Europe+1990?2000\#0. Acesso em: 10 jan. 2021.

EKINS, P. et al. A framework for the practical application of the concepts of critical natural capital and strong sustainability. Ecological Economics, Amsterdam, v. 44, n. 2-3, p. 165-185, 2003.

EKINS, P.; MAX-NEEF, M. Real-life economics: understanding wealth creation. London, UK: Routledge, 1992.

EMBRAPA - EMPRESA BRASILEIRA DE PESQUISA AGROPECUÁRIA. Panorama da ovinocultura e da caprinocultura a partir do Censo Agropecuário 2017. Boletim do Centro de Inteligência e Mercado de Caprino e Ovinos, Sobral, CE, n. 7, dez. 2018. Disponível em:

https://ainfo.cnptia.embrapa.br/digital/bitstream/item/192532/1/CNPC-2018-BoletimCl-n7.pdf. Acesso em: 20 dez. 2020. 
EMBRAPA - EMPRESA BRASILEIRA DE PESQUISA AGROPECUÁRIA. Número de frigorificos e abatedouros ovinos e caprinos. Disponível em:

https://www.embrapa.br/cim-inteligencia-e-mercado-de-caprinos-e-ovinos/frigorificose-laticinios. Acesso em: 11 dez. 2019.

FAOSTAT. foot and agriculture organization (FAO). Disponível em: http://www.fao.org/faostat/en/\#data/RL. Acesso em: 25 ago. 2020.

FAOSTAT. Food and agriculture organization of the United Nations. Disponível em: http://www.fao.org/faostat/en/\#data/QA. Acesso em: 7 fev. 2020.

FARIAS, J. et al. Análise socioeconômica de produtores familiares de caprinos e ovinos no semiárido Cearense, Brasil. Archivos de Zootecnia, Cordoba, v. 63, n. 241, p. 13-24, 2014.

FILIPIN, R.; VIEIRA, E. P.; WINCK, D. R. A utilização do custeio ABC na avaliação de resultados em culturas agrícolas: estudo de caso em uma empresa agrícola no estado do MA. In: CONGRESSO BRASILEIRO DE CUSTOS, 20., 2013, Uberlândia. Anais eletrônicos. [S.I.], 2013. Disponível em: https://anaiscbc.abcustos.org.br/anais/article/view/7. Acesso em: 7 fev. 2020.

FIRETTI, R. et al. Identificação de demanda e preferências no consumo de carne ovina com apoio de técnicas de estatística multivariada. Revista de Economia e Sociologia Rural, Brasília, v. 55, n. 4, p. 679-692, 2017.

FORTINO, C. O livro da economia. São Paulo: Globo SA, 2012.

GABARDO, M.; CALDARELLI, C. E. Expansão canavieira e o uso da terra no estado de São Paulo. Estudos Avancados, São Paulo, v. 30, n. 88, p. 93-116, 2016.

GAMEIRO, A. H. Análise econômica aplicada à zootecnia: avanços e desafios. In: SANTOS, M. V. dos et al. (org.). Novos desafios da pesquisa em nutrição e produção animal. Pirassuninga: 5D, 2009. p. 9-32.

GARNETT, T. Livestock-related greenhouse gas emissions: impacts and options for policy makers. Environmental Science and Policy, New York, v. 12, n. 4, p. 491503, 2009.

GARNETT, T. et al. Sustainable intensification in agriculture: premises and policies. Science, London, v. 341, n. 6141, p. 33-34, 2013.

GEORGESCU-ROEGEN, N. The entropy law and the economic process. Cambridge: Harvard University Press, 1971.

GERBER, P. J. et al. Tackling climate change through livestock: a global assessment of emissions and mitigation opportunities. Rome: FAO, 2013.

GITZ, V. et al. Climate change and food security: risks and responses. [Rome]: FAO, 2016. Disponível em: http://www.fao.org/3/a-i5188e.pdf. Acesso em: 20 fev. 2021.

HADEN, A. C. Emergy analysis of food production at s\&s homestead farm. S\&S

Center for Sustainable Agriculture, Island, p. 1-33, 2002. 
HE, S. et al. Application and problems of emergy evaluation: A systemic review based on bibliometric and content analysis methods. Ecological Indicators, Amsterdam, v. 114, art. 106304, 2020.

HOWELL, R. J.; BUCKIUS, O. R. Principios de termodinámica para Ingeniería. México: McGraw-Hill Book Company, 1990.

IBGE - INSTITUTO BRASILEIRO DE GEOGRAFIA E ESTATÍSTICA. Censo agropecuario 2006: resultados preliminares. Rio de Janeiro: IBGE, Disponível em: https://biblioteca.ibge.gov.br/visualizacao/periodicos/49/agro_2006_resultados_preli minares.pdf. Acesso em: 4 nov. 2019.

IBGE - INSTITUTO BRASILEIRO DE GEOGRAFIA E ESTATÍSTICA. SIDRA Censo agropecuário 2017. Disponível em: https://sidra.ibge.gov.br/tabela/6930. Acesso em: 4 nov. 2019.

IBGE - INSTITUTO BRASILEIRO DE GEOGRAFIA E ESTATÍSTICA. O que é PIB. Disponível em: https://www.ibge.gov.br/explica/pib.php. Acesso em: 20 ago. 2021.

IPCC. Climate Change 2014: synthesis report. Contribution of Working Groups I, II and III to the Fifth Assessment Report of the Intergovernmental Panel on Climate Change. Geneva, Switzerland: IPCC, 2014. 151 p.

IPCC. Summary for Policymakers. In: Climate Change 2021: The Physical Science Basis. Contribution of Working Group I to the Sixth Assessment Report of the Intergovernmental Panel on Climate Change. Cambridge University Press, 2021.

KLEIDON, A. A basic introduction to the thermodynamics of the Earth system far from equilibrium and maximum entropy production. Philosophical Transactions of the Royal Society B: Biological Sciences, London, v. 365, n. 1545, p. 1303-1315, 2010.

KNIGHT, F. H. The Common sense of political economy and selected papers and reviews on economic theor. Journal of Political Economy, Chicago, v. 54, n. 2, p. 660-773, 1934.

KNIGHT, F. H. A Suggestion for simplifying the statement of the general theory of price. Journal of Political Economy, Chicago, v. 36, n. 3, p. 353-370, 1928.

KOCJANČIČ, T. et al. Incorporation of emergy into multiple-criteria decision analysis for sustainable and resilient structure of dairy farms in Slovenia. Agricultural Systems, Barking, v. 164, n. April 2017, p. 71-83, 2018.

KOUTSOYIANNIS, A. Microeconomía moderna. España: Amorrortu Editores, 2002.

LAGERBERG, C.; BROWN, M. Improving agricultural sustainability: The case of Swedish greenhouse tomatoes. Journal of Cleaner Production, Amsterdam, v. 7, n. 6, p. 421-434, 1999.

LAMPERT, J. Caderno didático de administração rural. Administração Rural, Santa Maria, v. 4, p. 287, 2003.

LOTKA, A. J. Contribution to the energetics of evolution. National Academy of

Sciences, Washington, v. 8, p. 147-155, 1922. 
MAGALHÃES, K. et al. Características da produção de ovinos e caprinos em propriedades modais da BA, MS, RS e MG. Boletim Ativos de Ovinos e Caprinos, Brasília, v. 3, n. 3, p. 1-4, 2016.

MAHER, M. Contabilidade de custos: criando valor para a administração. São Paulo: Atlas, 2001.

MARQUES, J. Valiração ambiental. Jaguariúna: Embrapa Meio Ambiente, 2004. Disponível em:

https://www.agencia.cnptia.embrapa.br/recursos/Marques_valoracaolD8c4EUMn3Bm.pdf. Acesso em: 23 mar. 2021.

MARQUES, K. Custos de produção sob a ótica contábil e econômica. Enfoque Reflexão Contábil, João Pessoa, v. 28, n. 1, p. 27-39, 2009.

MARQUES, L. Capitalismo e colapso ambiental. 3. ed. Campinas: Unicamp, 2018.

MARTINEZ-ALIER, J.; NAREDO, J. M. A Marxist precursor of energy economics: Podolinsky. The Journal of Peasant Studies, London, v. 9, n. 2, p. 207-224, 1982.

MARTÍNEZ-ALIER, J.; ROCA, J. Economía ecológia y política ambiental. Mexico: Fondo de Cultura Económica, 2015.

MARTÍNEZ-ALIER, J.; ROCA, J.; SÁNCHEZ, J. Curso de Economía ecológica. México, D.F.: Rede de Formación Ambiental, 1998. (Programa de las Naciones Unidas para el Medio Ambiente; Oficina Regional para América Latina y el Caribe PNUMA).

MAY, P. Economia do medio ambiente: teoria e pratica. 3. ed. São Paulo: Elsevier, 2018.

MEA. Ecosystems and human well-being: synthesis. Washington, DC.: Island Press, 2005. v. 2017.

MEGLIORINI, E. Custos: análise e gestão. 2. ed. São Paulo: Pearson Prentice Hall, 2006.

MELLINO, S.; BUONOCORE, E.; ULGIATI, S. The worth of land use: A GIS-emergy evaluation of natural and human-made capital. Science of the Total Environment, Amsterdam, v. 506-507, p. 137-148, 2015.

MENDES, F. et al. Custos e receita bruta com o processamento de ovinos morada nova submetidos a diferentes manejos. Informações Econômicas, São Paulo, v. 46, n. 4, p. 1-11, 2016.

MENGER, C. Principles of economics. Auburn, Alabama: Ludwig von Mises Institute, 1976.

MORAES, M. C. et al. Nova perspectiva de custo de produção na agropecuária: proposta de avaliação para sistemas de integração Lavoura-Pecuária-Floresta (iLPF). In: CONGRESSO BRASILEIRO DE CUSTOS, 21., 2014, Natal. Anais [...]. 2014. Disponível em:

http://www.alice.cnptia.embrapa.br/alice/bitstream/doc/1006441/1/cpamt2014moraes custoproducaoagropecuarioilpf.pdf. Acesso em: 20 fev. 2020. 
OCDE/FAO. OCDE-FAO Perspectivas Agrícolas 2019-2028. Roma: OECD Publishing, 2019. (Organización de las Naciones Unidas para la Alimentación y la Agricultura (FAO), 2019.

ODUM, H. T. Energy, ecology, and economics. Royal Swedish Academy of Sciences, [Stokholm], v. 2, n. 6, p. 220-227, 1973.

ODUM, H. T. Systems Ecology: an introduction. New York, USA, 1983.

ODUM, H. T. Environmental accounting: emergy and environmental decision making. New York, USA: Jhon Wiley \& Sons INC, 1996.

ODUM, H. T.; ODUM, E. C. Energy Basis for man and Nature. New York, USA.: McGraw-Hill Book Company, 1976.

ODUM, H. T.; ODUM, E. C. A Prosperous wat down: principles and policies. Colorado: University Press of Colorado, 2001.

ORTEGA, E. et al. Brazilian soybean production: emergy analysis with an expanded scope. Bulletin of Science, Technology \& Society, [s.I.], v. 25, n. 4, p. 323-334, 2005.

PASSOS, C. R. M.; NOGAMI, O. Princípios de economia. 5.ed. São Paulo: Cengage Learning, 2008.

PAUL, C. et al. Rebound effects in agricultural land and soil management: Review and analytical framework. Journal of Cleaner Production, Amsterdam, v. 227, p. 1054-1067, 2019.

PEARCE, D.; TURNER, R. K. Economics of natural resources and the enviromental. Geart Britain: Pearson Education Ltd, 1990.

PEREIRA, A. C. et al. Custo de oportunidade: conceitos e contabilização. Caderno de Estudos, São Paulo, n. 2, p. 2-25, 1990.

PINHO, D. Manual de economia. 6. ed. São Paulo: Saraiva, 2013.

PRETTY, J. Agricultural sustainability: Concepts, principles and evidence.

Philosophical Transactions of the Royal Society B: Biological Sciences, London, v. 363, n. 1491, p. 447-465, 2008.

PRETTY, J.; BHARUCHA, Z. P. Sustainable intensification in agricultural systems. Annals of Botany, Oxford, v. 114, n. 8, p. 1571-1596, 2014.

RAINERI, C.; ROJAS, O.; GAMEIRO, A. Custo de produção na agropecuaria: da teoria economica á aplicação no campo. Empreendedorismo, Gestão e Negócios, [s.l.], v. 4, n. 4, p. 194-211, 2015.

RAINERI, C.; STIVARI, T. S.; GAMEIRO, A. H. Development of a cost calculation model and cost index for sheep production. Revista Brasileira de Zootecnia, Viçosa, v. 44, n. 12, p. 443-455, 2015a.

RAINERI, C.; STIVARI, T. S. S.; GAMEIRO, A. H. Lamb production costs: Analyses of composition and elasticities analysis of lamb production costs. Asian- 
Australasian Journal of Animal Sciences, Seoul, v. 28, n. 8, p. 1209-1215, 2015b.

RAMOS, M. et al. Sistema agroindustrial da carne ovina no Oeste paranaense.

Revista de Política Agricola, Brasília, v. 23, n. 1, p. 18-32, 2014.

REIS, B. et al. Economic and environmental assessment using emergy of sheep production in Brazil. Sustainability, Basel, v. 13, art. 11595, p. 1-14, 2021.

RODRÍGUEZ-ORTEGA, T. et al. Does intensification result in higher efficiency and sustainability? An emergy analysis of Mediterranean sheep-crop farming systems. Journal of Cleaner Production, Amsterdam, v. 144, p. 171-179, 2017.

ROJAS-DOWNING, M. M. et al. Climate change and livestock: Impacts, adaptation, and mitigation. Climate Risk Management, [s.I.], v. 16, p. 145-163, 2017.

ROSADO J. A.; LOBATO, J. F. Desafios da contabilidade de custos no moderno agronegócio contribuições do método ABC. São Paulo: CRV, 2020.

RUDORFF, B. F. T. et al. Studies on the rapid expansion of sugarcane for ethanol production in São Paulo state (Brazil) using Landsat data. Remote Sensing, New York, v. 2, n. 4, p. 1057-1076, 2010.

SALAS, S. et al. Characterizing of the agroecosystem as a component of a traditional product quality by using emergy synthesis. A Bi-national Geographic Indication for Argentine Central Mesopotamia Region and Brazilian Alto Camaquã Region Sheep Meat Production. In: BIENNIAL EMERGY CONFERENCE, 9., 2016, Gainesville. Proceedings [...].Gainesville, 2016. p. 89-96.

SAMUELSON, P.; NORDHAUS, W.; PEREZ, D. Economía. Buenos Aires: McGrawHill Book Company, 2003.

SARTORELLO, G. L. Desenvolvimento de modelo de cálculo e de indicador de custos de produção para bovinos de corte em confinamento. 2016. $191 \mathrm{f}$. Dissertação (Mestrado) - Faculdade de Medicina Veterinária e Zootecnia, São Paulo, 2016.

SARTORELLO, G. L.; BASTOS, J. P. S.; GAMEIRO, A. H. Development of a calculation model and production cost index for feedlot beef cattle. Revista Brasileira de Zootecnia, Viçosa, v. 47, art. e20170215, 2018.

SIEBRECHT, N. Sustainable agriculture and its implementation Gap - Overcoming obstacles to implementation. Sustainability, Basel, v. 12, n. 9, art. 3853, p. 1-27, 2020.

SILVA, V. L. S. et al. Workshop sobre análise dos pontos críticos da cadeia da ovinocultura do estado de São Paulo. CARRER, C.C. (org.). A cadeia de negócios da ovinocultura paulista: diagnóstico de pontos críticos e propostas de estruturação técnica e mercadológica. Pirassununga: Lawbook, 2009

SMIL, V. Energy: a beginner's guide. England: Oneworld Publications, 2006.

SMITH, A. The Wealth of Nations. London: Thomas Cedell, 1776.

SMITH, J.; PEARCE, B. D.; WOLFE, M. S. Reconciling productivity with protection of 
the environment: Is temperate agroforestry the answer? Renewable Agriculture and Food Systems, Wallingford, v. 28, n. 1, p. 80-92, 2012.

SMITH, P. et al. Global change pressures on soils from land use and management. Global Change Biology, Oxford, v. 22, n. 3, p. 1008-1028, 2016.

STANLEY, L. História do pensamento econômico. 6. ed. São Paulo: Thomson, 2006.

SUKHDEV, P. et al. The economics of ecosystems and biodiversity: mainstreaming the economics of nature: a synthesis of the approach, conclusions and recommendations of TEEB. Malta: Progress Press, 2010.

TAKAHASHI, F.; ORTEGA, E. Assessing the sustainability of Brazilian oleaginous crops - possible raw material to produce biodiesel. Energy Policy, Guildford, v. 38, n. 5, p. 2446-2454, 2010.

THORNTON, P. K. Livestock production: recent trends, future prospects.

Philosophical Transactions of the Royal Society B: Biological Sciences, London, v. 365, n. 1554, p. 2853-2867, 2010.

TILMAN, D.; CLARK, M. Global diets link environmental sustainability and human health. Nature, London, v. 515, n. 7528, p. 518-522, 2014.

TRABELSI, M. et al. How to measure the agroecological performance of farming in order to assist with the transition process. Environmental Science and Pollution Research, Berlin, v. 23, n. 1, p. 139-156, 2016.

ULGIATI, S.; BROWN, M. Monitoring patterns of sustainability in natural and manmade ecosystems. Ecological Modelling, Amsterdam, v. 108, n. 1-3, p. 23-36, 1998.

UNDESA. Total population (both sexes combined) by region, subregion and country, annually for $\mathbf{1 9 5 0 - 2 1 0 0 ~ ( t h o u s a n d s ) . ~ D i s p o n i ́ v e l ~ e m : ~}$

https://population.un.org/wpp/Download/Standard/Population/. Acesso em: 25 jun. 2020.

USDA. Sustainable agriculture: definitions and terms. Disponível em: https://www.nal.usda.gov/afsic/sustainable-agriculture-definitions-and-terms. Acesso em: 1 jul. 2020.

VAQUEIRO, S. V.; JÚNIOR, C. F. L. Gestão de custos na pecuária: princípios e métodos de custeio aplicáveis na produção de touros da raça Canchim. In: CONGRESSO INTERNACIONAL DE CUSTOS, 9., Florianópolis, 2005. Anais eletrônicos [...]. 2005. Disponível em:

http://anaiscbc.emnuvens.com.br/anais/article/view/1922. Acesso em: 10 fev. 2021.

VELTEN, S. et al. What is sustainable agriculture? A systematic review.

Sustainability, [s.I.], v. 7, n. 6, p. 1-33, 2015.

VIANA, J. G. A.; SILVEIRA, V. C. P. Análise econômica e custos de produção aplicados aos sistemas de produção de ovinos. In: CONGRESSO DA SOCIEDADE BRASILEIRA DE ECONOMIA, ADMINISTRAÇÃO E SOCIOLOGIA RURAL, 46, 
2008, Rio Branco. Anais eletrônicos [...]. 2008. Disponível em:

http://coral.ufsm.br/extrural/vicentepp/arquivospdf/AN\%C1LISE\%20ECON\%D4MICA \%20E\%20CUSTOS\%20DE\%20PRODU\%C7\%C3O\%20APLICADOS.pdf. Acesso em: 20 jan. 2021.

VIANA, J. G. A.; WAQUIL, P. D. Uma perspectiva evolucionária da economia agrícola: o caso da produção ovina no Brasil e Uruguai. RESR, Piracicaba-SP, v. 52, n. 3, p. 471-494, 2014.

VIANA, J.; REVILLION, J.; SILVEIRA, V. Alternativa de estruturação da cadeia de valor da ovinocultura no Rio Grande do sul. Revista Brasileira de Gestao e Desenvolvimento Regional, Taubaté, v. 9, n. 1, p. 187-210, 2013.

VIVIEN, F. D. et al. The Hijacking of the Bioeconomy. Ecological Economics, Amsterdam, v. 159, n. December 2018, p. 189-197, 2019.

VON BERTALANFFY, L. General systems theory. New York, USA., 1968.

WACKERNAGEL, M. et al. National natural capital accounting with the ecological footprint concept. Ecological Economics, Amsterdam, v. 29, n. 3, p. 375-390, 1999.

WALL, G. Exergy - A useful concept within resource accounting. GöteborgSweden: Chalmers University of Tecnology, 1977.

WALL, G.; GONG, M. On exergy and sustainable development-Part 1: Conditions and concepts. Exergy, An International Journal, [s.I.], v. 1, n. 3, p. 128-145, 2001.

WILHELM, J. A.; SMITH, R. G. Ecosystem services and land sparing potential of urban and peri-urban agriculture: A review. Renewable Agriculture and Food Systems, Wallingford, v. 33, n. 5, p. 481-494, 2018.

WORLD BANK. Gross domestic product, World Bank Group. Disponível em: https://data.worldbank.org/indicator/NY.GDP.MKTP.CD. Acesso em: 30 ago. 2021a.

WORLD BANK. World development indicators database, World Bank Group. Disponível em: https://databank.worldbank.org/data/download/GDP.pdf. Acesso em: 30 ago. 2021b.

ZHEN, L.; ROUTRAY, J. K. Operational indicators for measuring agricultural sustainability in developing countries. Environmental Management, New York, v. 32 , n. 1, p. 34-46, 2003 


\title{
CAPÍTULO III: CAN WE OBTAIN HIGHER PRODUCTIVITY ALLIED TO ENVIRONMENTAL GAINS? AN EMERGY-ECONOMIC STUDY OF SHEEP MEAT PRODUCTION SYSTEMS 1
}

\begin{abstract}
The increase of food demand by a growing population allied to a linear and anthropocentric production model paradigm, has pushed agricultural production to be more and more dependent on non-renewable resources mainly based on fossil energy. However, in a world with reduced resources availability and under serious climate constraints, those most sustainable instead of exclusively profitable production systems must be prioritized. For such a task, ecological economics rather than the neoclassical perspective has huge importance to allow a better understanding under a systemic perspective the relationship between production systems and energetic resources. Among others, the emergy (with an ' $m$ ') accounting method appears as an alternative to quantify the effort of nature in providing resources from a donor side view in quantifying value. Aiming to discuss about the importance in considering beyond simply economic indicators to support decision towards sustainable production systems, this study assess the economic and emergy performance of three different sheep farms in Brazil managed under different levels of intensification: Intensive, Semi-intensive, and Feedlot. Results show that from an economic perspective, the Feedlot system is more attractive $(9,800 \mathrm{US} \$ / \mathrm{yr}$ for net profit) than Intensive and Semi-intensive ones, while emergy synthesis show that Semi-intensive system (30\% for renewability) should be prioritized. On the other hand, when emergy is analyzed from an economic perspective based on Emdollars $(E m \$)$, the economic advantage regarding the production cost of Feedlot on the Semi-intensive system becomes less evident. The Intensive system obtained the worst performance for economic, and emergy indicators. More than contributing to the discussions about the importance in considering a systemic perspective when quantifying the economic performance of production systems, this study also (i) establishes the most sustainable sheep farm system that could be supported in
\end{abstract}

\footnotetext{
${ }^{1}$ Chapter submitted to the Journal of Cleaner Production of the Elsevier editorial on October 28, 2021.
} 
Brazil, and (ii) make available new unit emergy values that would enrich the existing emergy databases.

Keywords: Brazil. Ecological economy. Real wealth. Sheep production. Sustainability.

PODEMOS OBTER MAIOR PRODUTIVIDADE ALIADA A GANHOS

AMBIENTAIS? UM ESTUDO ECONÔMICO-EMERGETICO DOS SISTEMAS DE PRODUÇÃO DE CARNE OVINA

\section{RESUMO}

O aumento da demanda de alimentos em uma população crescente, aliado a um paradigma de modelo de produção linear e antropocêntrico, tem levado à produção agropecuária a ser cada vez mais dependente de recursos não-renováveis baseados principalmente em energia fóssil. No entanto, em um mundo com disponibilidade reduzida de recursos e sob sérias restrições climáticas, aqueles sistemas de produção mais sustentáveis devem ser priorizados ao invés dos exclusivamente lucrativos. Para tal, a economia ecológica, diferente da perspectiva neoclássica, tem grande importância para permitir melhor entendimento sob uma perspectiva sistêmica da relação entre sistemas de produção e recursos energéticos. Entre outros, o método de contabilidade em emergia (com um ' $m$ ') aparece como uma alternativa para quantificar o esforço da natureza em fornecer recursos do lado do doador na quantificação de valor. Com o objetivo de discutir sobre a importância de se considerar além de indicadores meramente econômicos para subsidiar a decisão por sistemas de produção sustentáveis, este estudo avaliou o desempenho econômico e emergético de três diferentes sistemas de produção ovinos no Brasil sob diferentes níveis de intensificação: Intensivo, Semi-intensivo e Confinamento. Os resultados mostram que do ponto de vista econômico, o sistema de confinamento é mais rentável (9.800 US\$/ano de lucro líquido) do que o intensivo e semi-intensivo, enquanto a Síntese em Emergia mostra que o sistema semiintensivo ( $30 \%$ de renovabilidade) deve ser priorizado. Por outro lado, quando se 
analisa a emergia a partir de uma perspectiva econômica baseada em Emdollars (Em\$), a vantagem econômica em relação ao custo de produção do Confinamento sobre o Sistema Semi-intensivo torna-se menos evidente. O sistema Intensivo obteve o pior desempenho para indicadores econômicos e emergéticos. Mais do que contribuir para as discussões sobre a importância de se considerar uma perspectiva sistêmica na quantificação do desempenho econômico dos sistemas de produção, este estudo também (i) estabelece o sistema de criação de ovinos mais sustentável que poderia ser apoiado no Brasil, e (ii) disponibiliza novos valores unitários de emergia que enriqueceriam os bancos de dados de emergia existentes.

Palavras-chave: Brasil. Economia ecológica. Riqueza real. Produção ovina. Sustentabilidade.

\section{$3.1 \quad$ INTRODUCTION}

According to the Food and Agriculture Organization of the United Nations (FAO), Brazil ranked 1st and 19th places in 2018 for having the largest sheep herd in the continent and in the world, respectively, with about 18.9 million animals (FAOSTAT, 2019). Despite having one of the largest sheep herds on the continent, between 2009 and 2018 Brazil imported about 83 thousand tons of lamb meat, mainly from Uruguay and Argentina (AGROSTAT, 2019). In Brazil, the state of São Paulo has been considered one of the main consumer markets for lamb meat (FIRETTI et al., 2017), due to population concentration (46.2 million people) (IBGE, 2021 ) and to hold about $28 \%$ of the certified sheep slaughterhouses in the country (EMBRAPA, 2019).

Despite the prominent role played by Sao Paulo state in this production chain, $78 \%$ of its sheep production farms has a surface area lower than 50 ha each (EMBRAPA, 2018), because of land competition with other agricultural activities as sugarcane for sugar and ethanol production (GABARDO; CALDARELLI, 2016; RUDORFF et al., 2010). As a consequence of the reduced available land and increasing market demand, sheep producers in the region have been pushed to adopt increasingly intensive production practices to achieve economic profitability to keep producing, but under land restrictions and accelerating production stages. This 
new way of sheep production through intensive use of land and higher demand for non-renewable inputs is moving away from the so-called more 'natural' way of production, which leads to a detriment to future productive potential, compromising the long-term food security (BARIONI et al., 2019; TILMAN; CLARK, 2014). Furthermore, this intensification increases the discrepancy between economic interests and the conservation of natural ecosystems, stimulating even more environmental problems (CASTELLINI et al., 2006; SMITH et al., 2016; WILHELM; SMITH, 2018). Recognizing the socioeconomic importance of sheep production and its environmental impacts, the following question arises: Is it possible to optimize economic performance and environmental sustainability in lamb production? From the different management models of sheep production existing in the focused region, a deeper knowledge of how they work becomes vital to understand their environmental and economic performance, identify the best practices, propose improvements, and support public policies.

From an economic point of view, detailed production costs of a certain activity are considered as essential to assist decision-makers for a rational management of production factors (PF, henceforth) as land, labor and capital (LAMPERT, 2003; PASSOS; NOGAMI, 2008). Different studies have shown advances in understanding the economic aspects of agricultural production (DEBORTOLI et al., 2021; RAINERI; STIVARI; GAMEIRO, 2015a, 2015b; SARTORELLO; BASTOS; GAMEIRO, 2018; TANDOĞAN; ÇIÇEK, 2016), including detailed description for different stages of production system, micro analysis, specificities regarding costs allocation, among others that be of help for more precise decisions. On the other hand, the growing environmental awareness that would affect production calls attention of researchers and producers to have a broader perception about how production is linked to the environment and society. An increasingly importance is related to how to account for natural resources into economic analyzes, either as supplier of resources or acting as a sink for wastes (by-products released for dilution).

According to Odum $(1996,2001)$, natural resources are the true driving forces of society since all anthropic production and consumption processes depends on them. Based on the ecology of systems and thermodynamics, emergy synthesis (with an 'm'; ODUM, 1996) has provided a scientific and objective theoretical basis for the 
evaluation of complex systems (HE et al., 2020) from the perception that energy rather than money is able to provide a common basis for the integration of economic and ecological sciences (AMARAL; MARTINS; GOUVEIA, 2016). The emergy method has being considered as an effective tool to evaluate the interface between man and nature, by accounting for both the contributions of socioeconomic activities (fertilizers, machinery, fuel, labor, services, etc.) and the previous work carried out by the natural systems (wind, rain, water from wells or springs, soil, sediments, biodiversity, etc.) to make available goods and services for humans' development.

Emergy synthesis has been widely used in the evaluation of the efficiency and sustainability of specialized livestock systems (AGOSTINHO et al., 2019; ALLEGRETTI et al., 2018; DAVID; PINHO; GARCIA, 2018; RÓTOLO et al., 2007; WANG et al., 2015), aquaculture (DAVID et al., 2021a, 2021b; LI et al., 2011), agriculture systems (CUADRA; RYDBERG, 2006; DE OLIVEIRA et al., 2018; ORTEGA et al., 2005; TAKAHASHI; ORTEGA, 2010; ZHAO et al., 2019), and croplivestock integrated systems (BULLER et al., 2015; CAVALETT; QUEIROZ; ORTEGA, 2006). Additionally, in the search of a multicriteria evaluation, the emergy synthesis has been used together with other methodologies as the traditional economic analysis as an attempt to quantify the environmental and economic performance of agricultural systems (CAVALETT; ORTEGA, 2009; CHEN et al., 2020; CUADRA; BJÖRKLUND, 2007; LU et al., 2010; REIS et al., 2021). Environmental aspects should become a principle that guides social and economic decision-making, thereby the search for sustainability in the agricultural sector is considered essential for long-term sustainable global development (SIEBRECHT, 2020; UN, 2015). In this way, the comprehensive evaluation of agricultural systems would provide relevant information to support the formulation of policies that lead the sector towards sustainable production. For this purpose, the simultaneous use of economic analysis and emergy synthesis offers a broader perspective of the sheep production systems.

This paper aims to evaluate the economic and environmental performance using emergy synthesis of three representative sheep production systems with different degrees of intensification in the state of São Paulo, Brazil. Besides presenting a comparative performance analysis under both economic and emergy 
perspectives, a theoretical discussion about the importance of incorporating natural free resources into traditional economic analysis is provided to support further discussions on the sustainability of sheep production. As an additional contribution, this work also provides new unit emergy values (UEV's) of sheep production to increase the available UEV's databases and support future studies.

\subsection{METHODS}

\subsubsection{Data collection}

In collaboration with the Sao Paulo State Sheep Farmers Association (ASPACO), three representative sheep farms located at São Paulo State were selected as case studies, considering data for 2020 as reference. ASPACO has been promoting sheep activities in the region since 1960, playing an important role in the sheep production chain, which makes it as relevant source of information on regional sheep production systems. The three chosen sheep production systems present different degrees of specialization and intensification, but all they have effective participation in the market. Information on environmental, productive, and economic characteristics were obtained for each case study through in situ surveys applied during fieldwork; surveys were previously approved by the human research ethics committee of University of São Paulo.

Survey's structure was divided into nine groups: (i) environmental characteristics (rainfall, wind, water, sunlight, soil type, area, etc.); (ii) information on pasture land (land use, irrigation vs. rainfed area, species, productivity, inputs, etc.); (iii) flock details (breeds, size, etc.); (iv) flock handling (productive stages of production cycle, health and reproductive management, feeding and wastes); (v) production indicators (pregnancy and prolificacy rate, weight at birth, weaning and slaughter, mortality rates, etc.); (vi) equipment, machinery and infrastructure; (vii) production outputs (number of heads produced, kilograms of lamb live weight and carcass produced, and by-products); (viii) labor force (role and quantity of permanent and temporary labor); (ix) market prices of all inputs, equipment, labor and services, and lamb meat/heads. 


\subsubsection{Description of the evaluated sheep farming systems}

The According to their characteristics, the evaluated systems were denominated as intensive sheep farming system of full-cycle (Intensive), intensive lamb finishing system (Feedlot), and semi-intensive sheep farming system with lamb finishing (Semi-intensive). These denominations will be used from this point forward. Figure 9 shows the main features of the evaluated systems, each one explained as follows. The Intensive system is located in the municipality of Cravinhos (latitude $21^{\circ} 20^{\prime} 25^{\prime \prime S}$ and longitude $\left.47^{\circ} 43^{\prime} 46^{\prime \prime} \mathrm{W}\right)$. It has a relatively large flock (1,200 ewes and 22 rams) compared to other sheep production systems within the region (EMBRAPA, 2018), and a total extension of $52 \mathrm{ha}$ with $46 \mathrm{ha}$ of grazing ( $30 \%$ with irrigation). Intensive system presents one breeding season per year (from February 15th to March 15th), featuring a lambing season in late winter and early spring. It also has an intensive rotational grazing system with pasture Marandu (Brachiaria brizantha) without irrigation (4 days of occupation) in which the ewes graze all day during the first 100 days of pregnancy. In this period, the ewes receive exclusively mineral supplements as white salt and mineral premix. During the last third of pregnancy (>100 days), the ewes are moved to better quality irrigated pastures (forage oats and ryegrass), and receive nutritional supplements until the lambs wean ( 60 days). The lactation period is divided into two stages: lactation I and lactation II. During lactation I, the ewes are confined with their lambs for 30 days, being fed with balanced diets to meet their nutritional requirements. During lactation II, which starts after the lambs achieve one month since they were birth and extends until they wean, the ewes graze on the forage oats and ryegrass (Lolium perenne) pastures during the day and at night they are kept indoors to nurse their lambs. During the lactation period, the lambs have access to creep feeding all the time for providing an extra nutrition. After lambs wean, there is the stage of finishing in feedlots, which lasts approximately 40 days. Finally, at day 100th of age, the lambs with best productive and phenotypic behavior are to continue in the rearing process until reaching about $57 \mathrm{~kg}$ weight, being classified as pure-breeding animals (PBA) and sale to the market; this is a byproduct of the Intensive sheep system. Those animals not selected are taken to the slaughterhouse; this is the main product of the Intensive systems. 
Figure 9 - General flow diagrams of the three evaluated sheep farms systems

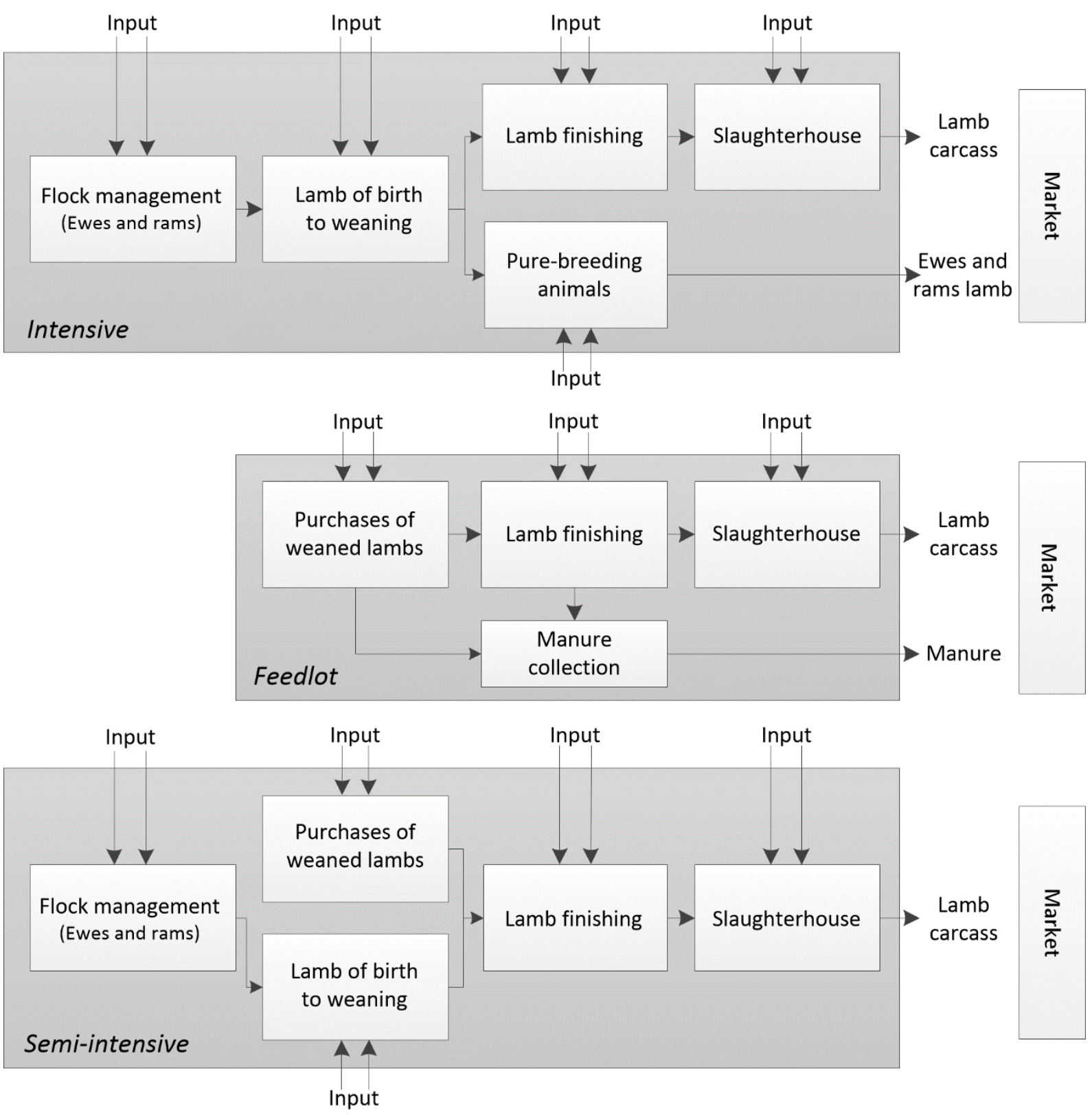

The word 'Input' refers to energy, materials, human labor and/or animal inputs from the larger economy; Source: own authorship.

The Feedlot system is located in the municipality of Botucatu $\left(22^{\circ} 50^{\prime} 02.5^{\prime \prime S}\right.$ and longitude $\left.48^{\circ} 33^{\prime} 51.8^{\prime \prime} \mathrm{W}\right)$. It is specialized in intensive lambs finishing, and thus it purchases animals with an average age and weight of 5 months and $28 \mathrm{~kg}$, approximately. The acquired lambs are confined for 65 days until they reach about $45 \mathrm{~kg}$ of live weight for later slaughter. Since it is a feedlot production system, the evaluated farm has 5 ha of area, the smallest one compared to other two evaluated in this study. About 3.5ha of its area is occupied with facilities, 1ha with pasture, the remaining 0.5 ha with native vegetation. The feedlot system has four productive 
cycles per year, reaching about 500 lambs per cycle. The purchased animals comes small farms located in other regions, mainly from south and northeast. During nutritional management, two types of diets for lambs are used: finishing $I$ and finishing II. Finishing I is used to improve the lamb's adaptation during feedlot period. This diet has a higher level of fiber than finishing II, and it is offered from day 0 to day 15. Finishing II is used in the last stage of lamb fattening (from day 16 to day 65), and it has high concentration of protein and energy to achieve better daily weight gains. During the productive cycle, the animals are weighed every 10 days to adjust the amount of feed to be offered. The main product of Feedlot system is lamb carcasses, but the sheep manure generated in the pens are sale as fertilizer, a by-product.

Finally, the Semi-intensive system is the most found among the sheep farmers in Sao Paulo state, which represents itself a transition from grazing to feedlot. It is located in the municipality of Bofete (latitude 23'14'57.7"S and longitude $48^{\circ} 24^{\prime} 26.7 \mathrm{WW}$ ), possessing 39ha of which 31 ha are destined to grazing without irrigation, 2ha for facilities, and 6ha for natural vegetation conservation. The Semiintensive evaluated system has a herd divided into two groups. The first one is composed of 86 ewes and 2 rams that are kept in an extensive grazing system; it has a single breeding season, producing about 90 lambs per year. The second group is composed by weaned lambs that comes from the previous group, as well lambs acquired outside the farm; both are keep in feedlot for finishing. The main output is finished lambs, which annually reaches 800 animals (initially acquired with 5 months and $28 \mathrm{~kg}$ ), confined for 70 days until they reach about $44 \mathrm{~kg}$ for slaughter. In relation to nutritional management, lambs in the finishing stage received controlled supplementation, while other animals (ewes and rams) are supplemented exclusively during the breeding season, last third of gestation, and lactation. Table 9 shows the main characteristics of the three sheep production systems evaluated in this study. 
Table 9 - Main characteristics of the three evaluated sheep farm systems

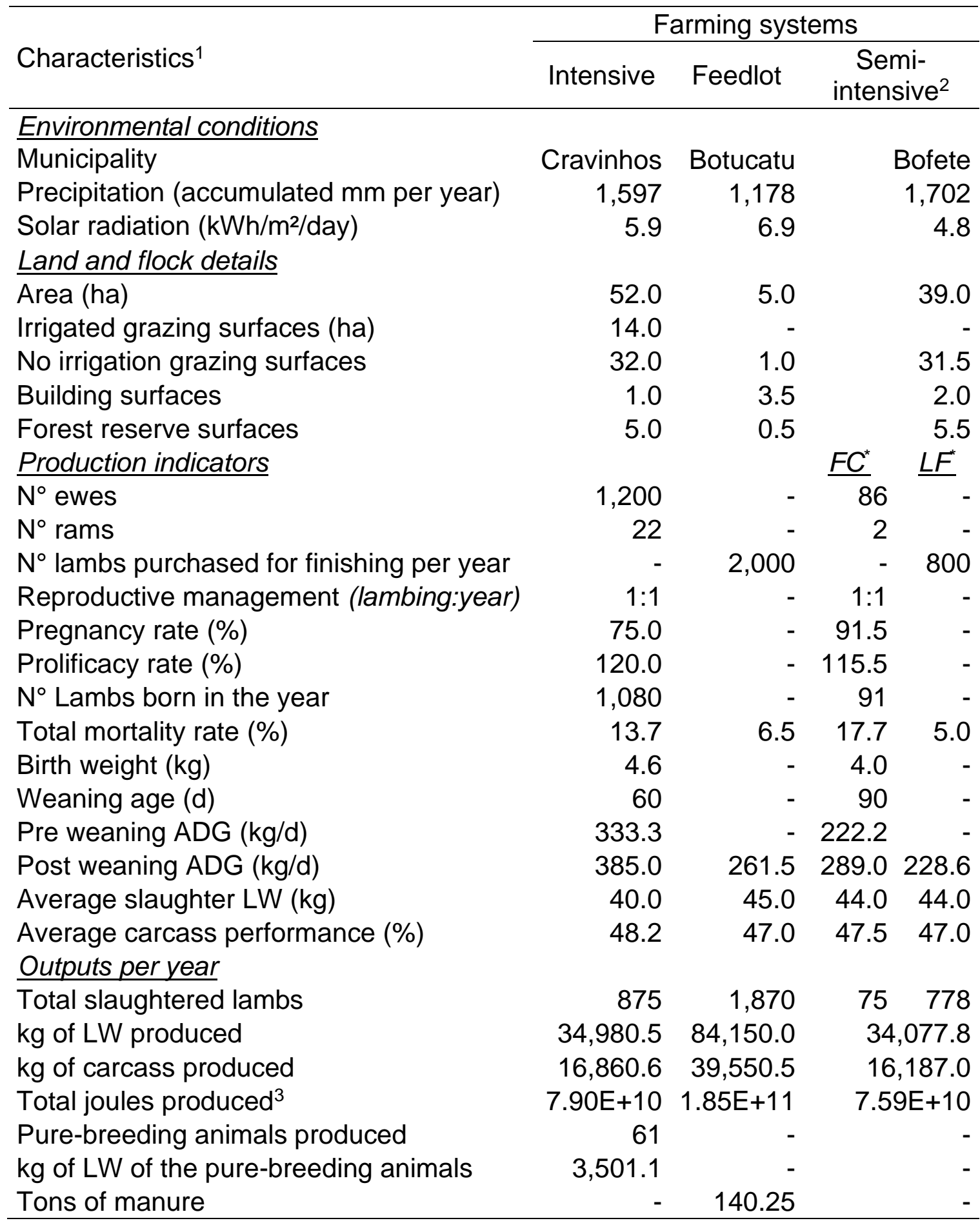

${ }^{1} A \overline{D G}$, average daily gain; LW: Live weight. ${ }^{2}$ Semi-intensive sheep farming system with lamb finishing has two different processes from which lambs are produced, farming system of full-cycle (FC*), and lamb finishing in feedlots $\left(\mathrm{LF}^{*}\right) .{ }^{3}$ The calculations of the energy produced in joules of each system and other specific characteristics of each system in Supplementary material A. Source: own authorship. 


\subsubsection{Economic assessment}

Based on the data collected for this study and on the neoclassical economics cost theory, a cost allocation scheme was developed to obtain the annual production cost of each farm. This allocation scheme sought to comply with the economic precepts, grouping costs in the following three categories: variable costs (VCost), fixed operations costs (FCost), and factors income (IFactor). The VCost are those costs that varied according to the volume of production, including all expenses (feed, medicines, purchase of lamb and slaughter service) that are directly related to the production of lambs and that generate the system economic revenue. The FCost are expenses associated with the operation of the property and their value is independent of the level of production. It is considered the expenses of feed and medicines of the fixed flock (ewes and rams), labor, fuel, energy, depreciation and maintenance of machinery and facilities. It is important to clarify that quantification of the economic costs in this study includes the explicit costs (monetary disbursement made for payment) and the implicit cost (no real payment is made), such as the opportunity cost $(\mathrm{OC})$ of land and capital. The $\mathrm{CO}$ is represented by the IFactor category, and is quantified by the monetary value that the activity (sheep production) should pay to the farmer (who owns the PF) for the use of PF. Thus, the IFactor becomes a cost for the firm but an income for the farmer. The basic interest rate of Brazil (named as 'Selic', 2.81\% per year) established in 2020 is used to calculate the $\mathrm{OC}$ of the VCost, and FCost. In relation to the $\mathrm{OC}$ of the land, this was calculated using the Selic rate on the rental value of the land for study period of each region. Although IFactor includes elements of the variable and fixed costs, some of them are separated in the cost scheme to facilitate understanding.

In relation to the revenue of each farm, the gross revenue (GReven) for a oneyear period is calculated. According to the survey with the farmers, a sale price of US\$ 4.40 per $\mathrm{kg}$ of carcass and US\$ 4.95 per $\mathrm{kg}$ of LW of pure-breeding animal are considered. Indicator of profitability and economic performance are also calculated, including net profit (NProf), and the cost-benefit ratio (CBR). For the $C B R>0$, it indicates the net economic return, while $\mathrm{CBR}<0$ indicates economic infeasibility. Table 10 shows the economic indices used in this study. 
Table 10 - Description of the economic indices used in this study

\begin{tabular}{|c|c|c|}
\hline Indicator & Equation & Meaning \\
\hline $\begin{array}{l}\text { Total cost } \\
\text { (TCost) }\end{array}$ & $T \operatorname{Cos} t=V \operatorname{Cos} t+F \operatorname{Cos} t+I F a c t o r$ & $\begin{array}{l}\text { It is the sum of all inputs } \\
\text { used in production, } \\
\text { according to economic } \\
\text { theory. }\end{array}$ \\
\hline $\begin{array}{l}\text { Gross } \\
\text { revenue } \\
\text { (GReven) }\end{array}$ & GReven $=$ Lproduct sales & $\begin{array}{l}\text { It is the income generated } \\
\text { by the sale of the firm's } \\
\text { goods and services }\end{array}$ \\
\hline $\begin{array}{l}\text { Net profit } \\
\text { (NProf) }\end{array}$ & NProf $=$ GReven - TCost & $\begin{array}{l}\text { It is the real financial benefit } \\
\text { of the firm, being the } \\
\text { difference between GReven } \\
\text { and TCost, which consider } \\
\text { the IFactor. }\end{array}$ \\
\hline $\begin{array}{l}\text { Cost- } \\
\text { benefit } \\
\text { ratio (CBR) }\end{array}$ & $C B R=\frac{N \text { Prof }}{T \operatorname{Cos} t}$ & $\begin{array}{l}\text { It is the relationship } \\
\text { between the benefits of the } \\
\text { activity and its production } \\
\text { costs. It is expressed in } \\
\text { monetary terms. }\end{array}$ \\
\hline
\end{tabular}

Source: own authorship.

\subsubsection{Emergy synthesis}

Emergy synthesis is a method of integral and systemic evaluation, which can quantify the potential energy (exergy) that was used directly and indirectly in the production of a resource, product or service; it is measured using a unit known as solar emergy expressed in solar emjoules and abbreviated as sej (BROWN; ULGIATI, 2004a; ODUM, 1996). The emergy method offers tools to assess the contributions made by natural ecosystems (from a donor-side perspective) to productive systems, which are generally not considered in traditional economic analysis based on a user-side approach (BROWN; ULGIATI, 1997; FRANZESE et al., 2009). Additionally, emergy accounting recognizes the quality of different kinds of energy according to the effort made by nature to make them available. This means that 1 joule of coal is different than 1 joule of electricity, since electricity demands more investments (or effort) in its production chain. Due to its intrinsic characteristics in recognizing the quality of energy from a donor side perspective, the emergy synthesis as described by Odum (1996) is used in this study synergistically with a traditional economic analysis (described above) to assess three lamb farming systems. Precisely, emergy synthesis is applied according to three steps: 
i) Energy diagrams

The symbols of the energy systems language proposed by Odum (1996, 1976) are used to represent the assessed sheep farms from a broader view, including the production unit and its relationship with external factors. System boundaries are defined to visualize and understand the relationships among energy drivers supporting system functioning. Energy, mass, and currency flows are identified and represented, as well internal storages, components (producers and consumers), and processes as interaction among energy flows. External energy sources or even some internal storages are classified as contributions from nature (I) and feedback from the larger economy $(F)$. The ' $l$ ' sources originate from the sum of renewable $(R)$ and non-renewable $(N)$ local resources, while that $F$ is comprehends materials (M) and services (S) from the economic system. Internal relationships among energy flows are represented, as well the yielded outputs including products and co-products.

\section{ii) Emergy tables}

Based on the energy diagram, the second step is to build the emergy table to convert each input energy, mass and/or monetary flow into the same unit of solar emergy, sej. This conversion is made by multiplying the amount of each input by their corresponding unit emergy value (UEV), which is defined as the emergy demanded to make available a unit of that good or service. Among others, the UEVs comprehend the so-called transformities (units in sej/J), specific emergy (sej/g), and the emergy per unit money (sej/US\$). UEVs can been seen as conversion factors that carriers all the memory embodied by natural efforts in making available that good or service, thus it represents the quality of different kinds of energy form from a donor-side perspective. After converting all inputs flows into sej, they can be added to represent the total emergy $(\mathrm{Y})$ demanded by the system. In this study, mostly UEVs are obtained from scientific literature, standardized to a global emergy baseline of $12.0 \mathrm{E}+24 \mathrm{seJ} / \mathrm{yr}$ (BROWN et al., 2016). The UEV for weaned lambs for finishing are estimated because they are unavailable in the literature. All UEVs used in this study are shown in Appendix A. The renewability fraction (RNF) concept is used in this work. This means that the renewability fraction of each input flow (energy, mass and/or monetary) supporting the lamb farms are considered. According to Ortega et 
al. (2002, 2005) and Cavalett et al. (2006), this approach allows a better representation of emergy performance for the evaluated systems. The RNF values used in this study are shown in Appendix B.

\section{iii) Emergy indices}

The third and final step is to calculate and discuss about the emergy indices (Table 11). Based on the relationship between the emergy flows from the environment and the economic system, emergy indices supports discussions about the global efficiency, renewability, emergy investments and yield, environmental load and environmental sustainability of the studied lamb farms under a comparative perspective.

Table 11 - Description of the emergy indices used in this study

\begin{tabular}{|c|c|c|}
\hline Indicator & Equation & Meaning \\
\hline Transformity (Tr) & $\operatorname{Tr}=\frac{Y}{\text { Output }}$ & $\begin{array}{l}\text { Shows the global efficiency of the } \\
\text { system, in converting resources into the } \\
\text { desired output. }\end{array}$ \\
\hline $\begin{array}{l}\text { Percentage of } \\
\text { renewability }(\% R)\end{array}$ & $\% R=\frac{R+M_{R}+S_{R}}{Y}$ & $\begin{array}{l}\text { It measures the percentage of } \\
\text { renewable resources supporting } \\
\text { systems production. }\end{array}$ \\
\hline $\begin{array}{l}\text { Emergy Yield Ratio } \\
\text { (EYR) }\end{array}$ & $E Y R=\frac{Y}{F}$ & $\begin{array}{l}\text { It measures the amount of emergy that } \\
\text { was stored (unused) and is now being } \\
\text { made available for use by society. }\end{array}$ \\
\hline $\begin{array}{l}\text { Environmental } \\
\text { Loading Ratio (ELR) }\end{array}$ & $E L R=\frac{N+M_{N}+S_{N}}{R+M_{R}+S_{R}}$ & $\begin{array}{l}\text { It measures the level of environmental } \\
\text { load (ratio of non-renewable resources } \\
\text { use) caused by production system. }\end{array}$ \\
\hline $\begin{array}{l}\text { Emergy } \\
\text { Sustainability Index } \\
\text { (ESI) }\end{array}$ & $E S I=\frac{E Y R}{E L R}$ & $\begin{array}{l}\text { It quantifies the level of environmental } \\
\text { sustainability of the system. The goal is } \\
\text { to obtain higher yield through lower } \\
\text { load. }\end{array}$ \\
\hline $\begin{array}{l}\text { Emergy Investment } \\
\text { Ratio (EIR) }\end{array}$ & $E I R=\frac{F}{R+N}$ & $\begin{array}{l}\text { It measures the farm's dependence on } \\
\text { the economic system. }\end{array}$ \\
\hline $\begin{array}{l}\text { Emergy Exchange } \\
\text { Ratio (EER) }\end{array}$ & $E E R=\frac{Y}{U S \$ x E M R}$ & $\begin{array}{l}\text { It quantifies the ratio of emergy } \\
\text { delivered to the money received back } \\
\text { (converted into emergy), showing the } \\
\text { economic advantage over one of the } \\
\text { agents (producer or consumer). EMR is } \\
\text { the emergy per money ratio, in sej/US\$. }\end{array}$ \\
\hline
\end{tabular}




\subsubsection{Method of analysis and discussion of results}

This study used Microsoft Excel® 2019 for data processing and graphics, and the technical flowcharts and systematic energy flow diagrams are designed using Microsoft Visio ${ }^{\circledR} 2010$. The indicators obtained by both methods (economic analysis and emergy synthesis) are discussed under three comparatives approaches among the three analyzed lamb production systems:

(i) The discussion of economic results is carried out isolated to provide insights about what would be the conclusions relying exclusively on economic indicators.

(ii) A radar chart is used to illustrate the emergy performance profile of lamb farms comprehensively and generally. For this, the emergy indices are normalized based on the maximum value of each index, assuming that the higher its value, the better its performance. For environmental sustainability (ESI) and emergy yield ration (EYR), only percentage normalization was carried out, since they already pointed that premise. In terms of renewability $(\% \mathrm{R})$ was used the percentage value of this index. For global efficiency (Tr), emergy investment ratio (EIR), and environmental load (EIR), the inverse of these indices are diagramed to indicates a 'higher-better' reading $(1 / \mathrm{Tr}, 1 / \mathrm{EIR}$, and $1 / E L R)$. Finally, for the real value $(E E R)$ of the $\mathrm{kg}$ of carcass, the relationship between the market value (US \$4.40) vs. the its value in Emdollar (Em\$).

(iii) Divergences and complementary insights between traditional economic analysis and emergy synthesis are presented. It is used a graphical representation (BONILLA et al., 2010) between global efficiency (transformity) and environmental sustainability (ESI). A comparison between the market price of $1 \mathrm{~kg}$ of lamb carcass and its Emdollar value is also presented to allow discussions about the extend in which traditional economy captures the natural effort in generating goods.

\subsection{RESULTS}

\subsubsection{Economic results}

Table 12 shows that Feedlot system was the farm with highest GReven (US\$ 173,848), while Intensive and Semi-intensive systems presented GReven of 52\% 
and $42 \%$ compared to the Feedlot. Notwithstanding, the Feedlot obtained the highest TCost (US\$ 164,003), followed by Intensive (US\$ 87,137) and Semi-intensive (US\$ $81,435)$ systems. Although TCost exhibiting a similar behavior of GReven for all three systems, differences can be observed within the cost scheme of each system. For example, the TCost of Feedlot and Semi-Intensive was mostly represented by the VCost, reaching $80 \%$ and $83 \%$ respectively. The VCost for these two systems was mainly influenced by the purchase of animals and feed. On the other hand, the Intensive farm presented an opposite behavior with higher FCost (US\$ 68,168) than VCost (US\$16,298), which achieves about 78\% and 18\%, respectively, of its TCost. Regarding the IFactor, the Feedlot system presented the highest cost (US\$ 4,510), anyhow, the IFactor achieved a low influence on the TCost for all the three lamb farms ranging from $2.7 \%$ to $3.1 \%$.

Table 12 - Economic indicators for the three lamb farms evaluated

\begin{tabular}{|c|c|c|c|}
\hline Profit and loss statement (US\$/yr) & Intensive & Feedlot & $\begin{array}{c}\text { Semi- } \\
\text { intensive }\end{array}$ \\
\hline (+) Gross Revenue & $91,425.68$ & $173,848.35$ & $73,513.20$ \\
\hline Lamb carcass sales & $74,112.47$ & $173,848.35$ & $73,513.20$ \\
\hline Pure-breeding animal sales & $17,313.21$ & - & - \\
\hline (-) Variable expenses & $16,298.64$ & $131,713.74$ & $68,988.93$ \\
\hline Acquisition of animals for finishing & - & $85,732.75$ & $37,179.49$ \\
\hline Feeding of animals for finishing & $10,927.35$ & $34,132.86$ & $26,607.14$ \\
\hline Veterinary expenses & 248.77 & $1,023.96$ & 90.19 \\
\hline Slaughter expenses & $5,122.52$ & $10,824.18$ & $4,458.12$ \\
\hline (-) Operational fixed expenses & $68,168.33$ & $27,779.09$ & $10,658.10$ \\
\hline Fixed flock feeding & $17,361.08$ & - & 784.84 \\
\hline Fixed flock veterinary expenses & 361.66 & - & 12.03 \\
\hline Forage production & $4,362.51$ & - & - \\
\hline Energy and fuels & $9,262.64$ & $4,534.29$ & 673.85 \\
\hline Labor & $14,634.55$ & $15,098.90$ & $5,919.78$ \\
\hline Depreciation of M\&F1 & $15,352.71$ & $7,262.13$ & $1,985.51$ \\
\hline Maintenance of $M \& F^{1}$ & $6,833.18$ & 883.78 & 484.21 \\
\hline (-) Income of factors ${ }^{2}$ & $2,670.94$ & $4,510.35$ & $2,420.34$ \\
\hline Remuneration on variable capital & 457.99 & $3,701.16$ & $1,920.21$ \\
\hline Remuneration on fixed capital ${ }^{3}$ & $1,915.53$ & 780.59 & 277.07 \\
\hline Remuneration on land & 297.41 & 28.60 & 223.06 \\
\hline (-) Total cost & $87,137.91$ & $164,003.18$ & $80,615.49$ \\
\hline Total cost per hectare & $1,675.73$ & $3,153.91$ & $1,520.30$ \\
\hline Total cost per kg of lamb (live weight) & 2.22 & 1.95 & 2.27 \\
\hline Total cost per kg of carcass & 4.60 & 4.15 & 4.82 \\
\hline
\end{tabular}


Total cost per $\mathrm{kg}$ of $\mathrm{PBA}^{3}$ (live weight)

Gross profit

Net profit

Cost-Benefit Ratio (CBR)
2.74

$6,958.70 \quad 14,355.52-4,681.95$

$4,287.77 \quad 9,845.17-7,102.29$

$0.05 \quad 0.06 \quad-0.09$

${ }^{1} \mathrm{M} \& \mathrm{~F}$ : machinery and facilities; ${ }^{2}$ Opportunity cost of land and capital; ${ }^{3} \mathrm{PBA}$ : pure breeding animal. Source: own authorship.

The Semi-intensive system was the one with highest production cost per $\mathrm{kg}$ of carcass (US\$ 4.89), followed by the Intensive (US\$ 4.60) and Feedlot (US\$ 4.15) systems, leading the Semi-intensive to a net economic loss (US\$-7,922 for NProfit) and consequent negative CBR of -0.10 . In contrast, Feedlot and Intensive showed a positive economic performance with CBR of 0.06 and 0.05 respectively. Calculation details on the economic analysis are available at Supplementary Material B.

\subsubsection{Emergy results}

Although existing specific differences among the three lamb farms evaluated, the main features for all of them are similar as represented by Figure 10; detailed and individual energy diagrams for each lamb farm are available in the Supplementary Material $C$. The resources from nature $(R$ and $N)$ and from the economic system (M and $S$ ) are the drivers that sustain systems functioning to generate the outputs as products and by-products (lamb carcass, pure- breeding animals, and manure). $R$ resources includes mainly solar radiation, wind power and rainfall, while $\mathrm{N}$ refers to soil loss and underground water consumption. F resources includes a larger amount of items, but those ones that most emergy contributors are lamb for finishing, ewes and rams, feed (soymeal, mineral premix), fertilizers, limestone, and human labor. Internal processes are quite simple, containing a pasture area producing vegetal biomass (grass), animals that convert grass and feed into animal protein, and the outputs including live animals send to market as breeders, animal carcasses from slaughterhouse (lamb meat), and manure sold as organic fertilizer. Monetary flows are represented in countercurrent way to biophysical flows of energy, in which money is received by the sale of products and co-products, fill the internal storage and it is used to pay both direct and indirect labor embodied in materials acquired from the larger economy; none monetary flow circulates on the components related to natural resources $\mathrm{R}$ and $\mathrm{N}$, since they are considered free-of-charge by the market 
according to the traditional economic concept. Dotted lines represent the loss of energy (entropy).

Figure 10 - Representation of an energy flow diagram of representative a sheep

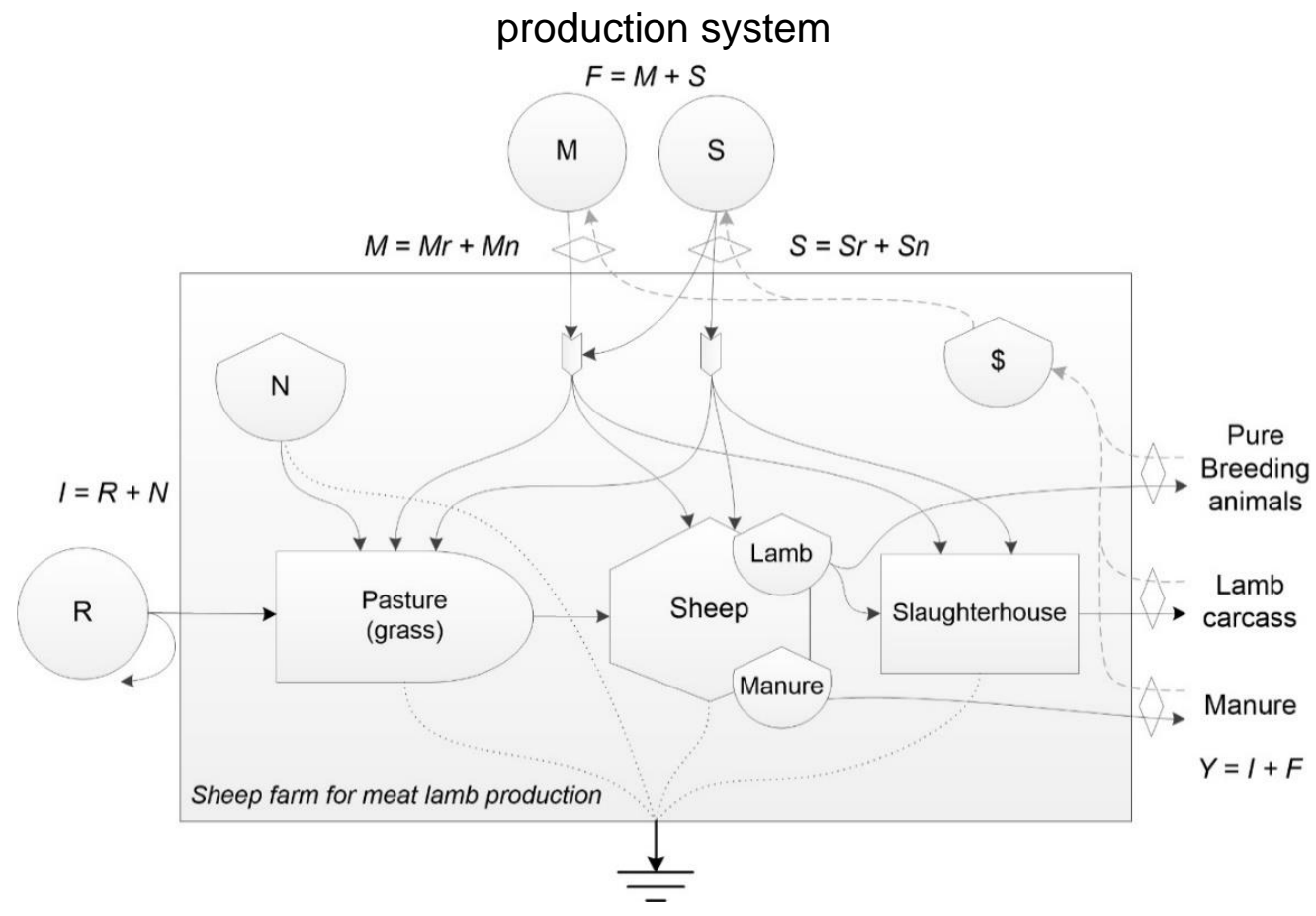

$\mathrm{R}$, renewable natural resources; $\mathrm{N}$, non-renewable natural resources; I, contribution from nature; $\mathrm{M}$, materials; $S$, services; $F$, feedback from the economy; $Y$, total emergy. The lowercase letters $r$ and $n$ represent the renewable and non-renewable fraction of materials and services.

After modeling systems functions to understand how they work by interacting energy flows from different sources to generate products and by-products, all energy flows are quantified and converted into emergy flows through the use of UEVs. Detailed emergy tables for each lamb farm system are available at Supplementary Material D, in which Table 13 provides the aggregated figures. Total emergy flow per hectare year demanded by Feedlot system is higher $(2.08 \mathrm{E}+17$ sej) than Intensive and Semi-intensive systems $(2.40 \mathrm{E}+16$ sej and $1.30 \mathrm{E}+16$ sej), achieving $11 \%$ and $6 \%$ of total Feedlot emergy, respectively. Although high emergy dependent, this absolute value does not reflect the emergy performance of Feedlot system, since all other emergy ratios should be considered for a deeper and more precise assessment. Before presenting emergy indices for the evaluated systems, it is important for the purposes of this study to provide an analysis of the emergy contribution from nature and that from the larger economy. This analysis is important of support discussion on the importance of accounting for those free-of-charge resources disregarded from pure traditional economic analysis. 
Table 13 - Emergy flows of the three sheep production systems evaluated (emergy flows in $\mathrm{E}+13$ sej/ha year)

\begin{tabular}{|c|c|c|c|c|c|c|c|c|c|}
\hline \multirow{2}{*}{ Inputs } & \multicolumn{3}{|c|}{ Total emergy flows } & \multicolumn{3}{|c|}{$\begin{array}{l}\text { Renewable fraction for } \\
\text { emergy flows }\end{array}$} & \multicolumn{3}{|c|}{$\begin{array}{l}\text { Non-renewable fraction for } \\
\text { emergy flows }\end{array}$} \\
\hline & Intensive & Feedlot & $\begin{array}{l}\text { Semi- } \\
\text { intensive }\end{array}$ & Intensive & Feedlot & $\begin{array}{l}\text { Semi- } \\
\text { intensive }\end{array}$ & Intensive & Feedlot & $\begin{array}{l}\text { Semi- } \\
\text { intensive }\end{array}$ \\
\hline Renewable resources $(R)$ & 147.02 & 108.17 & 156.28 & 147.02 & 108.17 & 156.28 & - & & \\
\hline Non-renewable resources $(N)$ & 38.27 & 95.51 & 37.49 & - & - & - & 38.27 & 95.51 & 37.49 \\
\hline Sum of Natural resources $(I=R+N)$ & 185.28 & 203.68 & 193.77 & 147.02 & 108.17 & 156.28 & 38.27 & 95.51 & 37.49 \\
\hline Materials $(M)$ & $1,694.50$ & $15,678.83$ & 878.94 & 212.22 & $2,944.13$ & 167.34 & $1,482.27$ & $12,734.70$ & 711.60 \\
\hline Services (S) & 517.19 & $4,894.65$ & 229.24 & 115.51 & $1,613.27$ & 75.29 & 401.69 & $3,281.38$ & 153.95 \\
\hline Feedback from the economy $(F=M+S)$ & $2,230.51$ & $20,573.48$ & $1,108.19$ & 327.73 & 4.557 .41 & 242.64 & $1,883.96$ & $16,016.07$ & 865.55 \\
\hline Total emergy $(Y=I+F)$ & $2,396.97$ & $20,777.16$ & $1,301.96$ & 474.75 & $4,665.58$ & 398.92 & $1,922.22$ & $16,111.58$ & 903.04 \\
\hline
\end{tabular}




\subsubsection{Emergy contributions from nature}

Sunlight, rain, and wind are those identified natural renewable resources that supports sheep farm systems. According to the emergy theory, to avoid double accounting, sunlight was not included in the sum of the renewable resources because both rain and wind are by-products of the sun energy (ODUM, 1996). Figure 11 shows a performance profile for the emergy demand by the three farms. In general, all systems have the same kind of input flows with exception for breeding flock, animals for finishing and forage production. Feedlot is characterized by presenting greater capitalization of free natural resources $(2.04 \mathrm{E}+15 \mathrm{sej} / \mathrm{ha} \mathrm{yr})$, although the amount of its ' $I$ ' resources shows the lowest participation $(0.9 \%)$ in its total emergy when compared to the other two evaluated sheep farms; the main inputs that contributed to this flow are rainfall $(0.5 \%)$ and net topsoil loss $(0.1 \%)$. For the Semi-intensive system, its ' $\mathrm{l}$ ' resources reached $1.94 \mathrm{E}+15 \mathrm{sej} / \mathrm{ha} \mathrm{yr}$, which represents about $14 \%$ of its total emergy; wind (11.9\%) and net topsoil loss (2.8\%) are the ones with highest contribution to 'l'. Finally, the Intensive farm shows the lowest emergy dependence on 'l' resources $(1,85 \mathrm{E}+15 \mathrm{sej} / \mathrm{ha} \mathrm{yr})$ with $7.7 \%$ on its total emergy. All these low values of ' $\mathrm{l}$ ' influencing ' $\mathrm{Y}$ ' suggest that the three evaluated systems are strong dependent on economic recourses, which are mostly non-renewable resources, causes higher load on the natural environment and reduces the systems renewability.

\subsubsection{Emergy feedback from the larger economy}

Figure 11 shows that inputs from the larger economy ' $F$ ' have higher participation on total emergy demanded by systems than natural 'l' resources. Intensive system demands $1.57 \mathrm{E}+17 \mathrm{sej} / \mathrm{ha} \mathrm{yr}$ of materials ' $\mathrm{M}$ ', that represents $76 \%$ of its total emergy. It can be seen two groups of inputs with the highest influence on 'M': purchase of lambs for finishing $(9.67 \mathrm{E}+16 \mathrm{sej} / \mathrm{ha} \mathrm{yr})$ that correspond to $46 \%$ of total 'M', and animals feed (5.22E+16 sej/ha yr) that correspond to about $25 \%$ (including $7.8 \%$ cotton bran, $7.1 \%$ soy meal, $3.1 \%$ barley, $2.7 \%$ mineral premix, $1.8 \%$ corn bran, $1.8 \%$ wheat bran, $0.4 \%$ corn silage, $0.1 \%$ limestone); other inputs such as fossil fuels $(1.7 \%)$, building materials $(0.8 \%$ steel, $0.2 \%$ sawdust), and electricity $(0.9 \%)$ showed lower influence. Additionally, to the 'M' importance as driver of Intensive system, the services ' $S$ ' flows reached $23 \%$ on total emergy $(4.89 \mathrm{E}+16$ 
sej/ha yr), which includes labor (9.3\% permanent, 1.4\% temporary), slaughter service $(5.5 \%)$, depreciation (3.9\%), technical services $(2.9 \%)$, and maintenance of machinery and facilities $(0.5 \%)$.

Intensive farm demands an emergy flow 1.69E+16 sej/ha yr for ' $M$ ', which represents $70 \%$ of its total emergy ' $Y$ '. The main drivers that have influence on ' $Y$ ' are feed $(25.6 \%)$, composed basically by mineral premix, soy meal, corn bran, barley, corn silage, limestone, and white salt. Agricultural inputs used in forage production showed an emergy value of $2.81 \mathrm{E}+13 \mathrm{sej} / \mathrm{ha}$ yr that represents $24.8 \%$ of ' $\mathrm{Y}$ ', followed by breeding flock with $3.60 E+15$ sej/ha yr (15\% of ' $Y$ '). While inputs such as, fossil fuels $(3.4 \%)$, electricity $(1.1 \%)$, and building materials $(0.7 \%)$ have low influence on ' $\mathrm{Y}$ '. Services with $5.17 \mathrm{E}+15$ sej/ha yr have high influence on ' $\mathrm{Y}$ ' (21.6\%), mainly including depreciation, maintenance of machinery and facilities, labor, technical services, and slaughter process.

Finally, Semi-intensive shows a flow of $1.11 \mathrm{E}+16 \mathrm{sej} / \mathrm{ha} \mathrm{yr}$ for ' $\mathrm{M}$ ' resources, achieving $67.5 \%$ of its total emergy ' $Y$ '. The acquisition of animals for finishing (4.96E+15 sej/ha yr; $38.1 \%$ of ' $Y$ ') together with feed $(3.27 \mathrm{E}+15 \mathrm{sej} / \mathrm{ha} \mathrm{yr} ; 25.1 \%$ of ' $Y$ ') were the main drivers on total emergy. Other inputs such as breeding flock $(2.6 \%)$, building materials $(0.9 \%)$, fossil fuel $(0.5 \%)$, and electricity $(0.3 \%)$ shows low influence on ' $Y$ '. Although not compared to the influence of ' $M$ ' on ' $Y$ ', the emergy from services achieved an influence on $17.6 \%$ on ' $Y$ ' (2.29E+15 sej/ha yr), in which the main drivers are the permanent labor and slaughter services. 
Figure 11 - Representation of the emergy flows (in \%) on total emergy for each lamb farm system evaluated

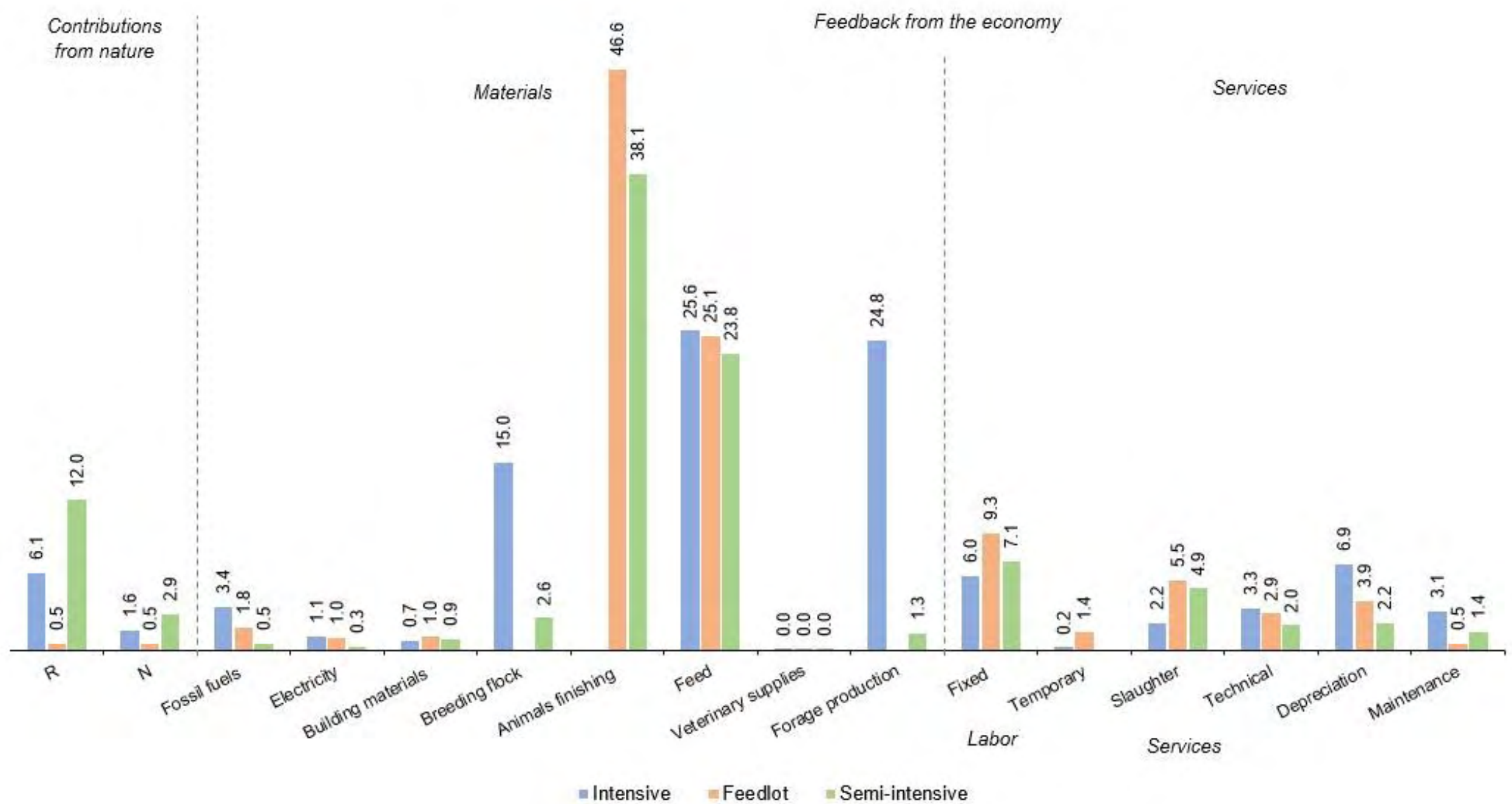

Source: own authorship. 


\subsubsection{Emergy indices}

Table 14 shows the emergy indices for the three systems evaluated. The Feedlot system shows the lowest transformity $(5.60 \mathrm{E}+06 \mathrm{sej} / \mathrm{J})$ of the three farms (6.69E+06 sej/J for Semi-intensive and 1.58E+07 sej/J for Intensive), suggesting that Feedlot is more efficient in converting global resources into lamb products and byproducts. Regarding renewability $(\% \mathrm{R})$, the Semi-intensive system is characterized with the highest $(30.6 \%)$ value compared to other two systems (22.4\% for Feedlot and $19.8 \%$ for Intensive); lower the \%R means lower use of direct and indirect renewable resources that in turn may explain their higher environmental load ratio (ELR) of 4.05 and 3.45 than the 2.26 obtained by the Semi-intensive. These numbers suggest that full cycle (Intensive system) and finishing lamb (Feedlot system) systems cause higher load on natural environmental than the system with the two finishing activities (Semi-intensive). In relation to the emergy yield ratio (EYR), the lowest possible value is 1 and indicates that system delivers the same amount of emergy that was demanded by it, and this occurs by simply transforming resources that already were made available in previous processes. According to Table 14, the best performance for EYR was obtained by the Semi-intensive system with a value of 1.17, showing that for each ' $F$ ' emergy invested, the system can make available 1.17 units of 'l' emergy for societal development; Intensive and Feedlot obtained values of 1.08 and 1.01. Regarding the emergy sustainability index (ESI), the Semi-intensive system obtained the highest performance with 0.52 compared to 0.29 for the Feedlot and 0.27 for the Intensive systems. Although possessing higher performance, the Semi-intensive systems still did not reach an ESI equal to 1 , which is considered a threshold ESI value to be considered as a sustainable system for short periods of time; in other words, all three lamb farms are characterized as unsustainable under emergy lens. The Semi-intensive system has lower dependence ' $F$ ' emergy (EIR of 5.72) than other two farms, indicating that for each sej from ' $I$ ' source, 5.72 sej from 'F' source are needed; Intensive and Feedlot reached EIR of 11.94 and 101.01. Specifically for the Feedlot, the astonishing number clearly shows this productive system as strongly dependent on ' $F$ ' resources. Finally, the EER shows that Intensive system provides 2.43 times more emergy to the market than it receives back in the form of money, a clear unbalance between products exchanges that is most 
favorable to buyers; although under a lower extend, similar unbalance happens for Semi-intensive and Feedlot systems (1.23 and 1.07), but Feedlot almost reached a balanced trade performance of 1:1.

Table 14 - Emergy indices for the three sheep production systems evaluated in this work

\begin{tabular}{lrrr}
\hline \multirow{2}{*}{ Emergy indices } & \multicolumn{3}{c}{ Farming systems } \\
\cline { 2 - 4 } & Intensive & Feedlot & $\begin{array}{c}\text { Semi- } \\
\text { intensive }\end{array}$ \\
\hline Tr (sej/J) & $15.8 \mathrm{E}+06$ & $5.60 \mathrm{E}+06$ & $6.69 \mathrm{E}+06$ \\
\%Ren & $19.81 \%$ & $22.46 \%$ & $30.64 \%$ \\
ELR & 4.05 & 3.45 & 2.26 \\
EYR & 1.08 & 1.01 & 1.17 \\
ESI & 0.27 & 0.29 & 0.52 \\
EIR & 11.94 & 101.01 & 5.72 \\
EER & 2.43 & 1.07 & 1.23 \\
Products & & & \\
Lamb meat - LW (sej/kg) & $3.56 \mathrm{E}+13$ & $1.23 \mathrm{E}+13$ & $1.49 \mathrm{E}+13$ \\
Lamb meat - carcass (sej/kg) & $7.39 \mathrm{E}+13$ & $2.63 \mathrm{E}+13$ & $3.14 \mathrm{E}+13$ \\
By-products & & & \\
Pure breeding animal - LW (sej/kg) & $3.56 \mathrm{E}+14$ & - & - \\
Sheep manure for compost (sej/kg) & - & $7.41 \mathrm{E}+12$ & - \\
\hline \multicolumn{2}{r}{ Source: own authorship. } \\
\end{tabular}

\subsection{DISCUSSION}

\subsubsection{Economic performance}

Behavior of the variable and fixed expenses presented a different behavior in the systems that had the lamb finishing activity (Feedlot and Semi-intensive) when compared to the complete cycle system (Intensive). The variable expenses were responsible for $83.9 \%$ and $80.3 \%$ TCost for Feedlot and Semi-intensive farms, respectively, while in the Intensive farm was lower (18.7\%). The higher variable expense was the result of these farms requiring a higher cash flow in the acquisition of weaned lambs for finishing mainly.

In relation to the items that make up the different types of costs, Pinheiro et al. (2019) reported that the costs of feeding in a lamb finishing system represented $46.2 \%$ of the TCost, for this proportion the authors did not consider the purchase 
value of the animals in their cost allocation. This percentage of TCost was relatively like that found in our study (43.6\%) for the Feedlot farm, when disregarding the acquisition of the lambs for finishing within the TCost. However, the portion of feeding costs incurred by the Semi-intensive farm were even more representative $(61.8 \%)$ than the other systems, probably due to the fact that this system, in addition to finishing the lambs in feedlot, had a complete cycle system. The IFactor of our study represented approximately $3 \%$ of the TCost in the analyzed system. Nevertheless, the items that make up the IFactor are often ignored by producers and researchers when conducting their analyses, which contributes to the underestimation of a more precise economic cost. In practice, many sheep farmers ignore the IFactor that, in addition to underestimating costs, it can decapitalize the producer in the long run (HEATON; RANDERSON; SLATER, 1999; RAINERI; STIVARI; GAMEIRO, 2015b). Under all these previous findings by other authors and the numbers obtained in this present study, it can be said that economic loss presented by the Semi-intensive farm is a result of disregarding the opportunity cost and remuneration of the owner's work in the economic analysis.

The economic results obtained in this study suggest at first sight that the Feedlot and Intensive systems are the best alternative for the sheep farmers to invest their money, since these systems presented a positive net profit. However, as it will be discussed in the following items, economic profit should not be the unique indicator to be taken into account in the search for more sustainable agricultural systems.

\subsubsection{Emergy performance}

According to Odum (1996, 2001), the emergy indices allow a comprehensive view of the interaction between the spheres of nature and society in the process of production of goods and/or services. Under this statement, the radar chart of Figure 12 shows the overall emergy performance profile of each sheep farm, where the system that reaches the largest area has the best performance. Comparatively, the lowest performance differences among the three sheep farms is related to \% $\mathrm{R}$ and EYR emergy indicators, while EIR, Tr, EER, ESI, and ELR present the largest differences. While Semi-intensive system shows better performance for \%R, ELR, EIR, EYR and ESI, and the Feedlot obtained better performance for EER and Tr, the 
Intensive system did not show outstanding performance for none of its emergy indicator.

Figure 12 - Emergy performance profile of the farming systems evaluated

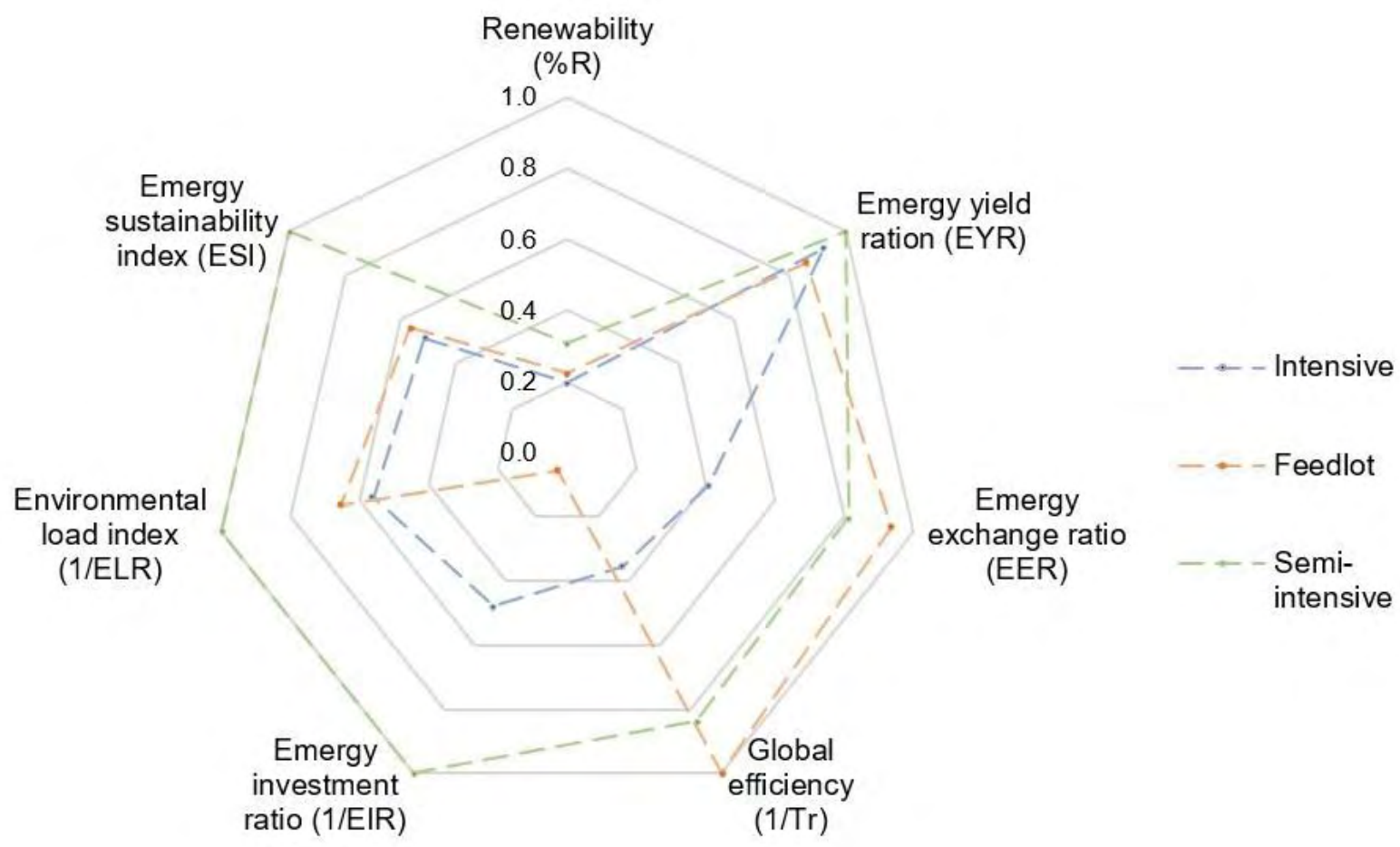

Area within lines indicates an overall emergy performance, from best to worst: Semi-intensive $=5.95$; Feedlot $=4.30$; Intensive $=3.44$; Source: own authorship.

The Semi-intensive farm is the one with higher area (5.95) in the radar chart, suggesting a best overall emergy performance followed by the Feedlot (4.30) and Intensive (3.44) systems. Important to highlight that this approach is a proxy for an overall interpretation, in which all emergy indicators have the same weight or importance. The outstanding performance of the Semi-intensive system is a result of its high \%R that leads to low dependence on resources from the economic system $(1 / E I R)$ and low environmental load (1/ELR), consequently achieving higher environmental sustainability (ESI). Simply stated, the pressure and environmental impact generated by an agricultural system will depend to a large extent on the amount of renewable energy used by the system, that is, the greater the amount of renewable energy used, the less the impact on the biosphere will be (CAVALETT; QUEIROZ; ORTEGA, 2006; LAGERBERG; BROWN, 1999; PRETTY, 2008; PRETTY; BHARUCHA, 2014; REIS et al., 2021; WANG et al., 2015). In contrast, the Intensive and Feedlot farms presented lower levels of renewability, showing higher 
environmental load and consequently lower environmental sustainability. However, even though the Feedlot system showed a higher \%R index than the Intensive system, it still presents a high dependence on resources from economy (101 for the EIR). This characteristic of the Feedlot system suggest its high susceptibility to market variations that would compromise its stability in the long-term due to the availability of resources. It is important to emphasize that the higher renewability performance of Feedlot compared to Intensive is a result of the existing partial renewability of the lambs acquired for finishing (14.6\%) allied to its high influence $(46.5 \%)$ on the total emergy.

Regarding the emergy yield ratio (EYR), although the performance among the three sheep farms is visibly close to each other, the Semi-intensive system is able to make available higher amount of emergy (1.17) to society than Feedlot and Intensive (1.08 and 1.01); Feedlot is a merely converter of ' $F$ ' emergy resource into other kind of ' $F$ ' resource, not contributing with emergy for societal development. The performance for EYR is strongly dependent on the amount of emergy from local natural resources, where systems with greater uses of these sources present higher EYR values and therefore tend to maximize this characteristic (DAVID et al., 2021a; ZHU et al., 2021). In relation to the global efficiency (1/Tr) and the emergy exchange ratio (EER), the Feedlot system presented the best performance for both, followed by Semi-intensive and Intensive. The Feedlot is more efficient than other systems in converting global resources into products and by-products. However, although Feedlot presented the higher performance for EER, the exchange value in Emdollar for $\mathrm{kg}$ of lamb carcass is still far from being the fair price. These last two emergy indicators are deeper discussed in the next item.

\subsubsection{Traditional economy and emergy: divergencies and complementary views}

Considering the values of specific emergy (emergy per kilogram of carcass, sej/kg) obtained for each evaluated sheep farm as show in Table 14, it can be observed that the Semi-intensive and Intensive systems demand 1.19 and 2.81 times more emergy to make available the same amount of carcass than the Feedlot system. This means that both Intensive and Semi-intensive systems demand a higher amount of global resources to produce $1 \mathrm{~kg}$ of carcass, leading to a lower efficiency than Feedlot. Although the Semi-intensive system presents lower efficiency 
than Feedlot, it has been proven to be the most environmentally sustainable system in this study with an ESI of 0.52 , although none of the three sheep farm systems were able to reach an ESI higher than 1 that means an unsustainable emergy scenario in the long-term (BROWN; ULGIATI, 1997, 2002).

In the search to satisfy the human consumption needs, achieve profitability, and considering all the environmental aspects regarding sustainability, sheep farmers manure issues related to the imbalance between efficiency and sustainability, because anthropic production systems are usually characterized with high levels of productivity and profitability (based on fossil energy) while presenting low performance for sustainability (KOCJANČIČ et al., 2018; PAUL et al., 2019). Trying to analyze both aspects at the same time (efficiency vs. sustainability) for a better decision about an overall best performance, Figure 13 shows a hierarchical organization based on the area obtained by each system, where a larger area may represent higher performance. Comparatively, the Semi-intensive system has the highest ESI and the second position on efficiency, which leads this system to a higher overall performance (higher area of 7.76) than Feedlot (5.22) and Intensive systems (1.70). This result suggests that Semi-intensive sheep farm should be promoted under political and economic incentives that seek to improve economic viability without moving away from sustainability.

An aspect that calls attention is the total emergy demanded by the Feedlot system (represented by the size of circles in Figure 13) that exceeds more than 5 times the emergy of Semi-intensive and Intensive systems together. In principle, this should not be considered as a problem since Feedlot system is the most efficient productive system (it can produce more using less), but the emergy indicators of Table 14 reflects that Feedlot emergy is mostly based on non-renewable resources, which leads to a low yield, high dependence on economic subsystem, high load on environment and low sustainability. Anyhow, it is interesting to note that emergy demand indicating the size of productive system is not directly related to system's sustainability or efficiency levels because Feedlot has better performance for both indicators than the Intensive system that demands lower amount of emergy. 
Figure 13 - Relationship between global efficiency and the emergy sustainability index (ESI) for the three evaluated sheep farms

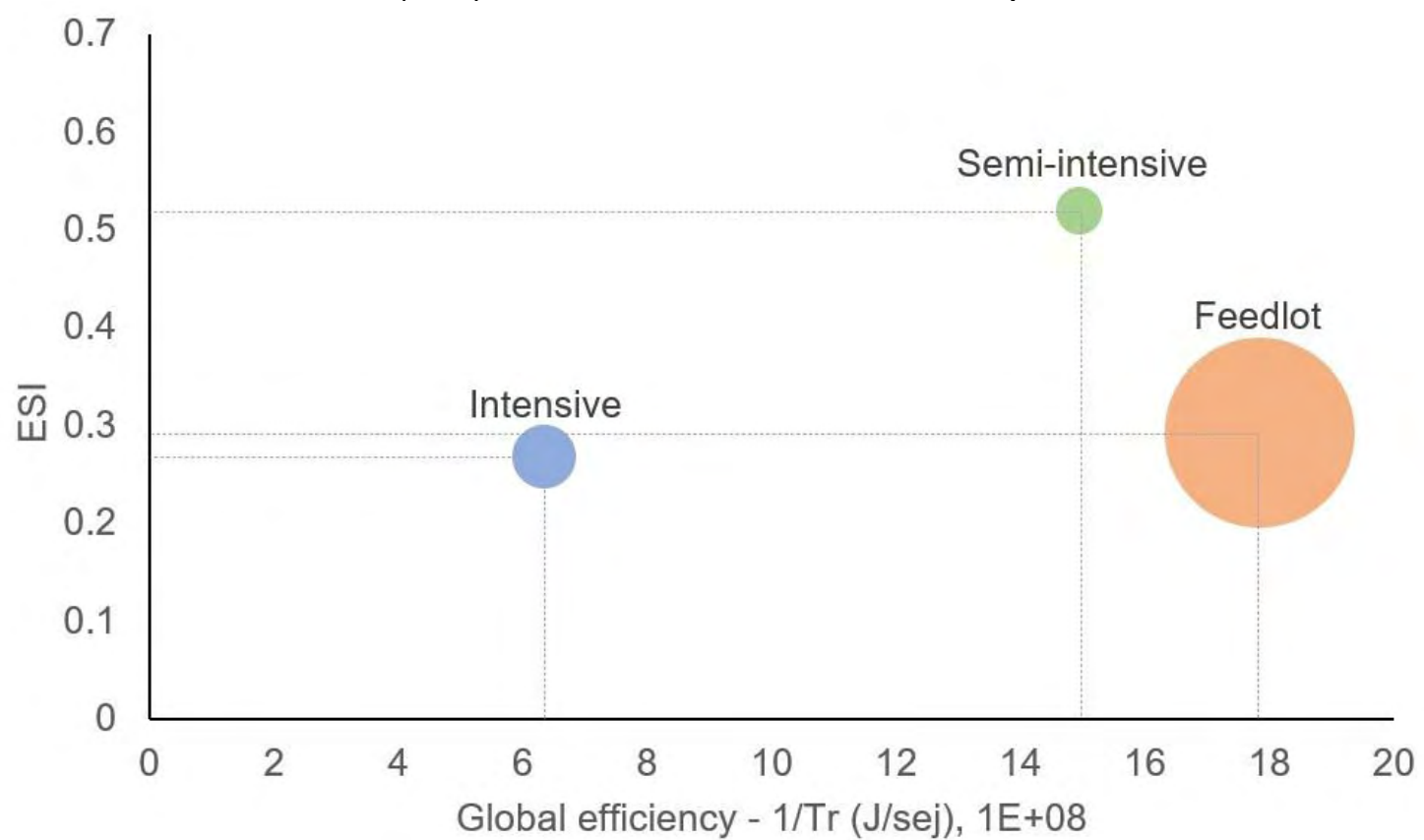

Area within lines, from best to worst performance: Semi-intensive $=7.76$; Feedlot $=5.22$; Intensive $=$ 1.70. The size of the circle represents the total emergy demanded by each system. Source: own authorship.

While from an emergy perspective based on ESI and Tr indicators the Semiintensive system should be supported, the traditional economic analysis supports Feedlot and Intensive systems. The economic benefits achieved by the Feedlot and Intensive systems lie in their level of intensification, since due to a greater use of non-renewable external inputs, these farms managed to indirectly capture a greater amount of environmental resource services (ALMEIDA et al., 2020; MARTIN et al., 2006; RÓTOLO et al., 2015). Thus, the improvement of productive efficiency is related to a larger scale production, which is fundamental for the reduction of production costs, and consequently, for the achievement of better economic results (DEBORTOLI et al., 2021). However, traditional economy approaches is not able to account for the efforts of nature in providing resources for anthropic uses, which probably leads to misinterpretations about the systemic relationships between human and natural systems. In this sense, the Emdollar (with ' $m$ ') values from the emergy method is an attempt to embrace and quantify all the hidden costs ignored by the neoclassical economic theory. Figure 14 shows a comparison between the market price per $1 \mathrm{~kg}$ of lamb carcass and the cost of production calculated in dollars (US\$) and Emdollars $(\mathrm{Em} \$)$ units, based on the theory of costs of neoclassical economics and the emergy exchange ratio (EER) of the emergy synthesis, respectively. At first 
sight, the cost of production in relation to the market price showed positive differences (advantage to farmer) for the Feedlot system (0.25 US $\$ / \mathrm{kg}$ carcass). However, the Semi-Intensive and Intensive systems obtained an economic loss (advantage to buyers) of -0.47 and $-0.20 \mathrm{US} \$ / \mathrm{kg}$ carcass, probably due to their lower efficiency. Despite the difference that the Intensive farm presented between the market price and the cost of production, its final net profit was positive due to the revenue from the sale of its by-product (pure-breeding animals).

Figure 14 - Comparison between the market price, cost of production and emergy cost of the lamb carcass $\mathrm{kg}$ of the three sheep farms considered

$\$ 10.70$

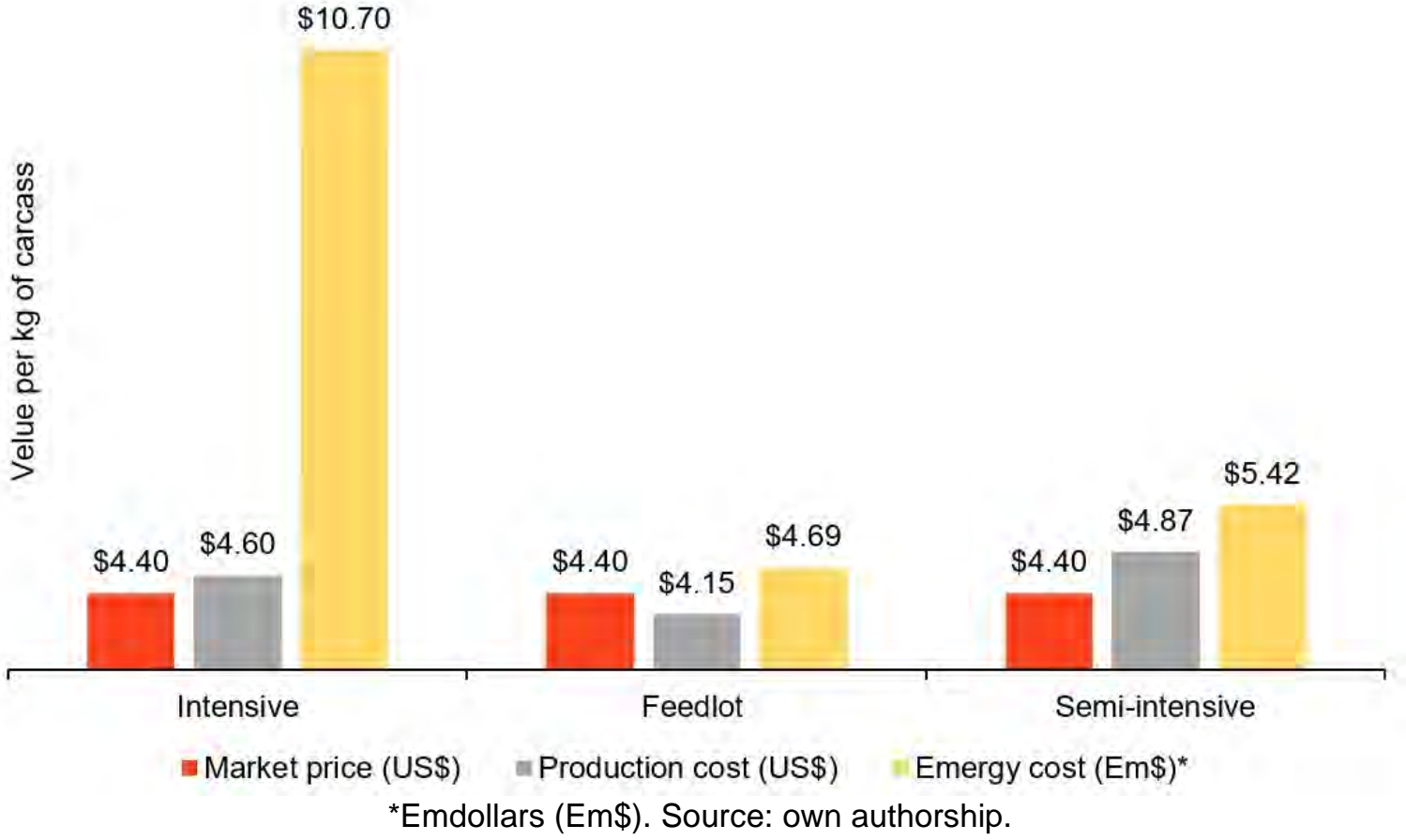

On the other hand, assuming that US\$1.00 is equivalent to $\operatorname{Em} \$ 1.00$, the EER indicator shows that the emergy cost of producing $1 \mathrm{~kg}$ of lamb carcass in Emdollars was underestimated not only by the market price, but also by the calculated production cost through the theory of costs. Thus, the Intensive farm was the system that presented the greatest inequality between costs and market price ($6.31 \mathrm{US} \$ / \mathrm{kg}$ of carcass), while for Semi-intensive and Feedlot they were lower (-1.03 and $-0.29 \mathrm{US} \$ / \mathrm{kg}$ of carcass). These monetary differences were expected results, since it is well known that the exchange value of a certain good is mainly driven by supply and demand rules, which underestimates its real value or real wealth as expressed by emergy (BROWN; ULGIATI, 2004b; ODUM, 1996). 
Coming back to the initial questions that supports this study (Can we obtain high productivity allied to environmental gains?), our results indicates that both methods traditional economic analysis and emergy synthesis should be synergistically applied on production systems to better understand under a systemic perspective how they can be improved, or even chosen the one with higher overall performance under economic and emergy lens. This approach can provide decisions towards higher productivity and environmental gains at the same time, which in this study is reflected by the Semi-intensive system.

In this way, the obtained results suggests that higher consumption of natural resources (higher emergy) together with intensive production techniques would lead to higher productive efficiency and economic profitability, as observed by the Feedlot sheep farm. However, human demand for resources must fit on a planet with limited biophysical capacity in providing them, that allied to current concerns on climate change, those most sustainable production systems must be supported to avoid global problems in the long-term (DALY; FARLEY, 2011; DALY, 1991; ODUM; ODUM, 2001). In the search for continuous growth, the current economic system encourages increased productivity to ensure the profitability of production systems, which explains in some extend the decisions taken based exclusively on economic indicators and leaving aside environmental issues. According to Cechin (2010), the methodological individualism of neoclassical economic theory systematically ignores the hierarchical nature of social and ecological systems. Therefore, decisions based exclusively on the traditional economic model can no longer be useful in a world with finite resources and increasing environmental impacts. At this point, the emergy method has a huge potential in offering a more comprehensive and systemic evaluation as an alternative to replace and/or complement the traditional ones to adequately face the degrowth phase that is on our doorstep (ODUM; ODUM, 2001).

\subsection{CONCLUSION}

Although more intensive management in sheep production systems can bring higher economic profitability, they are usually strongly dependent on external resources mostly non-renewable ones based on fossil energy, leading to higher load on the natural environment and towards an unsustainable biophysical scenario in the long-term. On the other hand, the lower intensive management of the sheep farms 
can result in higher environmental performance, but at the same time lower the economic profitability would be, which compromises their economic viability. These two sides of the same coin behavior was observed in this study for the Intensive, Semi intensive and Feedlot sheep farms considered as case studies. From an economic perspective, the Feedlot system shows to be most attractive $(9,800$ US $\$ / y r$ for net profit and 0.06 of cost-benefit ratio) than Intensive and Semi-intensive systems (4,300 US $\$ / y r$ and 0.05 of CBR; loss of $~ 7,900$ US $\$ / y r$ and -0.10 of CBR), while from a biophysical perspective (emergy synthesis), the Semi-intensive system (30\% for \%R, 0.52 for ESI, and 7.76 for ESIxTr) should be prioritized than Intensive and Feedlot ones (19\% for \%R, 0.27 for ESI, and 1.70 for ESIxTr; 22\% for \%R, 0.29 for ESI, and 5.22 for ESIxTr).

Under this antagonist behavior, the application of emergy method allowed to understand the system's economic performance through Emdollar $(E m \$)$, identifying and quantifying those hidden costs usually disregarded by the traditional economic disciplines. From the $\mathrm{Em} \$$ value calculation that accounts for the contribution of nature, the production costs per kilogram of carcass increased from 4.60 US\$ to $10.70 \mathrm{Em} \$$ for Intensive, from 4.87 US\$ to $5.42 \mathrm{Em} \$$ for Semi-intensive, and from 4.15 US $\$$ to $4.69 \mathrm{Em} \$$ for Feedlot systems. These numbers highlight that previous economic advantage of Feedlot on other two systems for carcass production was reduced, moving the Feedlot system to an uneconomical performance (costs per kilogram of carcass becomes higher than its market value). From this perspective, it can be concluded that the production cost in Emdollars were higher that those ones obtained by the traditional economy approach and leads to different decisions; specifically, the previous evident economic advantage of Feedlot system is lost under an emergy perspective. At this point, the Semi-intensive sheep farm can be considered as the one to be supported by public policies, since it has higher environmental performance at the same time a global efficiency close to that obtained by Feedlot, achieving high productivity allied to environmental gains.

Using the emergy for both, environmental and economic studies, biophysical resources would be used more rationally and contribute to an important step towards more sustainable sheep farms. This is mainly true under our current societal development pattern that exclusively consider economic indicators as basis for 
decision-making processes. Finally, it is important to emphasize that obtained findings of this work should not be directly generalized to any kind of sheep production system in other regions, because a broader regional characterization in which the productive systems are located is fundamental for developing alternatives.

\subsection{APPENDICES}

Appendix A - Unit emergy values considered in this study

\begin{tabular}{|c|c|c|c|}
\hline Item & Unit & $\begin{array}{c}\text { UEV } \\
\text { (sej/Unit) }\end{array}$ & References \\
\hline Sun & $\mathrm{J}$ & $1.00 \mathrm{E}+00$ & Odum (1996). \\
\hline Rain & $\mathrm{J}$ & $3.10 \mathrm{E}+04$ & Odum et al. (2000). \\
\hline Wind & $\mathrm{J}$ & $2.45 \mathrm{E}+03$ & Brown and Bardi (2001). \\
\hline Topsoil losses & $\mathrm{J}$ & $1.24 \mathrm{E}+05$ & Odum et al. (2000). \\
\hline Ground-water & $\mathrm{J}$ & $2.55 \mathrm{E}+05$ & Bastianoni and Marchettini (2000). \\
\hline Fossil fuels & $\mathrm{J}$ & $9.21 \mathrm{E}+04$ & Bastianoni et al. (2005). \\
\hline Electricity & $\mathrm{J}$ & $1.47 \mathrm{E}+05$ & Giannetti et al. (2015). \\
\hline Steel & g & $7.81 \mathrm{E}+09$ & Brown and Ulgiati, (2004b). \\
\hline wood & $\mathrm{J}$ & $9.60 \mathrm{E}+03$ & de Oliveira et al. (2018). \\
\hline Brick & $g$ & $4.21 E+08$ & Pulselli et al. (2007). \\
\hline Clay tile & g & $2.09 \mathrm{E}+09$ & Picchi et al. (2001). \\
\hline Ewes and rams & g & $1.44 \mathrm{E}+10$ & Haden (2002). \\
\hline $\begin{array}{l}\text { Lamb weaned for } \\
\text { finishing }\end{array}$ & g & +09 & $\begin{array}{l}\text { Estimated. See calculation details } \\
\text { at Supplementary Material D, Table } \\
\text { 24. Note } 11 \text {; Table } 26 \text {. Note } 12 \text {. }\end{array}$ \\
\hline Sawdust & $\mathrm{J}$ & $9.60 \mathrm{E}+03$ & de Oliveira et al. (2018). \\
\hline Corn silage & g & $1.62 \mathrm{E}+08$ & Yun et al. (2019). \\
\hline Fresh barley & g & $4.21 \mathrm{E}+08$ & Castellini et al. (2006). \\
\hline Corn bran & $g$ & $5.79 E+08$ & Yun et al. (2019). \\
\hline Wheat Bran & $\mathrm{g}$ & $8.41 \mathrm{E}+08$ & Yun et al. (2019). \\
\hline Soy meal & $\mathrm{kg}$ & $2.98 \mathrm{E}+12$ & Cavalett and Ortega (2009). \\
\hline Cotton bran & $\mathrm{kg}$ & $4.13 \mathrm{E}+12$ & Takahashi and Ortega (2010). \\
\hline Limestone & $\mathrm{J}$ & $2.72 \mathrm{E}+06$ & Brown and Ulgiati (2004b). \\
\hline White salt & $g$ & $1.05 \mathrm{E}+09$ & Laganis and Debeljak (2006). \\
\hline Mineral supplements & g & $1.48 \mathrm{E}+10$ & Castellini et al. (2006). \\
\hline Pasture & $\mathrm{J}$ & $1.60 \mathrm{E}+04$ & Rótolo et al. (2007). \\
\hline Vaccine & $\mathrm{g}$ & $1.48 \mathrm{E}+10$ & Castellini et al. (2006). \\
\hline Vermifuge & $g$ & $1.48 \mathrm{E}+10$ & Castellini et al. (2006). \\
\hline Organic Modifier & $g$ & $1.48 \mathrm{E}+10$ & Castellini et al. (2006). \\
\hline Permanent labor & $\mathrm{J}$ & $7.56 \mathrm{E}+06$ & Agostinho et al. (2008). \\
\hline Temporary employment & $\mathrm{J}$ & $7.56 \mathrm{E}+06$ & Giannetti et al. (2018). \\
\hline Technical services & US\$ & $5.60 \mathrm{E}+12$ & Giannetti et al. (2018). \\
\hline Slaughter service & US\$ & $5.60 \mathrm{E}+12$ & Giannetti et al. (2018). \\
\hline Depreciation of M\&F & US\$ & $5.60 \mathrm{E}+12$ & Giannetti et al. (2018). \\
\hline
\end{tabular}


Maintenance of M\&F 1 US\$ 5.60E+12 Giannetti et al. (2018).

${ }^{2} \mathrm{UEV}$ : unit emergy value; ${ }^{2} \mathrm{M} \& \mathrm{~F}$ : machinery and facilities. Source: own authorship.

Appendix B - Renewability fraction (RNF) for each system input flows considered in this work

\begin{tabular}{|c|c|c|}
\hline Item & $\begin{array}{l}\text { RNF } \\
(\%)\end{array}$ & References \\
\hline Sun & 100 & By definition. \\
\hline Rain & 100 & By definition. \\
\hline Wind & 100 & By definition. \\
\hline Topsoil losses & 0 & By definition. \\
\hline Ground-water & 0 & By the definition and origin of this resource. \\
\hline Fossil fuels & 0 & $\begin{array}{l}\text { By the definition and origin of this resource. } \\
\text { About } 80 \% \text { of total electricity generated in }\end{array}$ \\
\hline Electricity & 68 & $\begin{array}{l}\text { Brazil comes from hydropower sources } \\
\text { partial renewability of } 68 \% \text { from Brown and } \\
\text { Ulgiati (2002). }\end{array}$ \\
\hline Steel & & There is no reference in Brazil. \\
\hline wood & 82.4 & de Oliveira et al. (2018). \\
\hline Brick & - & There is no reference in Brazil. \\
\hline Clay tile & - & There is no reference in Brazil. \\
\hline Sawdust & 82.4 & $\begin{array}{l}\text { We were assumed the same renewability } \\
\text { value obtained by de Oliveira et al. (2018). }\end{array}$ \\
\hline Ewes and rams & 19.44 & Haden (2002). \\
\hline $\begin{array}{l}\text { Lamb weaned for } \\
\text { finishing }\end{array}$ & 14.58 & $\begin{array}{l}\text { Estimated. See calculation details at } \\
\text { Supplementary Material D, Table 24. Note } \\
11 \text {; Table } 26 \text {. Note } 12 \text {. }\end{array}$ \\
\hline Corn silage & 24.1 & Yun et al. (2019). \\
\hline Fresh barley & 45.0 & Castellini et al. (2006). \\
\hline Corn bran & 23.8 & Yun et al. (2019). \\
\hline Wheat Bran & 41.6 & Yun et al. (2019). \\
\hline Soy meal & 35.6 & Cavalett and Ortega (2009). \\
\hline Cotton bran & 16.9 & Takahashi and Ortega (2010). \\
\hline Limestone & 0 & By the definition and origin of this resource. \\
\hline White salt & 0 & By the definition and origin of this resource. \\
\hline Mineral supplements & 0 & By the definition and origin of this resource. \\
\hline Pasture & 85.3 & Rótolo et al. (2007). \\
\hline Vaccine & 0 & By the definition and origin of this resource. \\
\hline Vermifuge & 0 & By the definition and origin of this resource. \\
\hline Organic Modifier & 0 & By the definition and origin of this resource. \\
\hline Permanent labor & 60 & Agostinho et al. (2008). \\
\hline Temporary employment & 22 & Giannetti et al. (2018). \\
\hline Technical services & 22 & Giannetti et al. (2018). \\
\hline Slaughter service & 22 & Giannetti et al. (2018). \\
\hline Depreciation of ${\mathrm{M} \& \mathrm{~F}^{1}}$ & 0 & By the definition and origin of this resource. \\
\hline Maintenance of $M \& \mathrm{~F}^{1}$ & 0 & By the definition and origin of this resource. \\
\hline
\end{tabular}




\section{REFERENCES}

AGOSTINHO, F. et al. The use of emergy assessment and the Geographical Information System in the diagnosis of small family farms in Brazil. Ecological Modelling, Amsterdam, v. 210, n. 1-2, 2008.

AGOSTINHO, F. et al. Emergy accounting as a support for a strategic planning towards a regional sustainable milk production. Agricultural Systems, Barking, v. 176, n. 102647, 2019.

AGROSTAT. Estatísticas de Comercio Exterior do Agronegócio Brasileiro. Disponível em: http://indicadores.agricultura.gov.br/agrostat/index.htm. Acesso em: 20 jan. 2020.

ALLEGRETTI, G. et al. Insect as feed: An emergy assessment of insect meal as a sustainable protein source for the Brazilian poultry industry. Journal of Cleaner Production, Amsterdam, v. 171, p. 403-412, 2018.

ALMEIDA, C. M. V. B. et al. Integrating or Des-integrating agribusiness systems: Outcomes of emergy evaluation. Science of the Total Environment, Amsterdam, v. 729, p. 138733, 2020.

AMARAL, L. P.; MARTINS, N.; GOUVEIA, J. B. A review of emergy theory, its application and latest developments. Renewable and Sustainable Energy Reviews, Oxford, v. 54, p. 882-888, 2016.

BARIONI, L. et al. Food security. In: SHUKLA, P. R. et al. (ed.). Climate change and land: IPCC special report on climate change, desertification, land degradation, sustainable land management, food security, and greenhouse gas fluxes in terrestrial ecosystems. [S.I.]: IPCC, 2019. Chapter 5.

BASTIANONI, S. et al. The solar transformity of oil and petroleum natural gas. Ecological Modelling, Amsterdam, v. 186, n. 2, p. 212-220, 2005.

BASTIANONI, S.; MARCHETTINI, N. The problem of co-production in environmental accounting by emergy analysis. Ecological Modelling, Amsterdam, v. 129, n. 2-3, p. 187-193, 2000.

BONILLA, S. H. et al. Sustainability assessment of a giant bamboo plantation in Brazil: exploring the influence of labour, time and space. Journal of Cleaner Production, Amsterdam, v. 18, n. 1, p. 83-91, 2010.

BROWN, M. et al. The geobiosphere emergy baseline: A synthesis. Ecological Modelling, Amsterdam, v. 339, p. 92-95, 2016

BROWN, M.; BARDI, E. Folio 3: emergy of ecosystems folio. Gainesville, FL: Center for Environmental Policy, Environmental Engineering Sciences. 2001. 
BROWN, M.; ULGIATI, S. Emergy-based indices and ratios to evaluate sustainability: Monitoring economies and technology toward environmentally sound innovation.

Ecological Engineering, Amsterdam, v. 9, n. 1-2, p. 51-69, 1997.

BROWN, M.; ULGIATI, S. Emergy evaluations and environmental loading of electricity production systems. Journal of Cleaner Production, Amsterdam, v. 10, n. 4, p. 321-334, 2002.

BROWN, M.; ULGIATI, S. Energy quality, emergy, and transformity: H.T. Odum's contributions to quantifying and understanding systems. Ecological Modelling, Amsterdam, v. 178, n. 1-2, p. 201-213, 2004a.

BROWN, M.; ULGIATI, S. Emergy analysis and environmental accounting. Encyclopedia of Energy, Amsterdam, v. 2, p. 329-354, 2004b.

BULLER, L. et al. Soil improvement and mitigation of greenhouse gas emissions for integrated crop-livestock systems: Case study assessment in the Pantanal savanna highland, Brazil. Agricultural Systems, Barking Essex, v. 137, p. 206-219, 2015.

CASTELLINI, C. et al. Sustainability of poultry production using the emergy approach: Comparison of conventional and organic rearing systems. Agriculture, Ecosystems and Environment, Amsterdam, v. 114, n. 2-4, p. 343-350, 2006.

CAVALETT, O.; ORTEGA, E. Emergy, nutrients balance, and economic assessment of soybean production and industrialization in Brazil. Journal of Cleaner

Production, Amsterdam, v. 17, n. 8, p. 762-771, 2009.

CAVALETT, O.; QUEIROZ, J. F. DE; ORTEGA, E. Emergy assessment of integrated production systems of grains, pig and fish in small farms in the South Brazil.

Ecological Modelling, Amsterdam, v. 193, n. 3-4, p. 205-224, 2006.

CECHIN, A. A natureza como limite da economia, a contribuição de Nicholas Georgescu-Roegen. São Paulo: Senac, 2010.

CHEN, Y. et al. Emergy evaluation and economic analysis of compound fertilizer production: A case study from China. Journal of Cleaner Production, Amsterdam, v. 260 , p. $121095,2020$.

CUADRA, M.; BJÖRKLUND, J. Assessment of economic and ecological carrying capacity of agricultural crops in Nicaragua. Ecological Indicators, Amsterdam, v. 7, n. 1, p. 133-149, 2007.

CUADRA, M.; RYDBERG, T. Emergy evaluation on the production, processing and export of coffee in Nicaragua. Ecological Modelling, Amsterdam, v. 196, n. 3-4, p. 421-433, 2006.

DALY, E. H.; FARLEY, J. Ecological economics: principles and applications. 2nd ed. Washington, DC.: ISLANDPRESS, 2011. 
DALY, H. Towards an environmental macroeconomics. Land Economics, Madison, v. 67, n. 2, p. 225-259, 1991.

DAVID, L. H. et al. Assessing the sustainability of tilapia farming in biofloc-based culture using emergy synthesis. Ecological Indicators, Amsterdam, v. 131, n. July, p. 108186, 2021.

DAVID, L. H. et al. Emergy synthesis for aquaculture: A review on its constraints and potentials. Reviews in Aquaculture, London, v. 13, n. 2, p. 1119-1138, 2021b

DAVID, L. H. C.; PINHO, S. M.; GARCIA, F. Improving the sustainability of tilapia cage farming in Brazil: An emergy approach. Journal of Cleaner Production, Amsterdam, v. 201, p. 1012-1018, 2018.

DE OLIVEIRA, R. K. et al. Emergy-based sustainability assessment of a loblolly pine (Pinus taeda) production system in southern Brazil. Ecological Indicators, Amsterdam, v. 93, n. September 2017, p. 481-489, 2018.

DEBORTOLI, E. et al. Meat sheep farming systems according to economic and productive indicators: A case study in Southern Brazil. Revista Brasileira de Zootecnia, Viçosa, v. 50, p. 1-12, June. 2021.

EMBRAPA - EMPRESA BRASILEIRA DE PESQUISA AGROPECUÁRIA. Panorama da ovinocultura e da caprinocultura a partir do Censo Agropecuário 2017. Boletim do Centro de Inteligência e Mercado de Caprino e Ovinos, Sobral, CE, n. 7, dez. 2018. Disponível em: https://www.embrapa.br/cim-inteligencia-e-mercado-decaprinos-e-ovinos. Acesso em: 20 dez. 2020.

EMBRAPA - EMPRESA BRASILEIRA DE PESQUISA AGROPECUÁRIA. Número de frigoríficos e abatedouros ovinos e caprinos. Disponível em:

https://www.embrapa.br/cim-inteligencia-e-mercado-de-caprinos-e-ovinos/frigorificose-laticinios. Acesso em: 11 dez. 2019.

FAOSTAT. Food and Agriculture Organization of the United Nations. Disponível em: http://www.fao.org/faostat/en/\#data/QA. Acesso em: 7 fev. 2020.

FIRETTI, R. et al. Identificação de demanda e preferências no consumo de carne ovina com apoio de técnicas de estatística multivariada. Revista de Economia e Sociologia Rural, Brasília, v. 55, n. 4, p. 679-692, 2017.

FRANZESE, P. P. et al. Sustainable biomass production: A comparison between Gross Energy Requirement and Emergy Synthesis methods. Ecological Indicators, Amsterdam, v. 9, n. 5, p. 959-970, 2009.

GABARDO, M.; CALDARELLI, C. E. Expansão canavieira e o uso da terra no estado de São Paulo. Estudos Avançados, São Paulo, v. 30, n. 88, p. 93-116, 2016. 
GIANNETTI, B. F. et al. Multicriteria cost-benefit assessment of tannery production: The need for breakthrough process alternatives beyond conventional technology optimization. Environmental Impact Assessment Review, New York, v. 54, p. 2238, 2015.

GIANNETTI, B. F. et al. Human-nature nexuses in Brazil: Monitoring production of economic and ecosystem services in historical series. Ecosystem Services, [s.I.], v. 30, p. 248-256, 2018.

HADEN, A. Emergy analysis of food production at S\&S homestead farm. S\&S Center for Sustainable Agriculture, Island, p. 1-33, 2002.

HE, S. et al. Application and problems of emergy evaluation: A systemic review based on bibliometric and content analysis methods. Ecological Indicators, Amsterdam, v. 114, n. March, p. 106304, 2020.

HEATON, R. J.; RANDERSON, P. F.; SLATER, F. M. The economics of growing short rotation coppice in the uplands of mid-Wales and an economic comparison with sheep production. Biomass and Bioenergy, Oxford, v. 17, n. 1, p. 59-71, 1999.

IBGE - INSTITUTO BRASILEIRO DE GEOGRAFIA E ESTATÍSTICA. São Paulo. Disponível em: https://cidades.ibge.gov.br/brasil/sp/panorama. Acesso em: 10 jan. 2021.

KOCJANČIČ, T. et al. Incorporation of emergy into multiple-criteria decision analysis for sustainable and resilient structure of dairy farms in Slovenia. Agricultural Systems, Barking, v. 164, n. April 2017, p. 71-83, 2018.

LAGANIS, J.; DEBELJAK, M. Sensitivity analysis of the emergy flows at the solar salt production process in Slovenia. Ecological Modelling, Amsterdam, v. 194, n. 1- 3, p. 287-295, 2006.

LAGERBERG, C.; BROWN, M. Improving agricultural sustainability: The case of Swedish greenhouse tomatoes. Journal of Cleaner Production, Amsterdam, v. 7, n. 6, p. 421-434, 1999.

LAMPERT, J. Caderno didático de administração rural. Administração Rural, Santa Maria, v. 4, p. 287, 2003.

LI, L. et al. Emergy evaluations of three aquaculture systems on wetlands surrounding the Pearl River Estuary, China. Ecological Indicators, Amsterdam, v. 11, n. 2, p. 526-534, 2011.

LU, H. et al. Integrated emergy, energy and economic evaluation of rice and vegetable production systems in alluvial paddy fields: Implications for agricultural policy in China. Journal of Environmental Management, New York, v. 91, n. 12, p. 2727-2735, 2010. 
MARTIN, J. F. et al. Emergy evaluation of the performance and sustainability of three agricultural systems with different scales and management. Agriculture,

Ecosystems and Environment, Amsterdam, v. 115, n. 1-4, p. 128-140, 2006.

ODUM, H. T. Environmental accounting: emergy and environmental decision making. New York, USA.: Jhon Wiley \& Sons, INC, 1996.

ODUM, H. T.; BROWN, M.; BRANDT-WILLIAMS, S. Handbook of emergy evaluation: folio \# 1. Introduction and Global Budget. Gainesville, FL: Center for Environmental Policy, Environmental Engineering Sciences, 2000. Disponível em: http://www.cep.ees.ufl.edu/emergy/documents/folios/Folio_01.pdf. Acesso em: 13 nov. 2020.

ODUM, H. T.; ODUM, E. C. Energy Basis for man and Nature. New York, USA.: McGraw-Hill Book Company, 1976.

ODUM, H. T.; ODUM, E. C. A Prosperous wat down: principles and policies. Colorado: University Press of Colorado, 2001.

ORTEGA, E.; ANAMI, M.; DINIZ, G. Certification of food products using emergy analysis. In: INTERNATIONAL WORKSHOP ADVANCES IN ENERGY STUDIES, 3., 2002, Porto Venere. Proceedings [...]. Porto Venere, 2002. p. 227-237.

ORTEGA, E. et al. Brazilian soybean production: emergy analysis with an expanded scope. Bulletin of Science, Technology \& Society, [s.l.], v. 25, n. 4, p. 323-334, 2005.

PASSOS, C. R. M.; NOGAMI, O. Princípios de economia. 5. ed. São Paulo: Cengage Learning, 2008.

PAUL, C. et al. Rebound effects in agricultural land and soil management: review and analytical framework. Journal of Cleaner Production, Amsterdam, v. 227, p. 1054-1067, 2019.

PICCHI, M. P.; PORCELLI, M.; PULSELLI, F. M. Effects on the ecosystem of ceramics production in Sassuolo (Italy). Transactions on Ecology and the Environment, [s.l.], v. 46, p. 89-95, 2001.

PINHEIRO, M. et al. Economic viability of finishing lambs in the feedlot using bovine cheese whey as a dietary ingredient. Small Ruminant Research, Amsterdam, v. 170, p. 131-136, October. 2019.

PRETTY, J. Agricultural sustainability: concepts, principles and evidence. Philosophical Transactions of the Royal Society B: Biological Sciences, London, v. 363, n. 1491, p. 447-465, 2008.

PRETTY, J.; BHARUCHA, Z. P. Sustainable intensification in agricultural systems. Annals of Botany, Oxford, v. 114, n. 8, p. 1571-1596, 2014. 
PULSELLI, R. M. et al. Emergy analysis of building manufacturing, maintenance and use: Em-building indices to evaluate housing sustainability. Energy and Buildings, Lausanne, v. 39, n. 5, p. 620-628, 2007.

RAINERI, C.; STIVARI, T. S.; GAMEIRO, A. H. Development of a cost calculation model and cost index for sheep production. Revista Brasileira de Zootecnia, Viçosa, v. 44, n. 12, p. 443-455, $2015 a$.

RAINERI, C.; STIVARI, T. S. S.; GAMEIRO, A. H. Lamb production costs: Analyses of composition and elasticities analysis of lamb production costs. Asian-

Australasian Journal of Animal Sciences, Seoul, v. 28, n. 8, p. 1209-1215, 2015b.

REIS, J. C. et al. Integrated crop-livestock systems: A sustainable land-use alternative for food production in the Brazilian Cerrado and Amazon. Journal of Cleaner Production, Amsterdam, v. 283, 2021.

RODRÍGUEZ-ORTEGA, T. et al. Does intensification result in higher efficiency and sustainability? An emergy analysis of Mediterranean sheep-crop farming systems. Journal of Cleaner Production, Amsterdam, v. 144, p. 171-179, 2017.

RÓTOLO, G. et al. Emergy evaluation of grazing cattle in Argentina's Pampas. Agriculture, Ecosystems and Environment, Amsterdam, v. 119, n. 3-4, p. 383395, 2007.

RÓTOLO, G. C. et al. Environmental assessment of maize production alternatives: Traditional, intensive and GMO-based cropping patterns. Ecological Indicators, Amsterdam, v. 57, p. 48-60, 2015.

RUDORFF, B. F. T. et al. Studies on the rapid expansion of sugarcane for ethanol production in São Paulo state (Brazil) using Landsat data. Remote Sensing, New York, v. 2, n. 4, p. 1057-1076, 2010.

SARTORELLO, G. L.; BASTOS, J. P. S.; GAMEIRO, A. H. Development of a calculation model and production cost index for feedlot beef cattle. Revista Brasileira de Zootecnia, Viçosa, v. 47, art. e20170215, 2018.

SIEBRECHT, N. Sustainable agriculture and its implementation Gap - Overcoming obstacles to implementation. Sustainability, Basel, v. 12, n. 3953, p. 1-27, 2020.

SMITH, P. et al. Global change pressures on soils from land use and management. Global Change Biology, Oxford, v. 22, n. 3, p. 1008-1028, 2016.

TAKAHASHI, F.; ORTEGA, E. Assessing the sustainability of Brazilian oleaginous crops - possible raw material to produce biodiesel. Energy Policy, Guidford, v. 38, n. 5, p. 2446-2454, 2010. 
TANDOĞAN, M.; ÇIÇEK, H. Technical performance and cost analysis of broiler production in Turkey. Revista Brasileira de Ciencia Avicola, Campinas, v. 18, n. 1, p. 169-174, 2016.

TILMAN, D.; CLARK, M. Global diets link environmental sustainability and human health. Nature, London, v. 515, n. 7528, p. 518-522, 2014.

UN. Transforming our world: the 2030 Agenda for Sustainable Development. 2015. Disponível em:

https://www.un.org/en/development/desa/population/migration/generalassembly/docs /globalcompact/A_RES_70_1_E.pdf. Acesso em: 4 jan. 2020.

WANG, X. et al. Sustainability evaluation of the large-scale pig farming system in North China: An emergy analysis based on life cycle assessment. Journal of Cleaner Production, Amsterdam, v. 102, p. 144-164, 2015.

WILHELM, J. A.; SMITH, R. G. Ecosystem services and land sparing potential of urban and peri-urban agriculture: A review. Renewable Agriculture and Food Systems, Wallingford, v. 33, n. 5, p. 481-494, 2018.

YUN, L. et al. Emergy-based sustainability analysis of an ecologically integrated model with maize planting for silage and pig-raising in the North China plain.

Sustainability, Basel, v. 11, n. 22, 2019.

ZHAO, H. et al. Assessing the efficiency and sustainability of wheat production systems in different climate zones in China using emergy analysis. Journal of Cleaner Production, Amsterdam, v. 235, p. 724-732, 2019.

ZHU, J. et al. Evaluating the sustainability of rural complex ecosystems during the development of traditional farming villages into tourism destinations: A diachronic emergy approach. Journal of Rural Studies, Kidlington, v. 86, p. 473-484, 2021. 


\title{
CAPÍTULO IV: A SÍNTESE EM EMERGIA COMO FERRAMENTA DE CUSTEIO E GESTÃO ECONÔMICO-AMBIENTAL: PROPOSTA CONCEITUAL NA \\ AGROPECUÁRIA
}

\begin{abstract}
RESUMO
Os sistemas produtivos agropecuários vêm sendo cada vez mais forçados a aumentar sua produtividade e eficiência na procura da rentabilidade econômica. Em razão disso, aspectos produtivos e econômicos têm apresentado maior importância pelos produtores, relegadas para segundo plano as questões sociais e ambientais. Contudo, a comunidade científica junto às entidades governamentais, privadas e até os mesmos consumidores têm começado a exigir dos produtores um maior compromisso com questões ambientais. Entretanto, é difícil que os produtores deixem de lado as análises econômicas tradicionais devido à sua trajetória e consolidação teórica. Neste sentido, o presente trabalho objetiva realizar uma proposta conceitual de alocação dos fluxos em emergia em função do tipo de custo dos insumos que o compõem. Para isso serão levados em consideração os preceitos da teoria de custos da econômica neoclássica e a metodologia de contabilidade biofísica chamada de Síntese em Emergia. Espera-se que ao serem divididos e quantificados os fluxos de emergia em fluxos variáveis e fixos, seja possível calcular o seu valor não só em emergia (sej), mas também em Emdólar (Em\$), e assim, permitir a comparação entre o custo econômico (US\$) calculado pela teoria neoclássica e o custo econômico-ecológico quantificado em Emdólares.
\end{abstract}

Palavras-chaves: Contabilidade biofísica. Economia ecológica. Capital natural. Sustentabilidade. Valor de troca. 


\begin{abstract}
Agricultural production systems are being increasingly forced to increase their productivity and efficiency in the search for economic profitability. As a result, productive and economic aspects have been of greater importance for producers, with social and environmental issues relegated to the background. However, the scientific community together with government and private entities and even the same consumers have begun to demand from producers a greater commitment to environmental issues. However, it is difficult for producers to set aside traditional economic analyzes due to their trajectory and theoretical consolidation. In this sense, the present work aims to carry out a conceptual proposal for the allocation of emergy flows according to the type of cost of the inputs that compose it. For this, the precepts of the cost theory of neoclassical economics and the biophysical accounting methodology called Synthesis in Emergy will be taken into account. It is expected that when the emergy flows are divided and quantified into variable and fixed flows, it will be possible to calculate their value not only in emergy (sej), but also in Emdollar $(\mathrm{Em} \$)$, and thus allow the comparison between the economic cost (US\$) calculated by neoclassical theory and the economic-ecological cost quantified in Emdollars.
\end{abstract}

Keywords: Biophysical accounting. Ecological economics. Natural capital. Sustainability. Exchange value.

\title{
4.1 ASPECTOS TEÓRICOS
}

Esta seção procura explorar aspectos específicos das abordagens utilizadas neste estudo para avaliar os sistemas agropecuários.

\subsubsection{Teoria e conceito de mensuração dos custos de produção}

A teoria dos custos pertencente ao pensamento econômico neoclássico, encontra-se junto à teoria da produção e dos rendimentos, teorias que por sua vez estão inseridas dentro da teoria da firma. Esta última visa à compreensão da empresa como uma unidade técnica de produção, que adquire no mercado os 
fatores de produção (terra, trabalho e capital) oferecidos pelas famílias, para a produção dos bens e serviços que as famílias posteriormente consumirão. Com base no exposto, a teoria dos custos está voltada ao estudo, análise e interpretação dos custos gerados pela aquisição dos fatores que incorrem as firmas no processo de produção (PASSOS; NOGAMI, 2008). Esta teoria classifica os custos em dois grupos: custos variáveis (CV) e custos fixos (CF). Nos CV, encontram-se todos aqueles custos referentes aos fatores (mão de obra, combustível, insumos alimentares, etc.) que cuja modificação na sua quantidade pode gerar uma mudança imediata (aumento ou diminuição) no número de unidade produzidas pelo sistema. Os CF relacionam-se àqueles custos dos fatores (maquinaria, instalações, terreno, pasto etc.) que ao serem alterados não se consegue uma mudança imediata na quantidade produzida. Estes conceitos aplicam-se ao chamado "curto prazo", que é aquele no qual pelo menos um fator de produção tem a sua quantidade fixa. No "longo prazo", por sua vez, a firma é capaz de variar a quantidade de todos os fatores de produção.

Além da caraterização dos custos em fixos e variáveis, a teoria economia tem denominado os custos em explícitos e implícitos. Por um lado, os custos explícitos são definidos como todo custo que envolve desembolso monetário pelo pagamento dos fatores usados na produção (insumos alimentares, mão de obra, aluguel etc.). Enquanto os custos implícitos referem-se àqueles que a atividade deveria de pagar pelo uso dos fatores de produção próprios (geralmente, terra e capital). Segundo Buchanan (1969), o custo de oportunidade (CO) de um fator de produção não é apenas sua melhor alternativa de uso interno, mas também, o valor de seu melhor uso fora da empresa. Desta forma, CO pode ser compreendido como o custo do melhor uso alternativo dos fatores próprios dentro o fora da firma. Assim, este custo representa o valor que deveria de ser pago pela atividade ao produtor dono dos fatores, quando esses são próprios.

Diante do exposto, o custo econômico, diferente do custo contábil é capaz de calcular o custo de produção "verdadeiro", por meio da somatória dos custos explícitos e implícitos. A partir disso, o custo total (CT) da produção é obtido (Equação 15) pela soma dos CV, CF e CO, representando este último no estudo como remuneração dos fatores próprios $(\mathrm{RF})$. 
$C T=C V+C F+R F$

Tradicionalmente a teoria dos custos não separa os custos de oportunidade dos fatores próprios, como proposto na equação 15. Todavia, pela dificuldade que muitos agentes econômicos têm de compreender a remuneração dos fatores próprios, propõe-se a sua separação dos demais custos (sejam eles os fixos ou variáveis).

A alocação de custos em CV e CF é uma das metodologias de custeio amplamente utilizada na avaliação e gerenciamento das atividades agropecuárias devido a sua simplicidade e objetividade (CONAB, 2010; DEBORTOLI et al., 2021; GAMEIRO; ROCCO; CAIXATA, 2016; HEATON; RANDERSON; SLATER, 1999; RAINERI; STIVARI; GAMEIRO, 2015a, 2015b; SARTORELLO; BASTOS; GAMEIRO, 2018). Não obstante, na maioria das análises econômicas tradicionais, têm sido subestimado o valor do capital natural, devido à dificuldade de quantificação do seu valor monetário (CECHIN, 2010; EKINS et al., 2003; ODUM, 1996). Em razão disso, as análises econômicas têm-se concentrado apenas no "trabalho" e no "capital" monetário e manufaturado, afetando a estabilidade dos ecossistemas naturais. Sukhdev et al. (2010) concluíram que a incapacidade de contabilizar o valor econômico do estoque natural e dos serviços ecossistêmicos têm sido um fator significativo na contínua perda e degradação dos mesmos.

Diferentes pensamentos de valorização do capital natural têm sido desenvolvidos. Contudo, uma revisão dessas metodologias permite identificar dois grupos com abordagem diferenciados de valoração: i) métodos baseados em preferências, os quais são mais comumente usados pelo sistema econômico neoclássico; e ii) métodos de contabilidade biofísica, constituídos por uma variedade de abordagens biofísicas que permitem obter informação sobre os sistemas biológicos.

Por um lado, a abordagem baseada em preferência inserida na economia ambiental, que entende a maioria dos recursos naturais como bens públicos, e dos impactos ambientais, como externalidades geradas pelo funcionamento do processo econômico (MAY, 2018). Contudo, a valorização desses não é percebida na esfera de funcionamento dos mercados devido às falhas que este apresenta, embora 
podem ser estimados na medida em que se possa conhecer a disposição da sociedade e dos indivíduos a pagar pela preservação ou conservação dos recursos e serviços ambientais (MARQUES, 2004). Em razão disso, tem sido evidenciado crescimento na conscientização da dependência da sociedade pelos ecossistemas naturais, por meio da valorização monetário do capital natural e os serviços ecossistêmicos, implementando métodos de avaliação orientados para o mercado (LI et al., 2016; MAIA; ROMEIRO; REYDON, 2004; ROMEIRO; MAIA, 2011). Contudo, sua principal desvantagem é que a avaliação é aplicada com base na valoração monetária e na disposição ao pagamento (MELLINO; BUONOCORE; ULGIATI, 2015), critério de avaliação que não é apropriado para valorizar os ecossistemas e seus serviços pela sociedade nas escalas temporais e espaciais da biosfera, posto que apenas reflete valores para a sociedade de hoje, sem levar em consideração as futuras gerações e outras espécies (CECHIN, 2010; DONG et al., 2012; LAGERBERG; BROWN, 1999; ODUM; ODUM, 2001).

De outro ponto de vista, a contabilidade biofísica por meio de uma perspectiva de mais abrangente, e baseada nas medições dos custos físicos (em termos de trabalho, requisitos de superfície, energia ou insumos de materiais) das entradas (insumos) que interagem no processo de transformação dentro do sistema, consegue realizar uma valorização mais adequada dos recursos naturais ao quantificar seu valor em unidades físicas (valores absolutos), deixando de lado unidades monetárias (MAY, 2018; SUKHDEV et al., 2010).

\subsubsection{Teoria e conceitos relacionados à Síntese em Emergia}

A Síntese em Emergia, método de contabilidade biofísica proposta por Odum (1996), fundamenta-se na Análise de Energia de Sistemas Biológicos (LOTKA, 1922), na Teoria Geral de Sistemas (VON BERTALANFFY, 1968) e na Ecologia de Sistemas (ODUM, 1983). Assim, define-se a emergia como toda a exergia (energia potencial disponível) de um determinado tipo (emjoules solares, sej), que foi utilizada direta ou indiretamente na produção de um recurso, produto ou serviço (ODUM, 1996). Esta metodologia desenvolveu o conceito de unidade de valor emergético (UEV), que é definido como a emergia exigida para disponibilizar uma unidade daquele bem ou serviço. Entre outras, as UEVs compreendem as chamadas 
"transformidades" (unidades em sej/J), emergia específica (sej/g) e emergia por unidade monetária (sej/US \$) (BROWN; ULGIATI, 2004).

De acordo com Odum (1996), a emergia total (Y) demandada na geração de um produto em determinado sistema, é o resultado da somatória de todos os fluxos de emergia procedente dos recursos da natureza (I) e dos insumos provenientes do sistema econômico (F). Por sua vez, "l" é composto pelos recursos locais renováveis $(\mathrm{R})$ e não-renovável $(\mathrm{N})$ da natureza. Enquanto " $\mathrm{F}$ " conformam os fluxos provenientes dos materiais $(M)$ e serviços $(S)$. Além dessa categorização existente no fluxo de ' $F$ ', diferentes autores concluíram que ao serem consideradas as frações renováveis e não-renováveis dos materiais ( $\mathrm{Mr}$ e $\mathrm{Mn}$ ) e dos serviços ( $\mathrm{Sr}$ e $\mathrm{Sn}$ ), é possível atingir uma melhor representação do desempenho emergético do sistema avaliado (CAVALETT; QUEIROZ; ORTEGA, 2006; ORTEGA et al., 2005; ORTEGA; ANAMI; DINIZ, 2002). Na Figura 15 são expostas as equações dos diferentes fluxos de emergia que compõem um sistema de produção ovino tradicional.

Figura 15 - Diagrama de energia de um sistema de produção ovina tradicional

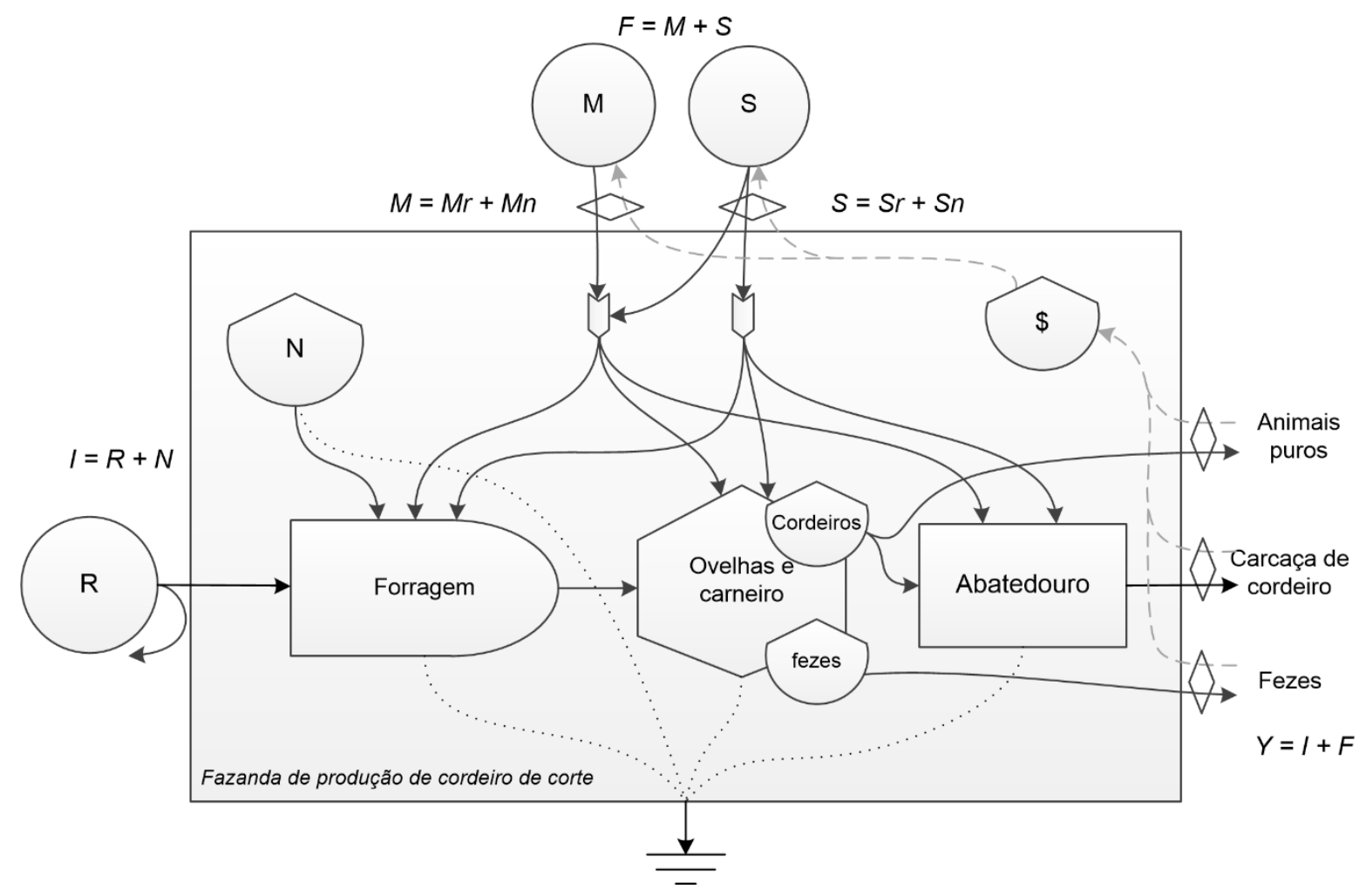

I: contribuição da natureza; R: recursos renováveis da natureza; $\mathrm{N}$ : recursos locais não-renováveis; $\mathrm{F}$ : feedback da economia; $\mathrm{M}$ : materiais, ( $\mathrm{Mr}$ e $\mathrm{Mn}$ representam a fração renovável e não renovável de M); S: serviços, (Sr e Sn representam a fração renovável e não renovável de S); e Y: emergia total demandada pelo sistema. Fonte: elaborado pelo autor baseado na linguagem de diagrama de energia do sistema. Fonte: Odum (1996), elaborado pelo autor. 
Deste modo, a Síntese em Emergia incorpora uma abordagem do lado do doador nas suas análises, por possuir a capacidade de quantificar as contribuições que a biosfera faz nos sistemas produtivos. Portanto, está metodologia permite contabilizar todas as diferentes vias de energia (sistema ecológico e subsistema econômico) que sustentam os subsistemas socioeconômicos (AGOSTINHO et al., 2019). A contabilidade emergética tem exibido crescimento de uso em estudos científicos devido a sua robustez e eficácia na avaliação da sustentabilidade por meio de índices (GIANNETTI et al., 2013; HE et al., 2020), na área das ciências agropecuárias (AGOSTINHO et al., 2019; REIS et al., 2021; RODRÍGUEZ-ORTEGA et al., 2017; WANG et al., 2015), como também, na valoração do capital natural (CAMPBELL; BROWN, 2012; YANG et al., 2019).

A taxa de intercâmbio emergético (EER) é um dos vários índices utilizados nas análises da Síntese em Emergia. A EER quantifica a relação entre emergia entregue e o dinheiro recebido de volta (CUADRA; RYDBERG, 2006). Assim, quando um bem é vendido e o dinheiro é recebido em troca, ambos fluxos (produto e dinheiro) são convertidos em unidades de emergia (sej e Emdólar, respetivamente) expressando qual dos agentes econômicos (produtor e comprador) apresentou a vantagem comercial relativa sobre o outro (Figura 16).

Figura 16 - Diagrama do processo da troca de emergia solar e da transação econômica na venda de carcaça de cordeiro e a forma como ela é calculada

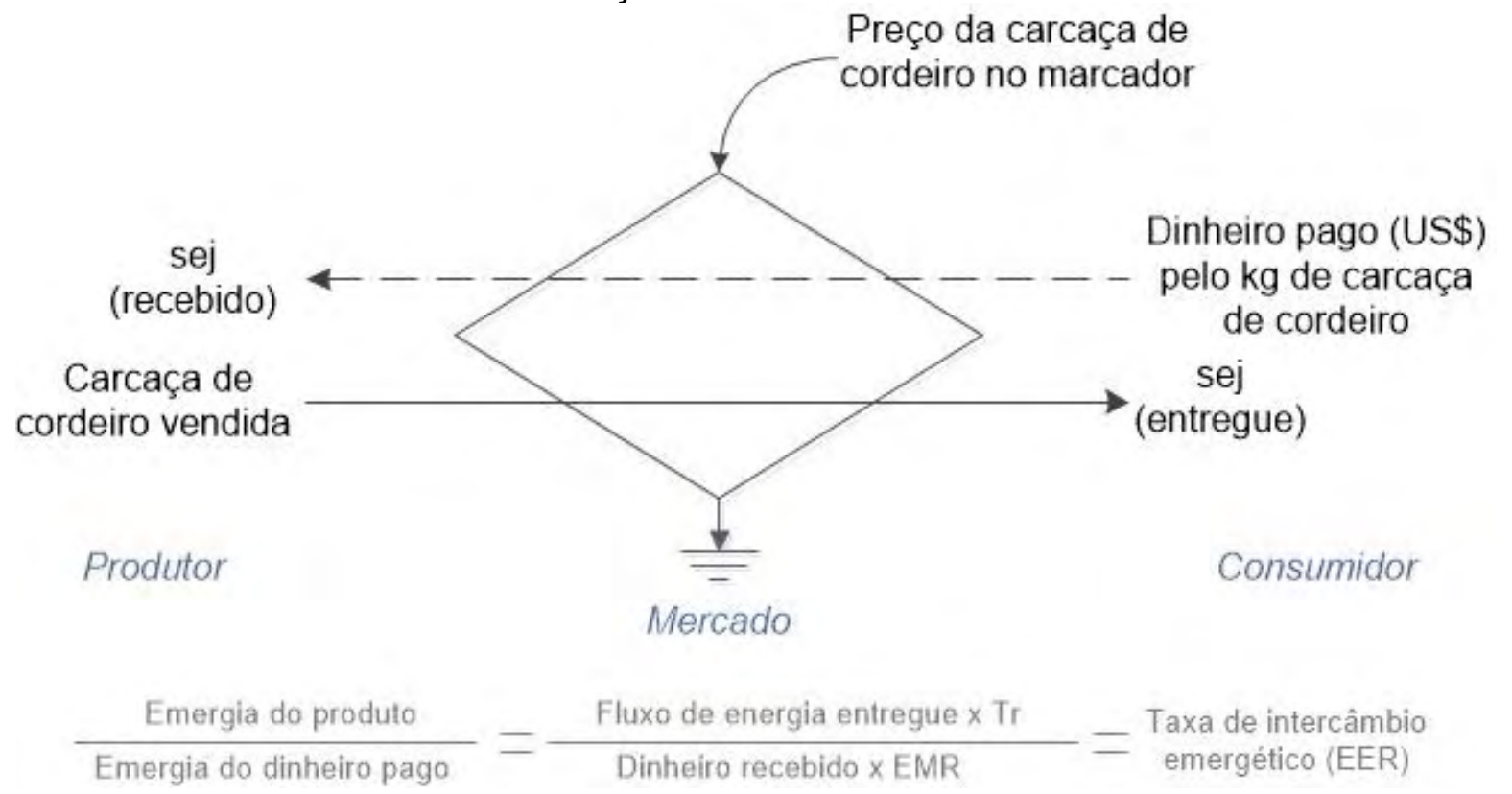

sej: Joules de emergia solar; Tr: transformidade; EMR: razão emergia por dinheiro, em sej/US\$.

Fonte: Odum (1996), adaptado pelo autor. 
O termo Emdólar (Em\$) cuja unidade é sej/US\$, foi desenvolvido com o objetivo de facilitar o entendimento das unidades de emergia utilizadas nas transações comerciais, para atender às pessoas que só pensam em unidades monetárias no processo de troca (ODUM, 1996). Desta maneira, o equivalente econômico do dólar denominado por Odum foi o Emdólar, e indica o dinheiro circulante cujo poder de compra está estabelecido pelo uso de uma determinada quantidade de emergia, em outras palavras, seu valor representa a quantidades de unidades de emergia (sej) que pode ser adquirida com uma unidade de dólar (US\$ 1,00). A relação emergia/dólar ou Emdólar, é obtida dividindo-se a emergia total produzida do país em determinado ano, pelo Produto Nacional Bruto (PNB) expresso em dólares (ODUM, 1996).

Desta forma, serão utilizados conceitos da teoria de custos associados à teoria da Síntese em Emergia, para propor a alocação dos diferentes fluxos emergéticos de acordo ao tipo de custo (variável ou fixo) em que sejam caraterizados os diferentes insumos que interagem no sistema na produção de cordeiro. Com isto, espere-se que a Síntese em Emergia também possa ser vista como uma ferramenta de custeio e de gestão econômico-ambiental.

\subsection{ALOCAÇÃO DOS FLUXOS EMERGÉTICOS BASEADO NO TIPO DE CUSTO: UMA PROPOSTA CONCEITUAL}

O desenvolvimento da proposta conceitual será baseado na caraterização do sistema ovino semi-intensivo com terminação de cordeiros ("Semi-intensive") apresentado no Capítulo III desta dissertação.

\subsubsection{Fluxos de emergia variáveis e fixos}

O esquema de alocação dos fluxos de emergia foram orientados por algumas premissas. Inicialmente decidiu-se classificar os fluxos em: fluxo total de emergia variável (Evari) e fixo ( $\left.E_{F i x o}\right)$. O Evari encontra-se conformado pelos fluxos de emergia variáveis proveniente da natureza (Ivari), materiais (Mvari) e serviços (Svari), como se observa na equação 17. Por outro lado, o EFixo é constituído pelos fluxos fixos da natureza (IFixo), materiais (MFixo) e serviços (S Fixo $_{\text {) }}$, conforme à equação 17. 


$$
\begin{aligned}
& E_{\text {Vari }}=I_{\text {Vari }}+M_{\text {Vari }}+S_{\text {Vari }} \\
& E_{\text {Fixo }}=I_{\text {Fixo }}+M_{\text {Fixo }}+S_{\text {Fixo }}
\end{aligned}
$$

Deste modo, os itens alocados no Evari serão todos aqueles insumos que ao apresentar modificação na quantidade de ingresso no sistema, gera uma mudança na produção, neste caso, nos quilogramas de cordeiros produzidos. Exemplos de insumos que conformarão este fluxo são: água subterrânea, insumos alimentares e veterinário consumidos pelos cordeiros, serviço de abate, etc. Enquanto no $\mathrm{E}_{\text {Fixo, }}$ alocam-se os insumos que, ao gerar uma mudança na sua quantidade, não gerariam variação imediata na quantidade de cordeiro produzido. Assim, insumos como energia solar, vento, chuva, solo, água, alimentação do rebanho reprodutor, mão de obra, depreciação e manutenção de maquinário e infraestrutura etc., fazem parte deste fluxo.

\subsubsection{Fluxos de emergia variáveis e fixos provenientes da natureza}

Além de quantificar a emergia demanda pelo sistema em fluxos de Evari e EFixo, segue-se o sugerido por Odum (1996) para se dividir os fluxos de emergia em fluxos proveniente da natureza (I) e o feedback do sistema econômico (F). É proposto calcular a proporção variável e fixa para cada um destes fluxos. No caso de "l", este fluxo é composto da somatória dos subfluxos IVari e lFixo (equação 18).

$I=I_{\text {Vari }}+I_{\text {Fixo }}$

Ivari é composto exclusivamente por aqueles recursos da natureza nãorenováveis variáveis ( $N$ vari), que podem influenciar imediatamente uma mudança na quantidade de cordeiro produzido, exemplo deste tipo de insumo é a água subterrânea (Equação 19); enquanto lFixo, será integrado por recursos naturais renováveis (sol, chuva, vento, etc.) e não-renováveis (solo e água subterrânea consumida pelo rebanho reprodutor), já que entende-se que estes estão presentes e ingressam ao sistema independentemente dos quilogramas de cordeiro que forem produzidos, estes últimos serão chamados de RFixo e NFixo, respetivamente (Equação 20).

$$
I_{\text {Vari }}=N_{\text {Vari }}
$$


$I_{\text {Fixo }}=R_{\text {Fixo }}+N_{\text {Fixo }}$

\subsubsection{Fluxos de emergia variáveis e fixos do feedback da economia}

Tradicionalmente o fluxo "F" é composto pelos fluxos de emergia provenientes dos materiais (M) e serviços (S) que são adquiridos pelo sistema. Assim, e aplicando os preceitos da teoria de custos, estes serão divididos em fluxos de emergia provenientes dos materiais variáveis (Mvari) e fixos (MFixo), e serviços $(S)$ variáveis (S Fixo $_{\text {) e fixos (S }}$ Fixo), conforme observa-se na equação 21.

$F=M_{\text {Vari }}+S_{\text {Vari }}+M_{\text {Fixo }}+S_{\text {Fixo }}$

Além de ser calculado o fluxo de 'F', de acordo ao exposto acima, este fluxo por sua vez pode ser dividido em fluxo de emergia do subsistema econômico variável (Fvari) e fixo $\left(F_{\text {Fixo }}\right)$. Deste modo, os fluxos $F_{\text {vari e }} F_{\text {Fixo }}$ serão calculados conforme o exposto nas equitações 22 e 23 , respetivamente.

$$
\begin{aligned}
& F_{\text {Vari }}=M_{\text {Vari }}+S_{\text {Vari }} \\
& F_{\text {Fixo }}=M_{\text {Fixo }}+S_{\text {Fixo }}
\end{aligned}
$$

\subsubsection{Fluxo de emergia total e alocação geral dos fluxos}

Por fim, o fluxo de emergia total (ETotal) demandado pelo sistema é resultado da somatória dos fluxos totais variáveis e fixos provenientes da natureza e do subsistema econômico (equação 24).

$E_{\text {Total }}=I_{\text {Vari }}+F_{\text {Vari }}+I_{\text {Fixo }}+F_{\text {Fixo }}$

Para um melhor entendimento no Quadro 1, é proposta a alocação dos diferentes tipos de fluxos de emergia que conformam um sistema produtivo ovino. 
Quadro 6 - Esquema resumido de alocação dos fluxos de emergia em um sistema de produção ovino

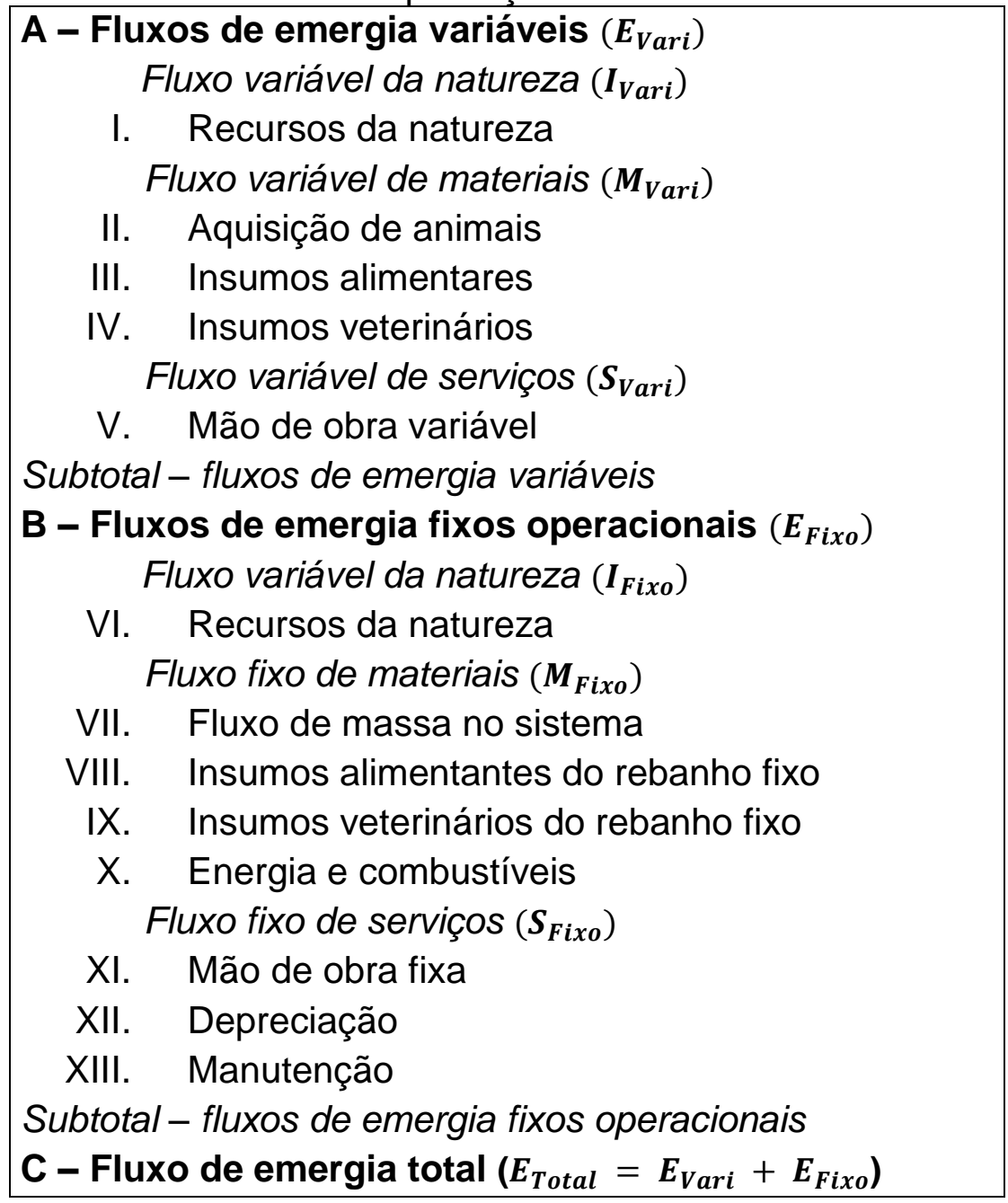

Fonte: Própria autoria.

$\mathrm{Na}$ Figura 17, apresenta-se o esquema genérico dos fluxos de energia, materiais e serviços em uma produção de cordeiro de corte utilizando os princípios de alocação dos fluxos segundo sejam variáveis e fixos. 
Figura 17 - Diagrama de energia exemplificando os fluxos fixos e variáveis que inferem na produção de cordeiro de corte

Fluxo de emergia do sistema econômico (F) $\mathrm{F}=$ MVari + SVari + MFixo + SFixo

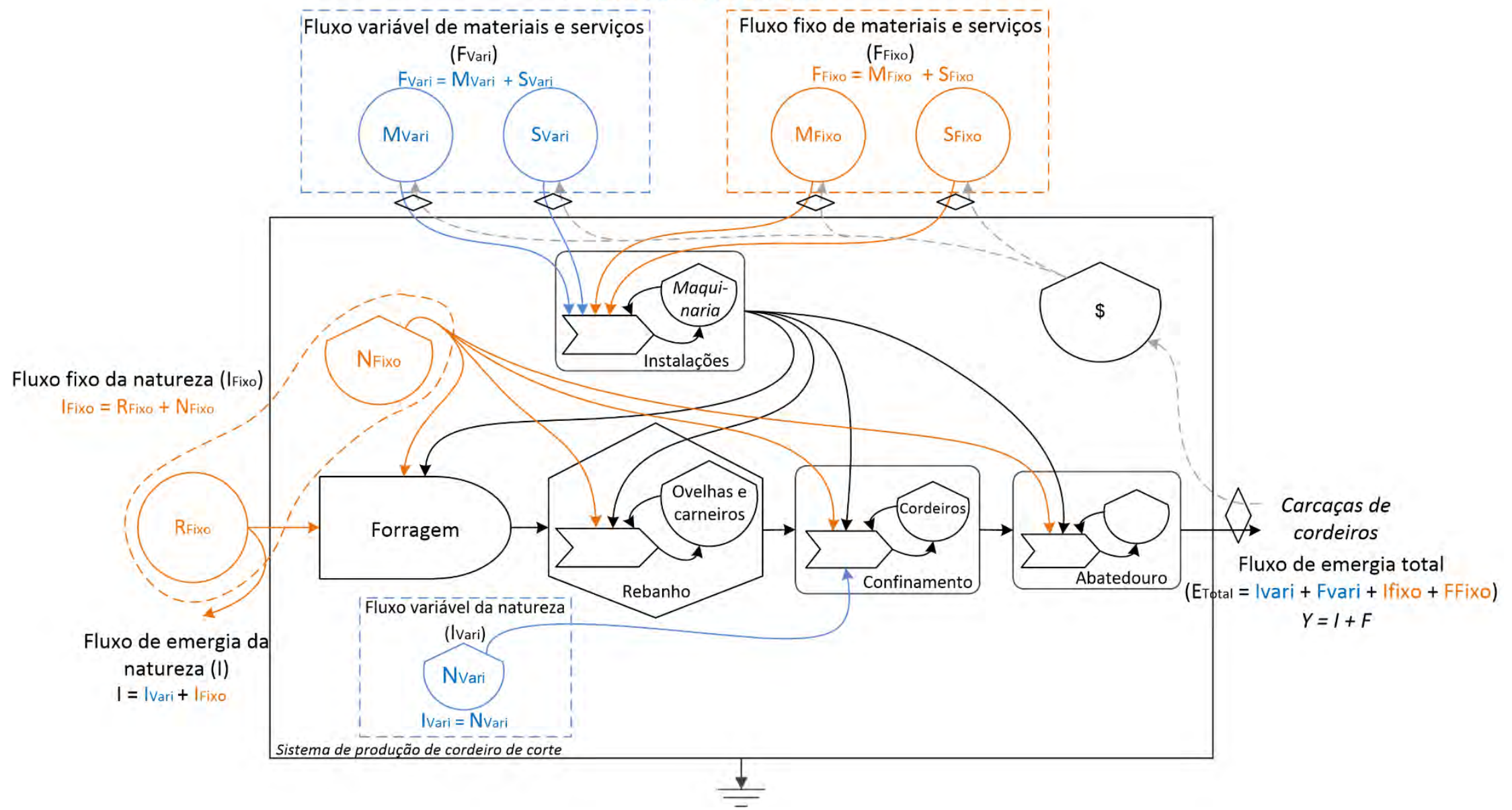

I: fluxo proveniente da natureza; Ivari: fluxo variável da natureza; $\mathrm{I}_{\mathrm{Fix} o}$ : fluxo fixo da natureza; $\mathrm{N}_{\text {vari: }}$ recursos variáveis e não-renováveis da natureza; $\mathrm{R}_{\mathrm{Fixo}}$ : recursos fixos e renováveis da natureza; RFixo: recursos fixos e não-renováveis da natureza; F: feedback proveniente da economia; FVari: fluxo variável da economia; F Fixo: fluxo fixo da economia; Mvari: fluxo variável dos materiais; MFixo: fluxo fixo dos materiais; Svari: fluxo fixo dos serviços; SFixo: fluxo fixo dos serviços; Y: emergia total; ETotal: fluxo total de emergia. Fonte: Própria autor. 


\subsection{CONSIDERAÇÕES SOBRE A PROPOSTA}

O entendimento e funcionamento da teoria de custos apresenta bases sólidas na aplicabilidade da gestão econômica de sistemas agropecuários, suportando a tomada de decisões exclusivamente em aspectos econômicos. Contudo, a desconsideração de aspectos ambientais, e a subestimação do capital natural que é catalogado na maioria das vezes como recursos "gratuitos" nas análises econômicas, têm levado à degradação do meio ambiente e ao esgotamento dos recursos naturais. Ainda assim, é indiscutível a trajetória e avanços teóricos e técnicos que a econômica neoclássica tem adquirido ao longo do tempo. Em vista disso, a Síntese em Emergia se apresenta como uma ferramenta que pode ajudar na tomada de decisões mais assertivas, ao considerar na sua contabilidade biofísica o esforço que faz a natureza nos sistemas socioeconômicos. Por conseguinte, espera-se que ao incluir preceitos teóricos das análises econômicas tradicionais, como os tipos de custos (variáveis e fixos) na contabilidade ambiental em emergia, possa ser contabilizado o custo biofísico de produção expresso em Emdólares $(\mathrm{Em} \$)$. Deste modo, esperasse proporcionar uma perspectiva mais abrangente em relação à gestão dos empreendimentos agropecuários, ao serem considerados aspectos ecológicos e econômicos fundamentais na procura de uma produção mais sustentável.

\subsection{PROPOSTA PARA TRABALHOS FUTUROS}

Atualmente esta proposta conceitual está sendo aplicada em um sistema de produção de cordeiros de corte. Esperasse que sua aplicabilidade junto aos seus resultados possa ser publicada para aceitação por parte da comunidade cientifica. Contudo, torna-se importante avaliar sua aplicabilidade nos diversos sistemas produtivos. 


\section{REFERENCES}

AGOSTINHO, F. et al. Emergy accounting as a support for a strategic planning towards a regional sustainable milk production. Agricultural Systems, Barking, v. 176, n. 102647, 2019.

BROWN, M.; ULGIATI, S. Energy quality, emergy, and transformity: H.T. Odum's contributions to quantifying and understanding systems. Ecological Modelling, Amsterdam, v. 178, n. 1-2, p. 201-213, 2004.

BUCHANAN, J. Cost and choice: an inquiry in economic theory. Indianapolis: Liberty Fund, Inc., 1969.

CAMPBELL, T.; BROWN, T. Environmental accounting of natural capital and ecosystem services for the US National Forest System. Environment, Development and Sustainability, Dordrecht, v. 14, n. 5, p. 691-724, 2012.

CAVALETT, O.; QUEIROZ, J. F. DE; ORTEGA, E. Emergy assessment of integrated production systems of grains, pig and fish in small farms in the South Brazil.

Ecological Modelling, Amsterdam, v. 193, n. 3-4, p. 205-224, 2006.

CECHIN, A. A natureza como limite da economia, a contribuição de Nicholas Georgescu-Roegen. São Paulo: Senac, 2010.

CONAB - COMPANHIA NACIONAL DE ABASTECIMENTO. Custos de produção agrícola: a metodologia da Conab. Brasília: Equipe da Biblioteca da Conab, 2010.

CUADRA, M.; RYDBERG, T. Emergy evaluation on the production, processing and export of coffee in Nicaragua. Ecological Modelling, Amsterdam, v. 196, n. 3-4, p. 421-433, 2006.

DEBORTOLI, E. et al. Meat sheep farming systems according to economic and productive indicators: A case study in Southern Brazil. Revista Brasileira de Zootecnia, Viçosa, v. 50, p. 1-12, June. 2021.

DONG, X. et al. The impact of human activities on natural capital and ecosystem services of natural pastures in North Xinjiang, China. Ecological Modelling, Amsterdam, v. 225, p. 28-39, 2012.

EKINS, P. et al. A framework for the practical application of the concepts of critical natural capital and strong sustainability. Ecological Economics, Amsterdam, v. 44, n. $2-3$, p. $165-185,2003$.

GAMEIRO, A.; ROCCO, C.; CAIXATA, J. Linear Programming in the economic estimate of livestock-crop integration: application to a Brazilian dairy farm. Revista Brasileira de Zootecnia, Viçosa, v. 45, n. 4, p. 181-189, 2016. 
GIANNETTI, B. F. et al. Primary evidences on the robustness of environmental accounting from emergy. Journal of Environmental Accounting and Management, Glen Garbon, v. 1, n. 2, p. 203-212, 2013.

HE, S. et al. Application and problems of emergy evaluation: A systemic review based on bibliometric and content analysis methods. Ecological Indicators, Amsterdam, v. 114, p. 106304, March. 2020.

HEATON, R. J.; RANDERSON, P. F.; SLATER, F. M. The economics of growing short rotation coppice in the uplands of mid-Wales and an economic comparison with sheep production. Biomass and Bioenergy, Oxford, v. 17, n. 1, p. 59-71, 1999.

LAGERBERG, C.; BROWN, M. Improving agricultural sustainability: The case of Swedish greenhouse tomatoes. Journal of Cleaner Production, Amsterdam, v. 7, n. 6, p. 421-434, 1999.

LI, L. et al. Economic evaluation of the air pollution effect on public health in China's 74 cities. Springer Plus, Heidelberg, v. 5, n. 1, 2016.

LOTKA, A. J. Contribution to the energetics of evolution. Proceedings of the National Academy of Sciences of the United States of America, Washington, v. 8, b. 6, p. 147-155, 1922.

MAIA, A. G.; ROMEIRO, A. R.; REYDON, B. P. Valoração de recursos ambientais Metodologias e recomendações. Texto para Discussão, Campinas, v. 116, p. 1- 38, 2004.

MARQUES, J. Valoração ambiental. Jaguariúna: Embrapa Meio Ambiente, 2004. Disponível em:

https://www.agencia.cnptia.embrapa.br/recursos/Marques_valoracaolD8c4EUMn3Bm.pdf. Acesso em: 10 jan. 2021.

MAY, P. Economia do médio ambiente: teoria e pratica. 3. ed. São Paulo: Elsevier, 2018.

MELLINO, S.; BUONOCORE, E.; ULGIATI, S. The worth of land use: A GIS-emergy evaluation of natural and human-made capital. Science of the Total Environment, Amsterdam, v. 506-507, p. 137-148, 2015.

ODUM, H. T. Systems ecology: an introduction. New York, USA, 1983.

ODUM, H. T. Environmental accounting: emergy and environmental decision making. New York, USA: Jhon Wiley \& Sons, INC, 1996.

ODUM, H. T.; ODUM, E. C. A Prosperous wat down: principles and policies. Colorado: University Press of Colorado, 2001. 
ORTEGA, E. et al. Brazilian soybean production: emergy analysis with an expanded scope. Bulletin of Science, Technology \& Society, [s.I.], v. 25, n. 4, p. 323-334, 2005.

ORTEGA, E.; ANAMI, M.; DINIZ, G. Certification of food products using emergy analysis. In: INTERNATIONAL WORKSHOP ADVANCES IN ENERGY STUDIES, 3., 2002, Porto Venere. Proceedings [...]. Porto Venere, 2002. p. 227-237.

PASSOS, C. R. M.; NOGAMI, O. Princípios de economia. 5. ed. São Paulo: Cengage Learning, 2008.

RAINERI, C.; STIVARI, T. S.; GAMEIRO, A. H. Development of a cost calculation model and cost index for sheep production. Revista Brasileira de Zootecnia, Viçosa, v. 44, n. 12, p. 443-455, 2015a.

RAINERI, C.; STIVARI, T. S. S.; GAMEIRO, A. H. Lamb production costs: analyses of composition and elasticities analysis of lamb production costs. Asian-

Australasian Journal of Animal Sciences, Seoul, v. 28, n. 8, p. 1209-1215, 2015b.

REIS, J. C. et al. Integrated crop-livestock systems: A sustainable land-use alternative for food production in the Brazilian Cerrado and Amazon. Journal of Cleaner Production, Amsterdam, v. 283, art. 124580, 2021.

RODRÍGUEZ-ORTEGA, T. et al. Does intensification result in higher efficiency and sustainability? An emergy analysis of Mediterranean sheep-crop farming systems. Journal of Cleaner Production, Amsterdam, v. 144, p. 171-179, 2017.

ROMEIRO, A. R.; MAIA, A. G. Avaliação de custos e benefícios ambientais. Brasília: ENAP, 2004.

SARTORELLO, G. L.; BASTOS, J. P. S.; GAMEIRO, A. H. Development of a calculation model and production cost index for feedlot beef cattle. Revista Brasileira de Zootecnia, Viçosa, v. 47, art. e20170215, 2018.

SUKHDEV, P. et al. Mainstreaming the Economics of Nature: A Synthesis of the Approach, Conclusions and Recommendations of TEEB. Malta, 2010.

VON BERTALANFFY, L. General systems theory. New York, USA, 1968.

WANG, X. et al. Sustainability evaluation of the large-scale pig farming system in North China: An emergy analysis based on life cycle assessment. Journal of Cleaner Production, Amsterdam, v. 102, p. 144-164, 2015.

YANG, Q. et al. Donor-side evaluation of coastal and marine ecosystem services. Water Research, New York, v. 166, p. 115028, 2019. 


\section{CAPÍTULO V: CONSIDERAÇÕES FINAIS}

A caraterização do desempenho econômica e ambiental dos sistemas produtivos avaliados neste estudo, ajudaram ao esclarecimento e entendimento de aspectos fundamentais a serem considerados no desenvolvimento de políticas que levem ao avanço de uma produção ovina eficiente e ambientalmente sustentável.

Desde a ótica econômica, a análise de custo demostrou que a aplicação de conceitos básicos da teoria neoclássica, como o são: os tipos de custos e o custo de oportunidade, são necessários para gerar informações relevantes na criação de estratégias que visem o aumento da produtividade, junto à diminuição dos custos, o que levara a um aumento da lucratividade no sistema. Além disso, evidenciou-se que sistemas que apresentaram maior nível de intensificação, podem ser mais lucrativos. Contudo, a lucratividade dependera da eficiência produtiva do sistema, visto que, uma maior produção traz consigo um aumento dos custos produtivos, e são estes custos os que precisaram de maior gerenciamento para atingir os níveis de lucratividade desejados pelo produtor.

Apesar do anterior, e baseados nos achados da presente dissertação os sistemas de produção agropecuários devem de ser considerados como sistemas abertos, termo usado na Termodinâmica para aqueles sistemas que apresentam um intercâmbio de energia e matéria com seu entorno. Embora, dadas as limitações das análises econômica tradicionais ao considerar estes intercâmbios nos seus estudos, torna-se como uma das principais causas da problemática ambiental gerada pelas ações antropogênicas.

A Síntese em Emergia ou chamada também de contabilidade ambiental em emergia, proporcionou outra perspectiva em relação à gestão dos sistemas ovinos avaliados nesta pesquisa. Neste caso, os sistemas intensivos caracterizam-se por apresentar um maior uso de insumos externos (na sua maioria não-renováveis), o que leva a esses sistemas a gerar uma maior carga ambiental (menor renovabilidade e maior pressão ambiental). Tal desempenho leva a estes sistemas a ser insustentável no longo prazo. Por outro lado, os sistemas que apresentam menor uso de insumos externos caracterizam-se por apresentar um maior uso de recursos renováveis locais, o que torna esses sistemas menos dependentes do subsistema 
econômico, mais autossuficientes, renováveis e sustentáveis, uma vez que sea carga ao meio ambiente é menor.

Diante o exposto, e baixo uma ótica econômico-ecológica é possível afirmar que sistema produtivos que apresentam maior intensidade e eficiência produtiva, podem alcançar maior rentabilidade econômica, como foi exposto anteriormente. No entanto, estes sistemas se caracterizam por apresentar maior dependência de insumos externos (não-renovais), o que repercute não só aumento nos custos de produção, mas também, em tornar estes sistemas insustentáveis ambientalmente. Em contrapartida, os sistemas que apresentam menor uso de insumos externos caracterizam-se por apresentar menor intensidade e eficiência produtiva, o que compromete sua viabilidade econômica. Apesar disso, o maior uso de recursos renováveis locais torna esses sistemas sustentáveis ambientalmente.

A metodologia proposta nesta pesquisa demostro uma maneira racional de avaliar os sistemas de produção ovinos, devido que ao aplicar a Síntese em Emergia junto a análise econômica são levados em conta aspetos ecológicos e econômicos. Esta visão, abrangente dos sistemas produtivos permite o desenvolvimento de estratégias que podem contribuir na formação de sistemas ovinos sustentáveis. Embora, é importante ressaltar que os achados obtidos neste trabalho não devem ser generalizados diretamente para nenhum tipo de sistema de produção ovina em outras regiões, pois uma caracterização regional mais ampla em que os sistemas produtivos estão localizados é fundamental para o desenvolvimento de alternativas.

Outra consideração deste trabalho tem relação à importância de contabilizar os recursos naturais dentro das análises econômicas. Em razão disso, a incorporação de conceitos da teoria de custos à metodologia de contabilidade ambiental em emergia, poderia oferecer um cálculo do custo, mas próximo à realidade desses insumos. Deste modo, esperasse que em futuras pesquisas seja implementada a proposta conceitual elaborada nesta dissertação para poder avaliar sua viabilidade. 


\section{SUPPLEMENTARY MATERIAL}

6.1 Supplementary material A - Characterization and productive indices of farming systems

Table 15 - Intensive sheep farming system of full-cycle (Intensive)

\begin{tabular}{|c|c|}
\hline Characteristic & Value \\
\hline Productive activity & $\begin{array}{r}\text { Sheep pasture and lamb } \\
\text { feedlot }\end{array}$ \\
\hline \multicolumn{2}{|l|}{ Environmental conditions } \\
\hline Region & Ribeirão Preto \\
\hline Location & $21^{\circ} 17^{\prime} 51.2^{\prime \prime S} 47^{\circ} 42^{\prime} 31.6^{\prime \prime W}$ \\
\hline Municipality & Cravinhos \\
\hline $\begin{array}{l}\text { Precipitation (accumulated } \mathrm{mm} \text { per } \\
\text { year) } \\
\underline{\text { Land details }}\end{array}$ & 1.597 \\
\hline Area (ha) & 52,0 \\
\hline Irrigated grazing surfaces (ha) & 14,0 \\
\hline No irrigation grazing surfaces & 32,0 \\
\hline Facilities surfaces & 1,0 \\
\hline Forest reserve surfaces & 5,0 \\
\hline \multicolumn{2}{|l|}{ Flock details $^{1}$} \\
\hline Breed & Poll Dorset \\
\hline$N^{\circ}$ ewes (head) & 1.200 \\
\hline$N^{\circ}$ rams (head) & 22 \\
\hline Production cycles for year & 1 \\
\hline Pregnancy rate (\%) & 75,00 \\
\hline Prolificacy rate (\%) & 120,00 \\
\hline Lambing interval (months) & 12 \\
\hline Lambs born in the year (heads) & 1.080 \\
\hline Pre weaning mortality rates (\%) & 10,70 \\
\hline Post weaning mortality rates (\%) & 3,00 \\
\hline Birth weight (kg) & 4,60 \\
\hline Weaning weight $(\mathrm{kg})$ & 24,60 \\
\hline Weaning age $(d)$ & 60 \\
\hline Pre weaning ADG (g/d) & 333,33 \\
\hline Slaughter age (d) & 100 \\
\hline Slaughter live weight $(\mathrm{kg})$ & 40,00 \\
\hline Post weaning ADG (g/d) & 385,00 \\
\hline Average carcass performance (\%) & 48,20 \\
\hline \multicolumn{2}{|l|}{ Outputs per year } \\
\hline Total lambs produced & 936 \\
\hline Total slaughtered & 875 \\
\hline $\mathrm{kg}$ of live weight produced & $34.980,47$ \\
\hline $\mathrm{kg}$ of carcass produced & $16.860,59$ \\
\hline
\end{tabular}


Total joules produced ${ }^{2}$

$7.90 \mathrm{E}+10$

Ram produced (pure-breeding)

37

Sheep produced (pure-breeding) ${ }^{*}$

24

$\mathrm{kg}$ of live weight produced

$3,501.1$

${ }^{1} \mathrm{ADG}$, average daily gain; ${ }^{2}$ The energy in joules $(\mathrm{J})$ of the total $\mathrm{kg}$ of carcass produced was estimated through the following equation: $\mathrm{J}$ produced per year = carcasses produced $\mathrm{kg} / \mathrm{yr}$ * $1,120 \mathrm{kcal} / \mathrm{kg}$ * $4,186 \mathrm{~J} / \mathrm{kcal}$. The result was used to calculate its transformation value by means the emergy synthesis. ${ }^{*}$ Average LW of sheep and ram is the $47 \mathrm{~kg}$ and $53 \mathrm{~kg}$, respectively. Source: own authorship.

Table 16 - Intensive lamb finishing system (Feedlot)

\begin{tabular}{lr}
\hline \multicolumn{1}{c}{ Characteristic } & \multicolumn{1}{c}{ Value } \\
\hline Productive activity & $\begin{array}{r}\text { Lamb } \\
\text { finishing }\end{array}$ \\
\hline Environmental conditions & Botucatu \\
\hline Region & $22^{\circ} 50^{\prime} 02.5^{\prime \prime S}$ \\
Location & $48^{\circ} 33^{\prime} 51.8^{\prime \prime} \mathrm{W}$ \\
Municipality & Botucatu \\
Precipitation (accumulated mm per year) & 1.178 \\
Land details & \\
\hline Area (ha) & 5,0 \\
Irrigated grazing surfaces (ha) & - \\
No irrigation grazing surfaces & 1,0 \\
Facilities surfaces & 3,5 \\
Forest reserve surfaces & 0,5 \\
Feedlot detals &
\end{tabular}

Feedlot details ${ }^{1}$

Texel -

Breed

Dorper -

Lambs fattened per cycle (head)

Production cycles for year

500

Lambs purchased for finishing per year

Lamb mortality rates in transport $(\%)^{2}$

2.000

Lamb mortality rates in the farm (\%)

1,50

Average age of entry into the system (d)

5,00

Weight of entry to the system $(\mathrm{kg})$

122

Period in the feedlot (d)

28,00

Average slaughter weight $(\mathrm{kg})$

65

Post weaning ADG $(\mathrm{g} / \mathrm{d})$

45,00

Average carcass performance (\%)

253,85

Outputs per year

47,00

Total slaughtered lambs 
Live weight produced

$84.150,0$

$\mathrm{kg}$ of carcass produced

$39.550,5$

Total joules produced ${ }^{3}$

$1.85 \mathrm{E}+11$

Tons of manure

140.25

${ }^{1} \mathrm{ADG}$, average daily gain; ${ }^{2}$ this value is taken into account as weight loss in the transport to the farm of the lot of lambs purchased for finishing; ${ }^{3}$ The energy in joules $(\mathrm{J})$ of the total $\mathrm{kg}$ of carcass produced was estimated through the following equation: $\mathrm{J}$ produced per year $=$ carcasses produced $\mathrm{kg} / \mathrm{yr}$ * $1,120 \mathrm{kcal} / \mathrm{kg}$ * $4,186 \mathrm{~J} / \mathrm{kcal}$. The result was used to calculate its transformation value by means the emergy synthesis. Source: own authorship.

Table 17 - Semi-intensive sheep farming system with lamb finishing (Semi-intensive)

\begin{tabular}{lr}
\hline \multicolumn{1}{c}{ Characteristic } & Value \\
\hline Productive activity & $\begin{array}{r}\text { Sheep pasture } \\
\text { and lamb } \\
\text { feedlot }\end{array}$ \\
Environmental conditions & Bauru \\
\hline Region & $23^{\circ} 14^{\prime} 57.7^{\prime \prime} \mathrm{S}$ \\
Location & $48^{\circ} 24^{\prime} 26.7^{\prime \prime} \mathrm{W}$ \\
Municipality & Bofete \\
Precipitation (accumulated mm per year) & 1.702 \\
Land details & \\
\hline Area (ha) & 39,0 \\
Irrigated grazing surfaces (ha) & - \\
No irrigation grazing surfaces & 31,5 \\
Facilities surfaces & 2,0 \\
Forest reserve surfaces & 5,5 \\
Flock details ${ }^{1}$ & \\
\hline Breed & Santa Ines - \\
No ewes (head) & Dorper \\
N ${ }^{\circ}$ rams (head) & 86 \\
Production cycles for year & 2 \\
Pregnancy rate (\%) & 1,00 \\
Prolificacy rate (\%) & 91,50 \\
Lambing interval (months) & 115,50 \\
Lambs born in the year (heads) & 12 \\
Pre weaning mortality rates (\%) & 91 \\
Post weaning mortality rates $(\%)$ & 12,70 \\
Birth weight (kg) & 5,00 \\
Weaning weight (kg) & 5 \\
Weaning age (d) & 20 \\
Pre weaning ADG (g/d) & 60 \\
Slaughter age (d) & 266,7 \\
Slaughter live weight (kg) & 152 \\
& 42 \\
&
\end{tabular}


Post weaning ADG $(\mathrm{g} / \mathrm{d})$

Average carcass performance (\%)

Feedlot details ${ }^{2}$

Lambs fattened per cycle (head)

200

Production cycles for year

Lambs purchased for finishing per year 800

Lamb mortality rates in transport (\%)

0,00

Lamb mortality rates in the farm (\%)

95,00

Average age of entry into the system (d)

152

Period in the feedlot (d)

Weight of entry to the system $(\mathrm{kg})$

28,00

Average slaughter weight $(\mathrm{kg})$

44,00

Post weaning ADG (g/d)

266,67

Average carcass performance (\%)

47,00

Outputs per year

Total lambs produced ${ }^{3}$

835

Lambs to be slaughtered produced in the full-

cycle

75

Lambs to be slaughtered produced in finishing

system

Live weight produced (kg per year)

$34,077.8$

$\mathrm{kg}$ of carcass produced

$16,187.0$

Total joules produced ${ }^{4}$

$1.59 \mathrm{E}+10$

${ }^{1} \mathrm{ADG}$, average daily gain; ${ }^{2}$ Details of the animals acquired off-farm for later fattening this value is taken into account as weight loss in the transport to the farm of the lot of lambs purchased for finishing; ${ }^{3}$ Sum of lambs produced in the full-cycle and finishing; ${ }^{4}$ The energy in joules $(\mathrm{J})$ of the total $\mathrm{kg}$ of carcass produced was estimated through the following equation: $\mathrm{J}$ produced per year = carcasses produced $\mathrm{kg} / \mathrm{yr} * 1,120 \mathrm{kcal} / \mathrm{kg}$ * 4,186 J/kcal. The result was used to calculate its transformation value by means the emergy synthesis. Source: own authorship. 
6.2 Supplementary material B - Economic analysis

Table 18 - Annual costs for the production of meat lambs in the Intensive sheep farming system of full-cycle (Intensive)

\begin{tabular}{lr}
\hline \multicolumn{1}{c}{ Cost items } & \multicolumn{1}{c}{$\begin{array}{c}\text { Annual cost } \\
\text { (USD } \$)\end{array}$} \\
\hline A - Variable costs & \\
1. Feeding finishing lambs and pure & $10,927.35$ \\
2. Veeders & 248.77 \\
3. Slaughter expenses & $5,122.52$ \\
Subtotal - Variable costs & $16,298.64$ \\
B - Fixed operating costs & \\
4. Feeding of ewes and rams & $17,361.08$ \\
5. Veterinary inputs of ewes and rams & 361.66 \\
6. Forage production & $4,362.51$ \\
7. Labor & $14,634.55$ \\
8. Energy and fuels & $9,262.64$ \\
9. Depreciation of M\&Fa & $15,352.71$ \\
10. Maintenance of M\&Fa & $6,833.18$ \\
Subtotal - Fixed operating costs & $68,168.33$ \\
C - Capital remuneration cost & \\
(opportunity cost) & \\
10. Remuneration on variable capital & 457.99 \\
11. Remuneration on fixed capital & $1,915.53$ \\
12. Remunerand) & 297.41 \\
Subtotal - Capital remuneration cost & $2,670.94$ \\
D - Total cost (A + B + C) & $87,137.91$ \\
Finished lamb & \\
Total head cost & 88.67 \\
Total cost kg live weight & 2.22 \\
Total cost kg carcass & 4.60 \\
Pure breeding lamb & \\
Total head cost & 157.33 \\
Total cost kg live weight & 2.74 \\
\hline
\end{tabular}

aM\&F: machinery and facilities; ${ }^{\mathrm{b} F i n i s h e d ~ l a m b}$ with 100 days old, $40 \mathrm{~kg}$ live weight and $48.2 \%$ carcass yield; 'Pure-breeding lamb with 187 days old and $57.4 \mathrm{~kg}$ live weight. Source: own authorship. 
Table 19 - Annual costs for the production of meat lambs in the Intensive lamb finishing system (Feedlot)

\begin{tabular}{lr}
\hline \multicolumn{1}{c}{ Cost items } & \multicolumn{1}{c}{$\begin{array}{c}\text { Annual cost } \\
\text { (USD } \$)\end{array}$} \\
\hline A - Variable costs & \\
1. Acquisition of lambs for finishing & $85,732.75$ \\
2. Feeding finishing lambs and pure & $34,132.86$ \\
$\quad$ breeders & $1,023.96$ \\
3. Veterinary inputs & \\
4. Slaughter expenses & \\
Subtotal - Variable costs & $15,098.90$ \\
B - Fixed operating costs & $4,534.29$ \\
5. Labor & $7,262.13$ \\
6. Energy and fuels & 883.78 \\
7. Depreciation of M\&Fa & $27,779.09$ \\
8. Maintenance of M\&F & \\
Subtotal - Fixed operating costs & \\
C - Capital remuneration cost & $3,701.16$ \\
(opportunity cost) & 780.59 \\
9. Remuneration on variable capital & \\
10. Remuneration on fixed capital & (except land) \\
11. Remuneration on land & 28.60 \\
Subtotal - Capital remuneration cost & $4,510.35$ \\
D - Total cost (A + B + C) & $164,003.18$ \\
Finished lamb & \\
Total head cost & 88.67 \\
Total cost kg live weight & 1.94 \\
Total cost kg carcass & 4.15 \\
\hline
\end{tabular}

aM\&F: machinery and facilities; ' Finished lamb with average live weight of $45 \mathrm{~kg}$ and $47.0 \%$ carcass yield. Source: own authorship. 
Table 20 - Annual costs for the production of meat lambs in the Semi-intensive sheep farming system with lamb finishing (Semi-intensive)

\begin{tabular}{|c|c|}
\hline Cost items & $\begin{array}{c}\text { Annual cost } \\
\text { (USD\$) }\end{array}$ \\
\hline \multicolumn{2}{|l|}{ A - Variable costs } \\
\hline 1. Acquisition of lambs for finishing & $37,179.49$ \\
\hline $\begin{array}{l}\text { 2. Feeding finishing lambs and pure } \\
\text { breeders }\end{array}$ & $26,607.14$ \\
\hline 3. Veterinary inputs & 90.19 \\
\hline 4. Slaughter expenses & $4,458.12$ \\
\hline \multicolumn{2}{|l|}{ Subtotal - Variable costs } \\
\hline \multicolumn{2}{|l|}{ B - Fixed operating costs } \\
\hline 5. Feeding of ewes and rams & 784.84 \\
\hline 6. Veterinary inputs of ewes and rams & 12.03 \\
\hline 7. Labor & $5,919.78$ \\
\hline 8. Energy and fuels & 673.85 \\
\hline 9. Depreciation of M\&Fa & $1,985.51$ \\
\hline 10. Maintenance of $M \& F^{a}$ & $1,282.09$ \\
\hline \multicolumn{2}{|l|}{$\begin{array}{l}\text { C - Capital remuneration cost (opportunity } \\
\text { cost) }\end{array}$} \\
\hline 11. Remuneration on variable capital & $1,920.21$ \\
\hline $\begin{array}{l}\text { 12. Remuneration on fixed capital (except } \\
\text { land) }\end{array}$ & 299.49 \\
\hline 13. Remuneration on land & 223.06 \\
\hline Subtotal - Capital remuneration cost & $2,442.76$ \\
\hline$D-$ Total cost $(A+B+C)$ & $81,435.79$ \\
\hline \multicolumn{2}{|l|}{ Finished lamba } \\
\hline Total head cost & 101.2 \\
\hline Total cost $\mathrm{kg}$ live weight & 2.30 \\
\hline Total cost $\mathrm{kg}$ carcass & 4.89 \\
\hline
\end{tabular}


Supplementary material C - Energy diagrams of the three contrasting farming systems

Figure 18 - Energy diagram of Intensive sheep farming system of full-cycle (Intensive)

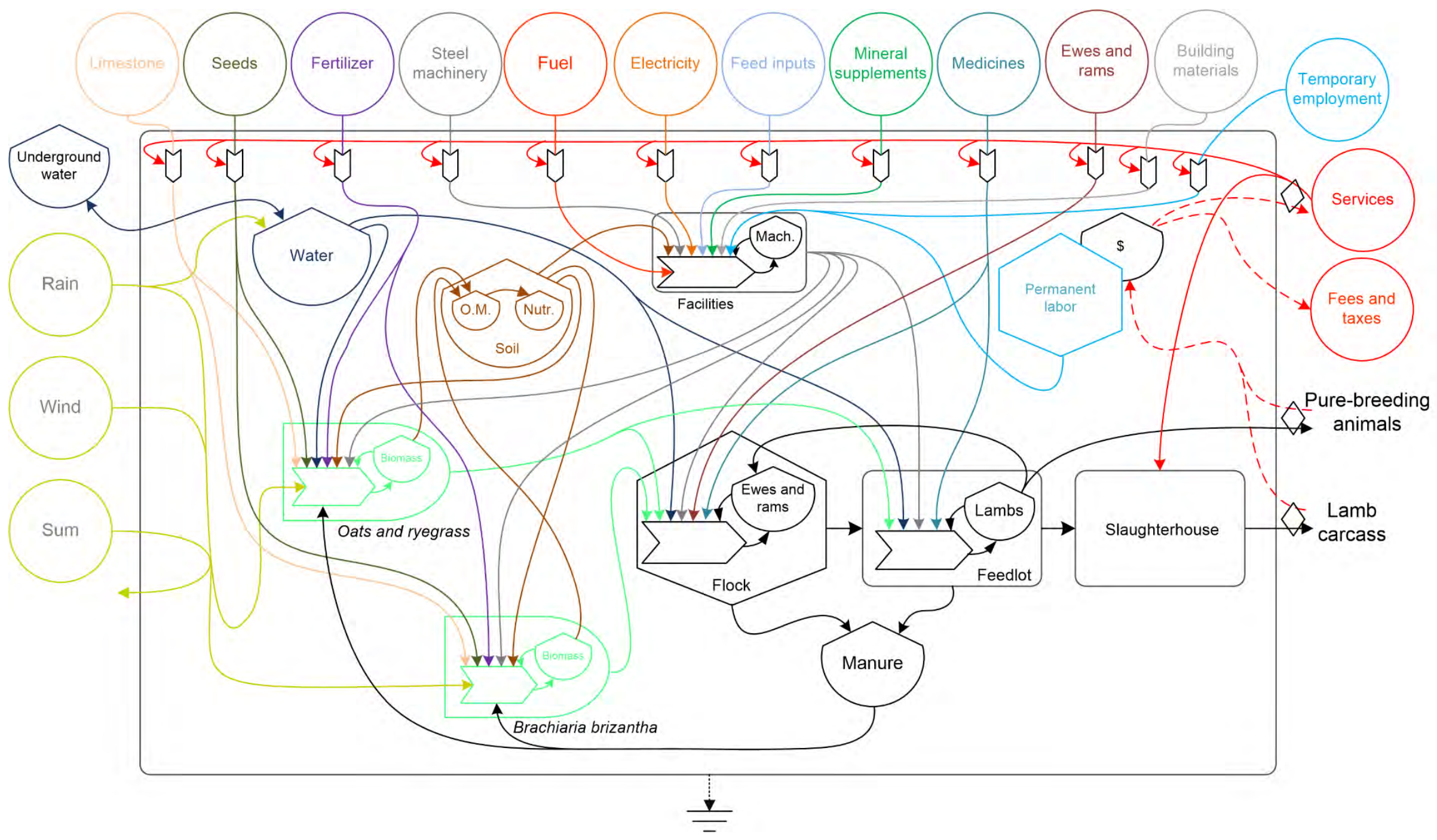

Source: own authorship. 
Figure 19 - Energy diagram of Intensive lamb finishing system (Feedlot)

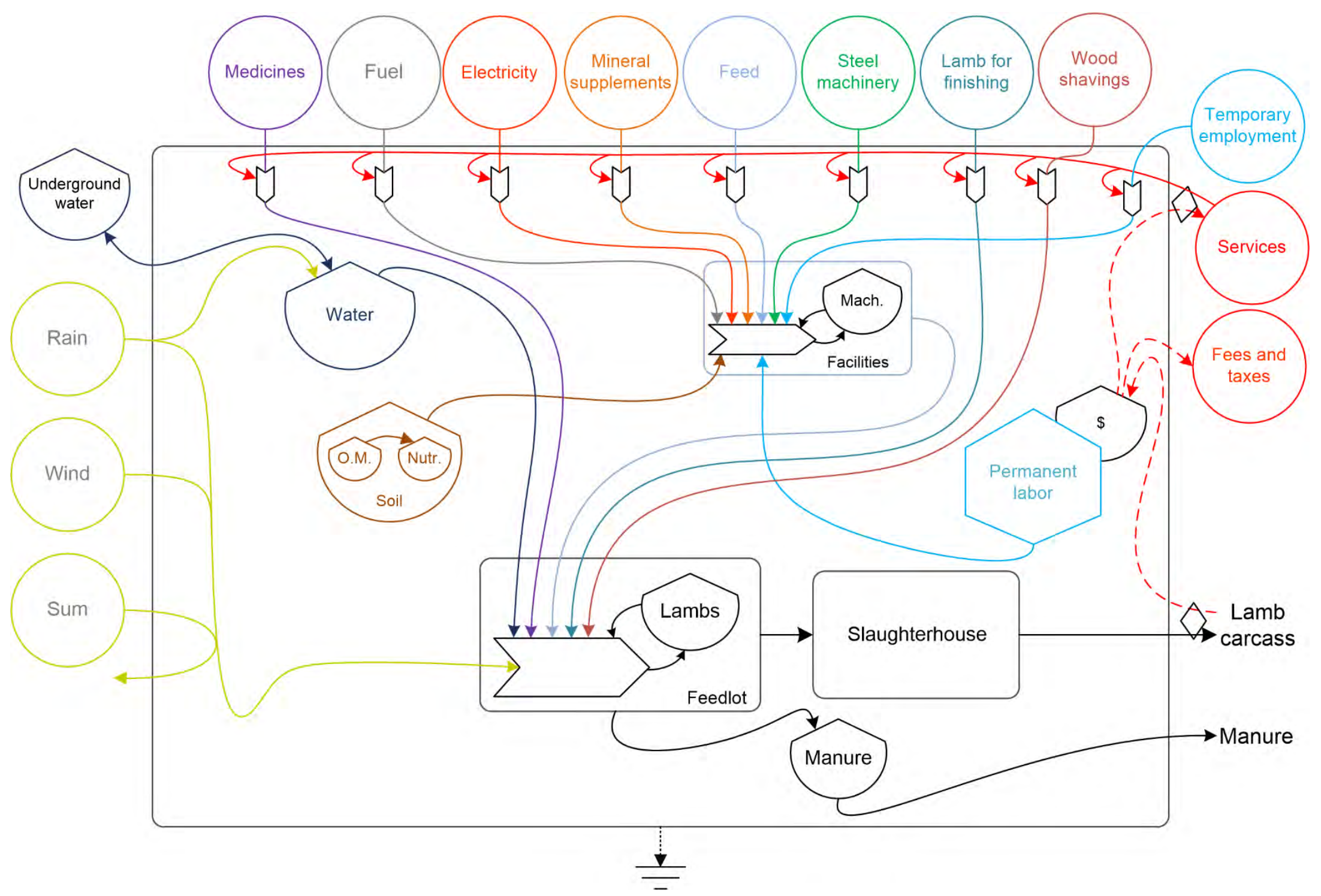

Source: own authorship. 
Figure 20 - Energy diagram of Semi-intensive sheep farming system with lamb finishing (Semi-intensive)

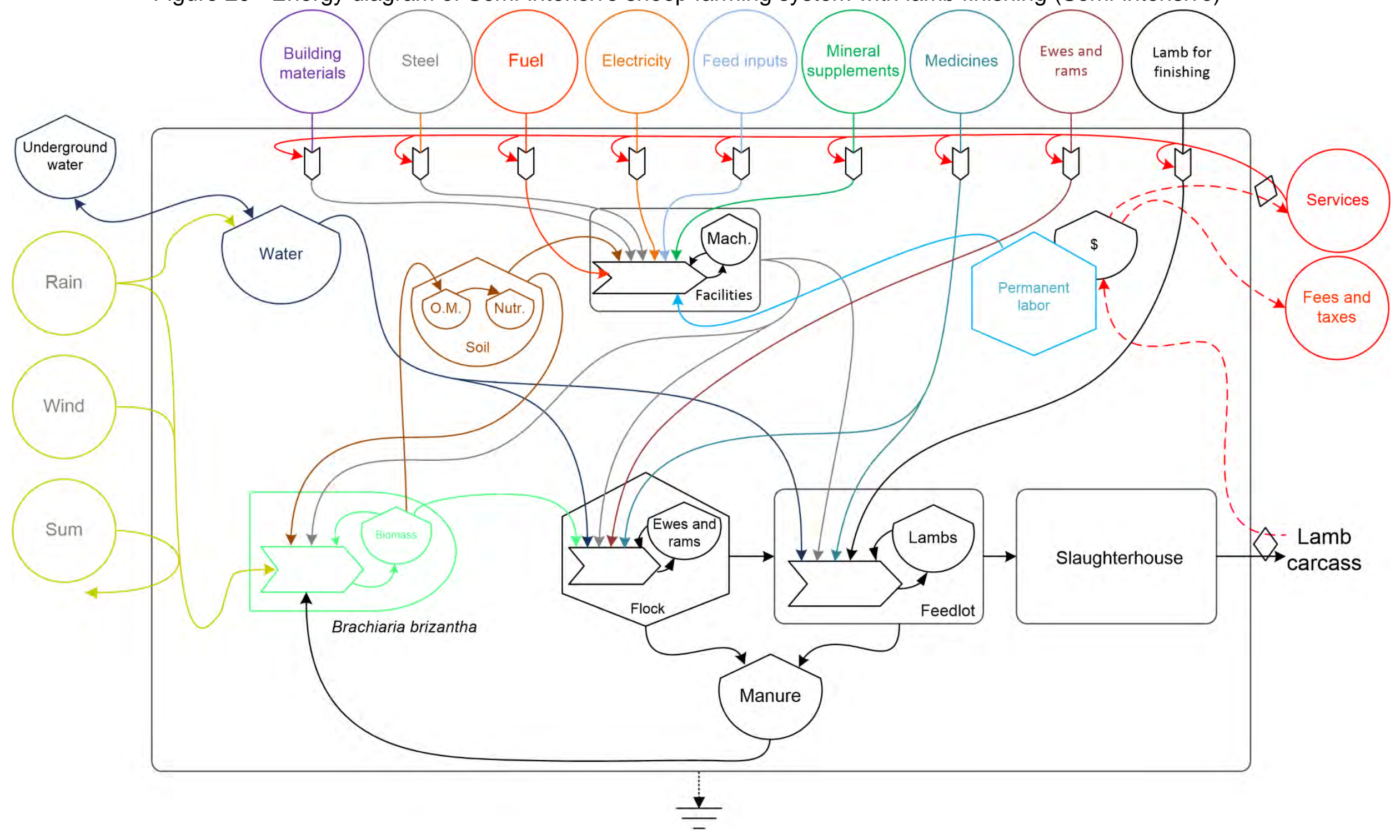

Source: own authorship. 
6.4 Supplementary material D - Emergy tables with detailed calculation of flows and renewability fraction

Table 21 - Emergy tables with detailed calculations of flows of Intensive sheep farming system of full-cycle (Intensive)

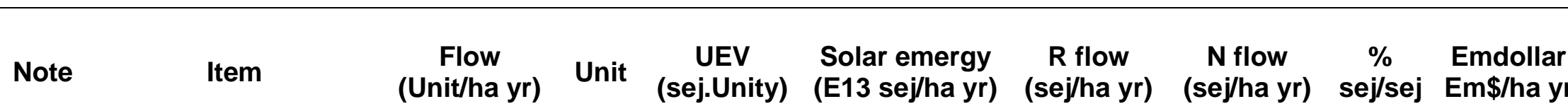

\begin{tabular}{|c|c|c|c|c|c|c|c|c|c|}
\hline \multicolumn{10}{|c|}{ Renewable resources (R) } \\
\hline 1 & Sun & $1.55 \mathrm{E}+13$ & $J$ & $1.00 \mathrm{E}+00$ & 1.55 & 1.60 & - & 0.06 & 2.77 \\
\hline 2 & Rain & $4.72 E+10$ & $J$ & $3.10 \mathrm{E}+04$ & 146.30 & 146.30 & - & 6.10 & 261.25 \\
\hline 3 & wind & 2.93E+09 & $J$ & $2.45 E+03$ & 0.72 & 0.70 & - & 0.03 & 1.28 \\
\hline \multicolumn{10}{|c|}{ Non-renewable resources $(\mathrm{N})$} \\
\hline 4 & Net Topsoil Loss & 2.93E+09 & $J$ & $1.24 \mathrm{E}+05$ & 36.34 & - & 59.90 & 1.52 & 64.90 \\
\hline 5 & Ground-water & $7.55 \mathrm{E}+07$ & $J$ & $2.55 E+05$ & 1.92 & - & 1.92 & 0.08 & 3.44 \\
\hline \multicolumn{10}{|c|}{ Materials (M) } \\
\hline 6 & Fossil fuels & 8.87E+09 & $J$ & $9.21 E+04$ & 81.70 & - & 81.70 & 3.41 & 145.90 \\
\hline 7 & Electricity & $1.83 E+09$ & $J$ & $1.47 \mathrm{E}+05$ & 26.87 & 18.27 & 8.60 & 1.12 & 47.98 \\
\hline 8 & Steel & $2.00 E+04$ & $g$ & $7.81 E+09$ & 15.59 & - & 15.59 & 0.65 & 27.85 \\
\hline 9 & wood & $4.71 E+07$ & $\mathrm{~J}$ & $9.60 E+03$ & 0.05 & 0.04 & 0.01 & 0.00 & 0.08 \\
\hline 10 & Brick & $6.00 \mathrm{E}+02$ & g & $4.21 \mathrm{E}+08$ & 0.03 & - & 0.03 & 0.00 & 0.05 \\
\hline 11 & clay tile & $9.91 E+03$ & $g$ & $2.09 E+09$ & 2.07 & - & 2.07 & 0.09 & 3.70 \\
\hline 12 & Ewes and rams & $2.50 \mathrm{E}+05$ & $g$ & $1.44 \mathrm{E}+10$ & 359.72 & 69.93 & 289.79 & 15.01 & 642.36 \\
\hline 13 & Fresh barley & $9.42 E+05$ & $g$ & $4.21 E+08$ & 39.67 & 17.85 & 21.82 & 1.66 & 70.84 \\
\hline 14 & Corn bran & $1.55 \mathrm{E}+06$ & $g$ & $5.79 E+08$ & 89.88 & 21.39 & 68.49 & 3.75 & 160.49 \\
\hline 15 & Soy meal & $7.29 E+02$ & $\mathrm{~kg}$ & $2.98 \mathrm{E}+12$ & 217.36 & 77.38 & 139.98 & 9.07 & 388.14 \\
\hline 16 & Corn silage & $1.74 \mathrm{E}+06$ & $g$ & $1.62 E+08$ & 28.24 & 6.81 & 21.44 & 1.18 & 50.43 \\
\hline 17 & Mineral Premix & $1.50 \mathrm{E}+05$ & $g$ & $1.48 \mathrm{E}+10$ & 222.14 & - & 222.14 & 9.27 & 396.67 \\
\hline 18 & White salt & $5.11 E+04$ & g & $1.05 E+09$ & 5.34 & - & 5.34 & 0.22 & 9.54 \\
\hline 19 & Limestone & $3.44 \mathrm{E}+07$ & $J$ & $2.72 E+06$ & 9.35 & - & 9.35 & 0.39 & 16.70 \\
\hline 20 & Tifton hay & $2.55 E+06$ & $\mathrm{~J}$ & $2.13 E+05$ & 0.05 & 0.02 & 0.03 & 0.00 & 0.10 \\
\hline 21 & Monensin & $1.17 \mathrm{E}+00$ & US\$ & $5.60 \mathrm{E}+12$ & 0.65 & - & 0.65 & 0.03 & 1.17 \\
\hline 22 & Vaccine & $1.01 E+02$ & $g$ & $1.48 \mathrm{E}+10$ & 0.15 & - & 0.15 & 0.01 & 0.27 \\
\hline
\end{tabular}




\begin{tabular}{|c|c|c|c|c|c|c|c|c|c|}
\hline 23 & Vermifuge & $3.66 \mathrm{E}+02$ & g & $1.48 \mathrm{E}+10$ & 0.54 & - & 0.54 & 0.02 & 0.97 \\
\hline 24 & Nitrogen (N) & $9.49 \mathrm{E}+04$ & $g$ & $2.40 \mathrm{E}+10$ & 227.69 & - & 227.69 & 9.50 & 406.59 \\
\hline 25 & Potash $\left(\mathrm{K}_{2} \mathrm{O}\right)$ & $3.05 E+04$ & g & 1.80E+09 & 5.49 & - & 5.49 & 0.23 & 9.81 \\
\hline 26 & Phosphorus ( $\left.\mathrm{P}_{2} \mathrm{O}_{5}\right)$ & $1.03 \mathrm{E}+04$ & $g$ & $2.20 \mathrm{E}+10$ & 22.56 & - & 22.56 & 0.94 & 40.29 \\
\hline 27 & Limestone & $1.24 \mathrm{E}+09$ & $\mathrm{~J}$ & $2.72 \mathrm{E}+06$ & 336.65 & - & 336.65 & 14.04 & 601.15 \\
\hline 28 & Seeds & $3.04 \mathrm{E}+04$ & g & $8.87 \mathrm{E}+08$ & 2.70 & 0.54 & 2.16 & 0.11 & 4.82 \\
\hline \multicolumn{10}{|c|}{ Services (S) } \\
\hline 29 & Permanent labor & $1.89 \mathrm{E}+08$ & J & 7.56E+06 & 142.86 & 85.72 & 57.15 & 5.96 & 255.11 \\
\hline 30 & $\begin{array}{l}\text { Temporary } \\
\text { employment }\end{array}$ & $6.31 \mathrm{E}+06$ & J & 7.56E+06 & 4.77 & 1.05 & 3.72 & 0.20 & 8.51 \\
\hline 31 & Technical services & $1.41 \mathrm{E}+02$ & US\$ & $5.60 \mathrm{E}+12$ & 78.89 & 17.36 & 61.54 & 3.29 & 140.88 \\
\hline 32 & Slaughter service & $9.24 \mathrm{E}+01$ & US\$ & $5.60 \mathrm{E}+12$ & 51.75 & 11.38 & 40.36 & 2.16 & 92.40 \\
\hline 33 & Depreciation of M\&F & $2.95 E+02$ & US\$ & $5.60 \mathrm{E}+12$ & 165.34 & 0.00 & 165.34 & 6.90 & 295.24 \\
\hline 34 & Maintenance of M\&F & $1.31 \mathrm{E}+02$ & US\$ & $5.60 \mathrm{E}+12$ & 73.59 & 0.00 & 73.59 & 3.07 & 131.41 \\
\hline \multicolumn{5}{|c|}{ TOTAL EMERGY $(\mathrm{Y})$} & $2,396.97$ & & & & $4,280.31$ \\
\hline
\end{tabular}

OUTPUTS (Y) and UEVs (calculated)

\begin{tabular}{lccccc}
\hline Note & Item & Unit & UEV & Unit \\
\hline With services & & & & \\
$35.1 \quad$ Lamb meat (live weight) & $6.73 \mathrm{E}+02$ & $\mathrm{~kg}$ & $3.56 \mathrm{E}+13$ & $\mathrm{sej} / \mathrm{kg}$ \\
$35.2 \quad$ Lamb meat (carcass weight) & $1.52 \mathrm{E}+09$ & $\mathrm{~J}$ & $1.58 \mathrm{E}+07$ & $\mathrm{sej} / \mathrm{J}$ \\
$35.3 \quad$ Lamb meat (carcass weight) & $3.24 \mathrm{E}+02$ & $\mathrm{~kg}$ & $7.39 \mathrm{E}+13$ & $\mathrm{sej} / \mathrm{kg}$ \\
By-product with services & & & & & \\
$36 \quad$ Lamb meat (pure breeding animal) & $6.73 \mathrm{E}+01$ & $\mathrm{~kg}$ & $3.56 \mathrm{E}+14$ & $\mathrm{sej} / \mathrm{kg}$ \\
Without services & & & & & \\
$35.1 \quad$ Lamb meat (live weight) & $6.73 \mathrm{E}+02$ & $\mathrm{~kg}$ & $2.79 \mathrm{E}+13$ & $\mathrm{sej} / \mathrm{kg}$ \\
$35.2 \quad$ Lamb meat (carcass weight) & $1.52 \mathrm{E}+09$ & $\mathrm{~J}$ & $1.25 \mathrm{E}+07$ & $\mathrm{sej} / \mathrm{J}$ \\
$35.3 \quad$ Lamb meat (carcass weight) & $1.69 \mathrm{E}+04$ & $\mathrm{~kg}$ & $1.11 \mathrm{E}+12$ & $\mathrm{sej} / \mathrm{kg}$ \\
By-product without services & & & & \\
$36 \quad$ Lamb meat (pure breeding animal) & $6.73 \mathrm{E}+01$ & $\mathrm{~kg}$ & $2.79 \mathrm{E}+14$ & $\mathrm{sej} / \mathrm{kg}$ \\
\hline
\end{tabular}


Table 22 - Detailed calculations for the emergy flows of Intensive sheep farming system of full-cycle (Intensive)

\begin{tabular}{|c|c|c|c|}
\hline $\begin{array}{c}\text { Not } \\
\text { e }\end{array}$ & Item & Value & Reference \\
\hline \multirow[t]{8}{*}{1} & Sun insolation, J & & \\
\hline & Annual energy = & $\begin{array}{l}\text { (Solar radiation }) *(365) *(\text { albedo }) *(3.60 \mathrm{E}+06) * \text { (area } \\
\left.\mathrm{m}^{2} / \mathrm{ha}\right)\end{array}$ & (Odum, 1996) \\
\hline & Solar radiation $=$ & $5.9 \mathrm{kWh} / \mathrm{m}^{2} /$ day & (SPARK, 2020) \\
\hline & Albedo $=$ & $20 \% 1-20 \%$ & $\begin{array}{l}\text { NASA eosweb } \\
\text { (https://eosweb.larc.nasa.gov/sse/) }\end{array}$ \\
\hline & Joules to $\mathrm{kWh}=$ & $3.60 \mathrm{E}+06 \mathrm{~J} / \mathrm{kWh}$ & \\
\hline & Area $=$ & $1.00 \mathrm{E}+04 \mathrm{~m}^{2}$ & \\
\hline & UEV = & 1 sej.J $J^{-1}$ & Definition \\
\hline & Annual energy = & $1.55 \mathrm{E}+13 \mathrm{~J} / \mathrm{ha} / \mathrm{yr}$ & \\
\hline
\end{tabular}

2 Rain chemical potential energy, $\mathbf{J}$

Annual energy $=($ precipitation $){ }^{*}($ Gibbs $){ }^{*}($ water density $) *$

Precipitation $=$

Gibbs free energy =

water density =

Evapotranspiration rate $=$

Area $=$

Annual energy =

$$
\text { UEV = }
$$

$$
1.597 \mathrm{~m}^{3} / \mathrm{m}^{2} / \mathrm{yr}
$$$$
4,940.00 \mathrm{~J} / \mathrm{kg}
$$$$
997 \mathrm{~kg} / \mathrm{m}^{3}
$$

$60 \%$

$1.00 \mathrm{E}+04 \mathrm{~m}^{2}$

4.72E+10 J/ha/yr

$3.10 \mathrm{E}+04 \mathrm{sej} / \mathrm{J}$

\section{Reference}

(Brown and Bardi, 2001)

(SPARK, 2020)

(ODUM, 1996)

\section{Wind, $\mathbf{J}$}
Annual energy $=(\text { air density) * (geotropic wind })^{\wedge} 3$ * $($ drag coefficient) * (area
Density of Air =

$$
\begin{aligned}
& \text { (air density) * (geotropic } \\
& \left.\mathrm{m}^{2} / \mathrm{ha}\right) *(3.15 \mathrm{E} 7 \mathrm{~s} / \text { year })
\end{aligned}
$$$$
1.28 \mathrm{~kg} / \mathrm{m}^{3}
$$
(Brown and Bardi, 2001)

(ODUM; BROWN; BRANDT-WILLIAMS, 2000) 

Avg. annual wind velocity $=$
Geostrophic wind =
Drag coefficient $=$
Annual energy =

$$
\text { UEV = }
$$
$3.23 \mathrm{~m} / \mathrm{s}$
$1.94 \mathrm{~m} / \mathrm{s}$
0.001
2.93E+09 J/ha/yr
$2.45 \mathrm{E}+03 \mathrm{sej} / \mathrm{J}$

Observed winds are about 0.6 of geostrophic wind

(SPARK, 2020)

(Miller, 1964 quoted by Kraus, 1972)

(ODUM; BROWN; BRANDT-WILLIAMS, 2000)

\section{Reference}

Loss of soil in grazing Annual energy = Total paddock area $=$ (Soil loss) * $($ O.M.) * (energy of O.M.) * $(4,186 \mathrm{~J} / \mathrm{kcal})$ * (total paddock area) / (property area) 46 ha

Loss of soil in pasture $=$ Organic matter (O.M.) =

Energy of the O.M. = Annual energy = Soil loss from buildings

Annual energy

Feedlot area $=$

Shed area $=$ Sheep handling pen area $-1=$ Sheep handling pen area $-2=$

Office area $=$ Total area of buildings $=$

Soil layer $=$

Organic matter (O.M.) =
$3400 \mathrm{t} / \mathrm{ha} / \mathrm{yr}$

$0.04 \mathrm{~kg} \mathrm{O.M./kg}$

$5,400.00 \mathrm{kcal} / \mathrm{kg}$ O.M.

$2.72 \mathrm{E}+09 \mathrm{~J} / \mathrm{ha} / \mathrm{yr}$

$\left(\right.$ Area in $\left.\mathrm{m}^{2}\right) *($ O.M. $){ }^{*}\left(0.0012 \mathrm{~kg} / \mathrm{cm}^{3}\right) *\left(1 \mathrm{E}+06 \mathrm{~cm}^{3} / \mathrm{m}^{3}\right)$ *

$(4,186 \mathrm{~J} / \mathrm{kcal}) *(5,400 \mathrm{kcal}) /($ property area $) / 30 \mathrm{yr}$

$600 \mathrm{~m}^{2}$

$756 \mathrm{~m}^{2}$

$48 \mathrm{~m}^{2}$

$35 \mathrm{~m}^{2}$

$80 \mathrm{~m}^{2}$

$1,519 \mathrm{~m}^{2}$

$0.2 \mathrm{~m}$

$0.04 \mathrm{~kg} \mathrm{O.M./kg}$

From field work

(EPAMIG, 1992)

(EPAMIG, 1992)
(Agostinho et al., 2019)

(EPAMIG, 1992)

(EPAMIG, 1992)
(Agostinho et al., 2019) 
Annual energy $=\quad 2.11 \mathrm{E}+08 \mathrm{~J} / \mathrm{ha} / \mathrm{yr}$

Total energy topsoil losses $=\quad 2.93 \mathrm{E}+09 \mathrm{~J} / \mathrm{ha} / \mathrm{yr}$

$\mathrm{UEV}=\quad 1.24 \mathrm{E}+05 \mathrm{sej} / \mathrm{J}$

(ODUM; BROWN; BRANDT-WILLIAMS, 2000)

5 Ground-water, J

Annual energy $=\left(\right.$ Total water consumption $\left.\mathrm{m}^{3} / \mathrm{yr}\right){ }^{*}($ water energy $) *$ (water density $\left.\mathrm{kg} / \mathrm{m}^{3}\right) /($ property area)

Lactating lambs $=\quad 43,242.60 \mathrm{~L} / \mathrm{yr}$

\section{Reference}

(Ortega et al., 2005)

Lambs weaned $=\quad 38,218.50 \mathrm{~L} / \mathrm{yr}$

0.4 liters of water/head/day

2.7 liters of water/ head /day

Finishing lambs $=213,150.00 \mathrm{~L} / \mathrm{yr}$

Ewes $=480,473.40 \mathrm{~L} / \mathrm{yr}$

Rams $=\quad 12,111.90 \mathrm{~L} / \mathrm{yr}$

Total water consumption $=\quad 787.2 \mathrm{~m}^{3} / \mathrm{yr}$

Water density $=\quad 9.97 \mathrm{E}+02 \mathrm{~kg} / \mathrm{m}^{3}$

Energy in water $=\quad 5.00 \mathrm{E}+03 \mathrm{~J} / \mathrm{kg}$

Annual energy $=\quad 7.55 \mathrm{E}+07 \mathrm{~J} / \mathrm{ha} / \mathrm{yr}$

$\mathrm{UEV}=2.55 \mathrm{E}+05 \mathrm{sej} / \mathrm{J}$

3.5 liters of water/ head/day

4 liters of water/ head/day

5.5 liters of water/ head /day

(TEDESCHI; GENE, 2016)

(BASTIANONI; MARCHETTINI, 2000)

\section{Materials (M)}

6 Fossil fuels, $\mathbf{J}$ (Includes: diesel, gasoline and lubricants)

Annual energy $=\begin{aligned} & (\mathrm{L} / \mathrm{yr}) * \\ & (\text { property area })\end{aligned}$

\section{Reference}

(Odum, 1996)

farm activities $=\quad 11,400.00 \mathrm{~L} / \mathrm{yr}$

Transport $=\quad 108 \mathrm{~L} / \mathrm{yr}$

Total diesel consumption $=\quad 11,508.00 \mathrm{~L} / \mathrm{yr}$

Density $=\quad 0.84 \mathrm{~kg} / \mathrm{L}$

fuel energy $=\quad 11,400.00 \mathrm{kcal} / \mathrm{kg}$

Annual energy $=\quad 8.87 \mathrm{E}+09 \mathrm{~J} / \mathrm{ha} / \mathrm{yr}$

$\mathrm{UEV}=\quad 9.21 \mathrm{E}+04 \mathrm{sej} / \mathrm{J}$

From field work

(ANP, 2014)

(BASTIANONI et al., 2005) 
7 Electricity, J

$$
\text { Annual energy }=\begin{aligned}
& \text { Energy } \\
& \text { area) }
\end{aligned}
$$

Electric power consumption $=$ Joules per $\mathrm{kWh}=$

Annual energy =

$$
\text { UEV = }
$$

\section{Reference}

From field work

(GIANNETTI et al., 2015)

8 Steel, $\mathbf{g}$

Annual mass flow $=(\mathrm{kg}$ of steel $) /($ lifetime $) /($ property area $)$

Mass of equipment $=$ $25,861.00 \mathrm{~kg}$

Mass of fence wire $=$

Mass of facilitiess $=$

Total mass of steel $=$ $4,603.20 \mathrm{~kg}$ $684 \mathrm{~kg}$

$3.11 \mathrm{E}+07 \mathrm{~g}$

$30 \mathrm{yr}$

From field work

Lifetime of material $(\mathrm{LM})=$

Annual mass flow $=$ $2.00 \mathrm{E}+04 \mathrm{~g} / \mathrm{ha} / \mathrm{yr}$

$\mathrm{UEV}=\quad 7.81 \mathrm{E}+09 \mathrm{sej} / \mathrm{g}$

\begin{tabular}{|c|c|c|}
\hline \multicolumn{3}{|c|}{9 Wood, J } \\
\hline & Annual energy = & $\begin{array}{l}((\text { wood g }) *(3.6 \mathrm{kcal} / \mathrm{g}) *(4,186 \mathrm{~J} / \mathrm{kcal})) /(\text { lifetime }) / \\
(\text { property area })\end{array}$ \\
\hline & Total mass of wood $=$ & $2.44 \mathrm{E}+06 \mathrm{~g}$ \\
\hline & wood energy = & $3.6 \mathrm{kcal} / \mathrm{g}$ \\
\hline & kcal to Joules $=$ & $4,186 \mathrm{~J} / \mathrm{kcal}$ \\
\hline & Lifetime of material $(\mathrm{LM})=$ & $15 \mathrm{yr}$ \\
\hline & Energy flow $(\mathrm{J})=$ & 4.71E+07 J/ha/yr \\
\hline & UEV $=$ & $9.60 \mathrm{E}+03 \mathrm{sej} / \mathrm{J}$ \\
\hline
\end{tabular}

(BROWN; ULGIATI, 2004);

10 Brick, g

Annual mass flow $=($ Brick g) $/($ lifetime $) /($ property area $)$

\section{Reference}

(Odum, 1996)

From field work

(Odum, 1996)

(DE OLIVEIRA et al., 2018) 
Total mass of brick $=\quad 9.36 \mathrm{E}+05 \mathrm{~g}$

Lifetime of material $(\mathrm{LM})=$

Annual mass flow =

UEV =
$30 \mathrm{yr}$

\subsection{E+02 g/ha/yr}

$4.21 \mathrm{E}+08 \mathrm{sej} / \mathrm{g}$

From field work

(PULSELLI et al., 2007)

\section{Reference}

From field work
$1.55 \mathrm{E}+07 \mathrm{~g}$
$30 \mathrm{yr}$
Lifetime of material $=$
Annual mass flow =
9.91E+03 g/ha/yr
$2.09 \mathrm{E}+09 \mathrm{sej} / \mathrm{g}$
UEV =

Annual mass flow =

12 Ewes and rams, $g$ (flock)

Annual mass flow = $\left((\mathrm{LW} \mathrm{kg}){ }^{*}(\right.$ heads $\left.) *(1,000 \mathrm{~g} / \mathrm{kg})\right) /($ lifetime $) /$ (property

Ewe live weight $=$

Lifetime of ewes $=$ live weight flock of ewes $=$

Ram live weight $=$

Lifetime of rams $=$ live weight flock of rams $=$

Annual mass flow =

UEV =

$\begin{array}{rl}60 & \mathrm{~kg} \\ 6 & \mathrm{yr} \\ 1.20 \mathrm{E}+07 & \mathrm{~g} / \mathrm{yr} \\ 90 & \mathrm{~kg} \\ 2 & \mathrm{yr} \\ 9.90 \mathrm{E}+05 & \mathrm{~g} / \mathrm{yr} \\ 2.50 \mathrm{E}+05 & \mathrm{~g} / \mathrm{ha} / \mathrm{yr} \\ 1.44 \mathrm{E}+10 \mathrm{sej} / \mathrm{g}\end{array}$

13 Fresh barley, $g$

Annual mass flow $=$ (Annual consumption) $/$ (property area)
(PICCHI; PORCELLI; PULSELLI, 2001)

\section{Reference}

From field work

From field work

From field work

From field work

(HADEN, 2002)

\section{Reference}

From field work

(CASTELLINI et al., 2006)

14 Corn bran, g

Reference


Annual mass flow $=($ Annual consumption $) /$ (property area)

$\begin{array}{rlr}\text { Annual consumption }= & 8.07 \mathrm{E}+07 \mathrm{~g} / \mathrm{yr} & \text { From field work } \\ \text { Annual mass flow }= & 1.55 \mathrm{E}+06 \mathrm{~g} / \mathrm{ha} / \mathrm{yr} & \end{array}$

(YUN et al., 2019)

15 Soy meal, $\mathrm{kg}$

$5.79 \mathrm{E}+08 \mathrm{sej} / \mathrm{g}$

Reference

Annual mass flow $=$ (Annual consumption) $/$ (property area)

$\begin{array}{lll}\text { Annual consumption }= & 3.79 \mathrm{E}+04 \mathrm{~kg} / \mathrm{yr} & \text { From field work }\end{array}$

Annual mass flow $=\quad 7.29 \mathrm{E}+02 \mathrm{~kg} / \mathrm{ha} / \mathrm{yr}$

$\mathrm{UEV}=2.98 \mathrm{E}+12 \mathrm{sej} / \mathrm{g} \quad$ (CAVALETT; ORTEGA, 2009)

16 Corn silage, $g$

Reference

Annual mass flow $=$ (Annual consumption) $/$ (property area)

Annual consumption $=\quad 9.07 \mathrm{E}+07 \mathrm{~g} / \mathrm{yr}$

From field work

Annual mass flow $=\quad 1.74 \mathrm{E}+06 \mathrm{~g} / \mathrm{ha} / \mathrm{yr}$

$\mathrm{UEV}=1.62 \mathrm{E}+08 \mathrm{sej} / \mathrm{g}$

(YUN et al., 2019)

17 Mineral supplement, $\mathrm{g}$

Annual mass flow $=$ (Annual consumption) $/$ (property area)

Annual consumption $=\quad 7.80 \mathrm{E}+06 \mathrm{~g} / \mathrm{yr}$

Reference

\section{Annual mass flow $=1.50 \mathrm{E}+05 \mathrm{~g} / \mathrm{ha} / \mathrm{yr}$}

$\mathrm{UEV}=1.48 \mathrm{E}+10 \mathrm{sej} / \mathrm{g}$

From field work

(CASTELLINI et al., 2006)

18 White salt, $g$

Annual mass flow $=$ (Annual consumption) $/$ (property area)

Annual consumption $=2.66 \mathrm{E}+06 \mathrm{~g} / \mathrm{yr}$

Reference

\section{Annual mass flow $=\quad 5.11 \mathrm{E}+04 \mathrm{~g} / \mathrm{ha} / \mathrm{yr}$}

$\mathrm{UEV}=1.05 \mathrm{E}+09 \mathrm{sej} / \mathrm{g}$

From field work

(LAGANIS; DEBELJAK, 2006)

19 Limestone, J

Annual energy flow $=\begin{aligned} & (\text { Annual consumption }) *(\text { Gibbs free energy of rock }) / \\ & (\text { property area })\end{aligned}$

Reference 
Annual consumption = Gibbs free energy of rock =

Annual energy flow = UEV =

\section{$2.93 \mathrm{E}+06 \mathrm{~g} / \mathrm{yr}$ \\ $6.11 \mathrm{E}+02 \mathrm{~J} / \mathrm{g}$ \\ 3.44E+07 J/ha/yr \\ $2.72 \mathrm{E}+06 \mathrm{sej} / \mathrm{J}$}

From field work

(BROWN; ULGIATI, 2004)

(BROWN; ULGIATI, 2004)

\section{Reference}

From field work

(DA SILVA et al., 2007)

(RÓTOLO et al., 2007)

21 Monensin, \$

Annual energy flow $=(\mathrm{AC}){ }^{*}(\% \mathrm{DM}) *(\mathrm{GE}) *(4,186 \mathrm{~J} / \mathrm{kcal}) /($ property area $)$

Annual consumption $(A C)=$

$8.19 \mathrm{E}+03 \mathrm{~kg} / \mathrm{yr}$

Dry matter of Tifton-85 hay $=$

Gross energy $(\mathrm{GE})=$

$\mathrm{kcal}$ to Joules $=$

Annual energy flow =

UEV $=$

\section{Reference}

Annual money flow $=(\mathrm{AC}){ }^{*}(\mathrm{USD} / \mathrm{kg}) /($ property area $)$

Annual consumption $(\mathrm{AC})=\quad 10.09 \mathrm{~kg} / \mathrm{yr}$

Purchase price $=\quad 6.01 \mathrm{USD} / \mathrm{kg}$

Annual money flow $=\quad 1.17 \mathrm{E}+00 \mathrm{USD} / \mathrm{ha} / \mathrm{yr}$

$\mathrm{UEV}=\quad 5.60 \mathrm{E}+12 \mathrm{sej} / \$$

22 Vaccine, $g$

Annual energy flow $=(A C) *($ quantity $\mathrm{ml} /$ dose $) *($ density $\mathrm{g} / \mathrm{ml}) /($ property area $)$ Annual consumption $(A C)=$ $\mathrm{ml}$ per dose $=$ 2.19E+03 dose/yr $2.18 \mathrm{ml} /$ dose Vaccine density $=$ Annual mass flow = $1.1 \mathrm{~g} / \mathrm{ml}$ 1.01E+02 g/ha/yr $\mathrm{UEV}=1.48 \mathrm{E}+10 \mathrm{sej} / \mathrm{g}$

From field work

From field work

(GIANNETTI et al., 2018)

\section{Reference}

From field work

From field work

From field work

(CASTELLINI et al., 2006)

23 Vermifuge, $g$

Reference


Annual mass flow $=(A C)^{\star}($ density $\mathrm{g} / \mathrm{ml}) /($ property area $)$

$\begin{array}{rrr}\text { Annual consumption }(A C)= & 1.46 \mathrm{E}+04 \mathrm{ml} / \mathrm{yr} & \text { From field work } \\ \text { Vermifuge density }= & 1.3 \mathrm{~g} / \mathrm{ml} & \text { From field work }\end{array}$

\section{Annual mass flow $=\quad 3.66 \mathrm{E}+02 \mathrm{~g} / \mathrm{ha} / \mathrm{yr}$}

$\mathrm{UEV}=1.48 \mathrm{E}+10 \mathrm{sej} / \mathrm{g}$

(CASTELLINI et al., 2006)

24 Nitrogen (N), g

\section{Reference}

Annual mass flow $=$ (Annual consumption) $/$ (property area)

Annual consumption $=4.93 \mathrm{E}+06 \mathrm{~g} / \mathrm{yr}$

From field work

Annual mass flow $=\quad 9.49 E+04 \mathrm{~g} / \mathrm{ha} / \mathrm{yr}$

$\mathrm{UEV}=2.40 \mathrm{E}+10 \mathrm{sej} / \mathrm{g}$

(PÉREZ-SOBA et al., 2019)

25 Potash $\left(\mathrm{K}_{2} \mathrm{O}\right), \mathrm{g}$

Reference

Annual mass flow $=$ (Annual consumption) $/$ (property area)

Annual consumption $=1.59 \mathrm{E}+06 \mathrm{~g} / \mathrm{yr}$

From field work

Annual mass flow $=\quad 3.05 E+04 \mathrm{~g} / \mathrm{ha} / \mathrm{yr}$

$\mathrm{UEV}=1.80 \mathrm{E}+09 \mathrm{sej} / \mathrm{g}$

(PÉREZ-SOBA et al., 2019)

26 Phosphorus $\left(\mathrm{P}_{2} \mathrm{O}_{5}\right), \mathrm{g}$

Annual mass flow $=$ (Annual consumption) $/$ (property area)

Annual consumption $=\quad 5.33 \mathrm{E}+05 \mathrm{~g} / \mathrm{yr}$

Reference

\section{Annual mass flow $=1.03 E+04 \mathrm{~g} / \mathrm{ha} / \mathrm{yr}$}

UEV $=2.20 \mathrm{E}+10 \mathrm{sej} / \mathrm{g} \quad$ (PÉREZ-SOBA et al., 2019)

27 Limestone, J

Reference

Annual energy flow $=($ Annual consumption $) *($ Gibbs free energy of rock $) /$

(property area)

Annual consumption $=1.05 \mathrm{E}+08 \mathrm{~g} / \mathrm{yr}$

From field work

Gibbs free energy of rock $=\quad 611 \mathrm{~J} / \mathrm{g}$

Annual energy flow $=\quad 1.24 \mathrm{E}+09 \mathrm{~J} / \mathrm{ha} / \mathrm{yr}$

$\mathrm{UEV}=2.72 \mathrm{E}+06 \mathrm{sej} / \mathrm{J}$

(BROWN; ULGIATI, 2004) 
28 Seeds, $g$

\section{Reference}

Annual mass flow $=$ (Annual consumption) $/$ (property area)

Annual consumption $=$

$1.58 \mathrm{E}+06 \mathrm{~g} / \mathrm{yr}$

From field work

Annual mass flow $=\quad 3.04 \mathrm{E}+04 \mathrm{~g} / \mathrm{ha} / \mathrm{yr}$

$\mathrm{UEV}=\quad 8.87 \mathrm{E}+08 \mathrm{sej} / \mathrm{g}$

(CASTELLINI et al., 2006)

\section{Services (S)}

29 Permanent labor, $\mathbf{J}$

\section{Reference}

Employee energy conversion $=($ No. of employees $){ }^{*}(\mathrm{kcal} /$ day $){ }^{*}(287$ days $/ \mathrm{yr}) *(4,186 \mathrm{~J} / \mathrm{kcal}) /($ property area $)$

No. of employees $=$ Energy per employee $=$ Annual energy flow =

Owner's energy conversion $=$

No. of owners $=$ Annual energy flow =

Total annual energy flow = UEV =

30 Temporary employment, $\mathbf{J}$

Annual energy flow Establishment P. Oats and ryegrass $=$ Establishment $\mathrm{P}$. Brachiaria $\mathrm{B}$. = Mainten. $P$. Oats and ryegrass = Mainten. $P$. without irrigation = No. of temporary work days $=$ Energy per employee = Total annual energy flow =
2 $2,500.00 \mathrm{kcal} / \mathrm{day}$

$1.16 \mathrm{E}+08 \mathrm{~J} / \mathrm{ha} / \mathrm{yr}$ $(2,500 \mathrm{kcal} /$ day $) *(365$ days / year $) *(4,186 \mathrm{~J} / \mathrm{kcal}) /$ (property area)

$\begin{array}{ll}7.35 \mathrm{E}+07 & \mathrm{~J} / \mathrm{ha} / \mathrm{yr} \\ 1.89 \mathrm{E}+08 & \mathrm{~J} / \mathrm{ha} / \mathrm{yr} \\ 7.56 \mathrm{E}+06 & \mathrm{sej} / \mathrm{J}\end{array}$

$($ Service days $/ \mathrm{yr}){ }^{*}(\mathrm{kcal} / \mathrm{day}){ }^{*}(4,186 \mathrm{~J} / \mathrm{kcal}) /$ (property area)

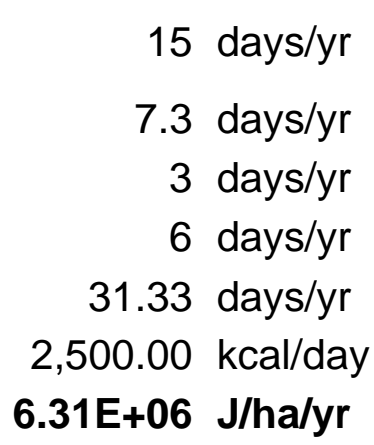

From field work

From field work

(BRANDT-WILLIAMS, 2002)

Reference

From field work 
31 Technical services, \$

Reference

Annual money flow $=($ Total cost of services $) /($ property area $)$

$$
\text { Accountant }=\quad 769.23 \mathrm{USD} / \mathrm{yr}
$$$$
\text { shearing }=\quad 895.24 \mathrm{USD} / \mathrm{yr}
$$

Veterinarian $=\quad 439.56 \mathrm{USD} / \mathrm{yr}$

Social charges $=\quad 5,076.92 \mathrm{USD} / \mathrm{yr}$

$$
\text { Tolls }=\quad 67.77 \mathrm{USD} / \mathrm{yr}
$$

Total cost of services $=\quad 76.92 \mathrm{USD} / \mathrm{yr}$

From field work

Annual money flow $=\quad 1.41 \mathrm{E}+02 \mathrm{USD} / \mathrm{ha} / \mathrm{yr}$

$\mathrm{UEV}=5.60 \mathrm{E}+12 \mathrm{sej} / \$$

(GIANNETTI et al., 2018)

32 Slaughter service, \$

Annual money flow $=($ Slaughter service cost $) /($ property area $)$

Slaughter service cost $=\quad 4,805.01 \mathrm{USD} / \mathrm{yr}$

Reference

Annual money flow $=\quad 9.24 \mathrm{E}+01 \mathrm{USD} / \mathrm{ha} / \mathrm{yr}$

$\mathrm{UEV}=5.60 \mathrm{E}+12 \mathrm{sej} / \$$

From field work

(GIANNETTI et al., 2018)

33 Depreciation of machinery and facilities, $\$$

Reference

Annual money flow $=$ (Total cost of depreciation) $/$ (property area)

Total cost of depreciation $=\quad 15,352.71 \mathrm{USD} / \mathrm{yr}$

From field work

Annual money flow $=\quad 2.95 \mathrm{E}+02 \mathrm{USD} / \mathrm{ha} / \mathrm{yr}$

$\mathrm{UEV}=5.60 \mathrm{E}+12 \mathrm{sej} / \$$

(GIANNETTI et al., 2018)

34 Maintenance of machinery and facilities, $\$$

Reference

Annual money flow $=($ Total cost of maintenance $) /($ property area $)$

Total cost of maintenance $=\quad 6,833.18 \mathrm{USD} / \mathrm{yr}$

Annual money flow $=1.31 \mathrm{E}+02 \mathrm{USD} / \mathrm{ha} / \mathrm{yr}$

$\mathrm{UEV}=5.60 \mathrm{E}+12 \mathrm{sej} / \$$

From field work

(GIANNETTI et al., 2018) 
Output

35 Lamb meat (Carcass)

Annual prod. in J. of lamb meat = $\mathrm{N}$. of lambs to be slaughtered $=$ Slaughter weight $=$ Total slaughtered weight $=$ Total slaughtered weight per ha $=$

Carcass yield $=$ Prod. Total lamb carcass $=$ Prod. Total lamb carcass per ha $=$ Energy in $100 \mathrm{~g}$ of meat $=$ Energy in $1 \mathrm{~kg}$ of meat = $\mathrm{kcal}$ to Joules $=$

Product in Joules of lamb meat

36 Pure-breeding sheep (by-product)

Annual prod. of pure-breeding $=(($ heads $/ \mathrm{yr}) *(\mathrm{~kg}$ per head $)) /($ property area $)$

No. of Lambs in maintenance $=$ Average weight $=$

Total $\mathrm{W}$ lambs in maintenance $=$

Annual mass flow =
$57.4 \mathrm{Head} / \mathrm{kg}$

$3,501.12 \mathrm{Kg} / \mathrm{yr}$

$6.73 \mathrm{E}+01 \mathrm{~kg} / \mathrm{ha} / \mathrm{yr}$

\section{Reference}

(Total slaughtered weight) * (Carcass yield \%) * (energy meat kcal/kg) * $(4,186 \mathrm{~J} / \mathrm{kcal})) /($ property area)

$$
\begin{array}{rl}
874.51 & \text { heads } / \mathrm{yr} \\
40 & \mathrm{~kg} / \mathrm{head} \\
34,980.47 & \mathrm{~kg} / \mathrm{yr} \\
672.7 & \mathrm{Kg} / \mathrm{ha} / \mathrm{yr}
\end{array}
$$

From field work

$48.2 \%$

From field work

$16,860.59 \mathrm{~kg} / \mathrm{yr}$

$324.24 \mathrm{Kg} / \mathrm{ha} / \mathrm{yr}$

$112 \mathrm{kcal} / 100 \mathrm{~g}$

$1,120 \mathrm{kcal} / 1 \mathrm{~kg}$

$4,186 \mathrm{~J} / \mathrm{kcal}$

\section{$1.52 \mathrm{E}+09 \mathrm{~J} / \mathrm{ha} / \mathrm{yr}$}

\section{Reference}

From field work

From field work 
Table 23 - Emergy tables with detailed calculations of flows of Intensive lamb finishing system (Feedlot)

\begin{tabular}{|c|c|c|c|c|c|c|c|c|c|}
\hline Note & Item & $\begin{array}{c}\text { Flow } \\
\text { (Unit/ha yr) }\end{array}$ & Unit & $\begin{array}{c}\text { UEV } \\
\text { (sej. Unity) }\end{array}$ & $\begin{array}{l}\text { Solar emergy } \\
\text { (E13 sej/ha yr) }\end{array}$ & $\begin{array}{c}\text { R flow } \\
\text { (sej/ha yr) }\end{array}$ & $\begin{array}{c}\mathrm{N} \text { flow } \\
\text { (sej/ha yr) }\end{array}$ & $\begin{array}{c}\% \\
\text { sej/sej }\end{array}$ & $\begin{array}{l}\text { Emdollar } \\
\text { Em\$/ha yr }\end{array}$ \\
\hline \multicolumn{10}{|c|}{ Renewable resources $(\mathrm{R})$} \\
\hline 1 & Sun & $1.80 \mathrm{E}+13$ & $J$ & $1.00 \mathrm{E}+00$ & 1.80 & 1.80 & - & 0.01 & 3.22 \\
\hline 2 & Rain & $3.48 \mathrm{E}+10$ & $\mathrm{~J}$ & $3.10 \mathrm{E}+04$ & 107.91 & 107.91 & - & 0.52 & 192.70 \\
\hline 3 & wind & 1.05E+09 & $J$ & $2.45 \mathrm{E}+03$ & 0.26 & 0.26 & - & 0.00 & 0.46 \\
\hline \multicolumn{10}{|c|}{ Non-renewable resources $(\mathrm{N})$} \\
\hline 4 & Net Topsoil Loss & $2.46 \mathrm{E}+10$ & $J$ & $1.24 \mathrm{E}+05$ & 30.55 & - & 30.55 & 0.15 & 54.55 \\
\hline 5 & Ground-water & $2.55 \mathrm{E}+09$ & $\mathrm{~J}$ & $2.55 \mathrm{E}+05$ & 64.96 & - & 64.96 & 0.31 & 115.99 \\
\hline \multicolumn{10}{|c|}{ Materials (M) } \\
\hline 6 & Fossil fuels & $4.00 \mathrm{E}+10$ & $J$ & $9.21 \mathrm{E}+04$ & 368.77 & - & 368.77 & 1.77 & 658.52 \\
\hline 7 & Electricity & $1.35 \mathrm{E}+10$ & $J$ & 1.47E+05 & 198.13 & 134.73 & 63.40 & 0.95 & 353.81 \\
\hline 8 & Steel & $2.20 \mathrm{E}+05$ & $g$ & 7.81E+09 & 171.79 & - & 171.79 & 0.83 & 306.77 \\
\hline 9 & wood & $9.00 \mathrm{E}+08$ & $\mathrm{~J}$ & $9.60 \mathrm{E}+03$ & 0.86 & 0.71 & 0.15 & 0.00 & 1.54 \\
\hline 10 & Brick & $1.05 \mathrm{E}+05$ & $g$ & $4.21 \mathrm{E}+08$ & 4.40 & - & 4.40 & 0.02 & 7.86 \\
\hline 11 & Lamb for finishing & $1.12 \mathrm{E}+07$ & $g$ & 8.64E+09 & $9,672.36$ & $1,880.31$ & $7,792.05$ & 46.55 & $17,272.07$ \\
\hline 12 & Sawdust & $3.62 E+10$ & $\mathrm{~J}$ & $9.60 \mathrm{E}+03$ & 34.72 & 28.61 & 6.11 & 0.17 & 62.00 \\
\hline 13 & Corn silage & $5.60 \mathrm{E}+06$ & $g$ & $1.62 \mathrm{E}+08$ & 90.65 & 21.85 & 68.81 & 0.44 & 161.88 \\
\hline 14 & Fresh barley & $1.53 \mathrm{E}+07$ & $g$ & $4.21 \mathrm{E}+08$ & 642.47 & 289.11 & 353.36 & 3.09 & $1,147.27$ \\
\hline 15 & Corn bran & 6.67E+06 & g & $5.79 \mathrm{E}+08$ & 386.43 & 91.97 & 294.46 & 1.86 & 690.06 \\
\hline 16 & Wheat Bran & $4.59 E+06$ & $g$ & $8.41 \mathrm{E}+08$ & 385.89 & 160.53 & 225.36 & 1.86 & 689.09 \\
\hline 17 & Soy meal & $4.98 \mathrm{E}+03$ & $\mathrm{~kg}$ & $2.98 \mathrm{E}+12$ & $1,485.45$ & 528.82 & 956.63 & 7.15 & $2,652.59$ \\
\hline 18 & Cotton bran & $3.96 \mathrm{E}+03$ & $\mathrm{~kg}$ & 4.13E+12 & $1,636.62$ & 277.57 & $1,359.05$ & 7.88 & $2,922.53$ \\
\hline 19 & Limestone & 8.92E+07 & J & $2.72 \mathrm{E}+06$ & 24.26 & - & 24.26 & 0.12 & 43.33 \\
\hline 20 & White salt & $1.25 \mathrm{E}+05$ & $g$ & $1.05 \mathrm{E}+09$ & 13.09 & - & 13.09 & 0.06 & 23.37 \\
\hline 21 & Mineral Premix & $3.75 \mathrm{E}+05$ & $g$ & $1.48 \mathrm{E}+10$ & 555.62 & - & 555.62 & 2.67 & 992.18 \\
\hline 22 & Vaccine & $9.45 \mathrm{E}+02$ & g & $1.48 \mathrm{E}+10$ & 1.40 & - & 1.40 & 0.01 & 2.50 \\
\hline 23 & Vermifuge & $1.56 \mathrm{E}+03$ & g & $1.48 \mathrm{E}+10$ & 2.31 & - & 2.31 & 0.01 & 4.12 \\
\hline 24 & Organic Modifier & $2.43 \mathrm{E}+03$ & $g$ & $1.48 \mathrm{E}+10$ & 3.60 & - & 3.60 & 0.02 & 6.42 \\
\hline
\end{tabular}




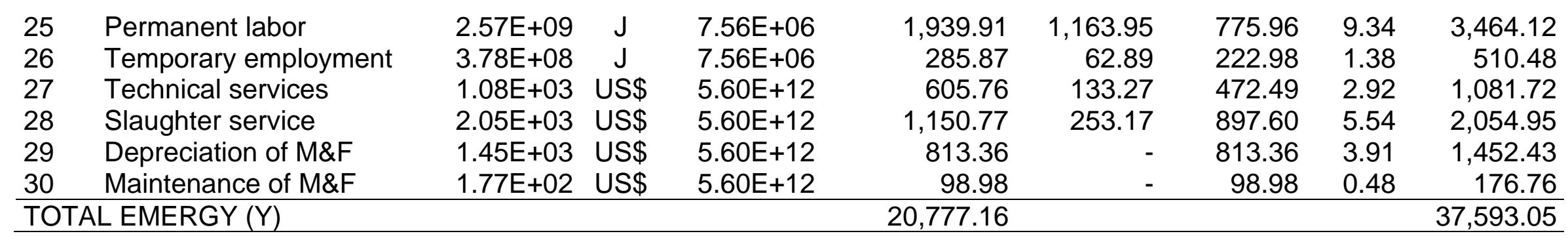

OUTPUTS (Y) and UEVs (calculated)

\begin{tabular}{|c|c|c|c|c|c|}
\hline Note & Item & Ep & Unit & UEV & Unit \\
\hline \multicolumn{6}{|c|}{ With services } \\
\hline 31.1 & Lamb meat (live weight) & $1.68 \mathrm{E}+04$ & $\mathrm{~kg}$ & $1.23 E+13$ & $\mathrm{sej} / \mathrm{kg}$ \\
\hline 31.2 & Lamb meat (carcass weight) & $3.71 E+10$ & $J$ & $5.60 \mathrm{E}+06$ & sej/J \\
\hline 31.3 & Lamb meat (carcass weight) & $7.91 E+03$ & $\mathrm{~kg}$ & $2.63 E+13$ & $\mathrm{sej} / \mathrm{kg}$ \\
\hline \multicolumn{6}{|c|}{ By-product } \\
\hline 32 & Sheep manure for fertilizer & $2.81 E+04$ & $\mathrm{~kg}$ & $7.41 \mathrm{E}+12$ & $\mathrm{sej} / \mathrm{kg}$ \\
\hline \multicolumn{6}{|c|}{ Without services } \\
\hline 31.1 & Lamb meat (live weight) & $1.68 \mathrm{E}+04$ & $\mathrm{~kg}$ & $9.44 \mathrm{E}+12$ & $\mathrm{sej} / \mathrm{kg}$ \\
\hline 31.2 & Lamb meat (carcass weight) & $3.71 E+10$ & $\mathrm{~J}$ & $4.28 \mathrm{E}+06$ & sej/J \\
\hline 31.3 & Lamb meat (carcass weight) & $3.96 \mathrm{E}+04$ & $\mathrm{~kg}$ & $4.02 \mathrm{E}+12$ & $\mathrm{sej} / \mathrm{kg}$ \\
\hline \multicolumn{6}{|c|}{ By-product } \\
\hline 32 & Sheep manure for fertilizer & $2.81 E+04$ & $\mathrm{~kg}$ & $5.66 \mathrm{E}+12$ & sej/kg \\
\hline
\end{tabular}


Table 24 - Detailed calculations for the emergy flows of Intensive lamb finishing system (Feedlot)

\begin{tabular}{|c|c|c|c|}
\hline Note & Item & Value & Reference \\
\hline \multirow[t]{8}{*}{1.} & \multicolumn{3}{|l|}{ Sun insolation, $\mathbf{J}$} \\
\hline & \multicolumn{2}{|c|}{ 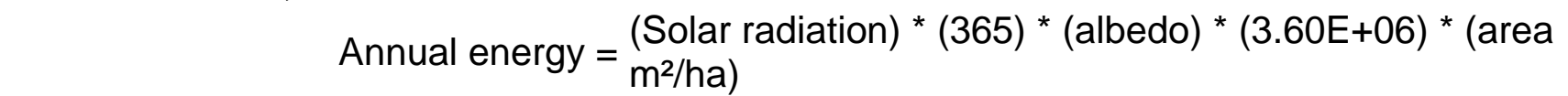 } & (Odum, 1996) \\
\hline & Solar radiation $=$ & $6.86 \mathrm{kWh} / \mathrm{m}^{2} / \mathrm{day}$ & \multirow{2}{*}{$\begin{array}{l}\text { (SPARK, 2020) } \\
\text { NASA eosweb } \\
\text { (https://eosweb.larc.nasa.gov/sse/) }\end{array}$} \\
\hline & Albedo $=$ & $20 \% 1-20 \%$ & \\
\hline & Joules to $\mathrm{kWh}=$ & $3.60 \mathrm{E}+06 \mathrm{~J} / \mathrm{kWh}$ & \multirow{4}{*}{ Definition } \\
\hline & Area $=$ & $1.00 \mathrm{E}+04 \mathrm{~m}^{2}$ & \\
\hline & UEV $=$ & $1 \mathrm{sej} \cdot \mathrm{J}^{-1}$ & \\
\hline & Annual energy = & $1.80 \mathrm{E}+13 \mathrm{~J} / \mathrm{ha} / \mathrm{yr}$ & \\
\hline \multirow[t]{9}{*}{2.} & \multicolumn{2}{|l|}{ Rain chemical potential energy, J } & Reference \\
\hline & \multicolumn{2}{|c|}{ Annual energy $=\begin{array}{l}(\text { precipitation }) *(\text { Gibbs }) *(\text { water density }) * \\
(\text { Evapotranspiration rate } / 100) *\left(\text { area } \mathrm{m}^{2} / \text { ha }\right)\end{array}$} & (Brown and Bardi, 2001) \\
\hline & Precipitation $=$ & $1.178 \mathrm{~m}^{3} / \mathrm{m}^{2} / \mathrm{yr}$ & (SPARK, 2020) \\
\hline & Gibbs free energy = & $4,940.00 \mathrm{~J} / \mathrm{kg}$ & (ODUM, 1996) \\
\hline & water density = & $997 \mathrm{~kg} / \mathrm{m}^{3}$ & \\
\hline & Evapotranspiration rate $=$ & $60 \%$ & \\
\hline & Area $=$ & $1.00 \mathrm{E}+04 \mathrm{~m}^{2}$ & \\
\hline & Annual energy = & $3.48 \mathrm{E}+10 \mathrm{~J} / \mathrm{ha} / \mathrm{yr}$ & \\
\hline & UEV = & $3.10 \mathrm{E}+04 \mathrm{sej} / \mathrm{J}$ & $\begin{array}{l}\text { (ODUM; BROWN; BRANDT-WILLIAMS, } \\
\text { 2000) }\end{array}$ \\
\hline
\end{tabular}

\section{Wind, $\mathbf{J}$}

$$
\begin{aligned}
& \text { Annual energy }=\begin{array}{l}
\text { (air density) } \left.\left.{ }^{*} \text { (geotropic wind }\right)^{\wedge} 3 \text { * (drag coefficient }\right) \text { * } \\
\left(\text { area } \mathrm{m}^{2} / \mathrm{ha}\right) * \\
\text { * }
\end{array} \\
& \text { Density of Air }=\quad 1.28 \mathrm{~kg} / \mathrm{m}^{3}
\end{aligned}
$$

Avg. annual wind velocity $=$
(Brown and Bardi, 2001)

Observed winds are about 0.6 of geostrophic wind 


\section{Geostrophic wind = \\ Drag coefficient $=$ \\ Annual energy =$$
\mathrm{UEV}=2.45 \mathrm{E}+03 \mathrm{sej} / \mathrm{J}
$$

\section{Topsoil losses, $\mathrm{J}$}

$$
\begin{aligned}
& \text { Annual energy = } \\
& \text { Feedlot area } 1= \\
& \text { Feedlot area } 2=
\end{aligned}
$$

Sheep handling pen area $=$

Office area $=$

Concentrate plant $=$

Total area of buildings $=$

Soil layer $=$

Organic matter (O.M.) =

Annual energy =

Total energy topsoil losses =

$\left(\right.$ Area in $\left.\mathrm{m}^{2}\right) *($ O.M. $){ }^{*}\left(0.0012 \mathrm{~kg} / \mathrm{cm}^{3}\right) *\left(1 \mathrm{E}+06 \mathrm{~cm}^{3} / \mathrm{m}^{3}\right)$ *

$(4,186 \mathrm{~J} / \mathrm{kcal}) *(5,400 \mathrm{kcal}) /$ (property area) $/ 30 \mathrm{yr}$

$$
\begin{gathered}
697 \mathrm{~m}^{2} \\
574 \mathrm{~m}^{2} \\
108 \mathrm{~m}^{2} \\
225 \mathrm{~m}^{2} \\
99 \mathrm{~m}^{2} \\
1,703.00 \mathrm{~m}^{2} \\
0.2 \mathrm{~m} \\
0.04 \mathrm{~kg} \mathrm{O} \text { OM./kg soil } \\
2.11 \mathrm{E}+09 \mathrm{~J} / \mathrm{ha} / \mathrm{yr} \\
2.46 \mathrm{E}+09 \mathrm{~J} / \mathrm{ha} / \mathrm{yr}
\end{gathered}
$$

$$
\mathrm{UEV}=1.24 \mathrm{E}+05 \mathrm{sej} / \mathrm{J}
$$

5. Ground-water, J

$$
\begin{array}{rc}
\text { Annual energy }=\begin{array}{c}
\text { (Total water consumption } \\
\text { density } \left.\mathrm{kg} / \mathrm{m}^{3}\right) /(\text { prope }
\end{array} \\
\text { Fattening lambs }= & 2.56 \mathrm{E}+06 \mathrm{~L} / \mathrm{yr} \\
\text { ater consumption }= & 2,555.00 \mathrm{~m}^{3} / \mathrm{yr} \\
\text { Water density }= & 9.97 \mathrm{E}+02 \mathrm{~kg} / \mathrm{m}^{3} \\
\text { Energy in water }= & 5.00 \mathrm{E}+03 \mathrm{~J} / \mathrm{kg} \\
\text { Annual energy }= & \mathbf{2 . 5 5 E + 0 9 ~ J / h a / y r}
\end{array}
$$

(SPARK, 2020)

(Miller, 1964 quoted by Kraus, 1972)

(ODUM; BROWN; BRANDT-WILLIAMS, 2000)

\section{Reference}

(Agostinho et al., 2019)

From field work

(EPAMIG, 1992)

(EPAMIG, 1992)

(ODUM; BROWN; BRANDT-WILLIAMS, 2000)

\section{Reference}

(Ortega et al., 2005)

3.5 liters of water/ head/day (TEDESCHI; GENE, 2016) 


\section{Materials (M)}

6. Fossil fuels, $\mathbf{J}$ (Includes: diesel, gasoline and lubricants)

\section{Reference}

Annual energy $=(\mathrm{L} / \mathrm{yr}) *(0,84 \mathrm{~kg} / \mathrm{L}) *(11.400 \mathrm{kcal} / \mathrm{kg}) *(4.186 \mathrm{~J} / \mathrm{kcal}) /$ (property area)

(Odum, 1996)

Farm activities $=\quad 240 \mathrm{~L} / \mathrm{yr}$

Tractor $=\quad 1,800.00 \mathrm{~L} / \mathrm{yr}$

Transport $=\quad 2,954.40 \mathrm{~L} / \mathrm{yr}$

Total diesel consumption $=\quad 4,994.40 \mathrm{~L} / \mathrm{yr}$

Density $=\quad 0.84 \mathrm{~kg} / \mathrm{L}$

From field work

fuel energy $=\quad 11,400.00 \mathrm{kcal} / \mathrm{kg}$

(ANP, 2014)

Annual energy $=4.00 \mathrm{E}+10 \mathrm{~J} / \mathrm{ha} / \mathrm{yr}$

$\mathrm{UEV}=\quad 9.21 \mathrm{E}+04 \mathrm{sej} / \mathrm{J}$

(BASTIANONI et al., 2005)

7. Electricity, J

Annual energy $=$ Energy flow $=(\mathrm{kWh} /$ year $) *(3.6 \mathrm{E}+06 \mathrm{~J} / \mathrm{kWh}) /$ (property

Reference

\begin{tabular}{|c|c|}
\hline \multicolumn{2}{|c|}{ Annual energy $=\begin{array}{l}\text { Energy flow }=(\mathrm{kWh} / \mathrm{ye} \\
\text { area })\end{array}$} \\
\hline Electric power consumption $=$ & $18,720.00 \mathrm{kWh} / \mathrm{yr}$ \\
\hline Joules per $\mathrm{kWh}=$ & $3.60 \mathrm{E}+06 \mathrm{~J} / \mathrm{kWh}$ \\
\hline Annual energy $=$ & $1.35 \mathrm{E}+10 \mathrm{~J} / \mathrm{ha} / \mathrm{yr}$ \\
\hline UEV $=$ & 1.47E+05 sej/J \\
\hline
\end{tabular}

From field work

(GIANNETTI et al., 2015)

8. Steel, $\mathbf{g}$

Annual mass flow $=(\mathrm{kg}$ of steel) $/$ (lifetime) $/$ (property area)

Mass of equipment $=$

Mass of fence wire $=$

$31,730.00 \mathrm{~kg}$

$216 \mathrm{~kg}$

Mass of facilitiess $=$

$1,048.10 \mathrm{~kg}$

Total mass of steel $=\quad 3.30 \mathrm{E}+07 \mathrm{~g}$

Lifetime of material $(\mathrm{LM})=\quad 30 \mathrm{yr}$

From field work 
Annual mass flow $=2.20 \mathrm{E}+05 \mathrm{~g} / \mathrm{ha} / \mathrm{yr}$

$\mathrm{UEV}=\quad 7.81 \mathrm{E}+09 \mathrm{sej} / \mathrm{g}$

(BROWN; ULGIATI, 2004);

9. Wood, J

$$
\text { Annual energy }=\begin{aligned}
& ((\text { wood } \mathrm{g}) *(3.6 \mathrm{kcal} / \mathrm{g}) \\
& (\text { property area })
\end{aligned}
$$

\section{Reference}

(Odum, 1996)

From field work

Total mass of wood $=4.48 \mathrm{E}+06 \mathrm{~g}$

(Odum, 1996)

wood energy =

$3.6 \mathrm{kcal} / \mathrm{g}$

$4,186 \mathrm{~J} / \mathrm{kcal}$

$15 \mathrm{yr}$

Lifetime of material $(\mathrm{LM})=$

Energy flow $(\mathrm{J})=\quad 9.00 \mathrm{E}+08 \mathrm{~J} / \mathrm{ha} / \mathrm{yr}$

$\mathrm{UEV}=9.60 \mathrm{E}+03 \mathrm{sej} / \mathrm{J}$

(DE OLIVEIRA et al., 2018)

10. Brick, g

Annual mass flow $=($ Brick g) $/($ lifetime $) /($ property area $)$

Total mass of brick $=1.57 \mathrm{E}+07 \mathrm{~g}$

Reference

From field work

Lifetime of material $(\mathrm{LM})=$

$30 \mathrm{yr}$

Annual mass flow $=1.05 \mathrm{E}+05 \mathrm{~g} / \mathrm{ha} / \mathrm{yr}$

$\mathrm{UEV}=\quad 4.21 \mathrm{E}+08 \mathrm{sej} / \mathrm{g}$

(PULSELLI et al., 2007)

11. Lamb for finishing, $\mathbf{g}$

Annual mass flow $=(($ Lamb LW kg $) *($ heads $) *(1,000 \mathrm{~g} / \mathrm{kg})) /($ property area $)$

Lamb LW of entry to the system =

No. of lambs entering the system $=$

Total live weight in the year $=$

Annual mass flow =

UEV and \%R Estimation for weaned

lambs for finishing

$$
E U V=1.44 \mathrm{E}+10 \mathrm{sej} / \mathrm{g}
$$

LW of lamb obtained by Haden (2002) =
$28 \mathrm{~kg}$

2,000 Heads

$5.60 \mathrm{E}+07 \mathrm{~g} / \mathrm{yr}$

1.12E+07 g/ha/yr

$46.7 \mathrm{~kg} / \mathrm{head}$

\section{Reference}

From field work

From field work

From field work

(HADEN, 2002)

(HADEN, 2002) 
(UEV of LW lamb obtained by

Haden (2002)) / ((LW lamb obtained Equation 1.1.

Estimated UEV per g of lamb $=\quad 3.08 \mathrm{E}+05 \mathrm{sej} / \mathrm{g}$ by Haden $\left.(2002))^{*}(1,000 \mathrm{~g} / \mathrm{kg})\right)$

$(1.44 \mathrm{E}+10 \mathrm{sej} / \mathrm{g}) /((46.7 \mathrm{~kg} / \mathrm{head})$ * Estimated 1.1

$(1,000 \mathrm{~g} / \mathrm{kg}))$

(Estimated UEV per g of lamb

UEV used in this study for lambs with a $\mathrm{LW}$ of $28 \mathrm{~kg}=$

\subsection{E+09 sej/g}

according to Haden (2002)) * (LW of Equation 1.2.

the weaned lamb at entry into the

system) * $(1,000 \mathrm{~g} / \mathrm{kg})$

$\%$ Renewability per $\mathrm{g}$ of lamb $=$

$\%$ Renewability (estimated)
$19.44 \%$

((Estimated UEV of LW lamb) / (UEV

of LW lamb obtained by Haden

$14.58 \%$
$(3.08 \mathrm{E}+05 \mathrm{sej} / \mathrm{g}) *(28.00 \mathrm{~kg} / \mathrm{head})$ $(1,000 \mathrm{~g} / \mathrm{kg})$

Estimated 1.2.

(HADEN, 2002)

Equation 2. by Haden (2002))

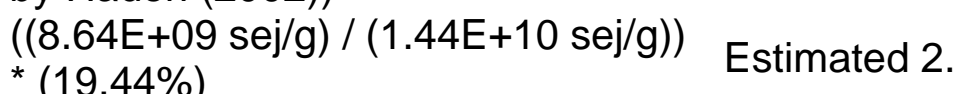

12. Sawdust, J

$$
\begin{array}{rc}
\mathrm{g} \text { of sawdust used per cycle }= & 3.00 \mathrm{E}+06 \mathrm{~g} / \text { cycle } \\
\text { sawdust used in the year }= & 1.20 \mathrm{E}+07 \mathrm{~g} / \mathrm{yr} \\
\text { Energy in the sawdust } & 3.6 \mathrm{kcal} / \mathrm{g} \\
\mathrm{kcal} \text { to Joules }= & 4,186 \mathrm{~J} / \mathrm{kcal} \\
\text { Annual energy flow }= & 3.62 \mathrm{E}+10 \mathrm{~J} / \mathrm{ha} / \mathrm{ano} \\
\text { UEV }= & 9.60 \mathrm{E}+03 \mathrm{sej} / \mathrm{J}
\end{array}
$$$$
\text { ((g of sawdust used per cycle) * (number of cycles pe }
$$$$
\text { Annual energy flow } \left.=\text { year }){ }^{*}(\mathrm{kcal} \text { in the sawdust }) *(4186 \mathrm{~J} / \mathrm{kcal})\right) /(\text { property }
$$

\section{Corn silage, $g$}

Annual mass flow $=($ Annual consumption $) /($ property area $)$

\section{Reference}

We were used the equation proposed by Odum (1996) to calculate the wood energy flow

From field work

(Odum, 1996)

(DE OLIVEIRA et al., 2018)

\section{Reference}


Annual consumption $=2.80 \mathrm{E}+07 \mathrm{~g} / \mathrm{yr}$

Annual mass flow $=\quad 5.60 \mathrm{E}+06 \mathrm{~g} / \mathrm{ha} / \mathrm{yr}$

$\mathrm{UEV}=1.62 \mathrm{E}+08 \mathrm{sej} / \mathrm{g}$

14. Fresh barley, $\mathrm{g}$

Annual mass flow $=($ Annual consumption $) /$ (property area $)$

Annual consumption $=\quad 7.63 \mathrm{E}+07 \mathrm{~g} / \mathrm{yr}$

Annual mass flow $=1.53 \mathrm{E}+07 \mathrm{~g} / \mathrm{ha} / \mathrm{yr}$

$\mathrm{UEV}=4.21 \mathrm{E}+08 \mathrm{sej} / \mathrm{g}$

15. Corn bran, $\mathrm{g}$

Annual mass flow $=($ Annual consumption $) /$ (property area $)$

Annual consumption $=3.34 \mathrm{E}+07 \mathrm{~g} / \mathrm{yr}$

Annual mass flow $=6.67 \mathrm{E}+06 \mathrm{~g} / \mathrm{ha} / \mathrm{yr}$

$\mathrm{UEV}=5.79 \mathrm{E}+08 \mathrm{sej} / \mathrm{g}$

16. Wheat Bran, $g$

Annual mass flow $=($ Annual consumption) $/$ (property area)

Annual consumption $=2.29 \mathrm{E}+07 \mathrm{~g} / \mathrm{yr}$

Annual mass flow $=\quad 4.59 \mathrm{E}+06 \mathrm{~g} / \mathrm{ha} / \mathrm{yr}$

$\mathrm{UEV}=\quad 8.41 \mathrm{E}+08 \mathrm{sej} / \mathrm{g}$

17. Soy meal, $\mathbf{k g}$

Annual mass flow $=($ Annual consumption $) /$ (property area $)$

Annual consumption $=2.49 \mathrm{E}+07 \mathrm{~kg} / \mathrm{yr}$

Annual mass flow $=\quad 4.98 \mathrm{E}+03 \mathrm{~kg} / \mathrm{ha} / \mathrm{yr}$

$\mathrm{UEV}=2.98 \mathrm{E}+12 \mathrm{sej} / \mathrm{kg}$

18. Cotton bran, $\mathrm{kg}$

Annual mass flow $=($ Annual consumption) $/$ (property area)

Annual consumption $=1.98 \mathrm{E}+04 \mathrm{~kg} / \mathrm{yr}$
From field work

(YUN et al., 2019)

Reference

From field work

(CASTELLINI et al., 2006)

\section{Reference}

From field work

(YUN et al., 2019)

\section{Reference}

From field work

(YUN et al., 2019)

\section{Reference}

From field work

(CAVALETT; ORTEGA, 2009)

\section{Reference}

From field work 
Annual mass flow $=\quad 3.96 \mathrm{E}+03 \mathrm{~kg} / \mathrm{ha} / \mathrm{yr}$

$\mathrm{UEV}=\quad 4.13 \mathrm{E}+12 \mathrm{sej} / \mathrm{kg}$

(TAKAHASHI; ORTEGA, 2010)

19. Limestone, J

Annual energy flow $=$ (Annual consumption) * (Gibbs free energy of rock) $/$

Reference

Annual consumption $=7.30 \mathrm{E}+05 \mathrm{~g} / \mathrm{yr}$

From field work

Gibbs free energy of rock $=\quad 6.11 \mathrm{E}+02 \mathrm{~J} / \mathrm{g}$

(BROWN; ULGIATI, 2004)

Annual energy flow $=\quad 8.92 \mathrm{E}+07 \mathrm{~J} / \mathrm{ha} / \mathrm{yr}$

$\mathrm{UEV}=2.72 \mathrm{E}+06 \mathrm{sej} / \mathrm{J}$

(BROWN; ULGIATI, 2004)

20. White salt, $g$

Annual mass flow $=($ Annual consumption $) /$ (property area $)$

Annual consumption $=\quad 6.26 \mathrm{E}+05 \mathrm{~g} / \mathrm{yr}$

Reference

Annual mass flow $=1.25 \mathrm{E}+05 \mathrm{~g} / \mathrm{ha} / \mathrm{yr}$

UEV $=1.05 \mathrm{E}+09 \mathrm{sej} / \mathrm{g}$

From field work

21. Mineral Premix, $\mathbf{g}$

(LAGANIS; DEBELJAK, 2006)

Annual mass flow $=($ Annual consumption $) /$ (property area $)$

Annual consumption $=1.88 \mathrm{E}+06 \mathrm{~g} / \mathrm{yr}$

Reference

Annual mass flow $=\quad 3.75 \mathrm{E}+05 \mathrm{~g} / \mathrm{ha} / \mathrm{yr}$

$\mathrm{UEV}=1.48 \mathrm{E}+10 \mathrm{sej} / \mathrm{g}$

From field work

(CASTELLINI et al., 2006)

22. Vaccine, $\mathbf{g}$

Annual energy flow $=(A C){ }^{*}$ (quantity $\mathrm{ml} /$ dose $){ }^{*}($ density $\mathrm{g} / \mathrm{ml}) /($ property area $)$

Annual consumption $(\mathrm{AC})=1.97 \mathrm{E}+03 \mathrm{dose} / \mathrm{yr}$

\section{Reference}

From field work

$\mathrm{ml}$ per dose $=\quad 2.18 \mathrm{ml} /$ dose

From field work

Vaccine density $=\quad 1.1 \mathrm{~g} / \mathrm{ml}$

From field work

Annual mass flow $=\quad 9.45 E+02 \mathrm{~g} / \mathrm{ha} / \mathrm{yr}$

$\mathrm{UEV}=1.48 \mathrm{E}+10 \mathrm{sej} / \mathrm{g}$

(CASTELLINI et al., 2006)

23. Vermifuge, $g$

Reference 
Annual mass flow $=(A C)^{*}($ density $\mathrm{g} / \mathrm{ml}) /($ property area $)$

Annual consumption $(\mathrm{AC})=6.00 \mathrm{E}+03 \mathrm{ml} / \mathrm{yr}$

From field work

Vermifuge density $=\quad 1.3 \mathrm{~g} / \mathrm{ml}$

From field work

Annual mass flow $=1.56 \mathrm{E}+03 \mathrm{~g} / \mathrm{ha} / \mathrm{yr}$

$\mathrm{UEV}=1.48 \mathrm{E}+10 \mathrm{sej} / \mathrm{g}$

(CASTELLINI et al., 2006)

24. Organic modifier, $\mathbf{g}$

Annual mass flow $=($ Annual consumption $) /$ (property area $)$

Annual consumption $=9.35 \mathrm{E}+03 \mathrm{ml} / \mathrm{yr}$

Reference

$\begin{array}{rc}\text { Organic modifier density }= & 1.3 \mathrm{~g} / \mathrm{ml} \\ \text { Annual mass flow = } & \mathbf{2 . 4 3 E + 0 3 ~ g / h a / y ~}\end{array}$

From field work

From field work

$\mathrm{UEV}=1.48 \mathrm{E}+10 \mathrm{sej} / \mathrm{g}$

(CASTELLINI et al., 2006)

\section{Services (S)}

25. Permanent labor, $\mathbf{J}$

Reference

Employee energy conversion $=($ No. of employees $){ }^{*}(\mathrm{kcal} /$ day $){ }^{*}(287$ days $/ \mathrm{yr}){ }^{*}(4,186 \mathrm{~J} / \mathrm{kcal}) /($ property area $)$

No. of employees $=$

3

From field work

Energy per employee $=\quad 2,500.00 \mathrm{kcal} /$ day

Annual energy flow $=1.80 \mathrm{E}+09 \mathrm{~J} / \mathrm{ha} / \mathrm{yr}$ Owner's energy conversion $=\begin{aligned} & (2,500 \mathrm{kcal} / \text { day }) *(365 \text { days } / \text { year }) *(4,186 \mathrm{~J} / \mathrm{kcal}) / \\ & (\text { property area })\end{aligned}$

No. of owners $=\quad 1$

Annual energy flow $=7.64 \mathrm{E}+08 \mathrm{~J} / \mathrm{ha} / \mathrm{yr}$

Total annual energy flow $=2.57 \mathrm{E}+09 \mathrm{~J} / \mathrm{ha} / \mathrm{yr}$

$\mathrm{UEV}=7.56 \mathrm{E}+06 \mathrm{sej} / \mathrm{J}$

From field work

(BRANDT-WILLIAMS, 2002)

26. Temporary employment, $\mathrm{J}$

Annual energy flow $=$ (Service days $/ \mathrm{yr}){ }^{*}(\mathrm{kcal} /$ day $){ }^{*}(4,186 \mathrm{~J} / \mathrm{kcal}) /($ property

Reference

temporary worker $=$

180 days/yr 
Driver. $=\quad 16$ hours $/ y r$

No. of temporary work days $=\quad 180.67$ days $/ \mathrm{yr}$

Energy per employee $=\quad 2,500.00 \mathrm{kcal} /$ day

Total annual energy flow $=\quad 3.78 \mathrm{E}+08 \mathrm{~J} / \mathrm{ha} / \mathrm{yr}$

$\mathrm{UEV}=7.56 \mathrm{E}+06 \mathrm{sej} / \mathrm{J}$

27. Technical services, $\$$

Annual money flow $=($ Total cost of services $) /$ property area $)$

Social charges $=\quad 2,901.10 \mathrm{USD} / \mathrm{yr}$

Veterinarian $=\quad 549.45 \mathrm{USD} / \mathrm{yr}$

Accountant $=\quad 659.34 \mathrm{USD} / \mathrm{yr}$

Transport services expenses $=\quad$ 1,298.69 USD/yr

Total cost of services $=\quad 293.04 \mathrm{USD} / \mathrm{yr}$

Annual money flow $=1.08 \mathrm{E}+03 \mathrm{USD} / \mathrm{ha} / \mathrm{yr}$

$\mathrm{UEV}=5.60 \mathrm{E}+12 \mathrm{sej} / \$$

28. Slaughter service, $\$$

Annual money flow $=($ Slaughter service cost $) /($ property area $)$

Slaughter service cost $=\quad 10,274.73 \mathrm{USD} / \mathrm{yr}$

Annual money flow $=2.05 E+03 \mathrm{USD} / \mathrm{ha} / \mathrm{yr}$

$\mathrm{UEV}=5.60 \mathrm{E}+12 \mathrm{sej} / \$$

29. Depreciation of machinery and facilities, $\$$

Annual money flow $=($ Total cost of depreciation $) /($ property area $)$

Total cost of depreciation $=\quad 7,262.13 \mathrm{USD} / \mathrm{yr}$

Annual money flow $=1.45 \mathrm{E}+03 \mathrm{USD} / \mathrm{ha} / \mathrm{yr}$

$\mathrm{UEV}=\quad 5.60 \mathrm{E}+12 \mathrm{sej} / \$$

30. Maintenance of machinery and facilities, $\$$

Annual money flow $=($ Total cost of maintenance $) /($ property area $)$

Total cost of maintenance $=\quad 883.78 \mathrm{USD} / \mathrm{yr}$
From field work

(BRANDT-WILLIAMS, 2002)

From field work

(GIANNETTI et al., 2018)

\section{Reference}

From field work

(GIANNETTI et al., 2018)

\section{Reference}

From field work

(GIANNETTI et al., 2018)

\section{Reference}

From field work 


\section{Annual money flow $=\quad 1.77 \mathrm{E}+02 \mathrm{USD} / \mathrm{ha} / \mathrm{yr}$}

$\mathrm{UEV}=5.60 \mathrm{E}+12 \mathrm{sej} / \$ \quad$ (GIANNETTI et al., 2018)

\section{Output}

31. Lamb meat (Carcass)

\section{Reference}

Annual prod. in Joules of lamb ((Total slaughtered weight) * (Carcass yield \%) * (energy meat kcal/kg) * $(4,186 \mathrm{~J} / \mathrm{kcal})) /($ property meat $=$ area $)$

Number of lambs to be slaughtered

$1,870.00$ heads/yr

Slaughter weight $=$

Total slaughtered weight $=$

Total slaughtered weight per ha $=$

Carcass yield $=$

Prod. Total lamb carcass $=$

Prod. Total lamb carcass per ha $=$

Energy in $100 \mathrm{~g}$ of meat $=$

Energy in $1 \mathrm{~kg}$ of meat $=$

kcal to Joules =

Product in Joules of lamb meat

$45 \mathrm{~kg} / \mathrm{head}$

$84,150.00 \mathrm{~kg} / \mathrm{yr}$

$16,830.00 \mathrm{Kg} / \mathrm{ha} / \mathrm{yr}$

$47 \%$

$39,550.50 \mathrm{~kg} / \mathrm{yr}$

$7,910.10 \mathrm{Kg} / \mathrm{ha} / \mathrm{yr}$

$112 \mathrm{kcal} / 100 \mathrm{~g}$

$1,120 \mathrm{kcal} / 1 \mathrm{~kg}$

$4,186 \mathrm{~J} / \mathrm{kcal}$

3.71E+10 J/ha/yr
From field work

From field work

From field work

From field work

\section{Reference}

(kg of manure per cycle) * (number of cycles per year) / (property area)

$35,062.50 \mathrm{~kg}$

From field work

From field work
$1.40 \mathrm{E}+05 \mathrm{~kg} / \mathrm{yr}$

2.81E+04 kg/ha/yr 
Table 25 - Emergy tables with detailed calculations of flows of Semi-intensive sheep farming system with lamb finishing (Semiintensive)

\begin{tabular}{|c|c|c|c|c|c|c|c|c|c|}
\hline Note & Item & $\begin{array}{c}\text { Flow } \\
\text { (Unit/ha yr) }\end{array}$ & Unit & $\begin{array}{c}\text { UEV } \\
\text { (sej.Unity) }\end{array}$ & $\begin{array}{l}\text { Solar emergy } \\
\text { (E13 sej/ha yr) }\end{array}$ & $\begin{array}{c}\text { R flow } \\
\text { (sej/ha yr) }\end{array}$ & $\begin{array}{l}\mathrm{N} \text { flow } \\
\text { (sej/ha yr) }\end{array}$ & $\begin{array}{c}\% \\
\text { sej/sej }\end{array}$ & $\begin{array}{l}\text { Emdollar } \\
\text { Em\$/ha yr }\end{array}$ \\
\hline \multicolumn{10}{|c|}{ Renewable resources $(\mathrm{R})$} \\
\hline 1 & Sun & $1.26 \mathrm{E}+13$ & J & $1.00 \mathrm{E}+00$ & 1.26 & 1.26 & - & 0.10 & 2.25 \\
\hline 2 & Rain & $5.03 E+10$ & J & $3.10 \mathrm{E}+04$ & 155.92 & 155.92 & - & 11.98 & 278.42 \\
\hline 3 & wind & $1.48 \mathrm{E}+09$ & $\mathrm{~J}$ & $2.45 \mathrm{E}+03$ & 0.26 & 0.26 & - & 0.03 & 0.65 \\
\hline \multicolumn{10}{|c|}{ Non-renewable resources $(\mathrm{N})$} \\
\hline 4 & Net Topsoil Loss & 2.93E+09 & J & $1.24 \mathrm{E}+05$ & 36.35 & - & 36.35 & 2.79 & 64.92 \\
\hline 5 & Ground-water & 4.47E+07 & $\mathrm{J}$ & $2.55 \mathrm{E}+05$ & 1.14 & - & 1.14 & 0.09 & 2.03 \\
\hline \multicolumn{10}{|c|}{ Materials (M) } \\
\hline 6 & Fossil fuels & $7.40 \mathrm{E}+08$ & $J$ & $9.21 E+04$ & 6.82 & - & 6.82 & 0.52 & 12.17 \\
\hline 7 & Electricity & $2.66 \mathrm{E}+08$ & J & 1.47E+05 & 3.91 & 2.66 & 1.25 & 0.30 & 6.98 \\
\hline 8 & Steel & $1.42 \mathrm{E}+04$ & $g$ & $7.81 \mathrm{E}+09$ & 11.09 & - & 11.09 & 0.85 & 19.81 \\
\hline 9 & wood & $9.52 \mathrm{E}+07$ & $J$ & $9.60 \mathrm{E}+03$ & 0.09 & 0.08 & 0.02 & 0.01 & 0.16 \\
\hline 10 & Brick & $1.14 \mathrm{E}+04$ & $g$ & $4.21 \mathrm{E}+08$ & 0.48 & - & 0.48 & 0.04 & 0.86 \\
\hline 11 & Ewes and rams & $2.32 \mathrm{E}+04$ & $g$ & $1.44 \mathrm{E}+10$ & 33.42 & 6.50 & 26.92 & 2.57 & 59.67 \\
\hline 12 & Lamb for finishing & $5.74 \mathrm{E}+05$ & $g$ & 8.64E+09 & 496.02 & 96.43 & 399.59 & 38.10 & 885.75 \\
\hline 13 & Corn bran & $1.31 \mathrm{E}+06$ & g & $5.79 \mathrm{E}+08$ & 75.65 & 18.00 & 57.65 & 5.81 & 135.09 \\
\hline 14 & Wheat Bran & $2.43 \mathrm{E}+05$ & $g$ & $8.41 \mathrm{E}+08$ & 20.42 & 8.49 & 11.92 & 1.57 & 36.46 \\
\hline 15 & Soy meal & $2.64 \mathrm{E}+02$ & $\mathrm{~kg}$ & $2.98 \mathrm{E}+12$ & 78.60 & 27.98 & 50.62 & 6.04 & 140.36 \\
\hline 16 & Cotton bran & $2.10 \mathrm{E}+02$ & $\mathrm{~kg}$ & $4.13 E+12$ & 86.60 & 14.69 & 71.91 & 6.65 & 154.64 \\
\hline 17 & Mineral Premix & $2.83 E+04$ & $g$ & $1.48 \mathrm{E}+10$ & 41.81 & - & 41.81 & 3.21 & 74.67 \\
\hline 18 & White salt & $1.01 \mathrm{E}+04$ & $g$ & $1.05 \mathrm{E}+09$ & 1.06 & - & 1.06 & 0.08 & 1.89 \\
\hline 19 & Limestone & $4.72 \mathrm{E}+06$ & g & $2.72 E+06$ & 1.28 & - & 1.28 & 0.10 & 2.29 \\
\hline 20 & Tifton hay & $1.10 \mathrm{E}+07$ & $J$ & $2.13 E+05$ & 0.23 & 0.09 & 0.15 & 0.02 & 0.42 \\
\hline 21 & Barley & $9.18 \mathrm{E}+04$ & $g$ & $4.21 \mathrm{E}+08$ & 3.86 & 1.74 & 2.12 & 0.30 & 6.90 \\
\hline 22 & Pasture & $1.09 \mathrm{E}+10$ & $\vec{J}$ & $1.60 \mathrm{E}+04$ & 17.36 & 14.80 & 2.56 & 1.33 & 31.00 \\
\hline 23 & Vaccine & $5.95 \mathrm{E}+01$ & g & $1.48 \mathrm{E}+10$ & 0.09 & - & 0.09 & 0.01 & 0.16 \\
\hline 24 & Vermifuge & 1.03E+02 & $g$ & $1.48 \mathrm{E}+10$ & 0.15 & - & 0.15 & 0.01 & 0.27 \\
\hline
\end{tabular}




\begin{tabular}{|c|c|c|c|c|c|c|c|c|c|}
\hline \multicolumn{10}{|c|}{ Services (S) } \\
\hline 25 & Permanent labor & $1.22 \mathrm{E}+08$ & J & $7.56 \mathrm{E}+06$ & 92.59 & 55.55 & 37.03 & 7.11 & 165.33 \\
\hline 26 & Technical services & $4.59 E+01$ & US\$ & $5.60 \mathrm{E}+12$ & 25.73 & 5.66 & 20.07 & 1.98 & 45.94 \\
\hline 27 & Slaughter service & $1.14 \mathrm{E}+02$ & US\$ & $5.60 \mathrm{E}+12$ & 64.01 & 14.08 & 49.93 & 4.92 & 114.31 \\
\hline 28 & Depreciation of M\&F & $5.09 E+01$ & US\$ & $5.60 \mathrm{E}+12$ & 28.51 & - & 28.51 & 2.19 & 50.91 \\
\hline 29 & Maintenance of M\&F & $3.29 E+01$ & US\$ & $5.60 \mathrm{E}+12$ & 18.41 & - & 18.41 & 1.41 & 32.87 \\
\hline \multicolumn{2}{|c|}{ TOTAL EMERGY (Y) } & & & & $1,301.96$ & & & & $2,327.18$ \\
\hline
\end{tabular}

OUTPUTS (Y) and UEVs (calculated)

\begin{tabular}{lcclcl}
\hline Note & Item & Ep & Unit & UEV & Unity \\
\hline With services & & & & \\
30.1 & Lamb meat (live weight) & $8.74 \mathrm{E}+02$ & $\mathrm{~kg}$ & $1.49 \mathrm{E}+13$ & $\mathrm{sej} / \mathrm{kg}$ \\
30.2 & Lamb meat (carcass weight) & $1.95 \mathrm{E}+09$ & $\mathrm{~J}$ & $6.69 \mathrm{E}+06$ & $\mathrm{sej} / \mathrm{J}$ \\
30.3 & Lamb meat (carcass weight) & $4.15 \mathrm{E}+02$ & $\mathrm{~kg}$ & $3.14 \mathrm{E}+13$ & $\mathrm{sej} / \mathrm{kg}$ \\
& & & & \\
Without services & $8.74 \mathrm{E}+02$ & $\mathrm{~kg}$ & $1.23 \mathrm{E}+13$ & $\mathrm{sej} / \mathrm{kg}$ \\
$30.1 \quad$ Lamb meat (live weight) & $1.95 \mathrm{E}+09$ & $\mathrm{~J}$ & $5.51 \mathrm{E}+06$ & $\mathrm{sej} / \mathrm{J}$ \\
30.2 & Lamb meat (carcass weight) & $1.62 \mathrm{E}+04$ & $\mathrm{~kg}$ & $6.63 \mathrm{E}+11$ & $\mathrm{sej} / \mathrm{kg}$ \\
\hline 30.3 & Lamb meat (carcass weight) & 1.62 & &
\end{tabular}


Table 26 - Detailed calculations for the emergy flows of Semi-intensive sheep farming system with lamb finishing (Semi-intensive)

\begin{tabular}{|c|c|c|c|}
\hline Note & Item & Value & Reference \\
\hline \multicolumn{4}{|c|}{ 1. Sun insolation, $\mathbf{J}$} \\
\hline \multicolumn{4}{|c|}{ Annual energy $=($ Solar radiation $) *(365) *($ albedo $) *(3.60 E+06) *($ area m²/ha) $)($ Odum, 1996) } \\
\hline & Solar radiation $=$ & $4.80 \mathrm{kWh} / \mathrm{m}^{2} /$ day & (SPARK, 2020) \\
\hline & Albedo = & $20 \% 1-20 \%$ & $\begin{array}{l}\text { NASA eosweb } \\
\text { (https://eosweb.larc.nasa.gov/sse/) }\end{array}$ \\
\hline & Joules to $\mathrm{kWh}=$ & $3.60 \mathrm{E}+06 \mathrm{~J} / \mathrm{kWh}$ & \\
\hline & Area $=$ & $1.00 \mathrm{E}+04 \mathrm{~m}^{2}$ & \\
\hline & UEV $=$ & $1 \mathrm{sej} \cdot \mathrm{J}^{-1}$ & Definition \\
\hline & Annual energy = & $1.26 \mathrm{E}+13 \mathrm{~J} / \mathrm{ha} / \mathrm{yr}$ & \\
\hline
\end{tabular}

2. Rain chemical potential energy, $\mathbf{J}$

Annual energy $=\frac{(\text { precipitation }) *(\text { Gibbs }) *}{\text { rate } / 100) *\left(\text { area } \mathrm{m}^{2} / \mathrm{ha}\right)}$ (water density $) *($ Evapotranspiration

$$
\text { Precipitation }=\quad 1.702 \mathrm{~m}^{3} / \mathrm{m}^{2} / \mathrm{yr}
$$

Reference

(Brown and Bardi, 2001)

Gibbs free energy $=\quad 4,940.00 \mathrm{~J} / \mathrm{kg}$

water density $=\quad 997 \mathrm{~kg} / \mathrm{m}^{3}$

(SPARK, 2020)

(ODUM, 1996)

Evapotranspiration rate $=\quad 60 \%$

Area $=\quad 1.00 \mathrm{E}+04 \mathrm{~m}^{2}$

Annual energy $=\quad 5.03 \mathrm{E}+10 \mathrm{~J} / \mathrm{ha} / \mathrm{yr}$

$\mathrm{UEV}=\quad 3.10 \mathrm{E}+04 \mathrm{sej} / \mathrm{J}$

(ODUM; BROWN; BRANDT-WILLIAMS, 2000)

3 Wind, $\mathbf{J}$

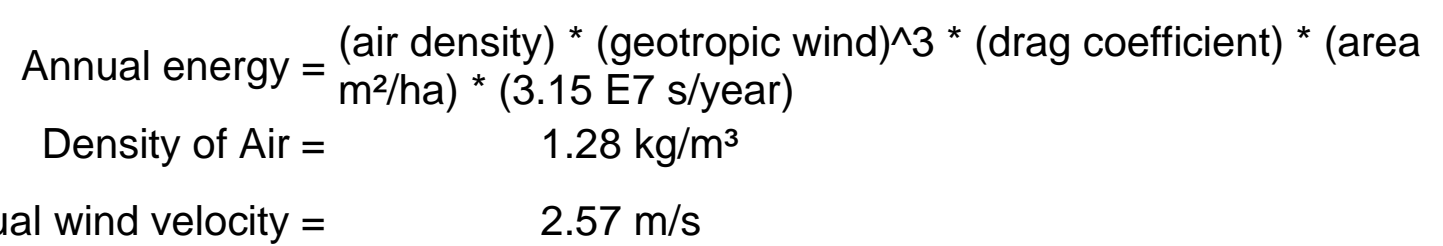

(Brown and Bardi, 2001)

Observed winds are about 0.6 of

Avg. annual wind velocity $=\quad 2.57 \mathrm{~m} / \mathrm{s}$

geostrophic wind 


\section{Geostrophic wind = \\ Drag coefficient $=$ \\ Annual energy =

$$
\mathrm{UEV}=
$$ \\ $1.54 \mathrm{~m} / \mathrm{s}$ \\ 0.001 \\ 1.48E+09 J/ha/yr \\ $2.45 \mathrm{E}+03 \mathrm{sej} / \mathrm{J}$}

(SPARK, 2020)

(Miller, 1964 quoted by Kraus, 1972)

(ODUM; BROWN; BRANDT-WILLIAMS, 2000)

\section{Reference}

\section{Loss of soil in grazing}

$$
\text { Annual energy }=\frac{(\text { Soil loss }) *(O . M .)}{\text { paddock area }) /(\text { property area })} \text { (energy of O.M.) * }(4,186 \mathrm{~J} / \mathrm{kcal}) * \text { (total }
$$

Total paddock area $=$ Loss of soil in pasture $=$ Organic matter (O.M.) = Energy of the O.M. = Annual energy = Soil loss from buildings

Shed $\# 1$ for the flock $=$

$$
\text { Annual energy }=\left(\text { Area in } \mathrm{m}^{2}\right) *(\mathrm{O} . \mathrm{M} .) *\left(0.0012 \mathrm{~kg} / \mathrm{cm}^{3}\right) *\left(1 \mathrm{E}+06 \mathrm{~cm}^{3} / \mathrm{m}^{3}\right) \text { * }
$$

Feedlot area $=$ Shed area $=$

Sheep handling pen area $=$ Office area $=$

Total area of buildings $=$ Soil layer $=$

Organic matter (O.M.) = Annual energy =

$$
31.5 \text { ha }
$$$$
3400 \mathrm{t} / \mathrm{ha} / \mathrm{yr}
$$$$
0.04 \text { kg O.M./kg soil }
$$$$
5,400.00 \mathrm{kcal} / \mathrm{kg} \text { O.M. }
$$$$
2.48 \mathrm{E}+09 \mathrm{~J} / \mathrm{ha} / \mathrm{yr}
$$

(Agostinho et al., 2019)

(EPAMIG, 1992)

(EPAMIG, 1992)

(Agostinho et al., 2019)
From field work

(EPAMIG, 1992)

(EPAMIG, 1992) 
Total energy topsoil losses $=\quad 2.93 \mathrm{E}+09 \mathrm{~J} / \mathrm{ha} / \mathrm{yr}$

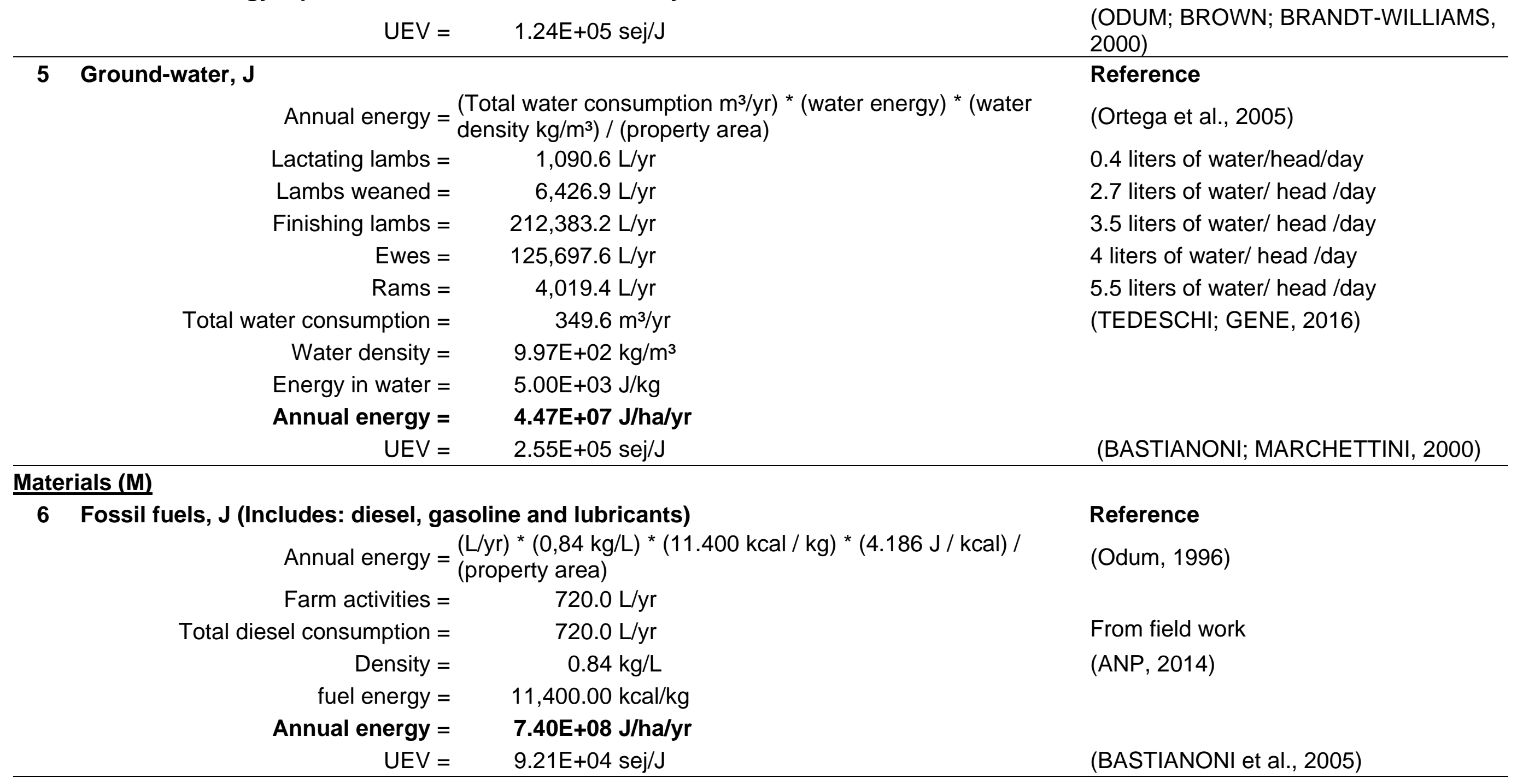

7 Electricity, J

Annual energy $=$ Energy flow $=(\mathrm{kWh} /$ year $) *(3.6 \mathrm{E}+06 \mathrm{~J} / \mathrm{kWh}) /($ property area $)$

\section{Reference}


Electric power consumption $=\quad 2,880.0 \mathrm{kWh} / \mathrm{yr}$

From field work

Joules per $\mathrm{kWh}=\quad 3.60 \mathrm{E}+06 \mathrm{~J} / \mathrm{kWh}$

Annual energy $=\quad 2.66 \mathrm{E}+08 \mathrm{~J} / \mathrm{ha} / \mathrm{yr}$

$\mathrm{UEV}=\quad 1.47 \mathrm{E}+05 \mathrm{sej} / \mathrm{J}$

(GIANNETTI et al., 2015)

8 Steel, $\mathbf{g}$

Annual mass flow $=(\mathrm{kg}$ of steel $) /$ (lifetime) $/$ (property area $)$

Mass of equipment $=$

$7,980.0 \mathrm{~kg}$

Mass of fence wire $=\quad 1,809.4 \mathrm{~kg}$

Mass of facilitiess $=\quad 6,828.0 \mathrm{~kg}$

Total mass of steel $=\quad 1.66 \mathrm{E}+07 \mathrm{~g}$

From field work

Lifetime of material $(\mathrm{LM})=\quad 30 \mathrm{yr}$

Annual mass flow $=\quad 1.42 \mathrm{E}+04 \mathrm{~g} / \mathrm{ha} / \mathrm{yr}$

$\mathrm{UEV}=\quad 7.81 \mathrm{E}+09 \mathrm{sej} / \mathrm{g}$

(BROWN; ULGIATI, 2004);

9 Wood, J

Annual energy $=\underset{\text { area })}{((\text { wood g }) *(3.6 \mathrm{kcal} / \mathrm{g}) *(4,186 \mathrm{~J} / \mathrm{kcal})) /(\text { lifetime }) /(\text { property }}$ Reference

(Odum, 1996)

From field work

Total mass of wood $=\quad 3.70 \mathrm{E}+06 \mathrm{~g}$

(Odum, 1996)

$\mathrm{kcal}$ to Joules $=\quad 4,186 \mathrm{~J} / \mathrm{kcal}$

Lifetime of material $(\mathrm{LM})=15 \mathrm{yr}$

Energy flow $(\mathrm{J})=\quad 9.52 \mathrm{E}+07 \mathrm{~J} / \mathrm{ha} / \mathrm{yr}$

$\mathrm{UEV}=\quad 9.60 \mathrm{E}+03 \mathrm{sej} / \mathrm{J}$

(DE OLIVEIRA et al., 2018)

10 Brick, g

Annual mass flow $=($ Brick g) $/($ lifetime $) /($ property area $)$

Total mass of brick $=\quad 1.33 \mathrm{E}+07 \mathrm{~g}$

Reference

From field work

Lifetime of material $(\mathrm{LM})=\quad 30 \mathrm{yr}$

Annual mass flow $=\quad 1.14 \mathrm{E}+04 \mathrm{~g} / \mathrm{ha} / \mathrm{yr}$ 
11 Ewes and rams, $g$

\section{Reference}

Mass flow of flock (ewes and rams)

Annual mass flow $=\left((\mathrm{LW} \mathrm{kg}) *\right.$ (heads) $\left.{ }^{*}(1,000 \mathrm{~g} / \mathrm{kg})\right) /($ lifetime $) /($ property area)

Ewe live weight $=$

Lifetime of ewes $=$ live weight flock of ewes $=$

Ram live weight $=$

Lifetime of rams $=$ live weight of rams $=$

Annual mass flow $=$ UEV =
$60 \mathrm{~kg}$

$6 \mathrm{yr}$

$8.60 \mathrm{E}+05 \mathrm{~g} / \mathrm{yr}$

$90 \mathrm{~kg}$

$2 \mathrm{yr}$

$4.50 \mathrm{E}+04 \mathrm{~g} / \mathrm{yr}$

$2.32 \mathrm{E}+04 \mathrm{~g} / \mathrm{ha} / \mathrm{yr}$

$1.44 \mathrm{E}+10 \mathrm{sej} / \mathrm{g}$
From field work

From field work

From field work

From field work

(HADEN, 2002)

\section{Lambs for finishing, $g$}

Annual mass flow $=(($ Lamb LW kg $) *($ heads $) *(1,000 \mathrm{~g} / \mathrm{kg})) /($ property area $)$

Lamb LW of entry to the system = No. of lambs entering the system =

Total live weight in the year $=$

Annual mass flow =

UEV and \%R Estimation for weaned lambs for finishing

$$
\mathrm{UEV}=\quad 1.44 \mathrm{E}+10 \mathrm{sej} / \mathrm{g}
$$

LW of lamb obtained by Haden (2002) =

Estimated UEV per g of lamb $=$
$28 \mathrm{~kg}$

800 Heads

$2.24 \mathrm{E}+07 \mathrm{~g} / \mathrm{yr}$

5.74E+05 g/ha/yr
From field work

From field work

From field work

(HADEN, 2002)

(UEV of LW lamb obtained by Haden

(2002)) / ((LW lamb obtained by Haden Equation 1.1.

$3.08 \mathrm{E}+05 \mathrm{sej} / \mathrm{g} \quad(2002)) *(1,000 \mathrm{~g} / \mathrm{kg}))$

$(1.44 \mathrm{E}+10 \mathrm{sej} / \mathrm{g}) /((46.7 \mathrm{~kg} / \mathrm{head})$ * Estimated 1.1. $(1,000 \mathrm{~g} / \mathrm{kg}))$

8.64E+09 sej/g (Estimated UEV per g of lamb 
UEV used in this study for lambs with a $L W$ of $28 \mathrm{~kg}=$ according to Haden (2002)) * (LW of

the weaned lamb at entry into the system) * $(1,000 \mathrm{~g} / \mathrm{kg})$

$(3.08 \mathrm{E}+05 \mathrm{sej} / \mathrm{g})$ * $(28 \mathrm{~kg} / \mathrm{head})$ * $(1,000 \mathrm{~g} / \mathrm{kg})$

$\%$ Renewability per $\mathrm{g}$ of lamb $=$

$\%$ Renewability (estimated)
$19.44 \%$

((Estimated UEV of LW lamb) / (UEV

of LW lamb obtained by Haden (2002))

* (\%R of LW lamb obtained by Haden (2002))

$((8.64 \mathrm{E}+09 \mathrm{sej} / \mathrm{g}) /(1.44 \mathrm{E}+10 \mathrm{sej} / \mathrm{g}))$ * $(19.44 \%)$

$14.58 \%$

13 Corn bran, $g$

Estimated 1.2.

(HADEN, 2002)

Equation 2.

Estimated 2.

Reference

Annual mass flow $=($ Annual consumption $) /$ (property area)

Annual consumption $=\quad 5.10 \mathrm{E}+07 \mathrm{~g} / \mathrm{yr}$

From field work

Annual mass flow $=\quad 1.31 \mathrm{E}+06 \mathrm{~g} / \mathrm{ha} / \mathrm{yr}$

$\mathrm{UEV}=\quad 5.79 \mathrm{E}+08 \mathrm{sej} / \mathrm{g}$

(YUN et al., 2019)

14 Wheat Bran, $g$

Reference

Annual mass flow $=($ Annual consumption $) /$ (property area $)$

Annual consumption $=\quad 9.47 \mathrm{E}+06 \mathrm{~g} / \mathrm{yr}$

Annual mass flow $=\quad 2.43 E+05 \mathrm{~g} / \mathrm{ha} / \mathrm{yr}$

$\mathrm{UEV}=\quad 8.41 \mathrm{E}+08 \mathrm{sej} / \mathrm{g}$

From field work

(YUN et al., 2019)

15 Soy meal, $\mathrm{kg}$

Reference

Annual mass flow $=($ Annual consumption $) /$ (property area $)$

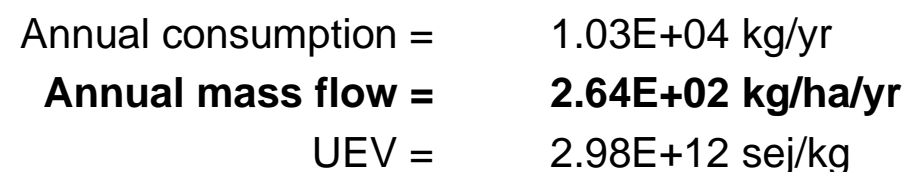

From field work

(CAVALETT; ORTEGA, 2009)

16 Cotton bran, $\mathrm{kg}$

Annual mass flow $=($ Annual consumption $) /$ (property area $)$ 
Annual consumption =

Annual mass flow =

UEV =
$8.18 \mathrm{E}+03 \mathrm{~kg} / \mathrm{yr}$

2.10E+02 kg/ha/yr

$4.13 \mathrm{E}+12 \mathrm{sej} / \mathrm{kg}$

17 Mineral Premix, g

Annual mass flow $=($ Annual consumption $) /$ (property area $)$

Annual consumption $=\quad 1.10 \mathrm{E}+06 \mathrm{~g} / \mathrm{yr}$

Annual mass flow $=\quad 2.83 \mathrm{E}+04 \mathrm{~g} / \mathrm{ha} / \mathrm{yr}$

$\mathrm{UEV}=1.48 \mathrm{E}+10 \mathrm{sej} / \mathrm{g}$

18 White salt, $g$

Annual mass flow $=($ Annual consumption $) /$ (property area)

Annual consumption $=\quad 3.94 \mathrm{E}+05 \mathrm{~g} / \mathrm{yr}$

Annual mass flow $=\quad 1.01 \mathrm{E}+04 \mathrm{~g} / \mathrm{ha} / \mathrm{yr}$

$\mathrm{UEV}=1.05 \mathrm{E}+09 \mathrm{sej} / \mathrm{g}$

19 Limestone, J

Annual energy flow $=$ (Annual consumption) * (Gibbs free energy of rock) $/$ (property

Annual consumption $=$

$3.01 \mathrm{E}+05 \mathrm{~g} / \mathrm{yr}$

Gibbs free energy of rock =

Annual energy flow =

$6.11 \mathrm{E}+02 \mathrm{~J} / \mathrm{g}$

4.72E+06 J/ha/yr

UEV =

$2.72 \mathrm{E}+06 \mathrm{sej} / \mathrm{J}$
From field work

(TAKAHASHI; ORTEGA, 2010)

\section{Reference}

From field work

(CASTELLINI et al., 2006)

\section{Reference}

From field work

(LAGANIS; DEBELJAK, 2006)

\section{Reference}

From field work

(BROWN; ULGIATI, 2004)

(BROWN; ULGIATI, 2004)

20 Tifton hay, J

Annual energy flow $=(\mathrm{AC}){ }^{*}(\% \mathrm{DM}) *(\mathrm{GE}) *(4,186 \mathrm{~J} / \mathrm{kcal}) /($ property area $)$
Annual consumption $(A C)=$

Dry matter of Tifton-85 hay $=$

Gross energy $(\mathrm{GE})=$

Annual energy flow = kcal to Joules $=$
$2.65 \mathrm{E}+04 \mathrm{~kg} / \mathrm{yr}$

$0.91 \% \mathrm{DM}$

$4.26 \mathrm{kcal} / \mathrm{kg}$ of DM

$4,186 \mathrm{~J} / \mathrm{kcal}$

1.10E+07 J/ha/yr
From field work

\section{Reference}

(DA SILVA et al., 2007) 
UEV =

$2.13 \mathrm{E}+05 \mathrm{sej} / \mathrm{J}$

21 Fresh barley, g

Annual mass flow $=($ Annual consumption $) /$ (property area)

Annual consumption $=\quad 3.58 \mathrm{E}+06 \mathrm{~g} / \mathrm{yr}$

Annual mass flow $=\quad 9.18 \mathrm{E}+04 \mathrm{~g} / \mathrm{ha} / \mathrm{yr}$

$\mathrm{UEV}=\quad 4.21 \mathrm{E}+08 \mathrm{sej} / \mathrm{g}$
(RÓTOLO et al., 2007)

\section{Reference}

From field work

(CASTELLINI et al., 2006)

22 Pasture, J

Annual energy flow $=((\mathrm{AC} * \% \mathrm{DM} * \mathrm{GE}) / 0.000001 \mathrm{Mcal} / \mathrm{cal})) *(4.1868 \mathrm{cal} / \mathrm{J}) /$

(property area)

Annual consumption $(A C)=\quad 94,510.00 \mathrm{~kg} / \mathrm{yr}$

Dry matter of Brachiaria pasture $=\quad 0.26 \% \mathrm{DM}$

Gross energy $(\mathrm{GE})=\quad 4.06 \mathrm{Mcal} / \mathrm{kg}$ of DM

(Velasco, 2011)

4.06 Mcal/kg of DM (Velasco, 2011)

Mcal to cal $=\quad 0.000001 \mathrm{Mcal} / \mathrm{cal}$

cal to Joules $=\quad 4.1868 \mathrm{cal} / \mathrm{J}$

Annual energy flow $=\quad 1.09 \mathrm{E}+10 \mathrm{~J} / \mathrm{ha} / \mathrm{yr}$

$\mathrm{UEV}=1.60 \mathrm{E}+04 \mathrm{sej} / \mathrm{J}$

22 Vaccine, $g$

Annual energy flow $=(A C) *$ (quantity $\mathrm{ml} /$ dose $) *($ density $\mathrm{g} / \mathrm{ml}) /($ property area $)$

Annual consumption $(\mathrm{AC})=\quad 9.67 \mathrm{E}+02$ dose $/ \mathrm{yr}$

$\mathrm{ml}$ per dose $=\quad 2.18 \mathrm{ml} /$ dose

Vaccine density $=\quad 1.1 \mathrm{~g} / \mathrm{ml}$

Annual mass flow $=\quad 5.95 E+01 \mathrm{~g} / \mathrm{ha} / \mathrm{yr}$

$\mathrm{UEV}=1.48 \mathrm{E}+10 \mathrm{sej} / \mathrm{g}$

(RÓTOLO et al., 2007)

\section{Reference}

From field work

From field work

From field work

(CASTELLINI et al., 2006)

23 Vermifuge, $g$

Annual mass flow $=(\mathrm{AC})^{\star}($ density $\mathrm{g} / \mathrm{ml}) /($ property area $)$

Annual consumption $(\mathrm{AC})=3.08 \mathrm{E}+03 \mathrm{ml} / \mathrm{yr}$

Vermifuge density $=\quad 1.3 \mathrm{~g} / \mathrm{ml}$

\section{Reference}

From field work

From field work 
Annual mass flow $=\quad 1.03 E+02 \mathrm{~g} / \mathrm{ha} / \mathrm{yr}$

$\mathrm{UEV}=\quad 1.48 \mathrm{E}+10 \mathrm{sej} / \mathrm{g}$

(CASTELLINI et al., 2006)

\section{Services (S)}

24 Permanent labor, $\mathbf{J}$

\section{Reference}

Employee energy conversion $=($ No. of employees $){ }^{*}(\mathrm{kcal} /$ day $){ }^{*}(287$ days $/ \mathrm{yr}){ }^{*}(4,186 \mathrm{~J} / \mathrm{kcal}) /($ property area $)$

No. of employees $=$

Energy per employee $=$

Annual energy flow =

Owner's energy conversion $=$

No. of owners $=$

Annual energy flow =

Total annual energy flow $=$

UEV =
1

$2,500.00 \mathrm{kcal} /$ day

$5.39 \mathrm{E}+07 \mathrm{~J} / \mathrm{ha} / \mathrm{yr}$

$(2,500 \mathrm{kcal} /$ day $) *(365$ days / year $) *(4,186 \mathrm{~J} / \mathrm{kcal}) /$

(property area)

$$
\begin{aligned}
& 6.86 \mathrm{E}+07 \mathrm{~J} / \mathrm{ha} / \mathrm{yr} \\
& \mathbf{1 . 2 2 E}+08 \mathrm{~J} / \mathrm{ha} / \mathrm{yr} \\
& 7.56 \mathrm{E}+06 \mathrm{sej} / \mathrm{J}
\end{aligned}
$$

25 Technical services, \$

Annual money flow $=($ Total cost of services $) /$ (property area $)$

$$
\text { Social charges }=\quad 1,315.38 \mathrm{USD} / \mathrm{yr}
$$

Veterinarian $=\quad 219.78 \mathrm{USD} / \mathrm{yr}$

Transport services expenses $=$

Total cost of services $=$

$256.41 \mathrm{USD} / \mathrm{yr}$

$1,791.58 \mathrm{USD} / \mathrm{yr}$

Annual money flow =

4.59E+01 USD/ha/yr

$\mathrm{UEV}=\quad 5.60 \mathrm{E}+12 \mathrm{sej} / \$$

26 Slaughter service, \$

Annual money flow $=($ Slaughter service cost $) /($ property area $)$

Slaughter service cost $=$

Annual money flow =

4,458.12 USD/yr

1.14E+02 USD/ha/yr

$\mathrm{UEV}=\quad 5.60 \mathrm{E}+12 \mathrm{sej} / \$$
From field work

From field work

(BRANDT-WILLIAMS, 2002)

\section{Reference}

From field work

(GIANNETTI et al., 2018)

\section{Reference}

From field work

(GIANNETTI et al., 2018) 
27 Depreciation of machinery and facilities, \$

\section{Reference}

Annual money flow $=($ Total cost of depreciation $) /($ property area $)$

Total cost of depreciation $=\quad 1,985.51 \mathrm{USD} / \mathrm{yr}$

From field work

Annual money flow $=\quad 5.09 \mathrm{E}+01 \mathrm{USD} / \mathrm{ha} / \mathrm{yr}$

$\mathrm{UEV}=\quad 5.60 \mathrm{E}+12 \mathrm{sej} / \$$

(GIANNETTI et al., 2018)

28 Maintenance of machinery and facilities, \$

Annual money flow $=($ Total cost of maintenance $) /$ (property area $)$

Total cost of maintenance $=\quad 1,282.09 \mathrm{USD} / \mathrm{yr}$

\section{Reference}

From field work

Annual money flow $=\quad 3.29 \mathrm{E}+01 \mathrm{USD} / \mathrm{ha} / \mathrm{yr}$

$\mathrm{UEV}=\quad 5.60 \mathrm{E}+12 \mathrm{sej} / \$$

(GIANNETTI et al., 2018)

\section{Output}

31 Lamb meat (Carcass)

\section{Reference}

Annual prod. in Joules of lamb meat $\left(\left(\right.\right.$ Total slaughtered weight) * $\left(\right.$ Carcass yield \%) * (energy meat kcal/kg) $\left.{ }^{*}(4,186 \mathrm{~J} / \mathrm{kcal})\right) /($ property $=$ area)

Number of lambs to be slaughtered

811.00 heads/yr

From field work

Slaughter weight $=$

$42.00 \mathrm{~kg} / \mathrm{head}$

From field work

Total slaughtered weight $=$ Total slaughtered weight per ha $=$

Carcass yield $=$

$84,150.00 \mathrm{~kg} / \mathrm{yr}$

$873.79 \mathrm{~kg} / \mathrm{ha} / \mathrm{yr}$

$47.50 \%$

From field work

Prod. Total lamb carcass $=$

$16,186.97 \mathrm{~kg} / \mathrm{yr}$

$415.05 \mathrm{~kg} / \mathrm{ha} / \mathrm{yr}$

$112 \mathrm{kcal} / 100 \mathrm{~g}$

From field work

Energy in $100 \mathrm{~g}$ of meat $=$

$1,120 \mathrm{kcal} / 1 \mathrm{~kg}$

$4,186 \mathrm{~J} / \mathrm{kcal}$

Product in Joules of lamb meat $=$

$1.95 \mathrm{E}+09 \mathrm{~J} / \mathrm{ha} / \mathrm{yr}$ 


\section{REFERENCES}

AGOSTINHO, F. et al. Emergy accounting as a support for a strategic planning towards a regional sustainable milk production. Agricultural Systems, Barking, v. 176, n. 102647, 2019.

ANP. Fatores de conversão, densidades e poderes caloríficos inferiores.

Brasília: ANP. Disponível em: http://www.anp.gov.br/images/publicacoes/anuarioestatistico/2015/76748.pdf. Acesso em: 10 fev. 2021.

BASTIANONI, S. et al. The solar transformity of oil and petroleum natural gas. Ecological Modelling, Amsterdam, v. 186, n. 2, p. 212-220, 2005.

BASTIANONI, S.; MARCHETTINI, N. The problem of co-production in environmental accounting by emergy analysis. Ecological Modelling, Amsterdam, v. 129, n. 2-3, p. 187-193, 2000.

BRANDT-WILLIAMS, S. L. Folio 4: emergy of Florida agriculture. Gainesville, FL: Center for Environmental Policy, Environmental Engineering Sciences, 2002.

BROWN, M.; BARDI, E. Folio 3: emergy of ecosystems folio. Gainesville, FL: Center for Environmental Policy, Environmental Engineering Sciences, 2001.

BROWN, M.; ULGIATI, S. Emergy analysis and environmental accounting. Encyclopedia of Energy, Amsterdam, v. 2, p. 329-354, 2004.

CASTELLINI, C. et al. Sustainability of poultry production using the emergy approach: Comparison of conventional and organic rearing systems. Agriculture, Ecosystems and Environment, Amsterdam, v. 114, n. 2-4, p. 343-350, 2006.

CAVALETT, O.; ORTEGA, E. Emergy, nutrients balance, and economic assessment of soybean production and industrialization in Brazil. Journal of Cleaner

Production, Amsterdam, v. 17, n. 8, p. 762-771, 2009.

DA SILVA, E. A. et al. Teores de proteína bruta para bovinos alimentados com feno de tifton 85: Consumo e digestibilidades total e parcial. Revista Brasileira de Zootecnia, Viçosa, v. 36, n. 1, p. 237-245, 2007.

DE OLIVEIRA, R. K. et al. Emergy-based sustainability assessment of a loblolly pine (Pinus taeda) production system in southern Brazil. Ecological Indicators, Amsterdam, v. 93, n. September 2017, p. 481-489, 2018.

EPAMIG. Conservação do solo e do meio ambiente. Belo Horizontel: EPAMIG, 1992. v. 16

GIANNETTI, B. F. et al. Multicriteria cost-benefit assessment of tannery production: The need for breakthrough process alternatives beyond conventional technology optimization. Environmental Impact Assessment Review, New York, v. 54, p. 2238, 2015. 
GIANNETTI, B. F. et al. Human-nature nexuses in Brazil: monitoring production of economic and ecosystem services in historical series. Ecosystem Services, [s.I.], v. 30, p. 248-256, 2018.

HADEN, A. C. Emergy analysis of food production at $s \&$ s homestead farm. S\&S Center for Sustainable Agriculture, Island, p. 1-33, 2002.

KRAUS, E. B. Atmosphere-ocean interaction. Oxford, U.K: University Press, 1972.

LAGANIS, J.; DEBELJAK, M. Sensitivity analysis of the emergy flows at the solar salt production process in Slovenia. Ecological Modelling, Modeling, v. 194, n. 1- 3, p. 287-295, 2006.

ODUM, H. T. Environmental accounting: emergy and environmental decision making. New York, USA: Jhon Wiley \& Sons INC, 1996.

ODUM, H. T.; BROWN, M.; BRANDT-WILLIAMS, S. Handbook of emergy evaluation: folio \# 1. Introduction and Global Budget. Gainesville, FL: Center for Environmental Policy, Environmental Engineering Sciences, 2000. Disponível em: http://www.cep.ees.ufl.edu/emergy/documents/folios/Folio_01.pdf. Acesso em: 13 nov. 2020.

PÉREZ-SOBA, M. et al. The emergy perspective: natural and anthropic energy flows in agricultural biomass production. Luxembourg, 2019.

PICCHI, M. P.; PORCELLI, M.; PULSELLI, F. M. Effects on the ecosystem of ceramics production in Sassuolo (Italy). Transactions on Ecology and the Environment, [s.I.], v. 46, p. 89-95, 2001.

PULSELLI, R. M. et al. Emergy analysis of building manufacturing, maintenance and use: Em-building indices to evaluate housing sustainability. Energy and Buildings, Lausanne, v. 39, n. 5, p. 620-628, 2007.

RÓTOLO, G. et al. Emergy evaluation of grazing cattle in Argentina's Pampas.

Agriculture, Ecosystems and Environment, Amsterdam, v. 119, n. 3-4, p. 383395, 2007.

SPARK, W. Condições meteorológicas médias de Cravinhos - Weather Spark. Disponível em: https://pt.weatherspark.com/y/30215/Clima-característico-emCravinhos-Brasil-durante-o-ano. Acesso em: 10 out. 2020.

TAKAHASHI, F.; ORTEGA, E. Assessing the sustainability of Brazilian oleaginous crops - possible raw material to produce biodiesel. Energy Policy, Guildford, v. 38, n. 5, p. 2446-2454, 2010.

TEDESCHI, L. O.; GENE, D. The ruminant nutrition system: An applied model for predicting nutrient requirements and feed utilization in ruminants. Texas: XanEdu, 2016. v. 1. 
YUN, L. et al. Emergy-based sustainability analysis of an ecologically integrated model with maize planting for silage and pig-raising in the North China plain.

Sustainability, Basel, v. 11, n. 22, 2019 